\title{
Anatomische Abhandlungen
}

über die

\section{Perennibranchiaten und Derotremen}

Dr. J. G. Fischer.

Frstes Heft.

H A M B U R G.

0 tto Meissner.

18664. 


\section{8,3}

Alez Agassiz:

还ibrary of the atturseum

oF

\section{COMPARATIVE ZOÖLOGY,}

AT IARTARD COLLEGE, CAMBRIDGE, IIASS.

Jounaca bo príbate subscription, in 1861.

Deposited by ALEX. AGASSIZ.

No. 14,040 
Am Aurtartond. Sgaveiz

in Cambridgo

fugaydingy now

13 Sectonlob4. In Bayfary.

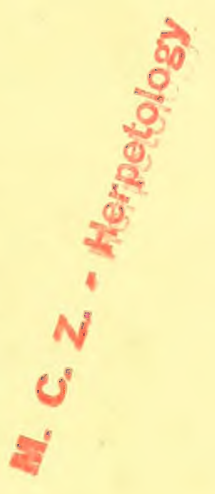





\section{Anatomische Abhandlungen}

über die

\section{Perennibranchiaten und Derotremen}

$\mathrm{V} O \mathrm{n}$

Dr. J. G. Fischer.

Frstes Heft:

Die Visceralbogen und deren Muskeln.

Die Gehirnnerven.

Mit sechs Tafeln Abbildungen.

H A M B U R G.

Otto M e issner.

${ }^{s m} 1 \quad 8 \quad 6 \quad 4$. 
Druck vull M, Rusenliore in Hamburo. 


\section{Naturwissenschaftlichen Vereine}

in Hamburg

zur Feier seiner Vereinigung

mit der

\section{Naturwissenschaftlichen Gesellschaft}

gewidmet. 



\section{Erste Abhandlung.}

Die Visceralbogen und deren Muskeln

bei den

Perennibranchiaten und Derotremen. 


\section{Vorwort.}

Dass die Jechanik des Athmens der Amphibien von derjenigen der Sängethiere, Vögel und Reptilien wesentlich verschieden sei, ist eine bekannte Sache. Sie haben kein wirkliches Zwerchfell, keine ächten Rippen, können also, wie die allgemeine Annahme lautet, keine Erweiterung des Lumens ihrer Rumpfhöhle schaffen, in die der atmosphärische Druck, wie bei den warmblütigen Wirbelthieren und den Reptilien, die Luft himeinpressen würde. Ihr Athmen ist ein wirkliches Hinunterschlucken der Luft. Durch eigene Inskelkraft müssen sie den atmosphärischen Druck ersetzen und die eingenommene Luft hinabpressen, um dieselbe später, ebenfalls durch eigene IIuskelkraft, wieder zu entlassen.

Dieser Vorgang ist seit Cuvier zunïchst für die ächten Batrachier, dam aber auch fuir alle anderen (nackten) Amphibien allgemein als richtig angenommen. Gleichwohl ist er bis jetzt melır Hypothese als bewiesene Thatsache, und ermangelt fiir einzelne Gruppen der nur durch Kenntnis des Athemmechanismus zu erlangenden Begründung. In ihrer vollen Ausdehnung kann jene Annahme namentlich auf diejenigen Amphibien keine Anwendung finden, die gleichzeitig mit Lungen und mit Kiemen oder doch Kiemenspalten versehen sind, die Perennibranchiaten und Derotremen. Der Bau der Naslöcher dieser Thiere, auf den sich die Cuvier'sche Hypothese für die Frösche theilweise stïtzt, ist ganz verschieden von demjenigen der ïchten Batrachier. Ansserdem bedürfen sie besonderer Vorrichtungen, welche der eingenommenen Luft in dem Augenblick, wo sie in die Lungen gepresst wird, den seitlichen Ausweg aus den Kiemenspalten versperren. Umgekehrt fragt man auch nach denjenigen mechanischen Mitteln, wodurch dem ins Maul genommenen und ans den Kiemenspalten heransgedriickten Wasser der Weg in die Lungen verschlossen wird.

Nicht bloss diese, auch andere, den abweichenden bau ihres Zungenbein- und Kiemenbogen-Gerüstes betreffende Fragen, deren Beantwortung bisher nicht gegeben scheint, liess mir eine vergleichende Untersuchung der mit Kiemen und Lungen gleichzeitig versehenen Imphibien wünschenswerth erscheinen. Und dies um so mehr, als die Arbeiten von Rathke, Henle und anderen Autoren nur einzelne der hier in Frage kommenden Knochen- und Muskel-Particen in vergleichender Weise behandeln.

Unsere Untersuchung wird sich nach dem eben gesagten zunächst auf das harte Gerüst des Zungenbein-Kiemenbogen-Apparates zu erstrecken haben. Wir bezeichnen dasselbe in

der ïblichen Weise als Visceralskelett, schliessen aber die anatomische lietrachtung des Unterkiefers davon aus, weil diese sich wegen seiner Beziehungen zu dem Schïdel passender 
an eine beabsichtigte spiitere Untersuchung des letzteren anreihen wird. - Ebenso wichtig wird fïr unseren Zweek dio Betrachtung del jenes harte Gerüst hewegenden Muskeln sein, an welche auch die den Schlund und die Luftröhre verengenden und erweiternden Muskehn, ja selbst diejenigen dre Naslïcher und die Muskehn der Kiefer angefïunt werdern müssen. Letztere nicht bloss deshalb, weil das Oeffnen und Schliessen des Maules auch bei den Amphibien als Athembewegung aufzufassen wäre, sondern weil die Muskeln des Unterkiefers in architektonischer Hinsicht nicht wohl vou denen der folgenden Visceralbogen getrennt werden könmen. - Endlich erschien es von Interesse zu erfaliren, aus welchen der Gehirnnerven-Gruppen die Serven der einzelnon tiir Kiemen- oder tür LungenAthmung bestimmten Muskehn stammen. Lis ist daher ïberall der Bescheiloung der letzturen eine Angabe über die sie versorgenden Nerven hinzugefügt worden, - wo sie nicht durch

eine fast mikroskopische Feinheit derselben unmöglich gemacht wurde. Eine Gesammtübersicht der hierher gehörigen Gehimnerven erfolgt passender in einer dieser. Schrift angefïgten besonderen Abhandlung.

Folgende Arten wurden untersucht:

Siren lacertina Cuv.

Siredon pisciformis Wagl.

Hypochthon Laurenti Merr.

Menobranchus lateralis Harl.

Amphiuma tridactylum Cuv.

Menopoma Alleghaniense Harl.

Cryptobranchus japonicus v. d. Hoev.

Siphonops annulatus Wagl.

Die Hinzuziehung der beiden letztgenannten Arten rechtfertigt sich für Cryptobranchus wohl durch seine ausserordentliche Verwandtschaft mit Menopoma, für Siphonops durch dessen nach einem ganz abweichenden Typus gebautes Zungenbein.

In den Specialbeschreibungen sind die einzelnen Thiere in ihrer natiirlichen Stellung, den Bauch nach der Erde gewendet, zu denken. Die Ausdrücke vorn - hinten, dorsal - ventral, medial - lateral sind demnach in dem ilunen ron Ecker in seiner Anatomie des Frosches beigelegten Sinne gebraucht worden.

Den grossten Theil des untersuchten Materials verdanke ich der ausserordentlichen Liberalität der Smithsonian Institution in Washington.

Hamburg, im November 1864. 
Erster Theil.

Die Visceralbogen. 
Von den parrigen Bogenschenkeln, die den Zungenbein-Kiemenhogen-Aplarat der Amphibus dipnou zusammensetzen, wird bestïndig das erste, gleich auf den Unterkiefer folgende, ihm parallel sich erstreckende Paar mit dem Namen der Zungenbeinhüruer bezeichnet. Dieselben stchen mit den Kiemen niemals in direkter bezichung. Ibie darauf nach hinten folgenden Bogenpare sind Kiemenbogen beuannt worden, wo sie als Stütze der Kiemen dienen, zweite Zungenbeinhürner jedoch da (Salamandrinen), wo sie zu äusseren Kiemen in keinerlei Beziehung stehen. Da es sich hier um verschiedene Namen für ein und dasselbe Organ handelt, werden wir ïberall, auch bei den kiemenlosen Gattungen, alle diejenigen Bogenpare als Kiemenbogen bezeichnen, die auf das oben berührte vordere Paar, (dir Zungenbeinhörner) folgen. Es ist indessen hervorzuheben, dass auch diese Unterscheidung zwischen (vorderen) Zungenbeinhörnern und Kiemenbogen sich nicht in genetischer Hinsicht sondern nur durch deren verschiedene Verwendung rechtfertigen lïsst.

Die Kiemenhogen der Fische sind bekanntich meist in mehre hinter einander folgende Abtheilungen gegliedert. Auch bei den Amphibir dipnor*) findet hïufig eine solehe Gliederung statt. Man hat in diesen Falle die der Mittellinie des Banches zunïchst liegenden, ventralen Stiicke durch besondere Namen (zweites Zungenbeinhorn, Columella) bezeichnet. Dies Verfahren lässt sich schon deshalb nicht rechtfertigen, weil Bogen; die bei einzelnen Gattungen ungetheilt sind (z. B. der erste Kiemenbogen von Amphimma), bei anderen gegliedert erscheinen (Menobrunchus, Siren, Siredon etc.). Sollen diese imneren Glieder wegen der Bedeutung, die sie als Träiger und Stützen der daran befestigten zweiten Kiemenbogensegmente gewinnen, durch einen besonderen Namen ausgezeichnet werden, so muisste man einen solchen wählen, der diese ihre ventrale Lage und gleichzeitig ihre Zusammengehörigkeit zu den eigentlichen kiementragenden Bogentheilen erkennen liesse. Wir werden sie als

*) Mit diesem Namen bezeichne ich der Kürze wegen diejenigen Amphibien, die lebenslänglich neben den Lungen auch Kiemen oder doch Kiemenspalten besitzen, also die Amphibia dipnoa anderer Autoren (Stannius) mit Ausschluss der Salamandrinen, Caecilien und ächten Batrachier. 
Ventralsegmente, die zweiten hinteren Glieder dagegen als Dorsalsegmente der Kiemenbogen bezeichnen.

Unter den umpaaren medialen Verbindungsgliedern, wodurch die Bogenschenkel der einen Körperhailfte mit denen der anderen in Verbindung stehen, ist bei den Amphibien dasjenige am stärksten entwickelt, das zwischen Zungenbeinhörnern und Kiemenbogen liegt, und den letzteren immer, den exsteren zuweilen als Stütze und Trïger dient. Dies mittlere Stiick int unter dem Namen Zungenbeinkürper dargestellt, und galt bisher als die einzig vorhandene, für die Zungenbeinhörner (das vorderste Bogenpaar) bestimmte Copula. Die Fische allein galten als mit besonderen, fïr die hinteren Bogen, die eigentlichen Kiemenbogen, bestimmten Verbindungsstücken ausgeriistet. In Wirklichkeit ist aber der sogenannte Zünenbeinkörper der Amphibia dipnoa mehr zur Anheftung der Kiemenbogen als der Zungenbeinhörner bestimmt. Die letzteren sind ausserdem noch bei einigen Gattungen (Amphinum, Mcnopoma, Cryptolwanches juponicus) mit einer besonderen Copula ausgestattet, die bei anderen Gattungen (Sirn) mit der Copula der Kiemenbogen, dem sogenannten Zungenbeiukürper, verwachsen ist. Es wïre daher richtiger, diese vordere Copula als Zungenbeinkürper, jene hintere als Kiemenbogenkörper zu unterscheiden. Wir scheuen uns indessen vor einer Aenderung der einmal eingefihrten Namen, und werden das hauptsïchlichste, und bei den meisten Gattungen einzig rorhandene Mittelstück als Zungenbeinkörper, das vordere, nur wenigen Gattungen eigenthümliche Verbindungsglied als rordere Copula bezeichnen.

Dem Zungenbeinkürper ist bei den meisten Gattungen ein stielfürmiger Fortsatz angefügt, der den Namen Zungenbeinstiel erhalten hat.

\section{Die Zungenbeinhörner.}

\section{Gliederung und Anbeftung.}

Jedes Zungenbeinhorn (auf den Abbildungen der Tafel I mit $h$ bezeichnet) stellt in der Regel cine einzige Platte ror. Bei Amphiuma und Menopoma ist dasselbe in zwei Segmente zerfallen (Tafel I, Fig. 5 und $6, h$ und $h^{\circ}$ ). Bei diesen beiden Gattungen stellt das bei weitem kleinere vordere Segment $\left(h^{\prime}\right)$ ein mit seiner grossen Achse schräg ron 
hinten und aussen nach vorn und innen liegendes Oval vor. Dasselbe grenzt mit seinem hinteren und ätsseren Rande an das zweite bei weitem grössere Segment, mit seinem vorderen und immeren Rande an eine diesen beiden Gattungen eigene abgetrennte vordere Copula (ch'). - Bei Cryptobunchus juponicus ist das Zungenheinhorn jeder Seite nicht gegliedert, wohl aber an eine mediale besondere Copula befestigt. Vergleicht man diese letztere mit der Form von Menopoma, so scheint sie bei Cryptobranchus die dort abgetrennten vorderen Segmente der Zungenbeinhörnes zu enthalten, da sie in zwei seitliche, der verwandten Gattung fehlende Arme ausläuft. Stanuius (Vergl. Anat. der Amphib. pag. 64) lässt wirklich Salamandra maxima mit einem vorderen Segmente der Zungenbeinhörner versehen sein, das mit demjenigen der anderen Seite verbunden ist. Die Vermuthung liegt nahe, dass hier eine Altersverschiedenheit vorliegt. In meinem Exemplar von 3 Fuss Länge, wie in demjenigen das der Abbildung in Schmidt, Goddart und v. d. Hoevens Werke ${ }^{1}$ zu Grunde lag, war eine Trennung nicht zu bemerken.

Bei allen anderen Gattungen stellt jedes Zungenbeinhoru eine einzige Platte vor. Bei MEnobranchus ist jedoch der vordere, dickere Theil derselben (Taf. 1, Fig. 3, $h^{\prime}$ ) von dem folgenden grösseren $(h)$ so deutlich ruer algesctzt, und ron ihm durch zwischengelagertes fibröses Gewebe getrennt, dass man auch hier ein epigonales Aneinanderrücken zweier Segmente annehmen muss. Bei Amphiuma (Taf. 1, Fig. 5) ist sogar nicht nur, wie erst crwihnt, ein vorteres Segment $\left(h^{\prime}\right)$ vollkommen ahgetrennt, sondern auch an dem zweiten Segment $(h)$ lässt wich der äussere vortere ganz knorpelige Theil $(h ")$ als von der übrigen knöchernen Partie dieses Bogenstiicks so scharf abgesetzt untercheiden, dass man auf ursprüuglich rorhanlene drei Segmente des Zungeubeinhorns schliessen müchte. Vielleicht sogar vier, wenn ander's das ïberknorpelte hintere Ende auf cinen früher vorhandenen knorpeligen aufsteigenten Ast schliessen lïsst. Für letzteres scheint in der. That eine bei Menopoma gemachte Beobachtung zu sprechen. Der bei einem grossen Exemplar ron 40 Centimeter Länge das hintere Ende des Zungenbeinhorns iiberziehende hyaline Kónorpel ist bei einem jüngeren Exemplar ron 24 Cent. Länge in der Gestalt eines spitzen dorsalwärts gerichteten aufstejgenden $\Lambda$ stes vorhanden. - Die Zungenbeinhörner beider Seiten hängen mit einander und der dazwischen gelegenen vorderen Copula, oder, wo diese fehlt, mit dem Anfange des Zungenbeinkörpers durch fibröses Gewele beweglich zusammen. Es leuchtet ein, dass diese Beweglichkeit bei Amphiuma und Afonpoma wegen des abgetrennten vorderen Segmentes bei meitem grüsser ist, als bei den übrigen mit ïusseren Kiemen rersehenen

1) Aanteekeningen over de Anatomie ran den Cryptobranchus Japonicus. Haarlem 1862. Pl. IX, Fig. VIII. 
Gattungen. Bei letzteren scheint die grössere Festigkeit dieses vordersten Theiles des Athmungsgerüstes in naher Beziehung zu der verschiedenen Athmungsweise zu stehen.

An jedem Zungenbeinhorne lässt sich ein oft längerer (Siredon, Siren, Menopoma, ('my)tobronchus) oft kürzerer (Mcnubronthes, Amphimma, Hypochthon) aufsteigender Ast unterscheiden, dessen Spitze hinter dem Schiidel nach oben vorragt. In demjenigen Falle, wo der aufsteigende Ast keine betrïchtliche Länge hat, liegt diese Spitze in ummittelbarer Nïhe des os tympunicum, tief versteckt unter den ummittelbar hinter dem Schïdel nach aussen gehenden Muskeln (Digustrius, Leratores aramm). Dieser aufsteigende Ast des Zungenbeinhorns ist olne alle Ausnahme duxch eine selten schmale und lange (Sirchon). meist breite und kurze Sehne an die hintere Fläche des os tympanicum angeheftet.

Bei Sircn findet diese Befestigung nicht an der dorsalen Spitze des anfsteigenden Astes statt. sondern gerade da, wo letzterer, knorpelig werdend, sich von dem ossificierten ventralen Theile unter einem mach vor"u offenen Winkel umbiegt. Das Kungenbeinhorn stellt liner' cinen eben in jener Biegungsstelle unterstïtzten Winkelhebel vor. Bei den Contractionen der zweiten Portion des Digastricus (vgl. diesen) wird der obere freie Schenkel an das Hinterhaupt gezogen, mit ihm das vordere Ende des Bogens nach unten gedrïckt und so der Boden der Mundhöhle vertieft.

Bei Iypochthon erstreckt sich von der dorsalen Spitze des Zungenbeiuhorns noch eine zweite starke Sehne, und zwar an den Unterkiefer. Dieselbe entspringt dicht vor dem lalbkugelförmigen Ende des Zungenbeinhorns, geht parallel mit der Richtung des letzteren schrïge abwïrts nach vorn und heftet sich an den linteren, für den Digastricus bestimmten spitzen Vorsprung des Unterkiefers, dicht iiber dem Insertionspunkt für die Selme dieses Muskels. Bei keiner der anderen Gattungen habe ich diese zweite befestigung an den Unterliefer beobachtet. Eine bei Menobranchus ausserlalb der hinteren Spitze des 7ungenheinhorns ('Tafel III, $h$ ) mit dem letzteren parallel schrïg abwärts nach vorn gehende Sehne (s) gehört der zweiten Portion des Digastricus $\left(d g^{\prime}\right)$ an. Doch hat diese insofern eine ähnliche Wirkung wie die bei Hypochthon geschilderte Vorrichtung, als auch sie das Ausweichen des Knochens nach aussen verhindert, und die Beweglichkeit seines hinteren Endes beschränkt.

\section{Substanz der Zungenbeinhörner.}

Nur bei Siredon, Menobranchus und Cryptobranchus jeponicus ist das ganze Zungenbeinhorn aus hyalinem Knorpel gebildet. Bei den übrigen Gattungen ist letzterer wenigstens theilweise von Kalkknorpel und auch von ächter Knocheusubstanz verdrängt. Diese Ver- 
knöcherung scheint sehr langsam vor sich zu gehen. Bei einem 24 Centimeter langen Menopoma funde ich noch keine spur von Kilkknorpel. Bei einem Exemplar ron 40 Centinetern dagegen geht der hyaline Kinorjel des vorderen horizontalen Theils ganz allmählich nach hinten in Káalkknorpel, und aus diesem in ächten Knochen ïber, aus welchem der samze aufsteigende Ast mit dusmahme der ibbermorpelten Spitze besteht (Taf. I, Fig. 6, $h$ ). liei Siren (welche Gattung nach C'uvier ein ganz knorpeliges Zungenlein haben soll) finde ich das Verhältnis zwischen Knorpel und Iínochen umgekehrt wie bei Menopoma. Mein Exemplar von 7 I Centimetern Totallïnge hat cinen ganz knöchernen horizontalen Schenkel ('Taf. I, Fig. 2, h). Gerade da, wo dieser, beträchtlich angeschwollen, nach oben umbiegt um reinen aufsteigenden Ast zu bilden. geht die Knochensubstanz ohne Unterbrechung der Continuität ${ }^{1}$ ) erst in Kalkknorpel, dann in wirklich lyalinen Ḱnorpel über, aus welchem letzteren das ganze aufstrebende Ende besteht.

Bei Amphinma (Taf. I, Fig. 5) ist das vordere kleinere Segment ( $h^{\circ}$ ) jedes Zungenbeinhorns ganz knorpelig. Das grössere hintere $(h)$ besteht in seinem vorderen lateralen Theile $\left(h^{\prime \prime}\right)$ aus hyalinem Knorpel, der jedoch nicht wie bei Mcnopoma allmählich in die knöcherne grössere Partie übergeht, sondern in einer Längslinie scharf von derselben abgesetzt erscheint.

Bei Cyptobranchus japonicus besteht jedes Zungenbeinhorn ganz aus Ínorpel und bildet eine einzige Platte mit einer besonderen vorderen Copula. Bei der grossen Verwandtschaft dieses Salamanders mit Menopoma ist es wichtig, die stärkere Verknöcherung bei der letzteren Gattung als eine, wem anch geringe Verschiedenheit hervorzuheben.

Bei Menobranchus und Sircton finde ich die Zungenbeinhörner ganz aus hyalinem Knorpel gebildet; bei Inymerhthen datgeren ganz mit Ausnahme der iiberknorpelten spitze aus ächter Knochensubstanz.

\section{Form der Zungenbeinhörner.}

Die Formen der Zungenbeinhörner zeigen bei den verschiedenen Gattungen wenig Uebereinstimmung. Fine rom wie hinten fast sleich breite I'latte mit leichter Krümmung des hinteren Endes nach oben findet sich bei Mcnobranchus (Taf. I, Fig. 3, h), Mcnopoma (Fig. 6, h), Cryptobranchus japonicus. Die Gestalt eines ungekehrten Ruders zeigt

1) Cuviers Abbildung (Ossem. foss. Pl. 255, Fig. 9) ist olne Zweifel nach einem trockenen Praeparate angefertigt und daher der Wirklichkeit durchaus nicht entsprechend. 
Amplemema (Fig. 5. h). Thei Sivelon (Fig. 1, h) int das Zungenheiuhorn fast walzenfürmigr mit allnühlich dünner werdendem aufsteigenden $\Lambda$ ste. Bei Sircn (Fig. '2, h) ist der mittlere Theil des horizontalen knöchernen Astes fast walzenförnig, schwillt aber sowohl nach vorn zu ciner Art Gelenkkopf für den Zungenbeinkörper, als auch mamentlich nach hinten in den aufsteigenden Ast betrïchtlich an.

Es scheint nicht wesentlich die einzelnen Formen genau zu beschreiben. Wir verweisen in dieser Beziehung auf die nach frischen (Weingeist-) Priteparaten angefertigten Abbildungen der 1sten Tafel.

\section{Die Zungenbeinhörner in ihrer Beziehung zu den Muskeln.}

In Bezurg auf die vergleichende Darstellung der. Muskeln sellost verweisen wir auf den zweiten Theil dieser Schrift. Eine kurze Aufzïhlung dersclben wird hier genügen um zu zeigen, welche Partieen der Zungenbeinhörner ihnen Stützpunkte gewähren.

Von dem vorderen Winkel der Unterkieferhitlfte legt sich nach hinten über die Dorsalflïche der Zungenbeinhörner eine schnige Fascie. An diese heftet sich der $\boldsymbol{M}$. genioglossus. An die Zungenbeinhörner befestigen sich solche Muskeln, die sich mach hinten entweder an die hinteren (Ceratohyoideus extemms, auf der Figur 4 mit $h p$ bezeichnet) oder an die vorderen Enden der Dorsalsegmente (Ceratohyoideus intrmus, auf Fig. 1, 3, 4 mit pu bezeichnet) der folgenden Bogen begeben. - Bei Hypochthon, Sirecton, Amphiuma, Mcnopomu, Cinytobranchus japonicus befestigt sich ein Theil des Mylohyoideus posterior an die Aussenkante des hinteren Theils des Zungenbeinhorns.

\section{Kiemenbogen.}

\section{Zahl und Vorhältnis zu den Kiomen.}

Hinter, dem Zungenbein finden sich bei den Peremibranchiaten und Derotremen höchstens vier Bogenpaare. Die Ziahl derselben ist bei IIenobronchus und IIypochthon auf drei reduciert, doch erfolgt diese Reduction nicht etwa durch Eingehen des letzten, vierten, Bogens, sondern höchst wahrscheinlich durch eine Verschmelzung der beiden ersten. Bei 
Menobranchus ist nämlich (Tafel I, Fig. 3) der erste Kiemenbogen von ungewöhnlicher Stïrke. Durch eine tiefe longitudinal an seiner Ventralfliche verlanfende Furche ist nicht nur das Ventralsegment in zwei mit einander verschmolzene Inilften getheilt ( $b^{\prime} v$ und $b^{\prime \prime} v$ ) sondern eine gleiche Theilung liisst sich an dem Dorsalsegnente ( $b^{*}$ und $\left.b^{\prime \prime}\right)$ bis zu dessen aufsteigendem Aste verfolgen. Es ist auffallend, dass gerade die durch friihzeitiges Schwinden der äusseren Kiemen sich auszeichnenden Gattungen Amphineme und Menopomu keine Reduction der Zahl ihrer Kiemenbogen zeigen, sondern mit der höchsten Zahl, nämlich vier, ausgeriistet sind. Bei Cryptobrandus juponicus dagegen erhalten sich nur zwei Kiemenbogen, die beiden ersten bei Menopoma bis ans Zungenbein reichenden (Fig. 6, bd, $b^{d}$ ). Der dritte und vierte Bogen von Mlenopoma $\left(b^{\prime \prime \prime}, b^{u \prime \prime}\right)$ schwinden bei der verwandten japanischen Gattung.

Wie bei den Fischen, sind auch bei den Perennibranchiaten die Kiemenbogen mit einer Fortsetzung der Rachenschleimhaut fest überzogen. Diese bildet häufig an der den Kiemeuspalten zugekehrten Fliche zahmartige Fortsïtze, die jedoch ciner solideren Grundlage günzlich ermangeln. bei Siredon und Siren simd dieselben am zahlreichsten und zugleich am regelmässigsten, so dass beim Schluss der Kiemenspalten die Zïhne des einen Bogens zwischen diejenigen des anderen eingreifen. Unregelmäissigen kleinen Lüppsehen gleichen sie bei Menobranchers und Hypochthon. Bei Henopomu bilden sie ebenfalls kleine Lappen an jedem der den letzten Kiemenbogen anhaftenden Hautsäume.

Wenn im erwachsenen Zustande Kiemenbüschel vorhanden sind, so finden sich deren drei, nie mehr, nie weniger. An ihrer Wurzel schnürt sich die allgemeine Körperbedeckung gewöhnlich in einen kurzen Stiel zusammen. Diese Stiele sind theils durch die Festigkeit der Haut, theils durch die den Kiemenbïscheln eigenen Nuskelı, theils auch durch ein ihre Muskeln, Gefässe und Nerven zusammenhaltendes Bindegewebe von etwas festerer Beschaffenheit, entbehren jedoch in ihrem Innern jeder knorpeligen Grundlage. Hei Sircdon allein fehlen solche Stiele, und die Kiemenbüschel erscheinen als schlaffe, lange Aussackungen der Haut.

Die Kiemenblïtter finden sich an der ventralen Seite der Büschel. Bei Siredon stehen dieselben am wenigsten gedrüngt, und sind meist einfach. Bei allen übrigen Gattungen sind die Büschel stark verzweigt, am stärksten das letzte von Siren, das Cuvier deshalb mit der Form dreifach gefiederter Blïtter verglich. - Uebrigens hat bekanntlich Mayer (Analekten pag. 95) auch bei einem ganz jungen Menopoma kleine in Büscheln stehende Kiemenblättchen entdeckt. 
Die Kiemenbïschel können durch ein eigenes System ron Lcratores und Depressores auf und $\mathrm{ab}$ bewegt werden. Bei Siren und Iypochthon gesellt sich dazu noch ein System ron Adductores. Ueber diese Muskeln wird später gehandelt werden.

\section{Gliederung und Anheftung der Kiemenbogen.}

Der erste Kiemenbogen ist bei Amphiuma, Menopoma und Cryptobranchus japanicus ganz ungegliedert. Man liönnte in Zweifel sein, ob der an das hintere Ende des Zungenbeinkörpers angeheftete erste Bogen ron Menopoma ('laf. I, Fig. 6, b') und Cryptobranchus japonicus wirklich den Namen eines liemenbogens verdiene, und ob er nicht vielmehr als cin besonderer Theil des Zungenbeins, etwa als zweites Horn, bezeichnet werden müsse, wie dies ron allen bisherigen Autoren geschehen ist. Wirklich tritt dieser Bogen zu den hiemenspalten - von hiemenhibscheln int ohmehin keine liede - in keine directe lieziehung. Bei Amphiuma indessen, dieser ebenfalls der Kiemenbüschel entbehrenden und gleich Mcnopoma mit nur einer perennierenden Kiemenspalte versehenen Gattung, tritt der erste, ebenfalls ungewhederte, Kiemenbogen zu den fulgenden bogen und dadurch zu der hiemenspalte in wirklich nahes Verhältnis. Dieselben Muskeln (Constrictor arcum u. a.) die sich bei allen übrigen Gattungen an den ersten Kiemenbogen heften, benutzen auch bei Menopoma denselben, bisher als zweites Zungenbeinhorn bezeichneten Bogen. Es ist in der That kein Grund zur Aenderung des Namens, es sei denu, dass man sich durch den Mangel der Kiemenbüschel anch hewogen fühte, die trotzdem vorlandene seitliche Halsöfinung nicht mehr Kiemenspalte, sondern Zuugenbeinspalte etc. zu nennen. Dies aber wïrde sich schwerlich rechtfertigen lassen.

Bei allen übrigen Gattungen ist der erste Kiemenbogen in ein, dem Zungenbeinkörper angeheftetes Ventralsegment (auf den Figuren der 'I'rfel I mit $b$ v bezeichnet) und ein mit seinem Ende hinter dem Schädel vorragendes Dorsalsegment $\left(l^{\circ}\right)$ zerfallen.

Die Anheftung des ersten Kiemenbogens an den Zungenbeinkörper erfolgt bei den mit einem Ventralsegment versehenen Gattumgen meist in ziemelich fester Weise. Der liecrelfürmige Zungenbeinkörper endigt hei diesen Gattungen nämlich an der ventralen seite seines linteren Endes in zwei für das rordere Ende des dem ersten Kiemenhogen juler Soite angehürigen Ventralsegmentes genau passende Flächen. An diese sind die entsprechenden Ventralsegmente durch fibröses Gewebe dicht, aber beweglich angeheftet. (Vgl. Tafel I, Fig. 1,

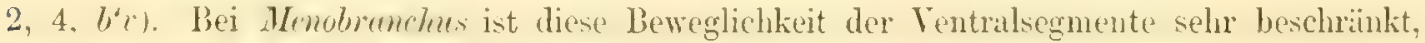
und zwar dadurch, dass die vorderen Enden derselben (Figur 3, $b^{\prime \prime} v$ ) noch durch 
den Anfang des Zungenbeinstiels zusammengehalten werden, der hier nicht an den Zungenbeinkörper, sondern durch fihrimes Gewebe an die Ventralsermente der (vershmolzenen) esrten und zweiten Kiemenbogen angeheftet ist.

Durch diese imnigere Befentigms gewïht der Zungenbeinkörper den I'eremibranchiaten eine weit festere Stütze für die von den Kiemenbogen auszuführenden Bewegungen, als den Derotremen. Bei letzteren und bei Cryptotranchus ist das vordere Ende des hier nicht gegliederten ersten Kiemenbogens (Taf. I, Fig. 5 und $6, h^{\circ}$ ) in ziemlich lockerer Weise der Ventralfliche des Zungenbeinkörpers ( $h$ ) angeheftet, welcher letzterer gïnzlich der für deren vorderes Ende geeigneten Gelenkflächen entbehrt. Bei Mcnopoma und Cryptobranchus wird die schon hierdurch verminderte F'estigkeit der dem ganzen Kiemenbogenapparat zur Stiitze dienenden Basis noch durch die geringe Festigkeit des nur aus einer breiten Knorpel-

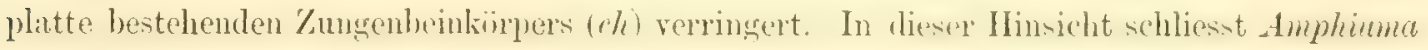
sich näher an die Perennibranchiaten an.

Dass bei Menobranclus die Ventralsegmente der beiden ersten Kiemenbogen (Taf. I, Fig. 3, $b^{\prime} v$ und $b^{\prime \prime} v$ ) ebenso mit einander verschmolzen sind, wie deren Dorsalsegmente $\left(b^{\prime}\right.$ und $\left.b^{\prime \prime}\right)$, ward schon friiher erwilhnt.

In der Regel ist auch der zweit e Kiem enbogen in ein Ventral- und Dorsalsegment zerfallen. Am deutlichsten, und ganz die Form des dem ersten Kiemenbogen angehörigen Ventralsegmentes wiederholend ist dasselbe bei Siren, Sirodon und den Larven der Salamandrinen gebildet. Bei Siren und Siredon (Taf. I. Fig. 1 und 2, b"v) ist sein vorderes

- Ende genau so an den Zungenbeinkörper", doch dessen Dorsalfläche näher angeheftet, wie das dem ersten Kiemenbogen angeheftete Ventralsegmenit. Ebenso bei den Larven der Salamandrinen (Fig. 7, g). Das hintere Lnde dieses Ventralsegments ist dann an das zugehïrige Dorsalsesment dhen-o wie bei dem exsten Kiemenbogen durch fibrimes Gewebe eingelenkt.

Bei Menopoma (Fig. 6, $b^{\prime \prime}$ und $b^{\prime \prime} v$ ) und bei der verwandten Gattung aus Japan, wo (wie bei Amphiuma) der erste Kiemenbogen $\left(b^{\prime}\right)$ ungegliedert bleibt, ist gerade der zweite ganz aus ächtem Knochen bestehende Bogen deutlich in ein Ventral- und ein Dorsalsegment gegliedert. Ersteres heftet sich mit seinem vorderen Ende an die ventrale Fläche des Zungenbeinkörpers.

Hiernach wären Hypochthon und Ampliuma die einzigen Gattungen, die eines Ventralsegmentes des zweiten Kiemenbugens enthehrend, nur das demselhen entsprechende Dorsalsegment besässen. Doch kann man, durch die Formen der ribrigen Gattungen geleitet, auch hier das dem zweiten Kiemenbogen angehörige Ventral.egment erkemen, das ebenso wie dort dem zugehörigen Iorsalsemmente als Stütze und Träiger dient, jedoch nicht mehr, 
wie bei den anderen, den Zungenbeinkörper erreicht. - Von IIypochthon hat schon Cuvier dasselbe abgebildet in den Ossem. foss. P1. 255, Fig. 16, 2. Ebenso Rusconi ${ }^{1}$ ), der dasselbe richtig als dem zweiten hiemenbogen angehörig crkannte. Es ist ein gebogenes, rorn dünues, linten dickeres Stäbchen (Taf. I, Fis. 4, $b^{\prime \prime}(v)$, dis sich um die convexe mediale Flïche des den ersten Kienenbogen angehürigen Dorsalsemmentes $\left(^{\circ}\right)$ herumschmiegt, nit seiner vorderen freien Spitze den Zungenbeiukürper nicht erreicht, hinten aber mit seinem dickeren Ende dem Dorstlsegmente des zweiten Kiemenbogens ( $b^{\prime \prime}$ ) als Stiutze dient.

Bei Amphiuma (Taf. I, Fig. 5) erscheint das Ventralsegment des zweiten Kiemenbogens als ein kleiner, hakenförmiger, medialwïrts gerichteter Fortsatz ( $b$ " $v$ ) des ersten Kiemenbogens $\left(b^{\prime}\right)$ und ist nicht mehr, wie bei Hypochthon, bloss an den letzteren angelehnt, sondern fest mit demselben rerwachsen. An diesen Haken ist das Dorsalsegment des zweiten Kiemenbogens ( $\left.b^{\prime \prime}\right)$ durch fibröses Gewebe angeheftet.

Auch der dritte Kiemenbogen hat zuweilen ein besonderes, von ihm abgegliedertes Ventralsegment. Ich vermisse ein solches hei Siren, Sivedsn, Iypochthon. Bei Amphiuma (Taf. I, Fig. 5) ist dasselbe ein kleines hnorpelstückchen (b“" $v)$ von länglich eiförmiger, rorn zugespitzter Gestalt. Es ist an den medialen, hakenfürmigen Fortsatz ( $b$ " $v$ ) des ersten Kiemenbogens, deu wir so ehen als rerkïmmertes Ventralsegment des zweiten Kiemenborgens bezeichnet haben, durch fibrüses Gewebe befestigt, hat eine vorlere freie spitze, und hïngt an seinem hinteren Ende durch fibrüses Gewobe innig mit dem Dorsalsegment des dritten Bogens $\left(b^{d \prime}\right)$ zusammen.

Ganz ähnlich finde ich bei einem jungen Menopoma von 24 Centimeter Länge innerhalb des dem dritten lỉemenbogen angehörigen Dorsalsegmentes (Taf. I. Fiø. 6, b“) ein kleines, sowohl mit ihm, wie mit dem zweiten Kiemenhogen $\left(b^{\prime \prime} v\right)$ verbundenes Kunpryelstïck $\left(b^{\prime \prime \prime} \gamma\right)$. Auch dies ist ohne 'Zweifel als das den dritten Bogen angehörige Ventralsegment zu betrachten, scheint jedoch in höherem Alter mit dem entsprechenden Dorsalsermente zu rerschmelzen.

Bei Menobranchus (Taf. I, Fig. 3), wo die beiden ersten Kiiemenbogen sowohl in ihren Ventral-als auch in ihren Dorsal-Segmenten rerwachsen erscheinen (s. oben pag. 17) ist das Ventralsegment des dritten (in Wirklichkeit jedoch zweiten) Kiemenbogens ein kleines ovales Knorpelstückchen $\left(b^{\prime \prime} r\right)$, medialwärts von den Anfïngen der verschmolzenen Dorsal-

1) 1. 1. pg. 42, Taf. IV Fig. 1, $g$. Zwischen diesem und dem Ventralsegmente des ersten Bogens besteht nach Rusconi nur die Verschiedenheit: ,che l'ossicino del secundo archetto non arriva fino alla estremità posteriore dell' osso ioide, ma si adossa all' ossicino intermedio (Ventralsegment) dell prima archetto". 
segmente des ersten und zweiten Bogens so gelegen. dass das dem dritten Bogen zuzusprechende Dorsalsegment $\left(b^{\prime \prime}\right)$ an dasselbe durch fibröses Gewebe angeheftet ist.

Währeud also der erste Kiemenbogen ziemlich allgemein (ausgenommen Mrchopoma, Amphinma und Cimptobranchus japonicus) ein getremntes Ventralsegment hat, und auch für den zweiten Bogen sich ganz allgemein cin solches nachweisen liisst, ermangelt schon der dritte Bogen riel häufiger einer solchen ron ihm abgegliederten Stütze. Noch mehr, ja ganz allgemein, enthehrt der letzte (sei dies nun der dritte, wie bei Mrypochthon und vielleicht Mcnobranchus, oder der vierte) Kiemenhogen eines hesonderen Ventralsegmentes. Von ihm ist immer nur das Iorsaliement anschebildet. Fs leuchtet ein, dass dieser letzte, für das Oeftnen und Schliessen der Kiemenspalte wichtigste Kiemenbogen, gerade durch die mehr lockere Befestigung an die rorherigen Bogen eine seiner Function entsprechende grössere Beweglichkeit erlangt.

Uebrigens scheint das Fehlen des Ventralsegmentes an einzelnen, und zwar immer an letzten Kiemenbogen nicht immer eine Folge der fortschreitenden Entwickelung sondern meist in der urspriugglichen Aulage begründet zu sein. Von Salamanderlarven bildete von Sieboldt (Obscrat. quacdam de Sulum. et Triton. fig. 1r) die Ventralsegmente der beiden ersten Kiemenbogen als gretremnte Kinorpelstäbchen al). Ebenso Dugès (Vgl. unsere nach dieses Forschers Abhildnugen copierte Figuren 7 und $\&$, $f$ und $y$, der 1 ten Tafel). Der dritte und vierte Kiemenbogen erscheinen nur in ihren Dorsalsegmenten ( $k$ und $i$, Fig. 7) ausgebildet.

Untersucht man trockene Prïperate, so scheint jedes Dorsalsegment eines Kiemenbogens, wenn es iiberhaupt ossificiert ist, - wie bei Hypochthon, Amphimma, Menopoma wieder aus meliren Abschnitten zusammengesetzt zu sein, weil seine knorpeligen Apophysen dann eingetrocknet sind, und sich scharf gegen den mittleren verkuöcherten Theil absetzen. Daher bildete Rusconi einen vorderen und hinteren abgesetzten Theil der drei Kiemenhogen ah. An frischen (Weingeist-) Exemplaren ist jedoch kein Absatz wahrzunehmen, sondern der ossificierte Theil geht allmählich durch Kalkknorpel in die knorpeligen Endstiicke über. 
Die hinteren dorsalen Enden der Kiemenbogen liegen dicht neben oder vielmehr hinter einander und häingen durch fibröses Gewebe zusammen. Mit der Wirbelsäule und dem Schädel findet im allgemeinen keine andere Verbindung, als durch die $\mathbf{M}$. levatores arcmum statt. Nur bei Siredon ist die dorsale Spitze des ersten Kiemenbogens durch eine lange und diume Selme an das Felsenbein geheftet. Ich kanm jedoch nicht bestitigen, wat Cuvier (1. 1. pag. 113) von Sivedon sagt: "Les quatre arcenux des branchies sont suspendus par lar bout extérieur ì la première vertèbre."

\section{Consistenz der Kiemenbogen.}

In Bezug auf den Grad, bis zu welchem der hyaline Knorpel des Kiemenbogengerüstes von Kalkknorpel und ächter Knochensubstanz verdrängt ist, findet sowohl bei den verschiedenen Gattungen, als auch bei den verschiedenen Bogensegmenten derselben wenig Uebereinstimmung statt.

Bei einem 31 Centim. grossen Exemplare von Menobranchus und einem Siredon von 20 Centim. Länge finde ich den ganzen Zungenbein-Kiemenbogen-Apparat aus hyalinem Knorpel gobildet mit alleinger lusnahme des ganz ositicierten Zmugenbeinstiels. Bei einem Hypochthon von 24 Centim. Lainge dagegen besteht der ganze Apparat aus ächter Knochensubstanz; nur die dorsalen Enden der Kiemenbogen sind mit hyalinem Knorpel tiberzogen und insbesondere dasjenige des ersten Bogens (Taf. I, Fig. 4, $b^{\circ}$ ) erscheint als ganz kurzer aufsteigender Ast ans hyalinem Knorpel gebildet. Bei Amphiuma (Fig. 5.) ist der erste, hier nicht in zwei Segmente zerfallene Kiemenbogen $\left(b^{\circ}\right)$, sowie sein als Ventralsegment des zweiten Bogens zu deutender hakenförmiger Fortsatz ( $\left.b^{\prime \prime} v\right)$ aus ächter Knochensubstanz gebildet. Nur seine dorsale, halbkugelförmig angeschwollene Spitze, so wie die Dorsalsegmente der drei folgenden Bogen $\left(b^{*}, b^{\prime \prime}, b^{\prime \prime \prime}\right)$ und das rudimentïre Ventralsegment des dritten Bogens $\left(b^{\prime \prime \prime} v\right)$ bestehen aus hyalinem Knorpel.

Bei einem Exemplar von Siren lacertina von 71 Centimetern Totallänge bestehen die Ventralsegmente der beiden ersten Kiemenbogen (Taf. I, Fig. 2, $b^{\prime} v$ und $b^{\prime} v$ ) aus ächter Knochensubstanz, die dorsalen Elemente dieser beiden, so wie die allein vorhandenen Dorsalsegmente der beiden folgenden Bogen ( $b^{\prime \prime}$ und $\left.b^{\prime \prime \prime}\right)$ aus hyalinem Knorpel.

Bei Ḿnopoma (Taf. I, Fig. 6) besteht der erste, hier ungegliederte Kiemenbogen $\left(b^{\prime}\right)$ so wie die vom dritten und vierten Bogen vorhandenen Dorsalsegmente ( $b^{\prime \prime \prime}$ und $b^{\prime \prime \prime}$ ) ganz aus hyalinem Knorpel; rom ganzen Kiemenbogenapparat ist nur der in zwei fast 
grleiche Segmente zerfallene zweite Kiemenlogen aus ächter Knochensubstauz geloildet. Datgegen finde ich bei einem nur 24 Centimeter langen Exemplar die hintere Hälfte des diesem (zweiten) Kiemenbogon angehürigen Dorsalsegmentes noch ans hyalinem Kunorpel gebillet.

Dieser zweite Kiemenbogen, den Mayer mit dem Namen "Kiemenknochen» bezeichnete, ist auch bei Cryptobranchus japronicus der allein verknöcherte Theil des ganzen Apparates. Ebenso wahrscheinlich bei der ausgestorbenen Art aus Oeningen. Wenigstens sind diese einzigen Stiicke des Zungenbein-Kiemenbogen-Apparates in den erhaltenen Petrefacten als die gleicharigen Stiicke ron Cryptobranchus japonicus und von MLenopoma zu unterschei(den $\left.{ }^{1}\right)$. Ihre Form ist derjenigen dieser beiden Arten so sehr entsprechend, dass sie auf den ersten Blick erkannt werden.

\section{Gestalt der Kiemenbogen.}

Die dorsalen, zur Umgrenzung der letzten, bei den Derotremen einzigen, Kiemenspaltc dienenden Abschnitte der beiden letzten Kiemenbogen haben immer eine einfach gekrümmte Bogenform mit dorsalwärts gerichteten Spitzen und einer nach aussen und unten gewandten Convexität. Bisweilen kommt diese einfachste Form auch den Dorsalsegmenten der ersten Tïiemenbogen zu. So bei Siredon und Siren (Taf. I, Fig. 1 und 2, b). Bei Menolranchus dagegen (Fig. 3), wo der erste Kiemenbogen, wie oben gezeigt, wahrscheinlich die Elemente zweier Bogen enthält $\left(b^{\prime}\right.$ und $\left.b^{\prime \prime}\right)$ ist der horizontale 'T'heil des Dorsalsegments ziemlich gerade, mit einer tiefen Längsfurche versehen, und setzt sich mit einer nicht unbeträchtlichen Anschwellung ziemlich deutlich gegen den aufsteigenden Ast ab. Auch bei Hypochthon (Fig. 4) ist der horizontale Theil des Dorsalsegments $\left(b^{\circ}\right)$ gerade und mit einer kurzen, knorpeligen aufsteigenden Spitze rersehen.

Eine ganz abweichende Form hat der erste Kiemenbogen von Ampliuma (Fig. 3, $b^{\prime}$ ). Nicht allein, dass er im Gegensatz zu den ächten Perennibranchiaten ungegliedert ist: er lat auch keinen deutlich erkennbaren aufsteigenden Ast, sondern läuft mit sehr leichter Krümmung nach aussen und hinten, um mit einem fast kugelformigen Endstïck aus hyalinem Knorpel zu schliessen. Die vordere, an den Zungenbeinkörper $(c h)$ grenzende Hälfte ist glatt; nach hinten wird der Konochen allmählich walzenfürmig. I as anfitllendste daran ist

1) Cuvier 0. f. P1. 254. Fig. 1 und 2, $h, h$. Dies sind offenbar die Dorsalsegmente. In Fig. 2 ist auch, hinter dem Schädel vorragend, das Ventralsegment zu erkennen. 
der schon oben (S. 20) erwïhnte hakenfürmige Fortsatz $\left(b^{\prime \prime}\right)$ an seiner medialen Kinte, etwa in der Mitte seiner Lünge, ein Fortsatz, in dem wir das mit dem ersten Kienenbogen verwachsene Element des dem zweiten Bogen angehörigen Ventralsegrmentes zu erblicken glauben. Dieser Fortsatz bildet zusammen mit dem linorpeligen Rudinent des dem dritten liogen angehörigen Ventralsegmentes $\left(b^{\prime \prime} v\right)$ cine kleine, rings von Kuochen und Knorpel begrenzte Höhle zur Aufuahme der auch hei Hypochthon und Ltenubrunchus an dieser Stelle liegenden traubenförmigen Drüse (Thyreoilde? auf den Figuren mit $(l \cdot$ bezeichnet).

Bei Menopoma (Fig. 6) und dem auch in dieser Hinsicht ilım vollkommen gleichen Cyyptobranchus japonicus weicht die Form des ersten Kiemenbogens von derjenigen der aichten Perennibranchiaten noch mehr ab. Er stellt hier (Taf. I, Fig. 6, $b^{\prime}$ ) eine leicht $S$ förmig schogene knorpelige Rime vor, deren Convexitait ventralwïrts, deren zur Aufnahme der Fasern des Coratohyoidcus citcmus bestimmte ausgehöhlte Oberflïche dorsalwäts gerichtet ist. Er ist, wie schon oben bemerkt, ungergliedert. Sein vorderes Ende hoftet sich an die Ventralthïche der den Zungenbeinkürper vorstellenden Krnorpelplatte (ch); die Enden beider Seiten bleiben bei Menopomu von einander getrennt, während sie bei Cryptobrunchus japonicus zu einer Art ron unvollkommenem Gelenk zusammenschliessen.

Die vorderen Enden der Dorsilsegmente aller Kiemenbogen liegen in der Regel in einer Lïngslinie unmittelbar hintereinander und sind nicht nur an ihre Ventralsegmente - wenn dereu vorhanden sind - sondern auch an einander durch fibrüses Gewebe beweglich angeheftet. Anders bei Hypochthon (Taf. I, Fig. 4). Hier liegen die überknorpelten Gelenkköpfe der dem zweiten und dritten Bogen augrehörigen Dorsalsegmente ( $b^{\prime \prime}$ und $b^{\prime \prime \prime}$ ) zwar auch hinter einander, aber nicht unmittelbar hinter dem des ersten, sondern etwa am ersten Drittheil von dessen Länge. Dieser scheimbar unwichtige Unterschied ist von Bedeutung für die Anheftung einzelner Muskeln, insbesondere des Constrictor arcum.

\section{Beziehung der Kiemenbogen zu den Muskeln.}

In Bezug auf die Muskeln der Kiemenbogen verweisen wir auf die spiiter folgende vergleichende Darstellung. Hier sollen nur einige Punkte hervorgehoben werden, in denen theils einige Bogen selbst, theils einzelne ihrer Particen sich vor den übrigen auszeichnen.

Die Ventralsegmente der Kiemenbogen dienen nur zur directen Anheftung solcher Muskeln, die bestimmt sind, den Zungenbein-Kiemenbogen-Apparat vor- oder rückwärts $z u$ bewegen. Namentlich die vordere Partie des grossen Seitenbauchmuskels, die wir als Ster- 
nolygoidus bezeichmet haben, findet hier eimen ihrer vorderen Ansatzpunkte. - Itei Hypochthon (Taf. I, Fig. 4) und Siren heftet sich auch unser Protractor (urcus ultimi (hp') an das dem zweiten Bogen augelörige Ventralsegment $(b " v)$.

Viel håufiger sind die mit jenen - wenigstens meistentheils - beweglich verbundenen Dorsalsegmente zur directen Anheftung von Muskeln benutzt, so dass jene ventralen, vorderen Segmente in der That mehr als Trïger und als Stützen für die von den hinteren, dorsalen Abschnitten ausgefülirten Bewegungen dienen.

Von den verschiedenen Muskelsystemen setzen sich diejenigen, deren Contractionen unmittelbar oder mittelbar (durch Krimmung der Bogen) eine Oeffung der Kiemenspalten

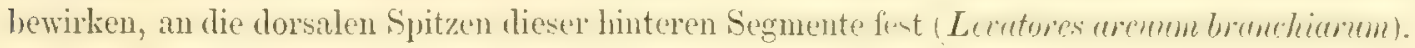

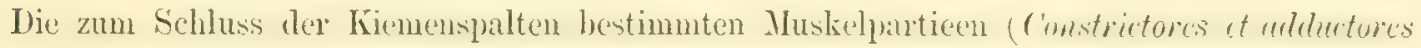
arcum heften sich dagegen an die vorderen Enden dieser Dorsalsegmente, nahe bei deren Gelenk. - Der convexe, nach aussen und unten gerichtete Rand dex Dorsalsegmente dient den Pexemibranchiaten zur Anheftumg dex die Kiemenbiischel beworenden Muskeh (Levetores, Depressores und Adluctores branchiarm).

Vor den übrigen ist der erste Kiemenbogen nicht nur oft, wie oben gezeigt, durch seine Form ausgezeichnet, er ist auch der hauptsächlichste Stiitzpunkt fuir MIuskeln. An seinen aufsteigenden $\Lambda$ st heftet sich der krïtigste und bestindigste aller Zungenbein-Kiemenbogen-Muskeln, der Ceratolyoideus extemus; an ihn heftet sich forner der schr starke $\boldsymbol{M}$. levator arcus primi. Er dient zuweilen einem 'Theil des Digastricus (Menobranchus), oder auch einer Partie des Mylohyoideus zur Stütze (Hypochthon). Das vordere Ende des Dorsalsegmentes dieses ersten Kiemenbogens wird von dem Ceratohyoideus intermus zur Anheftung benutzt.

Die zwischen dem ersten und letzten liegenden Bogen sind als besondere Stiitzpunkte für Muskeln nicht ausgezeichnet. An sie inserieren sich nur solche Muskeln, die eine

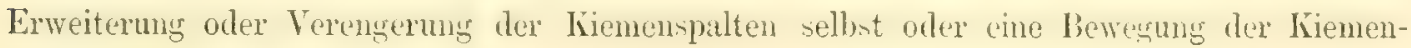
büschel veranlassen.

Desto merkwïrdiger ist der letzte Bogen, von dem, wie oben bemerkt, ganz allgemein nur das Dorsalsegment ausgebildet ist. Von seinem Anschluss an die iibrigen Kiemenbogen hïngt wesentlich die Verengerung der Kiemenspalten ah, un so mehr, wenn deren, wie bei Menopona und Amphiuma nur eine einzige, gerade vor diesem Bogen sich öffnende vorhanden ist. Umgekehrt ist es gerade der letzte Bogen, der an den Leib und von den übrigen ahgezogen, die Kiemenspalte üfhet. Nicht nur die Constrirtorcs urome (auf den Figuren mit $c a$ und $c t^{\prime}$ bezeichnet) sondern auch der die Kiemenspalten erweiternde ("unstrirtor 
pharyngis $(c p, h p)$, Dilatator aditus laryngis ron Henle beuannt, suchen an ihm ihren Stïtzpunkt. Durch letzteren Muskel tritt der letzte Kiemenbugen auch zum schlunde und zu der Luftröhre in nahe Beziehung, sofern er einen Theil der zum Verschluss derselben dienenden Fasern von sich ausgehen lässt. Doch ist diese Beziehung keineswegs eine so nahe, wie bei den Fischen, wo das Patar der oft sigenthümlich gestalteten und hewaftineten letzten Bogen den Ximen ron Schlundliefern erhalten hat. Wenn daher die Veranlassung zu dieser besonderen Benemnung schon bei den Fischen weder genetisch noch in architectonischer Beziehung eine zwingende war, so ist es noch weniger gerathen, sie auf das letzte Kiemenhogenpaar der. Amphibien zu ithertragen, wozu man nach Rat likes Darstellung sich genöthigt sehen könnte ${ }^{1}$.

\section{Die medialen Verbindungsglieder der Bogenpaare.}

Ein Vergleich der seitlichen Bogenpaare bei den verschiedenen Amphibiengattungen zeigt uns dieselbe Formveränderung, die bei der Entrickelung der Salamander und Tritonen beobachtet sind. Wo die Kiemenbiischel und endlich selbst die Kiemenspalten eingehen, da schwinden die letzten Bogenpare und die rorderen treten zu dem Zungenbeine in innigere Beziehung.

In Bezug auf die unpaaren mittleren Copulae dagegen stellen uns die Formen ron

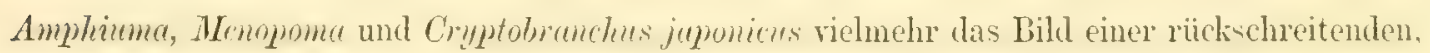
durch Hinzubildung neuer, den erwachsenen Salamandern fremder Stücke sich kund geben-

1) Anatom. philosoph. Intersuch. über den Kiemenapparat und das Zungenbein der Wirbelthiere, 1832, pag. 36. - Ganz unrichtig ist es, wenn R. meint, dass' $v$. Sieboldt die von ihm (Rathke) den Schlundkiefern der Fische verglichenen letzten Kiemenbogen der Salamanderlarven als diejenigen bezeichnet habe, die nach der Verwandlung mit dem vordersten Paare allein übrig blieben, während die zwischen ihnen liegenden zwei mittleren Bogenpaare allnählich verschwänden. In v. Sieboldts Schrift findet sich nichts, woraus diesem Forscher eine solche Ansicht zugeschrieben werden könnte. Ër lezeichnete in Gegentheil die Ventralsegmente der zwei ersten Kiemenbogen (zweites Horn und Columella) als die dem erwachsenen Zustande allein verbleibenden, den späteren Zungenbeinapparat mit constituierenden Elemente. - Dieser durch von Sieboldt und später durch $\mathrm{D}$ ugès aus directer Beobachtung der Salamanderlarven gezogene. Schluss bestätigt sich durch die Vergleichung von Mrenopoma und Cryptobranchus japonicus. Die letzten zwei Kiemenbogen der ersteren Gattung sind bei dem verwandten Geschlechte aus Japan geschwunden, und die mit dem Zungenbein verbunden bleibenden Elemente stammen aus dem ersten und zweiten Bogen. 
den Metamorphose dar. Bei den mit bleibenden Kiemen versehenen Gattungen ist nur Eine mediale Copula vorhanden, gleichzeitig der Anheftung der Lungenbeinhörner wie der Kiemenbogen dienend. Die drei letztgenannten Gattungen sind dagegen ausser dem sogenanuten Zungenbeinkörper - der ihnen nur als Copula für die Kiemenbogen dient noch mit einer besonderen, speciell für die Zungenbeinhörner bestimmten Copula versehen. Dieselbe ist bei Amphima (Taf. I, Fig. 5, ch') und bei Menopoma (Fig. 6, cht) beträchtlich kleiner, als die Hauptcopula $(c h)$, und stellt bei beiden eine kleine, ganz aus hyalinem Knorpel bestehende Platte vor, die durch fibröses Gewebe sowohl an die vorderen Enden der 'Jumgenbeinhöner als an dasjenige der zweiten Copula (des Zungenbeinkürpers) geheitet sind. Die schon durch die Gliederung ihrer Zungenbeinhörner ( $h$ und $h^{*}$ ) gesteigerte Beweglichkeit des rorderen Theils ihres Zungenbeinapparates wird oftenbar durch diese Einschaltung einer besonderen vorderen Copula noch beträchtlich erhöht. - Auch bei Cryptouranchus japonicus ist eine vordere Copula vorhanden, die durch zwei seitliche Arme den Zungenbeinhörmen zur Anheftung dient. Letztere erfolgt durch Bandmasse, durch Vermittlung. einer medialen hinteren Spitze.

Allen anderen, mit bleibenden Kiemen versehenen Gattungen kommt, wie erst bemerkt, nur ein einziges unparres Verbindungsglied zu. Es ist jedoch zu bemerken, dass seine innere Beschaffenheit bei einigen Gattungen auf eine erst später erfolgte Terschmelzung zweier Copulne schliessen lïsst. Bei Siren lacertina ist das vordere Ende (Taf. I, Fig. 2) des Zungenbeinkörpers $(c h)$ beträchtlich angeschwollen, und besteht ventralwiirts aus derselben ächten Knochensubstanz wie der ganze nachfolgende Theil. Der dorsale Theil (ch')

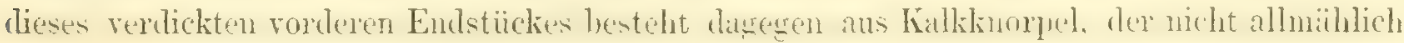
in jene Kónochensubstanz übergeht, sondern dieselbe - ähnlich wie die Epiphysen an den Gelenkköpfen der Batrachier - mützenartig umgiebt. Vielleicht, dass hier eine spätere Verwachsung ursprünglich getrennter Elemente vorliegt.

Ausser dieser vorderen, nur für die Zungenbeinhörner bestimmten und nur den kiemenlosen Gattungen getrennt zukommenden Copula haben alle Perennibranchiaten ein zweites grösseres mediales Verbindungsglied, das mit dem Namen "Zungenbeinkörper" bezeichnet worden ist. In der That aber ist dasselbe (auf den Figuren der Taf. I mit ch bezeichnet) nicht sowohl den Zungenbeinhörnern, als viehnehr den Kiemenbogen zuzuzïhlen, da es bei den mit einer vorderen Copula versehenen Gattungen jeder näheren Verbindung mit den ersteren ermangelt, bei denjenigen aber, wo diese Verbindung existiert (Siven, Siredon, Menobranclus, Hupochthon) rermuthlich auch die Elemente der vorderen. urspringrlich für die Zungenbeinhörner bestimmten Copula enthält. 
In der Regel ist die Forn dieser zweiten Copula die eines Kegels mit nach rorn gerichteter Spitze. Zuweilen ist diese Spitze kugelfömig verdickt (Siren, Fig. 2, ch; Amphimma, Fig. 5, ch; Mypurhthon, Fig. 4, ch), zuweileu aher auch spitz ohne jede Anschwellung (Sircton, Fig. 1, ch; Menobranchus, Fig. 3, ch). An dieselbe lehnen sich, durch fibröses Gewebe innig, aher beweglich damit rerbunden, die rorderen Enden der Zungenbeinhörner, während das hintere dickere Ende die Ventralsegmente der ersten Kïiemenbogen trägt.

Ganz abweichend von dieser Gestalt ist die zweite Copula von Menopoma und Cryptouranchus juponims. Bei beiden stellt sie eine duinne, biegsame, unregelmässig fünf- oder sechseckige Platte mit alogerumleten Ecken vor (Taf. I, Fig. 6, ch). Dem hinteren Theil ihrer Ventralfliche sind die zwei ersten liemenbogen angeheftet; der Vorderraud steht wit der vorderen Copula durch Bindegewebe in lockerer Verbindung.

Es ward schon oben erwähnt, dass die diesen beiden Gattungen zukommende Plattenform des Zungenbeinkörper's die Beweglichkeit der vorkeren Partie des Kiemenlogengeriistes wesentlich steigert. Ehenso gewiss ist es aber auch. dass gerade durch diese Beweglichkeit ıler feste Stiitzpunkt verloren geht, dessen die äichten Peremibranchiaten bei den Bewroungen ihrer Kiemenbogen bedürfen.

\section{Der Zungenbeinstiel.}

Bei unserem Erdsalamander beschrieb bekanntlich v. Sieboldt unter dem Namen Ossiculum thyrcoidtum ein kleines, schon von Me ckel entrlecktes dreieckiges Ḱnochenstückchen, das in der Mitte der Entfernung zwischen Herz und Zungenbein in den oberflïchlichen Schichten desjenigen Muskels liegt, der sich als Fortsetzung des grossen Bauchmuskels bis zum Zungenbein erstreckt.

D ugès erkannte die Zusammengehörigkeit dieses Tinochenstiickchens zu dem Zungenbeinapparat daran, dass dasselbe bei den Larren der Salamander mit letzterem durch einen feinen, später schwindenden Stiel zusammenhängt. Er wies ferner nach, dass auch die Tritonenlarven mit einem solchen, später schwindenden, Zungenbeinstiel — aber ohne jene dreieckige Endplatte - ausgerüstet scien. Auf unserer, nach D ugès copierten Figur 7 der Taf. I ist derselbe mit $c$ bezeichnet.

Alle ächten Perennibranchiaten (Siren, Siredon, Hypochthon, Menobranchus) sind mit einem solchen, dem Zungenbeinapparate angehängten medialen Stiele versehen. Er ist bei 
den ersteren drei Gattungen direct an das hintere Ende des Zungenbeinkörpers durch fibröses Gewebe beweglich angehängt (Taf. I, Fig. 1; 2; 4;s). Nur bei MTenobranchus (Fig. 3,s) ist das breite Vorderende dieses Stiels den beiden Ventralsegmenten der vordersten Kiemenbogen da angeheftet, wo diese unter einem mach hinten offenen Winkel zunammenstussen, so dass er bei dieser einzigen Gattung den Zungenbeinkörper nicht erreicht.

In der That hat der Zungenbeinstiel mit den Kiemenbogen und dem Zungenbein kaum etwas anderes als jenen vorderen Stützpunkt gemein. Keiner der die ersteren oder die Zungenbeinhörner bewegenden Muskeh setzt sich an denselben an. Nur das vordere Ende des grossen Bauchmuskels (des Sternohyoidens) und dessen bis an den Unterkiefer sich erstreckende vordere Partie (der Geniohyoiders) benutzen den Zungenbeinstiel, wo er sich findet. zur Anheftung. Seine Bedentung scheint keine andere zu sein. als eine Verknöcherung sonst sehniger Muskelstätzunkte, die sich bei langen Muskeln gewissermassen als Stationen in ihrem Verlaufe unter der Form von inscriptiones tendineae, und zwar zuweilen wirklich verknöchert, finden.

Der Zungenbeinstiel mit seiner Endplatte ist bei den verschiedenen Gattungen nicht ganz gleich gebildet. Am breitesten und zweitheilig ist die Endplatte bei Siredon (Fig. 1, s), schmaler bei Menotranchus (Fig. 3,s), am schmalsten und kaum breiter als der Stiel, bei Hypochthon (Fig. 4, s). Bei Siven (Fig. 2) tritt dieselbe ihrer Bestimmung, dem graden Bauchmuskel als Anheftungsfläche zu dienen, noch näher dadurch, dass ihr hinterer Raud in gleichen Abstinden Arei bis vier in die Substanz der Kinochenplatte eingebettete Streifen von hyalinem Knorpel ausschickt, an welche die in feine Sehnen auslaufenden oberflïchlichen Schichten des Stemohyoidens sich ansetzen. Diese Streifen entspringen ron den Enden der drei (bei einem anderen Exemplar fand ich deren vier) Fortsätze, in die sich die Endplatte theilt. (Vgl. Taf. I, Fig. 2 a und 2 b.) - Letztere besteht immer aus ächtem Linochen, selbst wo die übrigen Theile des Kiemengerüites nicht ossiticiert sind (Nenubranchus, Siredon). Nit alleiniger Ausuahme ron Siredun ist auch der die Endplatte tragende Stiel ans ächter Knochensubstanz gebildet. Lici dieser Gattung allein besteht er aus einer sehr biegsamen Masse, welche die Mitte zwischen filorüsem Gewebe und hyalinem Knorpel zu halten scheint.

Den Gattungen Amphinma, BInopoma und Cryptobranches joponicus fehlt bekantlich der Zungenbeinstiel. Die sonst an denselben sich anlehnenden Muskeln suchen hier theils an den Ventralsegmenten der Kiemenhogen, theils an einer Fascis ihren stiitzpunkt, welche die hinteren Zungenbeinmuskeln rentralwärts überzieht. 


\section{Der Zungenbein- und Kiemenbogen-Apparat der Salamandrinen.}

Eine ausfïhliche Schilderung des Ipparates bei den salamandern und Tritonen liegt ausserhalb der Grenzen dieser Schrift. Auch sind wir derselben durch die vortrefflichen Arbeiten von Sieboldt's mal Duges' überhoben. Wir beschräuken uns daher auf eine vergleichende Uelsersicht über die einzelnen Theile desselben und verweisen zu diesen Zwecke auf die dem Dugès'schen. Werke entlehnten Figuren 7, 8 und 9 unserer Taf. I.

Der Zungenbeinkiemenbogen-Apparat der Salamanderlarven (Fig. T, Larve von Tritun mamoratus) stimmt mit dem Baue der Peremibranchiaten, insbesondere von Siren und Sirulon (Fig. 1 und 2) so ausmehmend ïberein, dass es bei einer Vergleichung der Abbildumgen schwer hält, irgend welche wesentliche Interschiede aufzufiuden. Die Zungenbeinhörner (Fig, 7, c) sind wie bei Amphiuma und Menopoma in einen vorderen kleineren $(d)$ mul einen hinteren srösseren Abschuitt (e) zerfillen, und hïngen, hierdurch ebenfalls an diese beiden Gattungen erinnernd, durch eine vordere kleinere Copula $(\alpha)$ mit einander zusammen (glosso-hyal Dugès).

Durch die Zahl und Form der Kiemenbogen werden wir ganz an Siren und Siredon crinnert. Wie bei diesen sind deren vier vorhanden $(h, i, j, k)$, von denen die beiden (risten durch besondere Ventralsegmente (f und g) mit dem kegelformigen Zumgenbeinkürper (h) zusammenlü̈ngen. Der dritte und viurte Kiemenbogen exmangeln der Ventralsegmente. Die dorsalen Endspitzen aller vier Kiemenbogen sind durch fibrüses Gewebe mit tinander verbunden, und dienen wie bei den Perennibranchiaten den Levatures arum zur Anheftung.

Ein Zungenbeinstiel (Fig. 7, c) ist nach Dugès sowohl bei Tritonen- als bei Salamander-Larven vorhanden, ermangelt jedoch bei ersteren der den letzteren eigenthümlichen, und auch im späteren Alter verbleibenden Endplatte ${ }^{1}$ ).

Die Entwickelung aus dieser, im ganzen mit den Perennibranchiaten völlig übereinstimmenden Form geht nun nach Dugès bei fortschreitender Metamorphose in der Weise vor sich, dáss die Dorsalsegnente der drei letzten Kiemenhogen (Fig. 7, i, $j, l$ ) allmïhlich

1) Von Sieboldt übersah den in ganz jugendlichem Zustande der Salamanderlarven stattfindenden Zusammenhang dieser Endplatte mit dem Zungenbein. 
schwinden, und sonit schliesslich nur die beid ensegmente des ersten (Fig. $8, f$ und $h$ ) und das Ventralsegment des zweiten Kiemenbogens (g) ïbrig bleihen. Spuiter verknïchert sowohl das Veutralsegment (Fig. 9, $f^{\prime}$ ) als das Dorsalsegment (b) des crsten hiemenhogens, wïlurend das ehenfalls bleibende Ventralsegment $(g)$ des zweiten Iogens seine knorpelige Beschaffenheit behïlt.

Im Verlaufe der Entwickelung verändert sich auch der Zungenbeinkörper. Sein Stiel schwindet gänzlich mal nur den Salamandern bleibt als Rudiment desselben das Sieboldtsche Os thyreoideum für das ganze Leben erhalten. Vielleicht aus der vorderen Copula (Fig. 7, a), vielleicht auch aus dem vorderen Segmente (d) der Zungenbeinhörner bilden sich eigenthümliche, den Perennibranchiaten fremde seitliche Fortsätze (Fig. 8, d), von denen dem erwachsenen Zustande nur einer (Fig. 9, $l$ ) zu verbleiben scheint. Diese Fortsätze, die rordere breitere Hälfte und der Endknopf der 'Zungenbeinhörner, sowie die dem zweiten Kiemenhogen zuzusprechenden Ventralsegmente $(g)$ sind die einzigen Theile, die sich im erwachsenen Zustande als Knorpel erhalten. Alles andere rerkü̈chert rollstindig.

Wir haben soeben die bei Siren und Siredon gefundene Form des Zungenbein-Kiemenbogen-Apparates, als mit derjenigen der Salamanderlarven vülig übereinstimmend, mit der Form der erwachsenen Salamander verglichen. Dürfen wir ebenso mit den Formen von Menopona und Cryptobranchus japonicus verfahren, so kommt ein ganz ähnliches Resultat zum Vorschein, gleich als ob jene Gattung die bildung einer Latre, diese dargegen diejenige eines ausgewachsenen Thieres im Baue des Zungenbein-Apparates repraesentierte. Die beiden letzten Kiemenbogen von Mcnopoma (Fig. 6, $b^{\prime \prime \prime}, b^{\prime \prime \prime}$ ) sind bei dem Riesensalamander geschwunden; die vorteren sergmente der Zungenbeimhörner ( $h$ ) jener Gattung hahen sich bei der letzteren mit der vorderen Copula zu seitlichen Fortsätzen vereinigt: in jeder anderen Hinsicht entopricht der Zumgenbein-Riemenbogen-Apparat der japanischen fiattung vollkommen der Form des ihr rerwandten Geschlechtes aus Nordamerika. - Nur ist freilich der eine Unterschied ron der Metamorphose der Salamanderlarven zu beachten, dass den letzteren rom zweiten Kiemenbogen nur das Ventralsegment dauernd rerbleibt, währeml sich bei Cryptobranchus japonicus die ersten beiden Kiemenbogen von Menopoma durch das ganze Leben erhalten. 


\section{Das Zungenbein der Caecilien.}

Der Zungenbein - Kiemenbogen-Apparat der Caecilien weicht von demjenigen ailer übrigen Amplibien so sehr ab, dass sich nur wenige Vergleichungspunkte finden lassen.

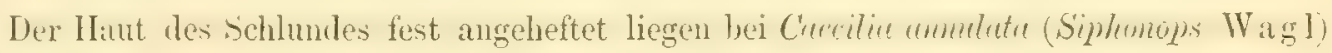
vor der odfumus der stimmlade drei feine Kunpellogren in kurzen Entfernungen hinter einander (Taf. VI, Fig. 1, $\left.b^{\prime}, b^{\prime \prime}, b^{\prime \prime \prime}\right)$. Diese Bogen erstrecken sich von der cinen Seite des Körpers quer unter dem Schlunde zur anderen hinüber. Ihre Continuität ist dabei weder in der Mitte noch sonst wo unterbrochen, so dass der Typus eines aus paarigen, durch mexliale Copulae verbundenen Schenkeh bestehenden Visceralkdelettes an diesen drei Bogeu nicht mehr zu erkennen ist. Dieselben drei bogen sind in gleicher Form und Latge

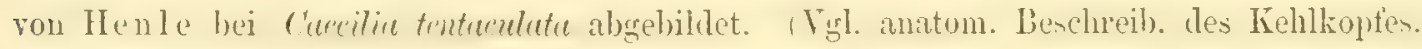
1839. Taf. I, Fig. 1, $c, d, e)$. Dieser parige Typus tritt dagegen sowohl vor dem ersten als hinter dem letzten dieser drei Konorpelbogen durch besondere, ihnen angeheftete. patarge Glieder hervor.

Vor dem ersten Bogen befinden sich nämlich bei Caccilia anmulata zwei Sförmig gebogene Knorpelstreifen (Taf. VI, Fig. 1, h), die mit ihrem einen, medialen Ende die Mitte des ersten jener drei ventralen Halbgürtel erreichen, und hier mit einander so wie mit den letzteren durch fibröses Gewehe zusammenhängen. Inas äussere Ende häugt mit dem nächsten Bogen wicht zusammen. - In den von Henle für Caccilia tentaculata gegebenen . Dbildungen sind diese beiden rordersten Kónorpelstreifen cbenfalls angegeben (a. a. 0. b), doch bilden sie bei dieser Gattung einen continuierlichen, von der einen Seite zur anderen hinïbergehenden Kinorpelstreifen, und wiederholen so die Form der drei folgenden Bogen. Wir glauben uns nicht zu irren, wenn wir jene als Zungenbeinhörner bezeichnen, und die drei folgenden knorpeligen continuierlichen Halbgürtel den Kiemenbogen der übrigen Amphibien vergleichen.

Dem unteren Ende des letzteren dieser Kiemenbogen ist bei $C$. tentaculata nach Henle ein fünftes Kinorpelstïbchen (a. a. O. e ) angeheftet, das dieser Forscher als fünftes Horn bezeichnet. Bei Caec. cmmulata ist dieses Stïbchen mit dem äusseren Endtheil des vorherigen Bogens zu einer einzigen ovalen Endplatte verwachsen (Taf. VI, Fig. 1, $U^{\prime \prime}$ ), die den betreffenden Kehlkopfsmuskeln ihre ventrale Fläche zur Anheftung bietet.

Von medialen Verbindungsgliedern ist bei Caccilia anmulata nichts zu entdecken. Die 
eimzelnen Bogen sind mit einander nicht verbunden, sondern längen (mit Ausuahme der erst erwähnten Anheftung der Zungenbeinhörner) nur durch Muskeln mit einander zusammen. Bei C. tentaculate wird dagegen von $\mathrm{Henle}$ ein kurzes longitudinales Kinorpelstïbchen abgebildet, das sich von der Nitte des ersten bogens, unserem Zungenbeine, bis zur Nitte des zweiten Bogens (des ersten Kiemenbogens) erstreckt. Henl e bezeichnete dasselbe als Zungenbeinkörper (a. a. O. a.).

Die wesentlichen Unterschiede des Visceralbogrenskelettes der Caecilien vou demjenigen der Perennibranchiaten bestehen denmach in folgenden Pmkten:

1. Die drei als Kiemenbogen von uns bezeichneten Bogen bilden continuierliche Halbgiurtel, ohne in paarige Schenkel zu zerfallen.

2. Mediale Verbindungsglieder als Stiitzpunkte für die den einzelnen Bogen eigenthümlichen Bewegungen existieren höchstens (Caccilia tentaculatu nach $\mathrm{Henle}$ ) zwischen dem ersten (Zungenbein) und dem zweiten Bogen (Ǩiemenbogen).

3. Ein Zungenbeinstiel ist nicht vorhanden.

4. Der letzte Bogen liefert durch ein seinen äusseren Eudstiicken angeheftetes zuweilen discretes (Caec. tentaculata) zuweilen auch mit ilm verwachsenes (Caec. amulat $\iota$ )

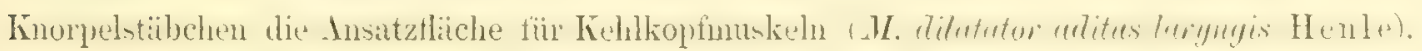

Die von den einzelnen Bogen ausgeführten Bewegungen werden bei den Caecilien durch Muskeln veranlast, die denjenigen der Perennibranchiaten verglichen werden kïmon. Die äusseren Enden der Kiemenbogen werden durch die auch jenen, eigenthümlichen Lcvatores arcum gehoben. Die Bogen selbst, namentlich deren mediale Partieen können durch Constrictoren mit longitudinal verlaufenden Fasern einander genïhert werden. Von der nach hinten gerichteten Concavitit des Sförmig gekrümmten ersten Burons (von uns dem Zungenbeinhorne verslichen) erstreckt sich mit schrigr nach hinten und atusien verlaufenden Fasern ein Muskel an den Vorderrand des folgendern (ersten Kiemen-) Bogrens, den wir mit dem Ceratohyoideus exterms der Perennibranchiaten vergleichen möchten. 



\section{Zweiter Theil.}

Die Mruskeln der Kiemenbischel und der Visceralbogen. 


\section{Muskeln der Kiemenbüschel.}

Dass die Kiemenbiischel des Axolotl durch hesundere, an die Kiemenhogren befestigte Muskeln gehoben und gesenkt werden kömen, ward schon ron Cuvier (Duremoy) angegeben ${ }^{1}$ ). Die genaue Angabe der Insertion dieser Muskeln jedoch, von der eben die den Kiemenbüscheln eigene Bewegung abhängt, wird an der angeführten Stelle vermisst. Mlayer ${ }^{2}$ ) bat bei Menobranclues mindestens unsere Depressores branchiarum erwähnt, jedoch ebenfalls nicht genau untersucht. Dasselbe gilt ron Léon-Vaillant³), der die ron einer lebenden Siren lacrotinu ausgeführten Bewegungen der Kiemenbiinchel beschreiht, in der anatomischen Lntersuchung des dieselhen veranlassenden Apparates aher nicht mit der nöthigen Genauigkeit zu Werke gegangen ist.

Bei den Perennibranchiaten kommen drei rerschiedene Muskelsysteme der Kiemenbüschel vor, von denen jedoch das eine (unsere Adductores) nur bei Siren lacertina vollkommen ausgebildet zu sein scheint. Wir bezeichnen diese drei Systeme mit dem Namen der Levatores, Depressores und Adductores branchiarum.

\section{Die Mm. levatores branchiarum.}

Der M. levator branchiae primae geht bei Siredon pisciformis rom oberen hinteren Ende des Dorsalsegmentes des zweiten Kiemenbogens nach unten und hinten an den

1) Sur les reptiles donteux pag. 115, in $\mathrm{Humboldt}$ Recueil d'Observatt, de Zoologie, ferner Cuvier, Leçons d'Anatomie comp. Tome IV, pag. 391 (Edit. 1805).

2) Analekten, pag. 84 .

3) Annal. des sciences natur. 1863, pag. 340: „Les branchies sont d'ordinaire étalées perpendiculairement à l'axe du corps pendant le repos; mais si l'on vient à toucher l'animal, il les abaisse sur les fentes branchiales en les rapprochant du corps." 
oberen hinteren Rand des ersten Kiemenbüschels. Ebenso heftet sich der Levator br. se("untur: $(17, ")$ an die entsprechende Stelle des dritten Kiemenbogens an, mu sich in das

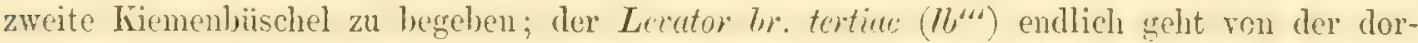
salen spitze des vierten Kiemenhogens an die hintere und obere Fliiche des dritten Büschels. - Die oberen Anheftungsunkte dieser drei Muskeln liegen dicht neben cinander, da die dorsalen Spitzen der Kiemenbogen einander beinale berihren. Doch sind sie deutlich getrennt, so dass jedes Büschel seinen Levator nicht von dem ihm der Zahl nach entsprechenten, sondern von dem folgenden lïiemenhogen erhiilt. - Von der dorwalen spitze iles ersten Kiemenbogens geht kein Levator an die Kiemenbischel ab.

Dieselben Muskeln, nur viel schwächer, finden sich bei Menobranchus (Taf. III, $\boldsymbol{W}^{\prime}$, $\left.l b^{\prime \prime}, l l^{\prime \prime}\right)$. Sie haben hier dieselbe Anheftungstweise, wie bei Siredon, nur mit derjenigen Modification, die durch den Mangel eines vierten Kiemenbogens bedingt ist. Es erstrecht sich nämlich der erste Levtor vom Aussemrande des Dorsalsegmentes des zweiten Kiemenbogens in das erste Biischel, dagegen sowohl der zweite, als auch der dritte Levator an den Aussenrand (uahe der dorsilen Spitze) des dritten Kiemenbogens befestirst sind, un sich von hier aus respective in die Dorsalflächen des zweiten und des dritten Biischels zu erstrecken.

Bei Hypochthon konnte ich von diesen Muskeln nur den äusserst schwachen, aus wenigen Fascikeln bestehenden Levator br. primae und den Lev. br. sccundae finden, die aber ganz denselben Ursprung und Verlauf haben, wie bei Siredon und Menobranchus. Einen Levator des dritten Büschels habe ich rergebens gesucht.

Umgekehrt gelang es nicht, bei Siren lacertina die Levatores der beiden ersten Kiemenbuischel aufzufinden. Nur für das dritte, bier stärkste Büischel existiert, wie es scheint, ein Levator. Dieser aber entspringt nicht, wie bei Siredon und Menobranchus von folgenden (vierten), sondern von vorhergehenden zweiten liemenhogen, und zwar wie gewöhnlich von dem convexen Rande des Dorsalsegmentes. Er geht in die Dorsalfläche des dritten Kiemenbiischels.

Die Levatores branchiamm stellen, wie sich aus deren Insertion ergiebt, ihre Kiemenbiischel nach oben und, je nachdem sie sich an das Dorsalsegment des folgenden (Siredon,

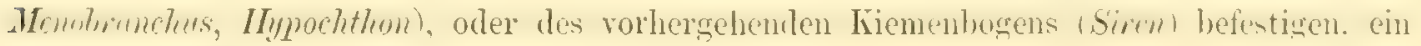
wenig nach hinten oder nach vorn. 
Ihre Antagonisten sind

\section{Die Mm. depressores branchiarum.}

Bei Siredon, wo auch die Levatores am stärksten ausgebildet sind, erstreckt sich rom ganzen unteren Rande des Dorsalsegmentes jedes der drei ersten Kímenbogen mit langer Basis ein Muskel, der nach aussen und oben sich zuspitzend längs des unteren Rimdes seines Kiemenbüschels his in die Nitte eines jeden derselben verlïuft (Taf. I, Fig. 1, $\left.a b^{\prime}, a b^{\prime \prime}, a b^{\prime \prime}\right)$. Jeder dieser Muskeln stellt sein Kiemenbüschel nach vorn und unten.

Menobranchus hat dieselben drei Muskeln (Fig. 3, $d b^{\prime}, d b^{\prime \prime}, d b^{\prime \prime}$ ) nur viel schwächer. Mayer (Analekten pag. 84) scheint die Depressores und Levatores zusammenzufassen, weun er angiebt: „Zu jerlem Kiemenbüschel gehen zwei ziemlich starke Iuskeln rom Kiemenbogen zu der Wurzel des Kiemenbüschels."

Bei Hypochthon habe ich, wie den Levator, so auch den Depressor branchiac tertiac vergebens gesucht. Es scheint, als ob das dritte Büschel der Bewegung des zweiten folge, mit dem die Haut seines Stiels sehr nahe zusammenhängt.

Bei Sircn lacertina konnte ich von den Kiemenbogen entspringende Depressores eben so wenig finden, wie die Lecatores der beiden ersten Büschel. Dagegen besitzt Siren, und zwar vollstindig ausgebildet nur diese Gattung ein drittes System von Muskeln, das zur Verstellung der Kiemenbüschel nach hinten und innen (an den Leib) dient.

Dies sind die

\section{Mm. adductores branchiarum.}

Der er ste derselben, der Adductor branchiae primae, ist ein sehr feiner, dünner Muskel, der sich von der freien dorsalen Spitze des zweiten Kiemenbogens schräg nach rorn und aussen in den Stiel des ersten Büschels erstreckt. In gleicher Weise geht der nur wenig stärkere Adductor br. secundae von der freien Spitze des dritten líiemenhogens, wo seine Anheftung unter dem Leveror bronchiue tertiue versteckt liegt, schrär nach vorn und aussen an die Wurzel des zweiten Kiemenbüschels.

Bei weitem der stärkste Muskel dieses Systems ist der' dritte, der $\boldsymbol{M}$. adductor $\mathbf{\text { ran- }}$ chiac tertiae. Dieser entspringt als sehr starker Muskel von dem rorn offenen Winkel, den die Pars clavicularis des Schultergerüstes mit der Pars scapularis bildet, und geht nach vorn und oben mit den meisten Fasem in den Stiel des dritten, stärksten Kiemenbüschels, mit wenigen Fasem auch an die dorsale Spitze des rierten Kiemenbogens. Er zieht das letzte Kiemenbüschel kräftig an den Leib. 
Der letztgenannte Muskel ist von Léon-Vaillant (Annales des sciences nat.

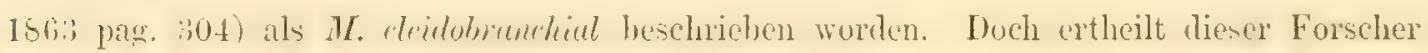
ihm nur eine Insertion an den letzten Krienenhogen, olne der in das letzte hiemenbüschel gehenden Partie, und ohne der zwei vorderen Muskeln dieses Systems zu erwähnen.

Hypochthon ist die einzige Gattung, bei der es gelang, einen Theil dieses, nur bei Sirrn ganz ansgebildeten Systems aufufimden. Nur der dritte Muskel scheint ausgebildet zu sein, der noch dazu nur indirect die Bervegung des Kiemenbüschels dadurch bewirkt, dass er den dritten, letzten Kiemenbogen nach hinten zieht. Es ist ein schmaler Muskel, der von der lateralen Kante der Pars clavicularis des Schultergerüstes, etwa in ler Mitte von deren Länge entspringt. Seine Fasern laufen hinter der Kiemenspalte schräg nach oben und vorn und inserieren sich von unten her an die Spitze des dritten (letzten) Kiemenbogens. - Die entsprechenden Muskeln fiir den ersten und zweiten Kiemenbogen konnte ich bei Hypochthon nicht finden.

Alle drei Systeme von Muskeln erhalten ohne Ausuahme ihre Nerven aus der Bahn des Vagus, und zwar aus den dessen Ganglion zuerst verlassenden Stämmen.

Dass auch die Larven der Salamander und Tritonen ihre Kiemenbüschel bewegen können, wird von mehren Forschern berichtet. $\mathrm{Ob}$ diese Bewegung indessen nur eine Folge der Bewegung der Kiemenbogen sei, oder auf der Action eigener IIuskel der liemenbiischel beruhe, ist nicht ermittelt worden. 


\section{Muskeln der Visceralbogen.}

\section{Muskeln des Unterkiefers.}

Wenn auch die anatomische Intersuchung des Unterkiefers sich nicht wohl von derjenigen des Schïdels trennen lïsst, sind die denselben bewesgenden MIuskeln doch passender zusimmen mit denjeuigen des Zungenbeins und der Kiemenbogen abzuhamkeh. Und dies nicht bloss wegen der Zusammengehörigkeit des Unterkiefers mit diesen Partieen des Visceralskelettes, sondern schon deshalb, weil die meisten seiner Iuskeln sich theilweise an Glieder des Visceralskelettes inserieren.

\section{a) Constrictores.}

1. M. mylohyoideus anterior (M. submaxillaris. Ecker, Anatomie des Frosches, Fig. 59, sm.).

Von dem vorderen Winkel der beiden Unterkieferhälften bis zur Gegend der Kiemenspalten erstrecken sich bei allen Peremnibranchiaten und Derotremen oberflächliche, quer verlaufende Muskelfasern, die meist in der Mittellinie zusammentliesen und so einen einzigen, zwischen den Unterkieferhälften beider Seiten sich erstreckenden Muskel bilden. Nur in einigen Fällen (Hypochthon, Menopoma) bleibt zwischen den Muskeln beider Seiten eine Art Linea alba, die zugleich an die Haut befestigt ist.

Bei genauerer Untersuchung lässt sich an diesen Querfasern leicht eine vordere und eine hintere Partie unterscheiden. Die vordere, die wir nach Hyrtl's Vorgange (bei Lepidosiren) als $M$. mylohyoidcus anterior bezeichnen wollen, entspringt bei allen Gattungen ganz gleichmässig von der medialen Fläche - dem Dorsalrande ziemlich nahe - der beiden Unterkieferäste. Ihre Insertion erstreckt sich längs der letzteren nicht ganz bis zum Gelenke, so dass hier zwischen ihr und den dam folgenden Fasern des Mylohyoidcus posterior ein kleiner dreieckiger Raum übrig bleibt. In diesem sieht man bei den mit starkem $\boldsymbol{M}$. pterygoideus versehenen Gattungen (Siren) diesen von unten her vorquellen.

2. M. mylohyoideus posterior.

Die Fasern dieser zweiten Partie treffen ebenfalls in der Mittellinie mit denen der anderen Seite zusammen, jedoch nicht immer in der Weise, dass sie sich unmittelbar hinter diejenigen der ersten Partie anlegen. Ihre Fasern sind vielmehr zuweilen deutlich von 
denen der ersten Partie ahgesetzt, ja es steigen sogar die vorderen Fasern der zweiten Partie oft etwas nach rorn schräge an und legen sich ïber diejenigen des $\boldsymbol{M}$. mylohyoideus (conterior (Mruopoma. 'Tat. IS. mh und mh'. Amphima). Sichon hieraus geht hervor, dass eine Trennung zweier wirklich rerschielener Muskelpartieen nothwendig ist, eine Unterscheidung, die sowoln in der verschiedenen Insertion der zweiten Partie, als auch in den verschiedenen Nervenhahmen, aus denen beide Partieen regelmässig versorgt werden, ihre Bestätigung erhält.

Die zweite Partie, unser $M$. mylohyoideus posterior, findet ihre laterale Anheftung niemals am Lnterkiefer. sondern stets an den auf letzteren folgenden Visceralbogen, und zwar an deren borsalsemmenten. Folgende Verschiedenheiten scheinen in dieser Hinsicht rou Interesse zu sein:

Bei Siredon, wo, wie bei Menobranchus, der Mylohyoideus posterior ganz in der I) uplicatur der Haut eingeschlossen ist, die sich einem Kiemendeckel ähnlich vor den Kiemenspalten herabzieht und unter den Halse bis zur anderen Seite herungeht. entspringt derselbe mit dem von ihm bedeckten Ceratohjoidtus externus von der ganzen Vorderfäche des dem ersten Kiemenbogen angehörenden Dorsalsegments.

Bei Siren lacertina dagegen hat der Mylohyoidens posterior einen doppelten Ursprung. Ine rorderp Hältte nämlich entspringt von dor Vorderfläche des aufsteigenden Astes des Zungenbeinhorns. die hintere wie bei simblon von der ganzen Vorlerflüche des dem ersten Kiemenbogen angehörigen Dorsalsegments, hier ebenfalls mit den Fasern des theilweise von ihr bedeckten Ceratohyoideus exterms verschmolzen ${ }^{1}$ ).

Auch bei Hyporhthon sind zwei Ursprungsportionen des Myloh. pasterior zu unterscheiden. Die vordere entspringt von dem nur leise aufsteigenden Endtheile des Zungenbeinhorates. Die hintere entspringt theilweise von einer Fascie, die den Digustricus lateralwïrts iiberzieht und sich am Nacken befestigt, theilweise anch rom hinteren Rande und der Spitze des dem ersten Kiemenbogen angehörigen Iorsalsegments. Diese hintere Partie verdeckt den Urspiung des C'eratohyoideus exterms.

Bei Amphiuma fehlt die Insertion an den ersten Kiemenbogen ganz. Der Myloh. postevin (Taf. Y. Fig. 2, my") entspringt allein von der lateralen Fläche des hinter dem Schidel vorragenten Endtheils des Zungenbeinhorms $(h)$ und von der breiten Sehne, wodurch

1) Léon-Vaillant betrachtet Myloh. anterion und posterior als einen einzigen Muskel und lässt diesen nur vom Lnterkiefer und dem ersten Kiemenbogen entspringen, ohne der Insertion am Zungenbeinhorn zu erwähnen. Ann. d. Sc. nat. 1863, pag 310. 
dieser an den oberen Theil des os tymprenicum angelseftet ist. Der Crsprung liegt hier verdeckt zunächst von der dritten Ursprungspartie des Digrestrines (Taf. V, Fig. 1 und :3 $d g^{\prime \prime)}$, sodann vom levator maxillue ascrudens (lus). Immerhalb, dieser Muskeln schlingt sich der breite Myloh. postevior nach unten, dann obertlichlich geworden, um die vordere Partie des Stemohyoideus nach innen, wo seine Fasern in der Mittellinie sich mit denen der andern Körperhälfte ohne Unterbrechung zu einem einzigen Muskel verbinden.

Bei Menopoma besitzt der Myloh. posterior ehenfalls eine doppelte Insertion, und ist dabei, wie bei Amphiumu, vom ersten Kiemenbogen ausgeschlossu. Die vordere. bei weitem kleinere Partie heftet sich, wie bei Amphinma, an die laterale Kante des hinter und unter dem Schädel vorragenden platten Endtheils des Zungenbeinhoris. I)ie hintere grössere entspringt von der den grossen Nackenmuskel iiberziehenden, der Haut dicht anliegenden Fascie. Diese (Taf. IV, Fig. 1, my) bedeckt von aussen theilweise die Levatores arcum (la) und die zweite Portion des Digustricus $\left.\left(d y^{\prime}\right)^{1}\right)$.

Bei Cryptobranchus japonicus lassen sich ausser dem Mylohyoideus antorior zwei deutlich getrennte Portionen des Myl. posterior unterscheiden.

Der $M$. anterior, der sich wie gewöhnlich an die mediale Fläche jeder Unterkieterhälfte befestigt, erstreckt sich hier etwa bis an das letzte Drittheil dieses Knochens.

Die dem Myl. posterio angehörige erste Partie entspringt nicht, wie die holländisclien Forscher angeben "), vom letzten Theile, des Unterkiefers und dem Quadratbein", welche

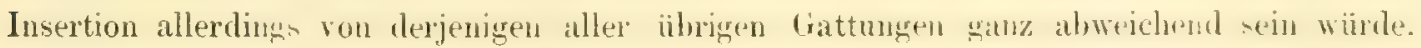
Sie lässt vielmelı, wie gewöhnlich, den Unterkieferrand vollkommen unberïhrt. Ihre Fasern steigen innerhalb desselben in die Höhe und befestigen sich an den Aussemrand der hinteren Partie des Zungenbeinhorns. Dieser Ursprung wstreckt sich nach hinten bis in die Gegend der Unterkieferecke. so dass nur das hinter dem Schädel vorragende Ende des Zungenbeinhorms von demselben unberïht bleibt. Nur ain kleiner 'Theil dieser" Partie des Myl. posterior setzt sich, wie jene Forscher richtig angeben, an das Os tympanicum fest, hart über dessen Gelenk mit dem Unterkiefer.

Die zweite Portion des Myl.posterior nimmt beim Riesensalamander ihren Ursprung

1) Mayer, 1. 1. pag. 79. erwähnt des Myloh. posterior nicht. Nach seiner Beschreilung wäre nur ein einziger Muskel vorhanden, "der sich von der hinteren Fläche des Unterkiefers bis zum oberen Brustknorpel erstreckt."

$\left.{ }^{2}\right)$ 1. 1. pag. 28: ,het achterste gedeelte van het onderkaksheen en van den onderrand van het os quadratum." 
ron der die Sackenmukeln iiberzichenten Aponeurose, welche bis an die Mittellinie des Rïckens reicht und sich dort an die processus spinosi der Wirbel befestigt. Ihre Fasern schlingen sich hinter dem Unterkiefer nach unten und innen herum, schliessen sich dabei eng an diejenigen der vorigen Yartis an, und gehen in der Mittellinie mit den entsprechenden Fasern der anderen Seite zu einem einzigen Muskel zusammen.

Die hollïudischen Anatomen, welche, wie bemerkt, irrthimlicher Weise dem Myloh. posterior einen Ursprung rom Unterkiefer zuschreiben, unterscheiden dieselbe gleichwohl als besonderen Muskel von dem, denselben Ursprung reigenden Myl. anterior, und benennen sie Constrictor faucium extermus. - Ich kann übrigens nicht bestätigen, dass dieser letztere, wie dort angegeben wird, unter dem Myloh. anterior liegen soll. Die Fasern des Myloh. posterior steigen im Gegentheil wie gewöhnlich schräge nach rorn an, legen sich vorn über (dorsalwärts ron denselben) die Fasern des MLyloh. anterior und sind bis zur Mittellinie nicht schwer vou diesen $z u$ tremnen.

Der zwischen den beiden Unterkieferhälften sich erstreckende Mylohyoidens anterior ist bei allen Gattungen gleich gebildet und kommt in derselben Form auch den Salamandrinen und den ungeschwinzten Batrachiern zu.

Der Myloh. posterior dagegen zeigt nach dem eben gesagten folgende uicht unwichtige Verschiedenheiten:

1. Die rom Ende des Zungenbeinhorns entspringende Partie, welche in geringer Ausbildung auch bei ungeschwänzten Datrachiem gefunden wurde (Ecker, Anatomie des Frosches, Fig. 59, sm', pag. 75), kommt allen Derotremen und dem Riesensalamander, von den Perennibranchiaten aber nur den Gattungen Hypochthon und Siren zu. Sie scheint nach Dugès' und vou Sieboldt's Beschreibungen auch den Saİamandrinen zu fehlen.

2. Die vom Dorsalsegment des ersten Kiemenbogens entspringende Portion fehlt dagegen den Derotremen und dem Riesensalamander. (sowie allen ausgewachsenen geschwänzten und ungeschwänzteu Batrachiern). Sie wird bei allen Perennibranchiaten gefunden. Ihre Beziehung zum Verschluss der Kiemenspalte, wovon gleich weiter die Rede sein soll, wird hierdurch sehr wahrscheinlich.

3. Endlich entspringen auch noch Fasern dieses Muskels von der Aponeurose, welche die Nackenmuskeln überzieht. So bei Hypochithon, Menopoma, Cryptobranchus japonicus. 
Bei den Froschlarven scheint nach Dugès (II. XIII, Fig. 80, 81, g) diese Portion die stärkste zu sein.

Ueberall fliessen die anfaugs getremten Ursprungsportionen des Myloh. posterior allmählich zu einem einzigen Muskel zusammen, der aber in der vorhin geschilderten Weise von dem My/oh. anterior getrennt bleibt.

Der Mylohyoideus anterior erhält überall seine $\mathrm{Ner}$ ren nur vom dritten Aste des Trigemims. Trotz des sehr benachbarten Verlaufes zweier ganz bestïndiger FascialisZweige (R. alveolaris und $R$. mentalis). die auf den ersten Blick mit jenem Aste des Trigomimus ein Geflecht zu bilden scheinen, zeigt sich doch bei der nicht ganz leichten Entwirrung und Verfolgung der einzelnen feinen Zweige, dass diejenigen des siebenten Paares sich nicht an der Versorgung des Mylohyoidens anterior betheiligen.

Dagegen gieht der Mylohyoidens posterior sich auch dadurch als besondere Muskelpartie zu erkennen, dass or ohme alle Ausnahme seine Nerven lediglich rom $N$. faciatis, und zwar vom Ramus jugularis desselhen erhïlt.

Es ist indessen hervorzuheben, dass der $N$. trigcminus bei allen Amphibien atuch Fasern aus dem siebenten Paare in seine Wurzeln aufnimmt, und dass daher auch die den Mylohyoideus anterior versorgenden Fasem bei den Peremibranchiaten und Derotremen, obgleich in der Bahn des Trigomimus verlaufend, nicht mit Sicherheit dem letateren zugeschrieben werden dïrfen. Ans Volckmann's bekannten Versuchen scheint im Gegentheil ihr Ursprung aus dem Fracialis zu folgen. Doch ist dort (Müll. Arch. 1838, pag. 84) nicht angegeben, ob die auf Reizung der Facialiswurzel entstandenen Contractionen nur die ganz kleine hintere Partie, oder auch die ganze vordere Partie mit ergriffen.

Soweit sich auf die Wirkung des Mylohyoideus auterior aus seiner Insertion und dem Verlaufe seiner Fasern schliessen lïsst, besteht dieselbe hauptsächlıch in einer Abflachung des Bodens der Mundhöhle. Ohne allen Zweifel haben auch die Contractionen des Myloh. posterior, der sich bisweilen bis unter den Anfing der Brust erstreckt, denselluen Erfolg. Nur gesellt sich bei den ïchten Perennibranchiaten, bei denen sich eine seiner Portionen 
constant an das Lorsalsecrment des ersten Kiemenbogens hettet. noch die weitere Wirkung dazu. dass er dieses medialwïts gegen die folgenden bogen drickt und an den Leib zieht, mithin die hiemenspaltan schliesst. Jieide Wirkmgen combinieren sich mit einander. Jene Abflaclung den hinteren Theils des Borlens der Mundhöhle kann durch den Mylohyoideus posterin mur answefïhrt wrolden, indem gleichzeitis ein Verschluss der Kiemenspalten erfolgt. - Hierdurch giebt sich der Myloh. posterior - von dem bei Batrachiern und

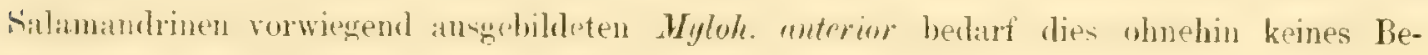
weises - wesentlich als Luftathmungsmuskel zu erkennen. Er wird im Stande sein, die ins Maul genommene Luft nach linten in die Lungen zu drängen, oder die aus den

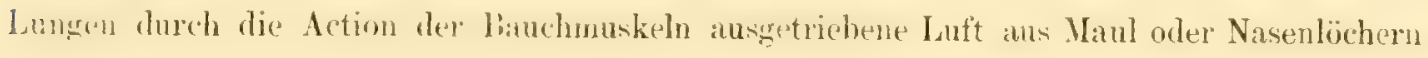
zu entfernen, indem er gleichzeitig die seitlichen Auswege verschliesst. Je nachdem die

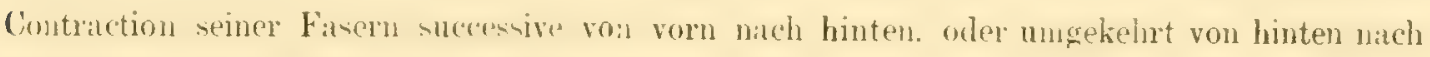

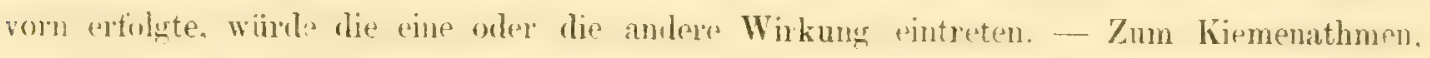
woluei es sich darum handtu wirrle, das eingenommente Medium nach hinten zu drängen

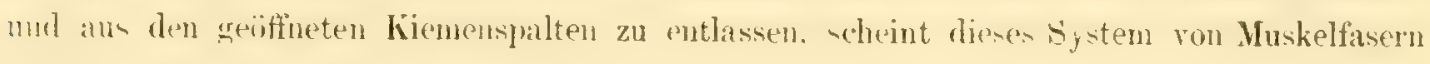
aus dem Grunde nicht geeignet zu sein, weil oben seine hintere Partie die Kiemenspalten schliesst.

bie Betrachtung der Fische scheint diese Vermuthung zn bestätigen. Bei den Teleostion und Ganoiden ist dieses System obertiachlich liegender Quertasern auf eine ganz kleine, zwischen beiden Unterkieferlältten sich erstreckende Partie reduciert. Um so ausgebikdeter ist dasselbe bei den Lungenathmern. Bei Lepidosiren paradoxa ist das system der beiden Myluhyoldci durch $\mathrm{Hyrtl}$ 's Untersuchungen bekannt (S. dessen Schrift jag. 15). Bei Lcpirlosiven ametems finde ich eine ganz ähnliche Anordnung. Man unterscheidet an ihrem Ursprunge leicht die beiden Mylohyoidei der Perennibranchiaten und I) keine Sclıeidung delselben erkennen lässt. - Der Myloh. anterior entspringt wie gewöhn-

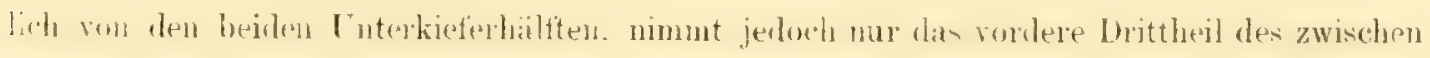
diesen liegenden Winkelrames ein. - Der Mylohyoidcus posterior entspringt: 1) von der

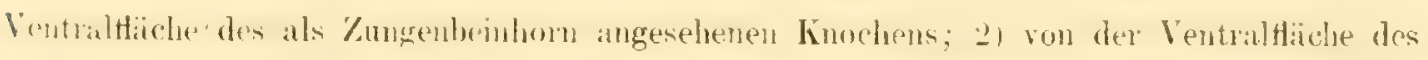
an diesen eingelenkten und ihm als Dorsalsegment angehörigen Bogenschenkels (d $\mathrm{r}$ :ls Rudiment des unteren hisunendeckelatioks beschrieben wudes. Beide Partien vereinigen sich zu einem einzigen Muskel, dessen vorkere Fasern, wie bei den Perennibranchiaten und Derotremen, nicht ganz quer himibrgehen zu denen der anderen Seite, sondern sich nach 
vorn divergierend ausbreiten, über die hinteren Fasern des My/h. anterior hinunsteigen, ja ganz vorn sogar wieder zum Theil die Unkieferhälfte der anderen Seite erreichen.

Auch hiernach scheint also der Myloh. posterior bei Luft athmenden Thieren überall ausgebildet zu sein, wo es darauf ankommt, seitliche Oeffnungen zu verschliessen, und rugleich, durch successive Contraction seiner Fasern, die Luft in die Lungen zu pressen. Auf seine Wichtigkeit in letzterer. Hinsicht deutet auch seine wrove Entwickelung bei den Schildkröten hin. Auch diese können das Lumen ihrer Brusthöhle nicht erweitern. Der Mylohyoideus posterior erstreckt sich hier über den ganzen Hals.

3. M. submentalis, Ecker. (M. transversus, Cuvier. M. sous-mentonnier, I) ug ès.)

Dieser kleine Muskel liegt bei den damic versehenen Gattungen wie beim Frosche im vordersten Winkel des Unterkiefers und erstreckt sich quer von dem einen Aste zum anderen hinüber.

Er fehlt durchaus allen Perennibranchiaten und der Gattung Amphima. ist dagegen bei Monopoma und Cryptobranchus japonicus ${ }^{1}$ ) sehr stark entwickelt.

Unter den übrigen Familien ist der $\boldsymbol{M}$. submmalis bei den ungeschwänzten Batrachiern auch schon im Larvenzustande (D) ugès Pl. XIII, Fig. 80) sehr stark entwickelt,

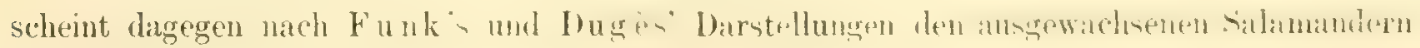
und Tritonen zu fehlen.

Dass dieser Muskel die Unterkieferïste kräftig an einander ziehe, und dass diese Wirkung namentlich an deren hinteren Enden - als den Enden langer Hebelarme - herrortrete, ist wohl keinem Zweifel unterworfen. Schwierig ist es indessen, von dieser Wirkung auf eine Beziehung zu der Mechansik des Athmens und Schlingens zu schliessen.

Dugès (1. 1. pag. 123. No. 4) zähit unsern Muskel ohne weiteres zu den "Moteulss de la narine». Nach ihm nähert er die unteren Ränder der ossa dentulia des Unterkiefers, hebt deren inneren Rand und in Folge dessen auch den darauf liegenden Zwischenkiefer, wodurch die Nasenlöcher von innen her geschlossen werlen sollen. Diese Wirkung ist dem

") Ich kann der Auffassung der holländischen Autoren nicht beitreten, die dicsen Muskel als ,Bulbus" des $\boldsymbol{M}$. genioglossus heschreiben (1. 1. pag. 29). Seine Fasern laufen vielmehr quer von ener Seite zur andern himüber, was auch in der Ahbildung der genanuten Forscher richtig angedeutet ist. 
M. submentalis bei Monopoma und Cryptobranchus japonicus sicher abzusprechen. Bei beilen Gattungen liegen die inneren Nasenlöcher so weit nach hinten geriekt, dass eine - wegen der ausserordentlichen Stärke des Zwischenkiefers an sich hier kaum denkbare Hebung desselben durch diesen Muskel sie nicht schliessen würde. Die äusseren Nasenlöcher beider fattungen bleiben alber, wie später gezeigt werden wird. beständig offen und sind überhaupt eines Verschlusses nicht fähig.

Bei Menopoma und der verwandten Gattung aus Japan möchte ein direkter Schluss ann den gesammten anatomischen Verhïlnissen der Köergegend anf die Wirkung des $M$. submentulis kamm gelingen. Der indirekte Weg, eine Vergleichums mit solchen Gattungen, die dieses Muskels eatbehren, scheint dagegen einiges Licht auf seine physiologische Bedeutung zu werfen. Auffallend ist es, dass gerade bei jenen beiden Gattungen der Muse. masseter, wie später genauer zu erörtern ist, sehr weit um die hintere Partie des Unterkiefers nach aussen und selbst nach unten herumgreift und sich nahe bei dessen ventralem Rande inseriert (Taf. IV, Fig. 2, $m$ ). Bei den Contractionen des Masseter muss bei dieser Anhertungsweise nicht nur jeder L'nterkieferast gehoben, sondern auch um seine longitudinale Achse so gedreht werden, dass seine ventrale Kante sich etwas nach aussen wendet, - wenn nicht andere Muskeln ihm die normale Lage erhalten. Ich möchte annehmen, dass - mindestens bei diesen beiden Gattungen - der M. summentulis, der durch seine Contractionen vorzugsweise auf die hinteren Enden der Unterkieferäste wirken muss, in der angredeuteten Hinsicht dem Masseter entgegen wirkt, und die durch jenen leicht gestrirte normale Lage der Achse jeder Unterkieferhälften wiederherstellt.

Ob der $\boldsymbol{M}$. submentalis seine Nerven vom dritten Aste des fünften Paares oder von den Endzweigen des $R$. mentulis oder des $R$. alreolaris nervi faciulis erhalte, die sich alle drei bis in seine Nähe vertolgen lassen, war wegen der ausserordentlichen Feinheit dieser Endzweige nicht zu ermitteh. Nach Volckmann 's Versuchen schemen seine Nerventisern beim Frosche aus der Wurzel des F'acialis zu stammen. 


\section{b) Depressores.}

4. Digastricus. Cuvier. (MI. sus-occipito-dorso-angulaire Dugès; Depressor maxillae inferioris Carus; Zencker; Sieboldt; Ecker.)

Alle Amphibien ohne Ausnahme sind mit einem Muskel ausgerüstet, dessen Fasern wenigstens zum Theil von der hinteren Fläche des Os tympanirm entspringend längs dieses Knochens abwärts und nach aussen treten, un sich - mit anderen accessorischen Fasern zugleich - an den hinter dem Gelenk vorstehenden Vorsprung des Unterkiefers zu heften.

Betrachtet man das Quadratbein als das Dorsalsegment des Visceralbogens, dessen ventraler Abschnitt durch den horizontalen L'nterkieferast gebildet wirl, und lïsst vorläufig die Frage unentschieden, ob nicht in jedem dieser Segmente die Elemente mehrer Visceralbogenabschnitte enthalten sind, so erscheint der eben seschilderte Theil des Digustrieus als ein solcher, der sich zum Ventralsegment eines Bogens ron dessen dorsalem Abschnitt aus erstreckt.

Schon beim Frosche gesellt sich indessen zu den so entspringenden Muskelfasern noch eine hintere Portion, die sich rermittelst der Fusria dorsulis an die Rücken- und Schädelwirbel heftet. Noch stïlker vergrüssert sich die Aubeftungsflüche der dem Digastricus zuzuzählenden Muskelfasern hei den Perennibranchiaten und Derotremen. Bei diesen tritt nïmlich noch ein Hinühergreifen an die dorsalen Śegmente der auf den Unterkiefer folgenden Visceralbogen hinzu.

Bei Siredon pisciformis lassen sich drei Portionen unterscheiden:

1. Von der ganzen hinteren und lateralen Fläche des Os tympanicum.

2. Von der der Haut dicht anhaftenden Fascie, welche die Nackenmuskeln überzieht und sich in der Mittellinie des Riickens an die processus spinosi der Wirbel heftet.

3. Von der Vorderfläche des dem ersten Kiiemenbogen angehörigen Dorsalsegments. Alle drei Portionen vereinen sich, um sich an den erst bezeichneten Fortsatz des Unterkiefers zu heften.

Siren lacertina besitzt zwei Portionen. Der Digastricus entspringt nämlich:

1. An der hinteren, von den Gelenktheilen des Hinterhauptbeins, dem verticalen Theile des Scheitelbeins und dem Quadratbein gebildeten verticalen Hinterfliche des Schädels. 
2. Von der vorderen und seitlichen Fläche des hinter dem Schädel vorragenden aufsteigenden Astes des Zungenbeinhorns.

Die Fasern beider Portionen steigen schräge abwärts und inserieren sich mittelst einer gemeinschaftlichen starken aber kurzen Sehme an den Fortsatz des Unterkiefers.

Bei Menobranchus ist der Digastricus zum grossen Theile bedeckt von dem nach hinten dick herausquellenden Masseter. Er entspringt in drei Portionen:

1. Die erste (Taf. III, $d g$ ) entspringt von der hinteren verticalen Fläche des Scheitelbeins und derjenigen des Os tympanicum, und geht schräge abwärts, medialwärts an der hier liegenden Spitze $(h)$ des Zungenbeinhorns vorbei, um sich mittelst einer kurzen starken Selne an den Unterkieferfortsatz zu befestigen.

2. Die Fasern der zweiten Portion $\left(d g^{\circ}\right)$ nehmen ihren Ursprung mit jener der ersten zugleich, wenn anch etwas mehr nach hinten, so dass sie anfangs mit ihnen einen einzigen Vuskel trilden. Sie gehen aber nicht wie diese medialwïrts vom Zungenbeinhom vorbei, sondern inserieren sich an eine gerade an der dorsalen Spitze $(h)$ des letzteren beginnende lange platte Sehne (s). Diese Sehne liegt der Aussenfliche des Zungenheinhorns dicht an. in einer Rinne, die von dem Periosterm des letzteren gebildet wird, und in der sie hinund hergleiten katm. Die Sehne, welche sich schliesslich an den Vorsurung des Unterkiefers heftet, füllt jene linne so vollständig aus, dass sie sehr leicht übersehen wird. Da nun die. Muskelfasern sich gerade am Ende des Zungenbeinhorns ganz plützlich an jene Sehne festsetzen, gewinnt es leicht den Anschein, als gehe unser Muskel $\left(d y^{*}\right)$ vom Hinterhaupt. an die Spitze des Zungenbeinhorns selbst. In der That aber existiert bei Menubrunchus kein Munkel. der vom Hinterhanpt an das Zungenhein, oder von diesem an den Vorsprung des Unterkiefers ginge.

3. Die dritte Portion des Digastricus (Taf. III, $d g^{\prime \prime}$ ) ist die stïrkste, und allein so stark, wie dic heiden ersten zusammengenommen. Ihre Fasern entspringen von der lateralen Flïche des dem ersten Kiemenbogen angehörigen Dorsalsegments $\left(, 0^{\circ}\right)$. Sie gehen schräge abwärts nach vorn, lateralwärts von der hinter dem Unterkiefer vorragenden Spitze des Zungenbeinhorns vorbei. Ohne sich an die dem letzteren $(h)$ anliegende Sehne $(s)$ der zweiten Portion unseres Vuskels zu inserieren, gehen sie vielmehr lateralwïrts von derselben in dieselbe kurze starke Sehne iiber, durch welche sich die erste Portion $(d g)$ an den Vorsprung des Unterkiefers befestigt.

Hypochthon zeigt zwei Ursprungsportionen:

1. Von der ganzen lateralen und hinteren Fläche des Os tympanicum und einer kleinen Knochenleiste, die an der Grenze zwischen Occipitale laterule und Scheitelbein liegt. 
2. Von der Vorderfläche des aufsteigenden Schenkels des dem ersten Kiemenbogen angehörigen Dorsalsegments.

Die Fasern beider Portionen vereinigen sich zu einem einzigen Muskel, der in seinem Verlaufe (schrïge abwärts nach vorn) die hintere Spitze des Zungenbeinhorns einhüllt ohne. sich daran zu inserieren, und heften sich an eine lange, an der Ventralseite des Muskels gelegene Sehne. Diese inseriert sich wie gewöhnlich an den hinteren Fortsatz des Unterkiefers.

Bei Amphiuma sind drei Ursprungsportionen des Digastricus zu unterscheiden:

1. Von der ganzen Hintertläche des Quadratbeins.

2. Yon der die Nackenmuskeh dicht hinter dem Schärdel tiberziehenden Aponeurose (Taf. V. Fir. 1. $d g^{\prime}$ ).

3. Diese beiden Portionen werden nach Entfernung der Haut gleich gesehen. Die dritte liegt tiefer, hinter und etwas unter der zweiten Portion rersteckt (Taf. $\mathrm{V}, \mathrm{Fig} .1, d g^{\prime}$ ). Sie entspringt ron der Aussenfläche des hinter dem Schädel rorragenden Endes des ersten Kiemenbogens (der Ursprung ist auf Taf. V, Fig. 2 mit $d g^{\prime}$ bezeichnet).

Alle drei Portionen vereinen sich zu einem einzigen starken Muskel, dessen Fasern schräge nach vorn und unten bis zur Ecke des Unterkiefers verlaufen. Hier scheiden sie sich jedoch in zwei Partieen mit getrennten Insertionspunkten. Die stärkere inseriert sich durch eine starke Sehne an den hier sehr scharfen Vorsprung des Unterkiefers. Die schwächere, aus den medialen Fasern der zweiten und dritten Ursprungsportion zusammengesetzt, geht innerhalb des Unterkiefers vorbei und heftet sich an dessen Innentläche, etwa dem Gelenke mit dem Os tympanicum gegenüber. Einige ihrer Fasern steigen hier in die Höhe und setzen sich an die Aussenkante des Zungenbeinhorns.

Viel einfacher ist die Form des Digastricus bei Menopoma. Er entspringt hier nämlich mit nur zwei Portionen.

1. Die erste heftet sich an die Gelenktheile des Hinterhauptbeins und an die hintere Fläche des Scheitelbeins, so wie an die Fascie, welche den seitlichen Theil der geraden Nackenmuskeln an deren Ursprung iiberzieht. Sie geht iiber das hier vorragende platte Ende des Zungenbeinhorns fort, ohne sich an dasselbe zu inserieren, wendet sich dann nach unten und heftet sich an den Vorsprung des Unterkiefers

2. Die zweite Portion entspringt weiter nach hinten, dorsalwårts von der Ursprungsstelle der Levatores arcum, ron der die Nackenmuskeln überziehenden, an die Haut und die Dornfortsätze der Wirbel angehefteten Fascie. Ihre Fasern gehen schräge nach vorn 
und unten und inserieren sich mit denen der ersten Portion zugleich an den Vorsprung des Unterkiefers.

Eine vom Dorsalsegment des ersten Kiemenbogens entspringende Portion existiert nicht.

Ganz genau wie bei Menopoma verhält sich der Digastricus bei Cryptobranchus japonicus. Er entspringt mit zwei Portionen. Die eine vordere, vom Os tympanicum und zum Theil von der Fascia dorsalis entspringend, setzt sich an die obere und äussere Fläche des Unterkiefervorsprungs. Die zweite, von der Fascia dorsalis unmittelbar hinter der ersteren entspringend, geht als von derselben getrennte Portion hinter ihr herab und heftet sich an die mediale Fläche des Unterkiefervorsprungs.

Aus den vorstehenden Specialbeschreibungen ergiebt sich, dass die Perennibranchiaten und Derotremen ausser der arsten. von dem Os tymmruminu entupringenden, auch den iibrigen Amphibien eigenthümlichen Portion des Digastricus noch eine zweite hintere besitzen. Letztere nimmt, mit alleiniger Ausnahme von Menopoma und Cryptobranchus japonicus von einem der auf den Unterkiefer folgenden Visceralbogen, und zwar von dessen dorsalem Endatiicke ihren Ursprung. Neist ist, wie frihher erwihnt, der aufsteigende lst des Zungenbeinhorns so kurz, dass er nicht weit hinter dem Schädel vorragt, also einem an den Unterkinfervorsprung sich heftenden krïfigen Mnskel nicht dip hinreichende Gröse gewähren wïrde. In diesem Falle (bei Siredon, Hypochthon, Menobranchus, Amphiuma) liefert das Dorsalsegment des ersten Kiemenbogens die Anheftungsflïche. Nur bei Siren, wo die dorsale Spitze des Zungenbeinhorns hart an und vor derjenigen des Dorsalsegments des

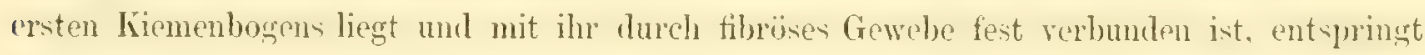
die zweite Partie unseres Muskels nicht von diesem selbst, sondern vom Zungenbeinhorn.

Ausser diesen beiden Portionen zeigen Siredon, Amphiuma, Menopoma und Cryptobranchus japonicus noch eine dritte, von der Fascia dorsalis entspringende Partie.

Im allgemeinen ist der Digastricus ein Muskel, der rnit seinen schräg nach rom absteigenden Fasern den Ramm zwischen dem Dorsalsegment des ersten Viscerallogens (dem Os tymmunimim) und demjenigen des ersten Kíemenbogens ausfüllt. Je nuchrlem die Entfernung dieser beiden Anheftungsflichen weringer oder grïser ist, genïgen sie allein, oder es gesellt sich zu ihnen noch eine dritte von der Fasciu dorsalis entspringende Portion. - 
Menopoma und Cryptobranchus japonicus eximern insofern an die Bildung der aichten Batrachier, als ihr Digastricus sich nur aus der vom Os tympanicum und von der Fascia dorsulis entspringenden Portion zusammensetzt.

Da der Digastricus ein Muskel ist, der sich von den Dorsalsegmenten eines oder mehrer Visceralbogen an das Ventralsegment des vordersten derselben begiebt, so ist er in architectonischer Hinsicht nicht mit den ihm benachbart liegenden Levatores arcum zu vergleichen, die sich von der Mittellinie des Rückens an die Dorsalsegmente der Kiemenbogen begeben. Eher dürfte ein Vergleich mit dem Ceratohyoidens extems zulïssig sein, der sich vom Dorsalsegnent eines Visceralbogens (des ersten Kriemenbogrens) an das Ventralsegment des zunächst vorderen (Zungenbeinhorn) erstreckt.

Die Wirkung aller drei Portionen auf den Unterkiefer ist anerkannter Weise die, ihn durch Heraufziehen seines hinter dem Gelenk vorragenden Fortsatzes zu senken. Der ersten, an das os tympanicum, und der mittleren, an die Fascia dorsalis angehefteten Portion mag auch in der That kaum eine andere Wirkung als diese zugeschrieben werden können. Anders ist es mit der zweiten (der Lage nach dritten), an das dorsale Ende des ersten Kiemenbogens angehefteten Portion. Sie trägt zwar ebenfalls mit zur Senkung des Unterkiefers, d h. zur Oeffnung des Maules bei, zieht aber ausserdem die Spitze des ersten Kiemenbogens (bei Siren durch Vermittlung der daran befestigten Spitze des Zungenbeinhorns) nach vorn von den ïbrigen Bogen ab. Eine weitere Oeffnung der Kiemenspalten ist die nothwendige Folge dieser Action.

Dass die erstere Wirkung, die Oefinung des Maules, zu den Fressbewegungen gezïhlt werden muss, ist selbstverständlich. Ob auch $\mathrm{zu}$ den Athembewegungen, wenigstens zu denen, die das Luftathmen bewirken, ist die Frage. Die ungeschwinzten Batrachier und die Salamandrinen wenigstens athmen beständig und ausschliesslich bei geschlossenem Munde durch die Nasenlöcher. Sie ersticken, wenn letztere sicher verschlossen werden, wie ich an mehrfach wiederholten Versuchen gesehen habe. Beim Luftschnappen der Perennibranchiaten dageren wird nach Weise der Fische das Mitul geöffnet und greschlossen ${ }^{1}$ ).

1) Léon-Vaillant sagt über das Athmen von Siren lacertina: "En effet, lorsqu'on l'observe en repos, on le voit à des intervalles plus ou moins fréquents élever la tête, pour aspirer l'air par la bouche, qu'il ouvre absolument à la manière de certains l'oissons, tels que les Carpes. (Annales des sciences naturelles, 1863, pag. 340). 
Dasselbe mag beim Wasserathmen der Fall sein. Hierbei spielt, wie mir scheint, die hintere Partie des Digastricus eine wichtige Rolle. In der That giebt sie sich durch Oeffnung der Kriemenspalte als ein zur Kiemenathmung bestimmter Muskel zu erkennen.

Man könnte behaupten, dass dies Oeffnen der Kiemenspalte, ohne mit dem Wasserathmen in irgend welcher Beziehung zu stehen, nur den Zweck habe, das beim Fressen und schlingen unter der Oberfliche etwa mit eingenommene Wasser wieder zu entlassen, aus welchem Grunde demn auch unser Iuskel gar nicht zu den Athemmuskeln zu zählen wïre. In diesem Falle aber mïsste die Oeffnung der Kitemenspalten erst stattfinden, wenn der Jisnen tingenommen. also das Maul wieder geschlonsen ist. Linser Munkel affnet aber gleichritig Maul und Kiemenspalte, und kann nicht eines allein thum. weil seine einzigen Anheftungspunkte eben der Vorsprung des Unterkiefers und der erste Kiemenbogen sind. Es wäre denn, dass andere Muskeln einen dieser Anheftungspunkte fixiert hätten.

Dem durch die Wirkung der grossen Einathmungsmuskeln, namentlich des später zu

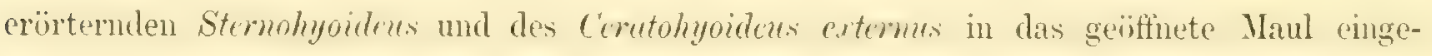
holten Wasser wird durch die letate Partie unseres Muskels sleichzeitig beim Eindringen ein seitlicher Ausweg geöfnet; es wird dadurch ein Verweilen der Flüssigkeit im Rachen verhütet, eine wirkliche Strömung eingeleitet, die sicher eben für das Athmen durch die Kiemen ganz wesentlich ist.

Femer existiert in functioneller Hinsicht ganz sicher eine innige Beziehung oder vielmehr Wechselwirkung zwischen der letzten Partie des Digastricus und der dritten Partie des Mylohyoidcus. Letztere, wach innen wirkend, driickt bei den Perennibranchiaten das Dorsalsegment des ersten. Kiemenbogens an den Leib, erstere, nach rorn wirkend, zieht dasselbe von den ibrigen Bogen ab. Erstere also trägt, wie es scheint, zum Verschluss, letztere zur Oeffinung der Kiemenspalten bei. Die ütnende Wirkung des Digatrims kamn, wie oben gezeigt, nur zum Vorschein kommen, wenn gleichzeitig das Maul durch Senkung des Unterkiefers geöffnet wird. Ebenso kann der schliessende Effect des Mylohyoideus posterior nur eintreten, indem seine quer an der Ventralseite verlaufenden Fasern den Boden der Rachenhöhle abflachen und deren Lumen verengern. Die hinter einander folgenden Querfasem des letzteren lassen die Möglichleit einer successiven Contraction und darlurch einer Weiterheföderung der eingenommenen Luft hei seschlontenem Matule zu. Eine solehe successive Wirkung ist bei der Befestignngsweise der letzten Portion des Digastricus von dieser nicht denkbar. Sie öftnet Maul und Kiemenspalte und verstattet dem durch andere Muskeln hereiugeholten Wasser freien Durchzug. Der Mylohyoidcus dagegen ibernimmt, wie es scheint, selbststïndig die Weiterbeförderung der - ebenfalls durch andere Muskeln 
hereingeholten - Luft und presst dieselbe an den durch ihn selbst verichlossenen Kiemenspalten vorbei in die Lungen.

Der Digastricus erhält ohne alle Ausnahme seine Nerven vom Facialis, und zwar von einem direct aus dem Ganglion austretenden Stamm, der keine Fasem des Vagus oder eines anderen Hirnnerven enthält. - Auch in dieser Hinsicht offenbart sich eine gewisse Analogie mit dem Mylohyoidcus posterior, der ebenfalls vom Facialis versorgt wird, freilich erst nachdem sich der betreffende Zweig meist durch Fasern aus dem Glossopharyngeus verstärkt hat.

5. Geniohyoideus. Aut.

Rectus lingualis, Funk; Levator maxillae inferioris sive Genio-thyreoideus, v. Sieboldt; Genio-sous-hyoidien, D ug ès.

Nach Wegrïumung des Mylohyoideus wird bei allen Amphibien an der Ventralseite ein schmales, langes Muskelpar sichtbar, das sich genau an der Mittellinie von hinten nach vorn erstreckt, um sich hier im vordersten Winkel des Unterkiefers an dessen Innenwand zu befestigen.

Seine hintere Anheftung zeigt folgende Verschiedenheiten:

Bei Siren, Siredon und Menobranchus findet die hintere Insertion an die ventrale Flïche des Zungenbeinstiels und seiner Endplatte statt. Pei IIyporhthon, wo eine eigentliche Endplatte des letzteren nicht vorhanden ist. verschmälert sich demgemïs das hintere Ende des Muskels, um zwischen den vorderen Partieen der beiden Stemohyoidei in die Höhe zu steigen und sich an den zwischen diese eingebetteten Zungenbeinstiel zu befestigen.

Als eine directe Fortsetzung der oberflächlichen Schicht des grossen Bauchmuskels, und hierdurch ganz an Lepidosiren erinnermd, erscheint unser Muskel bei Amphiuma. Seine Fasern (Taf. V, Fig. $3, g h$ ) entspringen hinten von der ersten der den Strmohyoideus (sh) durchsetzendeu Inscriptiones tendineae, welche in gleicher Höhe mit der liemenspalte liegt. Sie umfassen hier fast diesen, von unten geselıen heinale walzenfürmigen Muskel. 
indem einige mediale Fasern auch noch die zwischen den Strmoluyoide beider Seiten herabsteigende Fascie zur Anheftungr benutzen. Sämmtliche Fisern gehen gerade nach vom und inserieren sich mittelst ciner breiten dïnnen Sehne an den Ventralrand des Unterkiefers nahe der Mittellinie. Diese den rorderen Winkel des Unterkiefers breit üherspannende Sehue ist so fein, dass man durch sie hindurch die Fasern des hier sehr entwickelten Genioglossus durchscheinen sieht.

Bei Menopoma zeigt dieser Muskel eine sehr complicierte Form ${ }^{1}$ ).

Die rordere Anheftung (Taf. IV, Fig. 2, gh) erfolgt wie gewöhnlich neben der Mittellinie an der Hinterflïche der rordersten Enden der Unterkieferhilften. Finige seiner Faseru setzen sich an dieselbe über dem hier vorhundenen $M I$. sulmentalis (.sm). die anderen lateralwärts von letzterem fest.

Hinten wird der Muskel aus verschiedenen Portionen gebildet:

1. Die medial neben der Mittellinie verlaufenden Fasern kommen gerade ron hinten und nehmen ihren Trsprung etwa der hinteren Ecke des Unterkiefers gegenüber von einer quer ron aussen nach innen verlaufenden schmalen Fascie. An diese setzen sieh, jenen Fasern gerade gegenüber. zwei andere, ihmen so genau entsprechende Muskelportionen $\left(g h^{\prime}\right.$ und $\left.g h^{\prime \prime}\right)$, dass sie als deren Fortsetzung betrachtet werden mïssen. Die medial gelegene $\left(g h^{\prime \prime}\right)$ entspringt nahe der Mittellinie von der ersten Insriptio tendincu des Stcmohyoideus $(s h)$. Die zweite, lateralwärts gelegene $\left(g h^{\dagger}\right)$, kommt schräg von aussen und hinten von der Unterfläche des dem zweiten Kiemenbogen angehörigen Dorsalsegments $\left(b^{\prime \prime}\right)$.

2. Viele der lateralen Fasern des Geniohyoideus, welche ron der letztgenannten Insertionsflïche entspringen, gehen, ohne durch jene Fascie unterbrochen zu werden, direct in die Hauptpartie des Muskels über.

3. Andere der lateral und dorsal verlaufenden Faserm unseres Muskels entspringen ron der lateralen und ventralen Fläche des dem zweiten Kiemenbogen angehörigen Ventralsegments $\left(b^{\prime d} v\right)$ bis zu dessen Einlenkung an das Dorsalsegment.

4. Eine vierte Portion entspringt ron dem rudimentären Ventralsegment (Taf. T. Fig. 6, $b^{\prime \prime \prime} v$ ) des dritten Kiemenbogens.

5. Eine fünfte Portion kommt in der Spalte zwischen Stemohyoidens (Taf. IV, sh) und Cortohyoidens exterms (ceh) hervor, und entupringt ron einer Fascie, die den ersteren dieser beiden Muskel ïberkleidet und sich an die Haut der Mundhöhle festsetzt.

1) Mayer 1. 1. p. 79 sagt nur: Der Geniohyoideus kommt mit zwei Portionen vom grossen und kleinen Zungenbeinhorn. 
Es sei hier erwähnt, dass nicht alle rom Ventralsegment des zweiten Kiemenbogens entspringenden Fasern in unseren Muskel übergehen. Viele derselben steigen in der erwilhnten Spalte nach oben und heften sich an die Haut der Mundhöhle fest (Andeutung des $\boldsymbol{M}$. hyoglossus).

Cryptobranchus japonicus erinnert auch in Bezug auf diesen Muskel sehr an die Form von Menopoma, zeigt indessen insofern eine Vereinfachung, als ein dritter Kiemenbogen nicht existiert, die von diesem entspringende vierte Portion der verwandten Gattung also hier fehlt. Iner Genoluyoudeus ist hier ein platter, verhailtnismissig breiter und dimmer Muskel, der sich rorn lateralwärts und dorsalwirts rom $\boldsymbol{M}$. submentulis an den Lnterkieferrand befestigt. Auch hier werden seine Fasern in ihrem Verlaufe in der Gegend der Unterkieferecke ron einer sehnigen Aponeurose unterbrochen, die sich quer von innen nach aussen erstreckt. Jenseits derselben heften sich an dieselbe zwei Muskelpartieen wie bei Menop oma, die auch hier, den Fasem des Gemiohyoideus gerade gegenüberliegend, sich als dessen Ursprungsportionen zu erkemnen geben. Die mediale heftet sich an die erste der Inscriptiones tendincac, die den Stemohyoideus durchsetzen. Die laterale entspringt rom Dorsalsegment des zweiten Kiemenbogens. Auch hier giebt es laterale, nicht ron jener Fascie unterbrochene Fasern, die vom Ventralsegment des zweiten Kiemenbogens entspringend, direct in die vordere Masse des Muskels übergehen. Die Angaben der holländischen Autoren iber diesen Muskel kann ich nicht bestätigen. Dieselben erwähnen der Insertion an das Ventralsegment des zweiten Kiemenbogens nicht. Die beiden hinteren, jenseits der Querfascie liegenden Fortsetzungen unseres Muskels werden ron jenen Forschern als zwei besondere Muskeln beschrieben: die mediale als Levator maxillae inferioris brevis (Fig. XIII, No, 6), die laterale als Constrictor faucium extemus. Der Ursprung der lateralesı (Deze spier ontspringt van den achterhock van het os quadratum) ist indessen ganz anders, als dort angegeben: keine Faser dieser Muskelpartie setat sich an das Quadratbein fest, das bei allen in Rede stehenden Gattungen von dem Goniohyoidens unberüht bleibt; sie entspringt vielmehr, wie oben gesagt, allein von der Unterfläche des dem zweiteu Kiemenbogen angehörigen Dorsalsegnentes ").

1) Nur auf einem zufälligen Irrthum beruht es wohl, dass der (ioniohyoideus in jenem Werke $L e$ vator maxillae inferioris benannt ist. Die Verfasser geben richtig an, dass er den Unterkiefer. senke und so das Maul ötine. 
Die cinfuchste Form des Geniohyointens ist nach dem vorigen diejonige von Amphiuma, wo er ledighich als Fortsetzung der ventralen Schichten des geraden Bauchmuskels erscheint. Wihrend die Hauptmasse des letzteren als Stemohyoidens ihren Weg bis zum Zungenbein und I'harynx fortsetzt, lüst sich jene ventrale Schicht von ihm los, um sich als Goniohyoiricus bis zum Unterkieferrande zu erstrecken.

Wenig veriulert ist die Form bei den Gattungen, wo ein Zungenbeinstiel seine ventrale Fläche dem Gomohyoideus zur Anheftung darbietet. Statt dass dort eine eingeschaltete Sehnenschicht den Stemohyoidens auf seinem Wege nach vorn unterbricht, wirl diese Unterbrechung hier (Siren, Siredon, Menobranchus, Hypochthon) durch eine dem Zungenbein :ngeheftete Ossification bewirkt. In den Zungenbeinstiel setzen sich von hinten die Fasern des Stcrnohyoidcus fest, von ihm setzen sich nach vorn dicjenigen des Groniohyoidcus fort.

Auffillend versehieden von dieser einfachen Form ist diejenige von IEnopona und Cryptolrunchus japonicus, anffillend besonders durch die wichtige Rolle, die hier der zweite Kiemenbogen als hinterer Stuitzpunkt unseres Muskels spielt. Es ist schon früher hervorgehoben, dass dieser zweite Kiemenbogen der hervorragendste Theil des ganzen Kiemenbogen-Zungenbein-Apparates der beilen genannten Gattungen sei.

Auch hier indessen giebt sich die mediale Portion unseres Muskels als indirecte Fortsetzung des geraden Bauchmuskels zu erkennen. Bedenkt man nun, dass ausser dem Geniohyoideus auch noch der Digastricus eine Senkung des Unterkiefers bewirkt, und diss sowohl bei Mcnopona als bei Cryptobranchus japonicus gerade diejenige Partie des Digastricus vermisst wird, die bei den Perennibranchiaten und Amphiuma vom ersten Kiemenbogen ihren Ursprung nimmt, so wird man zu der Annahme geneigt, dass diese, bei $\boldsymbol{M}_{\epsilon}$ nopoma, Cryptobranchus japonicus und den übrigen Amphibien fehlende Portion des Diynstrims hier durch eine. den iibrigen fattungen fehlende, dbenfallswon einem Kiemenhogin entspringende Portion des Geniohyoidens ersetzt ist ${ }^{1}$ ).

1) Beim Frosche entspringt nach Ecker, pag, 76 , die mediale Portion des Geniohyoideus vom medialen Rande des hinteren Zungenbeinhorns. Letzteres dürfte als das Analogon des zweiten Kiemenlogens von Menopoma und Cryptobranchus japanicus zu betrachten sein. 
Der Geniohyoideus giebt auch dadurch seine innige Beziehung zu dem hauptsächlichsten Einathmungsmuskel. dem Sternohyoiders, zu erkennen, dass er, wie dieser. seine Nerven aus dem Hypoglossus erhält. Letzterer wird bei allen Perennibranchiaten und Derotremen aus Stämmen des ersten und zweiten Halsnerven zusammengesetzt.

\section{c) Levatores.}

6. Masseter Aut.

Bei allen Perennibranchiaten und Derotremen findet sich ein starker Hebemuskel des Unterkiefers, der von der vorderen Fläche des Os tympanicum und der lateralen des Scheitelbeins und Felsenheins entspringend mit seinen schräg nach vorn und abwärt gehenden Fasern sich dicht vor den Gelenke des Unterkiefers an dessen dorsalen Rand befestigt.

Die Verschiedenheit seiner Form ist wesentlich durch seine grössere oder gevingere Stärke bedingt. Ausserordentlich stark, nach oben und hinten über das Os tympanicum rorquellend ist der Masseter bei Menobranchus (Taf. III, m) und Menopome (Taf. IV, $m$ ), schwächer bei Siren und Siredon (Taf. II, $m$ ), aus zwei Portionen zusammengesetzt bei Amphinma (Taf. V, Fig .2, $\mathrm{m}^{\prime}, \mathrm{m}^{*}$ ). Bei Hypochthon hat er eine gestreckte, fast walzenförmige Gestalt.

Mit seiner unteren Insertion greift dieser Muskel mehr oder weniger über den dorsalen Rand des Unterkiefers bis auf dessen laterale Fläche hiuiber. Am meisten ist dies bei Cryptobranchus japonicus und Menopoma der Fall. Hier greift der gröste Theil seiner Fasern um die Pars opcrulo-angularis des Unterkiefers herum und befestigt sich an dessen Aussenfliche. Diese Partie des Muskels wird daher gesehen, wenn man nach Entfernung der Haut die betreffende Stelle ron der Ventralseite aus betrachtet (Taf. IV, I'ig. 2, m).

Bei Amphiuma sind diejenigen Fasern des Masscter, die aussen um den Unterkiefer herumgreifen, von den ibrigen als eine besondere äussere Portion getremt (auf Taf. V, Fig. 2, $m^{2}$, an der Ursprungsstelle abgeschnitten und zurückgeschlagen). Sie entspringen von der ganzen lateralen Flïche des breiten Quadratbeins (Taf. V', Fig. 2, ty) und in einer kleinen Grube, die zwischen dem oberen Theile des Vorterrandes dieses Kinochens und einem dem Felsenbein angehörigen Kinochenkanm $(x)$ gebildet wird. Von hier lanfen sie 
schrige abwïrts nach vorn und inserieren sich an die laterale Fläche des Unterkiefers, dicht vor dessen Gelenk, lateralwärts vom Proressus coronoidcus. Die zweite, mehr mediale Portion entspringt, von der vorigen beleckt, von dem vorderen Rande des Quadratbeins und der medialen Fliiche der eben erwïhnten Knochenleiste $(x)$. Sie inseriert sich an den dorsalen Rand des Unterkiefers, innerhalb der ersten Portion.

Ueber die Wirkung dieses Muskels, der sich, wie wir noch bemerken muissen, fast immer ohne Vermittelungr einer Sehne direct nit seinen Fasern an den Unterkiefer heftet -, kamn kaum ein Zweifel sein. Fr ist ein kriftiger Iebemuskel des Unterkiefers. Bei Cryptobranchus japonicus und Menopoma wird wegen der eben geschilderten unteren Insertion diese Wirkung nicht zu Staude kommen, ohne dass gleichzeitig die hintere Partie der Unterkieferiiste nach aussen gebogen und um ihre longitudinale Achse so gedreht wird, dass die Ventralränder mehr nach aussen kommen. Diese Wirkung wird theilweise durch die als $\boldsymbol{M}$. pterygoidens aufgefasste untere Partie des $\boldsymbol{M}$. temporulis aufgehoben, deren hier fist horizontale Fasern mehr von innen als von oben her an den hinteren Theil des Unterkiefers ziehen. Durch gleichzeitige Wirkung beider Muskeln wird letzterer in der Richtung der Resultierenden bewegt werden, ohne dass seine ventrale Kinte ihre Lage gexgen die longitudinale Achse des Knochens änderte. - Hierzu kommt, wie oben bemerkt, dass Henopoma und Cryptobranchus juponieus, und diese beiden Gattungen allein, mit einem sehr starken M. submentulis versehen sind. Dieser nähert die vorderen, noch mehr also die hinteren Partieen der Unterkieferiiste einander, und erscheint somit in sewisser Beziehung als Antagonist des Masseter. Wirkten beide Muskel zusammen, so müsste, wie ich glaube, eine Hebung des Unterkiefers bei unverinderter normaler Lage seiner dorsalen und ventralen Kante die Folge sein.

In architectonischer Hinsicht ist der M. masseter der vorderen Partie des Digastricus zu verefeichen. Wie diese an der hinteren Fläche des zum Unterkiefer gehörigen Dorsalsegments (des os tympmicum) entspringt und hinter dem letzteren herabgeht, um sich an den hinter dem Gelenk vorragenden kurzen Arm des Unterkiefers zu befestigen, so entspringt unser Muskel an der Vordertliche desselben serments, un vorn diesen hinteren Verlauf und die Insertion des Digastricus zu wiederholen. 
Der Masseter bekommt überall seine Nerven vom dritten Aste des Trigeminus (vgl. Taf. III, Jm; 'Taf. IV, Fig. 1, $\mu$ ), der vor ihm und an seiner Grenze mit dem Temporalis nach aussen und unten läuft.

\section{Temporalis Aut.}

Der Schläfenmuskel (Taf. III, $t$; Taf. IV, Fig. 1, te und te'; Taf. V, Fig. 1 und 2, te) ist bei allen Perennibranchiaten und Derotremen sehr ausgebildet. Seine obere Insertion umfasst die laterale und dorsale Flïche des ranzen Scheitelbeins und Stirnbeins, so wie des als Keilbeinflügel gedeuteten Kunochens. In der Mittellinie der dorsalen Fläche des Schädeldaches stossen die MIn. tomporules beider Körperhälften zusammen. Ihre Fasern laufen von hier nach beiden Seiten auseinander, um je nach der Richtung des Os tymprnicum mit diesem parallel nach aussen und unten zu treten. In diesem Verlaufe nach aussen werden sie vom $\boldsymbol{M}$. masseter von hinten her überdeckt, unter und vor welchem sie sich durch Vermittlung einer starken Sehne (Taf. III. t*) an den Processus coronoideus des Unterkiefers festsetzen.

Untel den Perennibranchiaten ist dieser Muskel bei Menobranchus am stärksten ausgebildet. Noch stirker bei den Derotremen, Amphiume, cryptobrandus juponicus und Mt:nopoma. Er besitzt hier (Taf. IV, Fig. 1) ausser der eben geschilderten auch den übrigen Gattungen eigenen vorderen Portion $\left(t t^{\prime}\right)$ noch eine zweite hintere $\left(t r^{\prime}\right)$, von V a y er" als "Nackenkiefermuskel!" unterschiedene Portion (1. 1. pag. 79). Diese entspringt von der Fascie, die von den Dornfortsätzen der. Wirbel aufstrigt, und erstreckt sich iiber die ersten drei ('ryptobranchus japonicus, Menopoma) oder vier (Amphiuma) Wirbel. Ihre Fasern setzen sich successive an eine allmïhlich stïrkr wordende, an der Ausvenseite des Muskels gelegene starke Sehne (Taf. V, Fig. 2, ts). Diese steigt vor dem Os tympanicum, medialwärts vom Masseter, abwärts nach aussen, nimmt in ihrem Verlaufe noch Fasern von der vorderen Portion (te) auf und heftet sich an die Innenfläche des Kronfortsatzes.

Der Schädel von Amphimma ist im Gegensatz zu den übrigen Gattungen mit einer ziemlich tiefen Schliffengrube versehen. die nach innen durch eme Kante des Scheitelheins, nach aussen durch eine starke kammithnlich vorragende, hallowistrimige Crista desselben Knochens begrenzt wird. In dieser Grube liegt der Temporalis anterior, dessen Insertion sich auch hier bis zum Auge, ja zum Theil vor dasselbe erstreckt (tc). Seine Fasern von denen nur die hinteren sich an die Sehne des Temporalis posterior festheften - con- 
vergieren nach unten und heften sich mittelst einer besonderen Sehne innerhalb des Processus coronoideus an den Unterkiefer.

Iie hintere Iartie des Trmporalis (Taf. V, Fig. 1 u. 2, $t e^{\prime}$ ) ron Amplimma entspringt von den Dornfortsätzen der ersten vier Wirbel und verhält sich ganz wie bei Menopoma. Die sehr starke Sehne $(t s)$ schlingt sich innerhalb des Knochenkammes, der die Schläfengrube von aussen begrenzt, nach rorn und unten, um sich schliesslich an den Processus coronoidens zu heften.

In gleicher Weise indessen, wie der Temporalis bei diesen drei Gattungen seinen Insertionsbezirk nach hinten ïber die Nackengegend ausdohnt, ist sein Bereich auch nach vorn vergrössert. Er erstreckt sich hier bis vor das Auge (Taf. IV, b), so dass dieses lateralwärts von der vordersten Partie dieses Muskels liegt. Die Fasern der letzteren müssen sich schrïg nach aussen und hinten wenden, um zur Anheftung an die erst erwähnte Sehne der ersten Portion zu gelangen.

Fügen wir dem eben gesagten hinzu, dass der Temporalis sehr häufig auch die Fasern des oft nicht deutlich getrennten $\boldsymbol{M}$. pterygoidens enthilt, so erscheint er als der kräftigst. Hebemuskel des Unterkiefers. -- Auch er bekommt, wie der Masseter, seine Nerren vom dritten Aste des Trigemimus.

In architectonischer Hinsicht ist der Temporalis ein Muskel, der von der dorsalen Mittellinie der Wirbelsäule - und zwar sowohl ron Deckknochen des Schädels als von Dornfortsaitzen ächter. Wirbel - an das Ventralsegment des vordersten Visceralhogens greht. In dieser Hinsicht findet er sein rollkommenes Analogon nur in der - übrigens nicht immer vorhandenen - mittleren, you der Fascia dorsalis entspringenden Partie des Digastricus. Den Lovatores arcum kann er nicht wohl verglichen werden, weil diese sich nicht an die Ventral- sondern an die Dorsalsegmente der hinteren Kiemenbogen inserieren.

In anderer Hinsicht erscheint der Temporalis an ter Rückentläche des. Körpers als

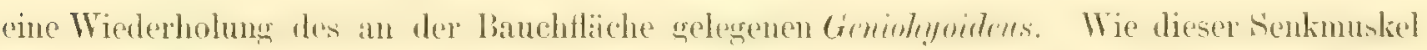
des Unterkiefers als eine Fortsetzung des geraden Bauchmuskels sich zu erkennen gab, so liisst insbesondere. die Form der Derotremen unseren Hebemuskel als einen dorsal gelegenen Muskel erscheinen, der die Insertionen der geraden Rückenmuskeln wiederholt und sich ebenfalls bis zum Ventralsegment des vordersten Visceralhogens fortsetzt. 
8. M. pterygoideus Aut.

Der $\boldsymbol{M}$. pterygoideus diufte nur da mit Recht als besonderer Muskel aufgefỉht werden, wo er durch eine besondere Sehne sich an die Innenflaiche des Unterkiefers heftet. Bisweilen ist dies allerdings mit dea untersten Fasern des Temporulis der Fall, die dann ohne jeloch immer an ihrem Ursprung als abgesouderte Muskelpartie zu erscheinen von dem Seitentheile der Schädelwandung (dem sogenannten Keilbointlïgel) und der Dorsaltliche des Flügelbeins entspringen. So bei Menopomu, wo diese nicht zahlreichen Fasern sich durch eine besondere breite Sehne an die Medialthiche des Unterkiefers, etwas unter und vor dem Processus coronoilcus befestigen. - Noch häufiger aber fehlt dieser Charakter des $\boldsymbol{M}$. pterygoideus und die von den genannten Knochenpartieen entspringenden IIuskelbündel heften sich mit denen des Temporalis an eine gemeinschaftliche Sehne.

Bei Siren lacertina ist dagegen der $.1 I$. pterygoidens selir stark ansgebildet. Er tritt hier als sehr dicker Muskel an der Innentïche des Unterkiefers vor dessen Gelenk dentlich nach immen heraus, und füllt, von unten gesehen, die dreieckige Lücke aus, welche die beiden Mylohyoidei zwischen sich lassen.

Ebenso ist auch Amphiuma mit einem sehr starken $\boldsymbol{U}$. pterygoideus versehen, der von der Unterfläche des $O s$ pterygoidcum, völlig getrennt vom Tomporalis, entspringt. $\mathrm{Er}$ ist lateralwärts von der inneren Partie des Masseter bedeckt. Seine Fasern convergieren nach hinten und setzen sich hinter dem Kronenfortsatz an die Imentläche des Unterkiefers.

Auch dieser Muskel ist, wo er gesondert auftritt, ein Heber des Unterkiefers, dessen hintere Partie er zugleich etwas nach innen biegt. - Rei Siren lacertina erhäl er seinen Nerv vom Facialis, und zwar aus unserem $R$. jugularis. 
9. II. levator maxillae inferioris ascendens.

$\mathrm{Zu}$ den gewöhnlichen Hehemuskeln gesellt sich hei cinigen wenigen Amphibien ein anderer, der von der Mittellinie der Bauches zu dem hinteren Unterkieferfortsatz heraufsteigt und den ich daher im Gegensatz zu jenen als Lerator usendens bezeichnen möchte.

Ich habe diesen Muskel bei den Peremibranchiaten gar nicht, unter den Derotremen nur bei Amphimme. unter den iibrigen Amphibiengattungen nur bei c'aeritin isiphonups. Wagl) gefunden.

Bei Amphiuma liegt derselbe (Taf. 5, Fig. 3, 7as) ganz an der Ventralfläche des Körpers. Er entspringt mit zwei Portionen:

1. Von der die Muskeln vor- und medialwärts rom Schultergerüst überziehenden Fascie, und zwar in einer Querlinie, die sich rom Oberamgelenk bis zur ventralen Mittellinie des Körpers erstreckt.

2. Von der äusseren Fläche des winzigen Oberarms nahe unter dessen Gelenk mit dem Schulterblatt.

Seine Fasern laufen convergierend nach vorn und oben und inserieren sich an die Spitze des bei Amphiuma ungewöhnlich langen hinteren Unterkieferfortsatzes.

Durch seine Contraction zieht der Muskel diesen Fortsatz herab. hebt also den Unterkiefer und schliesst das Maul. Ist der Unterkiefer durch andere Muskeln fixiert, so zieht der Levator ascendens den Oberarm rom Körper ab nach aussen und rorn. In letzterer Wirkung, die wohl wegen der minzigen Entwickelung des ganz knorpeligen Oberarms die überwiegende ist, ergänzt er diejenige des schwachen Deltoideus.

Auch bei Caecilia annulata wird der hintere Fortsatz des Unterkiefers, der sonst nur Senkmuskehn (den verschiedenen Portionen des Digastricus) zur Anheftung dient, ron einem mit der Form ron Amphiuma sehr übereinstimmenden Lerator ascendens benutzt. Jener Fortsatz ist hier noch viel länger, hinter dem Gelenk nach oben gebogen, und bildet so einen, sonst nicht vorhandenen, aufsteigenden Ast des Unterkiefers. So stellt er einen riemlich bedeutenden hinteren Arm eines im Gelenk am Os tympanicum unterstitzten Winkelhebels vor, dessen erster, nicht viel lïngerer Arm eben das zahntragende horizontale 
Stück des Unterkiefers selbst ist. Jener grosse, hakenfömige Arm wird durch den ron oben und vorn an ihn sich festsetzenden Digastricus nach oben, hierdurch del Unterkiefer selbst im Bogen herabbewegt. Bei den Perennibranchiaten und Derotremen ist es ebenso, nur sind wegen geringercr Grösse des Hebelarms die bewegenden Nuskeln unweit stärker als bei Caecilia. - Dem Digastricus gegenüber setzt sich bei dieser Gattung an die ganze hintere Fläche des aufsteigenden hinteren Unterkieferastes ein äusserst starker, aus mehren Portionen zusammengesetzter Muskel, dessen Analogie mit dem erst geschilderten Muskel des Amphiuma gar nicht zu verkennen ist, wenn auch natuirlich die dort vom Oberarm entspringende Portion fehlt. Die vordersten Fasern seiner ersten Portion entspringen medialwärts rom Unterkiefergelenk in der Mittellinie des Bauches von der Fascie, welche die geraden Bauchmuskeln überzieht. An diese Fasern fügen sich hinten und lateralwärts andere an, die mehr nach aussen eutspringen, so dass die innere und hintere Insertion der ersten Portion einen Halbkreis ron der ventralen Mittellinie bis zur lateralen Seitenlinie umfasst. - Die folgenden Portionen erreichen die ventrale Mittellivie nicht mehr, sondern greifen nur bis anf etwa das erste Drittel der Bauchfläche über; ihre Fasern entspringen von der den Seitenmuskel überziehenden Fascie, und zwar schichtweise, fast den Inscriptiones tondincae entsprechend, so dass immer die nächstfolgende Portion lateralwärts über die vorhergehende hinweggeht. Alle diese von hinten und unten her kommenden Fasern vereinigen sich zu einem sehr starken Muskel, der sich von hinten und unten her an die hintere Flïche des aufsteigenden Unterkieferfortsatzes heftet. Es liegt auf der Hand, dass dieser liräftige Muskel ganz geeignet ist, die Wirkung der schwachen, an Schärlel selbst entspringenden Hebemuskeln des Unterkiefers zu ergänzen und zu verstärken ${ }^{1}$ ).

1) In einer früheren Arbcit: Amplibiorum nu dorum Neurologiae Spec. I, 1ag. 42, hahe ich diesen Muskel als Apmessor maxillae inferioris bezeichnet und seine form kurz beschrieben. Auf der Taf. III, D, jener Schrift ist der Muskel vom Unterkieferast lasgeschnitten und zurückgeschlagen dargestellt. 
Bei Ampliuma erhïlt unser Muskel seine Nerven vom Facialis. Der $R$. jugu. laris sendet hier nach Aufnahme des $R$. communicans aus dem Glossopharyngeus einen $\Lambda$ st

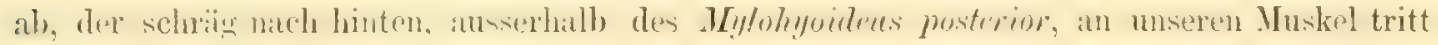
und sich in ilım ausbreitet.

Bei Cuc cilir erhält er seine Nerven von dem grossen Halsganglion des Vagus, in welches Zweige von Furiulis, Vugus und den beiden ersten Halsnerven eintreten (rogl. meine angefuhrte Schrift, pag. 41). Ich bin jetzt geneigt, aus der mir frïher nicht bekannten Form von Amphiuma zu schliessen, dass die aus dem Facialis stammenden Elemente jenes Ganglions es sind, die diesen Muskel versorgen.

\section{d) Muskeln der Zunge.}

10. II. Genioglossus Aut.

Die Múnkeln der Zunge wïrden bei den Peremibranchiaten und Derotremen richtiger als Muskeln des Bodens der Murdhöhle zu bezeichnen sein. Denn einer wirklich muskulösen Zunge ermangeln alle Gattungen ohne Ausnahme. Die das Zungenbein von oben her be-

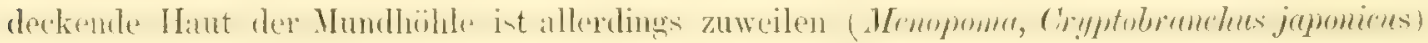
durch darunter gelagertes Binderewebe polsterartig anfgetrieben, oder bildet eine mit demselben angefiilite, voru freie Duplicatur. Letztere Bildung mag Rusconi bestimmt haben, pag. 56 von der Zunge des Mypochthon zu sagen: "La lingua del proteo anguino è per la maggior parte carnosan

Gleichwohl sind alle Gattungen ohne Ausnahme mit einem Muskel versehen, der von ler hinteren Fläche des volderen Endtheils des Unterkiefers ausgehend, sich unter diese Haut der Mundhöhle befestigt, und sie sammt dem daran festgewachsenen Zungenbein nach vorn zu ziehen vermag.

Bei Sircdon ist der Gonioglossus ein sehr kurzer, schwacher Muskel, von unten her bedeckt von dem Ursprunge des Geniohyoideus und mit dessen Fasern zugleich vom hintersten Rande des vordersten Theils der Unterkieferïste als pariger Iuskel entspringend. Er befestigt sich von unten her an die den Zungenbeinkörper und den Anfang des Zungenbeinhorns ïberziehende Haut des Mundes. 
Ganz ebenso finde ich unseren Muskel bei MLnobrunchus. Seine Fascikel rereinigen sich nicht zu einem einzigen Muskel, sondern bleiben in mehre Bündel getrennt. - Mcnopoma zeigt dieselbe, in viele Fascikel getrennte Form. Diese entspringen dorsalwärts rom $M$. submentalis und $M$. geniohyoideus. - Dass der von Schmidt, Goddart und van der Hoeven als M. gomoglossus beschriebene Muskel nicht als solcher zu deuten, sondern der $M$. sulmentalis sei, ist oben (S. 47) erwähnt.

Am stärksten entwickelt ist der Genioglossus bei Amphiuma. Lr wird hier schou nach Wegnahme der vordersten Fasern des Mylohyoidens anterior gesehen, da seine Fascikel durch die feine breite Sehne des Gomiohyoidcus durchscheinen. Seine getrennt bleibenden und von voln nach hinten divergierenden Bündel setzen sich vor, über und seitlich ron der vorderen accessorischen Copula des Zungenbeins an die Hatut des Mundes fest.

Eine ganz besondere Form hat dieser Muskel bei IIypochthon. Ein Theil seiner Fasem befestigt sich an eine breite Fascie, welche die vordere lartie des Zungenbeins und die vordere Insertion des $1 \%$. coralohyoilens extoms ventralwärts iiberzieht. Die lateralen Fasern dagegen lanfen in eine starke, platte und lange Selne aus, welche ventralwïts vom Unterkiefergelenk und der. Sehne des Digustricus nach hinten geht und sich an die Aussenkante des hinteren Endtheils des Zungenbenhorns befestigt.

Der Gerioyloswus zieht das Zungenbein nach vorn. Ist dagegen letzteres, etwa durch den Stemolyoidens fixiert, so trïgt er ebenso wie der Geniohyoidens dazu bei, das Maul rurch Herabziehen des Unterkiefers zu öfnen.

11. M. hyoglossus Aut.

Ein eigentlicher M. hyoglossus ron der beim Frosche ausgebildeten Form existiert weder bei den Peremilunnchiaten noch den Derotremen. Unter den letzteren könnte mam bei Menopoma eine vom Geniahyoudus nicht abgetrennte Partic als M. hyoglossus deuten, die sich rom Tentralsegment des zweiten Kiemenbogens an die Hant der Mundhöhle festheftet (vgl. pag. 57). Sonst habe ich nirgends Iiuskelfasern beobachtet, die sich ron Theilen des Zungenbeinkiemenhogenapparates an den Borlen der Mundhöhle erstreckten. Bei dem Mangel einer muskulösen Zunge wird der 11 . lyyoglossus offenbar durch diejenigen Muskeln ersetzt. die das Zungenbein und seine Bogentheile zurïckziehen. 


\section{e) Muskeln des Zungenbeins und der Kiemenbogen.}

\section{H. ceratohyoideus externus.}

(Ceratoglossus externus, I unk; Sieb.; Hyrtl. Hyopréstyloidien, Dugès. Hyoideus proprius, Zencker. Hyoglossus, Schmidt; Goddart und v. d. Hoeven.)

Dies ist der constanteste und stärkste derjenigen Muskeln, die sich von einem Bogenschenkel des Visceralskelettes zu einem anderen erstrecken. Ueberall entspringt er von der Ventralflïche der vorderen Partie des Zungenbeinhorns. Seine Fasern gehen nach hinten und inserieren sich an die Dorsalflüche des dem ersten Kiemenbogen angehörigen Dorsalsegmentes bis zu dessen hinterer Spitze. In der Regel wird das ganze Dorsalsegment des ersten Kiemenbogens von diesem Muskel eingehïllt, der gleich nach Wegnahme des Mylohyoideus und des Goniohyoideus als sehr starker, schräg ron innen und vorn nach aussen und hinten sich erstreckender Muskel wahrgenommen wird. Die vorderen Partieen der Coratohyoidei extermi beider Seiten stossen in der Mittellinie über den Gemiohyoidei zusammen. Man muss sie hier von einander nach aussen abheben. um die dariber liegenden Muskehn, namentlich den Ceratolyoidcus interms zu sehen.

Bei Siredon entspringt unser Muskel von der inneren Flïche der vorderen Hülfte des Zungenbeinhorns und von der ganzeu unteren Flïche derselben. Seine Fasern gehen nach aussen und hinten und vereinigen sich nahe der hinteren Unterkieferecke mit denen des Mylohyoincus postcrior, so dass sie mit diesen zusammen zu einer einzigen Muskelmasse verschmelzen, die sich an die Vorderfläche und die Endspitze des dem ersten Kiemenbogen angehörigen Dorsalsegmentes heftet. - Die mit einem Kiemendeckel verglichene Duplicatur der Haut, die sich bei Siredon und MLnobronchus quer unter dem Halse von cinel Seite zur andern hinüberzieht, enthült nicht nur den Mylohyoudeus posterior sondern auch den Cerutohyoideus cxtermes.

Siren und Menobranchus zeigen dieselbe Form dieses Muskels.

Bei Amphiuma setzen sich die Fasern des Ceratohyoidens extemus (Taf. V, Jig. 2, rch) an die VentralHïche des vorderen Theils der grösseren Hauptplatte (Taf. I, Fin. 5, h) des Zungenbeinhorns. Sie gehen von hier nach hinten und anssen und inserieren sich an die obere und seitliche Flïche des ersten Kiemenbogens, so das dessen aufsteigender Schenkel bis auf die frei bleibende iiberknorpelte Spitze ganz von ilm und dem Ursprunge der dritten Portion des Digastricus eingehiillt wird ('T'af. V, Figg. '2, d dg'). 
Menopoma zeigt eine etwas abweichende Form unseres Muskels (Taf. IV, Fig. 2, ceh). Seine hintere Insertion zeigt drei Portionen:

1. Die grössere, laterale, entspringt vom ganzen Unfangre der hinteren Hälfte des S förmig gebogenen ersten Kiemenbogens (Taf. IV, Figr. 2, $b^{d}$, und Taf. I, Iig. $6, b^{c}$ ).

2. Die zweite, melnr medial gelegene Portion entspringt von der Vorderfliche des dem zweiten Kiemenbogen angehörigen Dorsalsegments $\left(b^{*}\right)$.

3. Eine dritte Portion entspringt von einer Fascie, die sich an das Ventralsegment dieses (zweiten) Kiemenbogens $(b " v)$ befestigt.

Die Fasern aller drei Portionen vereinen sich bald zu einem einzigen starken Muskel, der dorsalwärts vom Mylohyoideus, medialwärts vom inneren Rande des Unterkiefers nach vorn lïuft. Seme vordere Insertion ist wieder eine doppelte, nämlich:

1. An die Ventralfliiche der grossen Hauptplatte des Zungenbeinhorns (Taf. I, Fig. 6, h).

2. An eine starke Fascie, welche die bewegliche Vorderplatte $\left(h h^{\circ}\right)$ des Zungenbeinhorns ventralwïrts ïberzieht.

Withrend von den hinteren Insertionen die erste und zweite dem Coratohyoideus extermus der ächten Perennibramchiaten entspricht, scheint die dritte Portion als Ceratohyoiders interms gedeutet werlen zu miissen. Wenigstens ermangelt Monopomre eines besonderen, diesem entsprechenden Muskels.

Bei Cryptobrauchus juponirus waltet die hintere Insertion am ersten Kiemenbogen vor. Fasern rom zweiten Kiemenhogen konnte ich nicht entdecken. - Die vordere Insertion ist ganz wie bei ILenopoma.

Bei der grossen Bestïndigkeit und de1 starken Entwickelung dieses Muskels ist man gezwungen, ihn fir einen sehr wesentlichen 'Theil des Athmungs- und Schling-Mechanismus zu halten. Doch ist es nicht ganz leicht, sich allein aus seiner Form und semer Anheftung ein klares Bild von seiner Wirkungsweise zu machen.

Das scheint zunichst ausser Zweifel zu sein, duss der (fortohyoidenes extemus das vordere Ende des Zungenbeinhorns nach unten, ventrulwïrts hewegt. I)as hintere Ende dieses Horns ist, wie oben exwähnt, stets an das Os tympanicum angeheftet. Wird also von einem unter jenem gelegenen Muskel dies Forderende nach hinten gezogen, so kam es mur nach unten nachgeben. Gleichzeitig wird das in den meisten Fitlen bicgsame Zungenbein- 
horn eben wegen seiner hinteren Anheftung gekrümmt, und zwar so, dass die entstehende Convexitiat mach unten kommt. Denn die Fasern unseres Muskels erstrecken sich nicht an die vordere Iartir. den Zungembeinhorns allein, sondern an denen Ventralflïche mehr oder weniger weit - meist bis zur Hälfte - nach hinten.

In ganz gleicher Weise wird der Coratohyoidens exterme durch seine Contraction auch den èrsten Kiemenbogen krimmen. Das vordere Ende des letzteren stiitzt sich gegen den Zungenbeinkörper. Wird nuu das hintere Ende nach vorn gezogen, so muss ebenfalls eine Biegung, und zwar — wenn ein solches vorhanden ist — im Gelenk zwischen Dorsalund Ventral-Segment entstehen. Auch hier muss die Convexität der entstehenden Biegung nach unten kommen, da die an den aufsteigenden Ast erfolgende Insertion an dessen nach rorn und unten gerichteten Fläche statt hat.

Beide lírummungen haben aber nothwendig eine Vertiefung der Mundhöhle zur Folge. Die Coratohyoilci extemi beider Seiten sind es wohl rorzugsweise die durch ihre Contractionen des Lumen der eigentlichen Iundhöhle erweitern, und für diese dasselbe leisten, wie der Stcmohyoidas für die hintere Partie der Rachenhöhle. Sie schaffen den Raum, in den der atmosphärische Iruck Wasser oder Luft eintreiben wird. Sie sind daher wirkliche Antagonisten der Constrictores, insbesondere des Mylohyoideus, der durch seine Contractionen den Boden der Mundhöhle abflacht, ihr Lumen rerengt.

Zweitens aber üht unser Muskel ohne Zweifel eine wichtige Wirkung auf die Kiemenspalten aus. Das Dorsalsegment des ersten - bei Menopoma des zweiten — Kiemenbogens ist, wie oben gezeigt, für die Oeffnung und den Verschluss der Tiemenspalten von der grössten Bedeutung. Jene erfolgt, wenn der genaunte Bogentheil von den iibrigen abgezogen, diese, wenn er an dieselben angedrückt wird. Dies Segment spielt gewissermassen die Rolle eines Kiemendeckels. Seine Fläche wird vergrössert durch die sich daran heftenden Muskeln, den Mylohyoidens postevior, die hintere Partie des Digastricus, den Coratolyoidens exterms. Unser Muskel num zieht wirklich das Dorsalsegment des ersten Kiemenbogens nach vorn, aber zugleich, da seine Fasern schräg nach imen laufen, nach inuen an den Leib und drückt iln somit gegen die ïbrigen Kiemenbogen. Er dïrfte somit zum Yerschluss der IKicmenspalten dienen.

Wenn also den Ceratohyoidas extermus sich in gewisser Beziehung als Antagonist des die MImdhöhle abflachenden Mylohyoideus zu erkennen gab, so verstärkt er doch in anderer Hinsicht diejenige, die dieser Muskel (der Myloh. posterior), wic oben gezeigt, anf * den Verschluss der Kiemenspalte ausibt. Hierin tritt er zugleich in Gegensatz zur hinteren Partie des Digntrims, die, wie fribher gezeigt, gleichzeitig Maul und Kiemenspalte öfnet. 


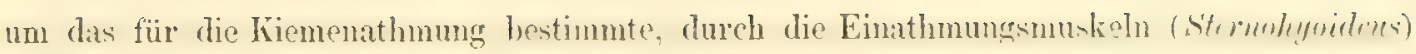
eingeholte Wasser in gleichförmigem Zuge vorn herein, seitwärts ausströmen zu lassen.

Hiernach scheint unser Muskel vorzugsweise zum $\mathrm{L}$ uftathmen bestimmt zu sein Wirklich findet er sich auch in ausgezeichneter Weise bei Salamandern und Tritonen, nur dass hier natürlich diejenige Kraftåusserung wegfällt, die bei den Pernnibranchiaten und Derotremen den Verschluss der Kiemenspalten bedingt.

Seine Nerven erhält der Ceratohyoideas cxterms wohl ohne Ausnahme vom Glossopharyngeus, oder, wo dieser mit dem Vagus verschmolzen ist, von dem ersten der aus dem Ganglion des letzteren austretenden Stiinme. Dieser Nervenstamm tritt meist von unten und hinten her an den Ceratohyoideus cxtcmus heran, lässt sich, immer dünner werdend, eine Strecke an seiner Ventralseite verfolgen und scheint endlich in dem unserem Muskel nahe liegenden Ceratohyoideus interms zu endigen, indem er nur feine Fäden nach oben in die Haut des Mundes schickt. In anderen Fällen scheinen die für unseren Muskel bestimmten Nerven aus der Bahn des Glossopharyngeus durch Vermittelung eines 12. communicans in diejenige des Facialis überzugehen und dann aus dessen liamus jugularis zu entspringen.

Bei den Larven der Tritonen und Salamander ist der Ceratolyoidens extermus ein sehr starker Muskel ganz von der Form der Perennibranchiaten. Vergl. die dem Werke von Duğès entlehnte Fig. 7, No. 8 unserer' 'Tafel I.

Auch die Cuccilicn haben einen Muskel der dem Coratohyoidas cxtcrms verglichen werden kann. Er erstreckt sich bei C. amuulatı von der hintern Fliche des ersten. gekrïmmten Bogens (dem Zungenbeine) mit schräg nach hinten und aussen tretenden Fasem an die Vorderfläche des zweiten Bogens (ersten Kiemenbogens). (Vgl. Taf. VI, Fig. 1, cch.)

13. M. Ceratohyoirleus internus.

II. pré-stylo-prébranchial, Dugès.

Alle ächten Perennibranchiaten - und num diese - sind mit einem Muskel ausgerüstet, dessen vordere Insertion, wie diejenige des Ceratohyoudus exterms, am vorderen 
Fude des Zumenenbeins stattfindet, der sich aber hinten nicht an das Ende. soudern an den Anfang des dem droten Kiemenbogen angehörigen Dorsalsegmentes anheftet. Er wird gesehen. wem man nach Entfernung des Góniohyoders die in der Mittellinie zusammentreffenden vorderen Partieen der Ceratohyoidei extemi beider Seiten von einander abhebt.

Bei Siredon hat dieser Muskel (Taf. I, Fig. 1, $p a$ ) eine schmale längliche Gestalt. Seine breitere Basis setzt sich an die vordere und ventrale Fläche des dem ersten Kiemenbogen angehörigen Dorsalsegmentes $\left(b^{\prime}\right)$. Von dort läuft der Nuskel nach rorn und spitzt sich in eine Sehne zu, die sich an die VentralHäche des Zungenbeinhorns, dicht neben dessen an den Zungenbeinkörper befestigter Spitze anheftet.

In Vergleich mit Siredon ist der Ceratohyoidens intomes ausserordentlich stark bei Siren lacertina. Er liegt wie gewöhnlich medialwärts vom Cerat. exterms und begrenzt von aussen die noch weiter nach innen gelegene, sehr stark entwickelte Glandula thyreoidca. Seine hintere Insertion umfasst die beiden Segmente des ersten Kiemenbogens an deren Verbindungsstelle mit einander, also das hintere Ende des Ventral-, das vordere des DorsalSegments, das Gelenk zwischen Segmenten rentralwärts bedeckend. Er heftet sich vorn an die hintere Fläche des Zungenbeinhorns, sehr nahe dem Winkel, den dieses mit dem Zungenbeinkőrper bildet.

Bei Menouranchus (Taf. I, Fig. 3, pa) und Hypochthon (Taf. I, Fig. 4, pa) hat

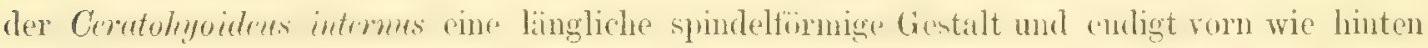
in eine Sehne. Die hintere inseriert sich an den Anfang des Dorsalsegmentes des ersten

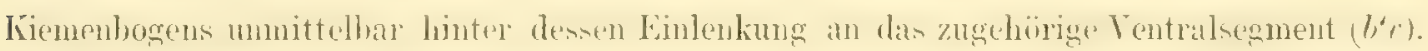
Die vordere setzt sich an die mediale und hintere Flïche des Zungenbeinhorns, und zwar bei Hypochthon (Fig. 4) dicht hinter dessen rorderem Ende, bei Mcnolranchus (Fig. 3) an das vordere Ende der Hauptplatte $(h)$ des Zungenbeinhorus, dicht hinter der ron ihr abgesetzten Vorderplatte $\left(h^{\prime}\right)$.

Bei Hypochthon, und, wie es scheint, nur bei dieser Gattung, existiert noch ein hinteres Analogon des Ceratohyoidens intermus in einem schwachen Nuskel (Taf. I, Fig. 4, $p a^{\circ}$ ). Diesèr entspringt vorn von einer Fascie, die den vorderen Theil des Sternohyoidens (sh) und den Zungenbeinkörper $(c h)$ ventralwärts überzieht, geht, anschwellend und dann wieder sich zuspitzend schräg nach hinten und aussen und heftet sich mit einer zweiten feinen Sehne an das Ventralsegment des ersten Kiemenbogens dicht ror der Insertionsstelle des Constrictor arcum. Auf der Ventralfläche dieses Muskels ist die auch bei den übrigen Gattungen in dieser Gegend gelegene, traubenförmige Glamdula thyrcoidea (dr) sichtbar. 
Den Gattungen Amphiuma, Menopoma und Cryptobranchus japonicus fehlt dieser Muskel. Er scheint hier mit dem Ceratohyoidens exterms verschmolzen zu sein. Bei Menopoma ist es die dritte Portion des letateren, die durch ihre hintere Insertion an den Ceratohyoidens interms der Perennibranchiaten erinnert.

Auch dieser Muskel ist zwischen zwei beweglichen Punkten des Zungenbein-Kiemenbogenapparates ausgespannt. Wegen seiner - mit Ausnahme von Siren — sehr betrïchtlichen Kürze und der benachbarten Lage seiner beiden Insertionspunkte wird er im allemenen nicht im Stande sein, den auf die dorsale. Spitze den ersten Kienenbogens durch den vorigen Muskel ausgeübten Zug nach innen wesentlich zu verstärken. Wohl aber dürfte seine Anheftung an die ventrale Fläche dieses Bogens dazu beitragen, die Krrümmung desselben nach unten und so die Austiefung des Bodens der Mundhöhle zu vermelıren.

Seine Nervenfasern erhält auch der Ceratohyoideus interms vom Glossopharyngeus. Nachdem derselbe in der Masse des Ceratohyoideus exterms nach vorn und innen getreten ist, sich auch zuweilen (Siren) mit dem Ende des aus dem Vagres stammenden ersten Kiemennerven verbunden hat, tritt sein feines Ende von aussen her an den Ceratolnyoideus interms heran, um diesen mit Fasern zu versorgen.

Auch ron der Larve des Triton mamoratus bildet Dugès den Ceratohyoideus intermes ab (Taf. XV, Fig. 114, d; copiert auf unserer Taf. I, Fig. 7, d). Jener Forscher bezeichnet ihn als M. pré-stylo-prébranchial.

\section{Constrict or arcum branchiarum.}

Interbranchial, Dugès; Constricteur des ares branchiaux, Léon-Vaillant, Pl. VIII, Fig. 2, 22.2.

Alle mit Dorsalsegmenten der letzten Kiemenbogen ausgerïsteten Amphibien können dieselben durch einen kräftigen Constrictor zusammenschliessen. Derselbe liegt, wie die beiden Ceratolyyoidei an der Ventralseite des Körpers, und wird ron unten erst uach Wegräumung des Mylohyoidens, des Geniohyoidens und meist auch des Ceratahyoidous extemus gesehen. Ueberall inseriert er sich an die Wurzel einzelner der den Kiemenbogen ange- 
hörigen Iorsalsegmente, und geht mit longitudinal verlaufenden Fasern hinüher an diejenigen der folgenden Bogen. Auch hier finden sich merkwürdige Verschiedenheiten, die insbesondere darin begründet sind, dass einzelne Bogen bald eine gewisse Selbstutiudigkeit in ihren Bewegungen zeigen können, bald auch den dureh die übrigen Bogen ausgeführten Bewegungen folgen müssen.

Bei Siredon (Taf. I, Fig. 1) entspringt der Constrictor arcum mit drei Köpfen $\left(c a, c a^{\prime}, c a^{\prime \prime}\right)$ von den vorderen Gelenkköpfen der Dorsalsegmente $\left(b^{\prime}, b^{\prime \prime}, b^{\prime \prime \prime}\right)$ der drei ersten Kiemenbogen. Ihre Fasern wenden sich nach hinten und etwas nach innen, vereinen sich zu einem einzigen Muskel, und inserieren sich an das vordere Ende des dem vierten Kiemenbogen angehörigen Dorsalsegments ( $\left.b^{\prime \prime \prime}\right)$.

Bei Siren (Taf. VI, Fig. 4, ca) ist unser Muskel einfacher, nicht wie bei Sired on aus drei Portionen zusammengesetzt. Seine vordere Insertion ist der untere, vordere Theil des dem ersten Kiemenbogen angehörigen Dorsalsemments, hart an dessen Grolenk mit seinem Ventralsegment $\left(\zeta^{\prime} v\right)$. Von hier aus erstrecken sich seine Fasern medialwiirts um die zwei mittleren Kiemenbogen herum, ohne sich an dieselben anzuheften, und inserieren sich an den vorderen inneren Theil des vierten Kiemenbogens ( $\left.b^{\prime \prime \prime}\right)$.

Menobranchus zeigt wieder eine andere Form. Hier sind drei Portionen mit verschiedenen Insertionen zu unterscheiden. Die innerste (Taf. I, Fig. 3, ca') geht, indem als Insertionsfliche bestïndig das vordere Endtheil der Dorsalsegmente benutzt wird, vom ersten Kiemenbogen an den zweiten; der äusserste (auf der Figur durch die mittlere verdeckt) vom zweiten an den dritten, dagegen sich die grösste mittlere (ca) vom ersten an den dritten Kiemenbogen erstreckt.

Hypochthon (Taf. I, Fig. 4) weicht insbesondere dadurch ab, dass nicht das vor dere Ende des dem ersten Kiemenbogen angehörigen Dorsalsegmentes $\left(b^{\prime}\right)$ der Auheftung unseres Muskels dient, sondern dass letztere erst ungefähr am ersten Drittheil von der Länge dieses Dorsalsegments erfolgt. Dies hängt offenbar damit zusammen, dass die vorderen Fnden der den folgenden Bogen angehörigen Dorsalsegmente $\left(b^{\prime \prime}, b^{\text {* }}\right)$ nicht, wie sonst. unmittelbar hinter demjenigen des zum ersten Kiemenbogen sehörigen Segmentes liegen, sondern weiter nach hinten und aussen gerïckt erscheinen. Es besteht aber der Constrictor arcum bei Iypochthon aus zwei Portionen. Die vordere (Fig. 4, ca) geht von der angedenteten stelle des dem ersten Kiemenbogen angehörigen Dorsalsegments unter dem zweiten durch, ohne sich an dieses zu inserieren, und heftet sich an das vordere Ende des dem dritten Bogen angehörigen Dorsalsegments. Die zweite Portion ( $c a^{\circ}$ ) geht vom vorderen Ende des zweiten an dasjenige des dritten Bogens. 
Amphiuma (Taf. I, Fig. 5) erinnert insofern an Hypochthon, als die vordere Insertion unseres Muskels auch hier etwa in der Mitte der Länge des ersten Kiemenbogens $\left(b^{\circ}\right)$ statt hat. Doch ist nicht zu vergessen, dass bei Amphiuma das Ventralsegment rom ersten Kiemenbogen nicht abgetrennt, sondern mit dem Dorsalsegment zu einem einzigen Knochen verschmolzen erscheint, was die Analogie mit den uibrigen Gattungen wieder herstellt. - Der Constrictor arcum ist hier aus zwei Portionen zusammengesetzt, oder vielmehr es lassen sich zwei in ihrer ganzen Ausdehuung getrennte Muskeln, ein Constrictor inferior und ein Constrictor superior unterscheiden. Dieser, zum grossen Theile ron jenem verdeckt, ist der eiufachere. Er entspringt von der Hintertlïche dos hakenförmigen Fortsatzes des ersten Kiemenbogens ( $\left.b^{\prime \prime} v\right)$ geht gerade nach hinten unter dem zweiten Bogen $\left(b^{*}\right)$ fort, ohue Fasern an denselben anzusetzen, und heftet sich an die Vordertläche der Wurzel des dritten Kiemenbogens $\left(b^{\text {** }}\right)$. Der Constrictor arcum inferior ist wieder aus drei I'ortionen zusammengesetzt. Die oberflächlichste, ventral gelegene (Fig. 5, ca) ist die stärkste. Ihre Fasern entspringen von demjenigen 'Theile des ersten Kiemenbogens, wo dessen dünnerer, mit dem Dorsalsegment der übrigen Gattungen zu vergleichender Theil anfängt. Die zweite über jener gelegene Portion entspringt ron der Wurzel des dritten Kiemenbogens. Alle drei Portionen vereinen sich zu einem einzigen, verhältnismässig starken Muskel, der innerhalb der Kiemenspalte nach hinten geht, über den äusseren Theil des $M$. hyotrachealis ( $\left.h h^{\prime} p\right)$ forttritt, sich dann längs des hinteren. Randes der Kiemenspalte nach oben biegt, und an die Hinterfläche der letzten Hälfte des, vierten Kiemenbogeus iuseriert.

Der Comstrictor inforior ron Amphiuma entspricht, wie man sieht, der Form des Constrictor arcum bei Siredon. Der C. superior dagegen hat, ohne auf die Verengerung der (zwischen drittem und viertem Bogen gelegenen) Kienenspalte einen Einfluss zu üben, durch seine Contraction nur die Annäherung der drei ersten. Bogen an einander zur Folge. Ja, er muss sogat, wenn der vierte Kiemenbogen fixiert ist, eine Oeffnung der Kiemenspalte bewirken, da er in diesem Falle die drei ersten Bogen vom vierten abzieht.

Bei Lenopoma (Taf. IV, Fig. 2, cu) ist unser Muskel aus zwei Portionen zusammengesetzt ${ }^{1}$ ). Die erste entspringt vom hinteren Rande des ersten Sförmig gebogenen Kiemen-

1) Mayer, Anal. pag. 80, sagt: «Vom ersten Kiemenbogen zum dritten geht ein besonderer kleiner Muskel, welcher den dritten Bogen dem ersten nähert und die liemenspalte schJiesst.» - M fasst nämlich unseren ersten Kiemenbogen als zweites Zungenbeinhorn auf und zählt demgemäss nur drei Kiemenbogen. 
bogens $\left(b^{\prime}\right)$ gerade dat. wo dieser mit leichter Convexitat semen aufsteigenden Schenkel alsschickt. Sie greht gerade mach hinten unter der vom zweiten Kiemenbogen (Dorsalsegment. $\left.b^{\prime \prime}\right)$ entspringenten Portion des Crufolugoidens ritermes fort, tritt ferner unter dem zweiten und dritten Kiemenburen durch, ohne sich an dieselben zu inserieren, und heftet sich an die Wurzel des visten (letzten) Kiemenbogens. - Die zweite Portion. betrïchtlich schwïcher als die erste, liegt mehr medial- und dorsalwärts als jene, so dass sie ventralwärts von ihr theilweise hedeckt wird. Sie entspringt mit jener zugleich von der Hinterfliche des ersten Kiemenhogens an desinn Biegungsstelle und geht, ohne sich an den zweiten Kiemenbogen zu inserieren, unter diesem fort nach hinten an die Wurzel des dritten (vorletzten) Kiemenbogens. Der zweite Kiemenbogen dient den Fasern des Constrictor areurm nicht zur Insertion.

Bei Cryptobranchus japonicus fehlt dieser Muskel gänzlich. Ebenso den erwachsenen Salamandern und Tritonen. - Bei den Larven der Salamandrinen ist dagegen der Constrictor arcum sehr ausgebildet, und hat ganz die Form von Sircdon. Vgl. unsere dem Werke von Dugès entlehnte Fig. 7 der I. Tafel, \& (Larve von Triton marmoratus).

Die verschiedenen Formen des Constrictor arcum gruppieren sich nach dem vorhergehenden in drei Kategorieen:

1. Wo derselbe nur geeignet ist, alle Kiemenbogen insgesammt, $d$. l. eigentlich den vordersten au den letzten heranzuziehen, ohne dass den einzelnen zwischenliegenden Bogen eine Annibherung mönglich ist. die nicht durch das Zusammenschlimen joner beiden bewirkt wiirde. Am ausgeprägtesten ist diese Form bei Siren. Bei Sirclon und den Salamanderlarven heften sich auch alle Partieen dieses Muskels an den letzten Kiemenbogen, doch ist es denkbar, dass der eine oder der andere der vorhergehenden Bogen allein an diesen herangezogen würde, weun nämlich der Fall eintrete, dass einzelne der von ihnen ausgehenden Muskelpartieen allein wirkten.

2. Wo ausser jenem Zusammenschluss aller Bogen und unabhängig von ihn auch noch einzelne derselben selbstständig einander genähert werden können (Menobranchus, Hypochthon, Mcnopoma). In diesem Falle existieren ausser der bei Sircn allein vorhandenen Muskelpartie (vom ersten Bogen an den letzten mit Uebergehung der dazwischen- 
liegenden) noch besondere Muskelpartieen, die sich rom ersten an den zweiten, oder von diesem an den dritten oder auch nux rom ersten an den dritten begeben.

3. Wo ein den Zusammenschluss aller Kiemenbogen mit einem Mal bewirkender Muskel nicht existiert, sondern jener nur dadurch bewirkt wird, dass die einzelnen Kiemenbogen durch ihre besonderen Muskeln cinander genähert werden (Amphima).

Henopoma und Siren sind die einzigen Gattungen, bei denen einzelne Kiemenbogen mit rev Insertion dieses Mnskels ganz ibbergangen werden. Es ist auffallend, dasis dies bei Menopoma der zweite, aus ganz ossificierten Segmenten zusammengesetzte Bogen ist, der sonst durch seine Muskelansïtze bei lieser Gattung eine so wichtige Rolle spielt. Er ist zugleich derselbe, der sich bei Cryptobranchus japonicus - wo unser Muskel fehlt perennierend erhält.

Der Constrictor arcmem erhiilt seine Nerven aus einem der ersten Stïmme des

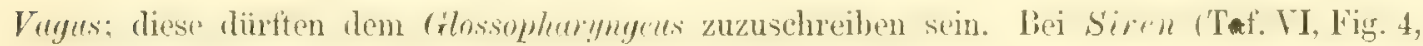
ca) giebt der Ramus recurrens des Vagus ( $r$ ) einen Zweig ( $a$ ) an den Constrictor arcum (ca).

15. Mm. adductores arcuum.

Bei einigen Gattungen erstrecken sich besondere kleine Muskeln von den ersten der Inscriptiones tendineac des Stemohyoideus quer lateralwïts an einzelne Kiemenbogen. Durch ihre Contraction werden die letzteren an den Leib gezogen.

Siredon ist mit einem Adductor arcum secundi ct tertii versehen (Taf. I, Fig. 1, $q a$, in welcher Figur der Stemohyoidcus mit der an ihm stattfindenden medialen Insertion unseres Muskels entfernt ist). Die hierzu gehörigen beiden sehr schwachen Muskelparticen finden ihre laterale Insertion an dem knorpeligen Vorderrande der dem zweiten und dritten Kiemenbogen angehörigen Dorsalsegmente, wo ihr Ursprung über dem Constrictor arcum liegt. Thre Fasern laufen quer nach imnen und inserieren sich an die zwei ersten der den Stemohyoideus durchsetzenden Inscriptiones tendineae.

Auch Siren und Menobranehus sind mit demselben, aus zwei Partieen gebildeten Muskel ausgeristet, von ganz derselben Form wie bei Sirclon. 
Bei Menopoma (Taf. IV, Fig. 2) entspringt von derjenigen Inscriptio tendinea, die vor der Pturs dovimluris des Schultergeriisten den geraden Bauchmuskel (sh) durchsetzt, lateralwärts mit feiner Selne ein schwacher Muskel (sp), dessen nach aussen laufende Fasem sich fiicherfömig ausbreiten. un sich ron unten her theils an die Haut des Schlundes, theils an den oberen Theil des rom letzten Kiemenbogen allein vorhandenen Dorsalsegmentes anzuheften. Diese Insertion erfolgt da, wo die Fasern des Hyotrachealis, die den letzten Kiemenbogen zn ihrer lateralen Insertion benutzen, aufhören und sich von denjenigen des ron der Fascie der Nackenmuskeln entspringenden Dorsotrachealis scheiden.

Menopoma weicht nach dem eben gesagten in drei Punkten von den übrigen Gattungen $\mathrm{ab}$ :

1. Die laterale Insertion unseres Muskels erfolgt nicht an einem der mittleren, sondern am letzten Kiemenbogen.

2. Sie findet nicht statt am ventralen. sondern am dorsalen Ende ron dessen Dorsalsegment.

3. Ausser an die genannten Kiemenbogen setzt sich unser Muskel, und zwar mit der Mehrzahl seiner Fasern, quer an die Haut des Schlundes.

Bei Cryptobranchus japonicus habe ich diesen Muskel nicht gefunden.

Sehen wir vorläufig von der zuletzt bei Menopoma erwähnten, an den Schlund gehenden Partie unseres Muskels ab, so haben die anderen Fasern und diejenigen, mit denen Sirdom, Sim und Menotromches allein ausgerüstet zu sein scheinest. ohne allen Zweifel bei ihrer Contraction rinen Zug der betreffenden stellen der Kiemenhogen an den Leib, also eine Gutfernung derselben von den iibrigen, namentlich dem ersten, mithin eine weitere Oeffnung der Kiemenspalten zur

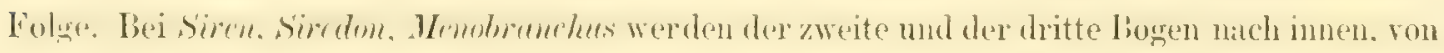

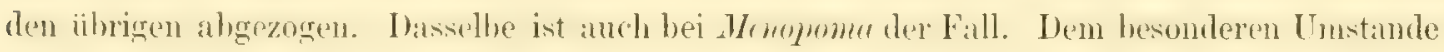
entsprechend, dass bei dieser Gattung nur eine, ummittelbar vor dem vierten Kiemenbogen gelegene Spalte sich erhält, ist es denn auch dieser letztere, der von den übrigen abgezogen werden muss, wenn die Kiemenspalte geöffnet werden soll, so dass die nur bei dieser Gattung sich findende Insertion gerade an diesen letzten Bogen ebeu der erwïhnten Function unseres Muskels vollkommen entspricht. - Die an den Schlund in einer zwischen Hyotrachealis und Dorsotrachealis liegenden Querlinie sich anheftenden, nit den übrigen rom 
Stemolyoideus entspringenden Fasern von Menopoma dagegen entsprechen einer bei Muobranchus in Stemohyoideres selbst enthittenen, die Erweiterung des Schlundes bewirkenden Partie.

Das vorstehende wird genügen, um in dem Adductor arcuum einen für die Kiemenathmung bestimmten Muskel erkennen zu lassen.

Aus welchem der ventral verlaufenden Nervenstïmme diese sehr kleine Muskelpartie versorgt wird, habe ich nicht ermitteln kömen. In ihrer Nähe verlaufen der Glossopharyngeus, die Endzweige des ersten und zweiten Kiemennerven und der Hypoglossus.

16. N. protractor arcus ultimi.

Einige Gattungen sind mit einem kleinen Muskel ausgerüstet, der von der Wurzel des letzten Kiemenbogens mit longitudinal verlaufenden Fasern nach vorn geht, um sich an das dem zweiten Kiemenbogen angehörige Ventralsegment zu heften. Ich habe ihn bei Siren und IIypochthon beobachtet. Seine Fitsern laufen bei beiden (xattungen medialwärts bei den ventralen Enden der den übrigan Kiemubogen angehörigen Dorsalsegmente vorbei. Bei Hypochthon (Taf. I, Fig. 4, $h p^{4}$ ) folgen seine Fasern nach vorn unmittelbar auf die nach innen an die Luftröhre gehenden des IIyotrurhe dis $(h p h)$, so dias mim versucht sein könnte, diesen kleinen Muskel für eine besondere Partie des letzteren zu halten. Bei Sircn (Taf. VI, Fig. 4, W) erscheint er selbstetindiger als besonderer Muskel ausgebildet und nicht mehr in Zusammenhang mit den Fasem des Hyotrachealis.

Bei Siren gelang es, die Nervenfasern zu verfolgen, die diesen kleinen Muskel versorgen. Sie entspringen (Taf. VI, Fig. 4, s) aus dem Rames recurrens des Vagus (rr), unmittelbar nach den für den Constrictor arcum bestimmten Zweigen (c).

Die Contractionen dieses Muskels haben ohne Kweifel eine weitere Oeffnung der letzten Kiemenspalte zur Folge. Sie ziehen den letzten Bogen von den iibrigen ab an den Leib. 
17. Mm. levatores arcuum.

M. élévateur branchial, Leon-Vaillant.

Alle Perennibranchiaten und Derotremen. ausserdem anch die Caecilien, sind mit einem System von Muskeln ausgerüstet, dessen Fasern vom Hinterhaupt und in einer nach Linten lateralwiirts von der Mittelline des Rück'ns laufenden Linie yon einer dex Haut dicht anhaftenden Aponeurose entupringen. Sie steigen von hier nach aussen abwärts und heften sich an die doralen Spitzen der Kiemenhogen. - Wegen ihrer Beständigkeit und des Umfanges ihrer dorsalen Insertion mussten sie allen die Derotremen um Permnibranchiaten studierenden Autoren in die Augen fallen. Schwieriger ist es, ihre Anheftungsweise an die einzelnen Kiemenbogen zu verfolgen, daher diese denn auch noch von keiner Gattung in genügender Weise beschrieben wurde.

Bei Siredon existieren vier, den einzelnen Kiemenbogen entsprechende Partieen, die an ihrem dorsalen und molialen Lropung als ein einziger Muskel erscheinen. bald aber in ihrem Verlaufe nach aussen sich in die den einzelnen Bogen entsprechenden Muskeln sondern. Die erste diescr Partieen (Levator arcus primi) entspringt von der hinten vorragenden Kante des Scheitelbeins und von der an diese, wie an die Dornfortsätze der Rückenwirbel sich heftenden Fascie ${ }^{1}$ ). Die drei anderen Partieen entspringen dicht hinter jener von derselben Fascie in einer etwas lateralwärts von der Mittellinie des Rückens gelegenen Längslinie. Alle vier Muskeln gehen schräg nach hinten und aussen, jedoch so, dass die Levatores arcum sccundi, tertii und quarti mehr nach hinten treten, als der Levator arcus primi. Es trennt sich dadurch der letztere bald von den drei übrigen Muskeln, und es entsteht zwischen ihm und dem Levator arcus secundi cine Lücke in Form eines mit der Spitze nach oben und vorn gerichteten Dreiecks. - Wähnend sich so der unmittelbar hinter der zweiten Portion des Digastricus verlaufende erste Levator schon durch seinen Verlauf als besondere Partie von den übrigen absetzt, ist auch seine Insertion an den ersten Kiemenbogen von derjenigen der anderen drei Muskeln verschieden.

1) Diese bei allen Perennibranchiaten und Derotremen vorhandene Fascia dorsalis, die meist auch anderen Musceln (Mylohyoidens posterior, zweite Partie des Digastricus, Dorsotrachealis) zur Anheftung dient, ist überall der Haut so dicht angeschlossen, dass sie meist bei Lüsung der letzteren an derselben haften bleibt. Fs bleiben alsdann auch die dorsalen Anheftungen der genannteu Muskeln an der Haut haften, und jene erlangen dadurch den Anschein von Iautmuskeln. Manche Widersprüche in der Beschreibung jener Muskeln rerdanken diesem Umostande ihren Ursprung. 
Es inseriert sich nämlich der Levator arcus primi an die ganze Vorderfläche des aufsteigenden Astes des dem ersten Kiemenbogen angehörigen Dorsalsegments ${ }^{1}$ ). Von den übrigen drei Muskeln wird nur die dorsale Spitze der betreffenden Kiemenbogen zur Insertion gewählt. Der zweite Levator heftet sich an die Innenfläiche der dorsalen Spitze des zweiten Kiemenbogens, der dritte an diejenige des dritten, der vierte an diejenige des vierten Kiemenbogens.

Die Form dieses Muskels bei Siren lacertina ist derjenigen von Siredon ganz :ahnlich ${ }^{2}$ ). Der erste Lcvator ist breiter, als jeder der folgenden und an seinem Ursprunge theilweise vom zweiten verdeckt, iibrigens gleich den drei folgenden wie bei Sircton ganz oberflïchlich gelegen. Er steigt ausserhalb der Nackemmuskeln nach unten mud hinten und heftet sich an die ganze Vordertliche des aufsteigenden Astes des zum ersten Kiemenbogen gehörigen Dorsalsegments. Auch hier gehen die drei folgenden mehr rückwïrts, so dass zwischen ihnen und dem ersten ebenfalls eine dreieckige Lücke bleibt. Auch sie gehen, wie bei der ersten Gattung, nicht an die Vorderflächen, sondern respective an die hinten frei vorragenden Enden des zweiten, dritten und vierten Kiemenbogens.

Bei Menobranchus haben die Levatores arcum eine von Siredon und Siren ganz abweichende Form $^{3}$ ). Die schon dort angedeutete grössere Selbstständigkeit des ersten dieser Muskeln ist hier so gesteigert, dass man zwei der Lage und der Anheftung nach ganz getrennte Muskelpartieen zu unterscheiclen hat.

Der Levator arcus primi ist kein oberfächlicher Muskel mehr, wie bei jeuen zwei Gattungen, sondern dorsalwärts ganz bedeckt von einem Theil der geraden Nackenmuskeln und des Digastricus. Nach Entfernung derselben erkennt man ihn als starken, rom Gelenktheil des Hinterhauptheins und dem Felsenhein mit breiter Selme ent-

1) Es ist oben (S. 22) hervorgehoben worden, dass bei Siredon die dorsale Spitze des ersten Kiemenbogens durch ein langes dünnes Ligament an den Schädel befestigt ist.

2) Die Schilderung von Léon-Vaillant (Annales des sciences natur., 1863, pag. 312) kann ich nicht bestätigen. Dieser Forscher sagt von seinem Elévateur branchial: "Il se divise en deux corps, qui s'insèrent au dernier arc branchial, l'un à sa partie supérieure, l'autre à la partie inférieure.»

", Mayer (Annal. pag. 84) sagt: “Es sind vier vordere Kiemenbogenmuskeln vorhanden, diese auf und niederziehend." Es ist mir nicht deutlich geworden, welche Muskeln damit gemeint waren. II. fährt fort: "Auch hintere drei Levatores der Kiemenbogen und untere (innere) drei Depressores sind zugegen,s - Mit den Leratores sind ohne Zweifel unsere Levatores, mit den Depressores ist vielleicht der Constrictor arcuum gemeint. 
springenden Muskel, der sich schräge nach aussen und hinten wendet, um sich an die mediale Flïche des dem ersten Kiemenbogen angehörigen Dorsalsegments da anzuheften, wo dieses seinen aufsteigenden Schenkel nach oben abschickt. Die Levatores arcuum secundi ct tertii (ein dem vierten Kiemenbogen zuzuschreibendes Dorsalsegment fehlt, wie oben gesagt, dieser Gattung) werden dagegen nach Entfernung der Haut mit ihrem oberflichlichen Ursprung gleich gesehen (Taf. III, la). Ihnen gehört die vordere Partie derjenigen Muskelfasern an, die, den Kiemenspalten gegeuüber, in einer halbkreisförmigen Linie von der mit der Haut innig verbundenen Fascia dorsalis entspringen (die mit ihnen zugleich in der hinteren Hälfte jenes Halbkreises entspringenden Fasern gehören dem System des Constrictor pharyngis). Von diesem Ursprunge aus gehen die unseren Muskeln angehörigen Bündel convergierend nach aussen und unten, wenden sich innerhalb der Kiemenbogenspitzen $\left(b, b^{\prime}\right)$ in die Tiefe, um sich an die Innenfliche der dem zweiten und dritten Kiemenbogen angehörigen Dorsalsegmente da anzuheften, wo diese sich nach oben krümmen.

Hypochthon schliesst sich auch in Bezug auf diesen Muskel an Menobranchus an Der Levator urcus primi entspringt rom Hinterhaupt und von der Hinterfläche einer kleinen queren Knochenleiste, die an der Grenze des Os occipitale laterale und des Scheitelbeins liegt (die Vorderfläche dieser Crista dient dem grösseren Theil der ersten Portion des Digastricus zur Insertion). Er geht schräg nach aussen und hinten und heftet sich breit an die Innenflïche des ersten Kriemenbogens an, da wo dieser sich als aufsteigender Ast nach oben krümmt. Die letztere Insertion ist ron aussen und oben bedeckt rom hinteren Anfange des Ceratohyoideus extermus und der hinteren Partie des Digastricus.

Die Lerrtores arcum serumli ct tertii entspringen hinter einander in einer Längslinie von der Fascie, welche der Haut dicht anhaftend die geraden Rückeumuskeln uiberzieht. In ihrem Verlaufe nach hinten, aussen und unten trennen sie sich ein wenig ron einander und lassen einen schmalen dreieckigen Raum zwischen sich. Der erste dieser beiden Muskeln inseriert sich an die Innentläche des dem zweiten, der andere an diejenige des dem dritten Kiemenbogen angehörigen Dorsalsegmentes, dicht unter der dorsalen spitze derselben.

Dieselbe Verschiedenheit, welche bei Menobranchus und Hypochthon zwischen dem Lovator arcus primi und den Levatoren der übrigen Bogen besteht, zeigt sich auch bei Amphiuma. Jener ist auch hier kein oberflächlicher Muskel, sondern wird erst nach Fortmalme der zweiten Partie des $\boldsymbol{M}$. tempuralis und der seitlichen Purtie der geraden Nackenmuskeln gesehen. Er entspringt ron der dorsalen Portion des Occipitale laterale, ron wo 
seine Fasern unter denen des geralen Hinterhauptmuskels schriige wach linten und aussen gehen, um sich mittelst einer kurzen Selne au die Spitze des ersten Kiemenbogens zu inserieren. - Die Mm. levatores arcum secundi et tertii (Taf. V, Fig. 1 und 2, la) entspringen als eine einzige breite Muskelmasse vor dem Dorsotruchectis ( $(p)$ und wie dieser von der die Nackeumuskeln überkleidenden, der Haut dicht anhaftenden Aponeurose. Ihre Fasern steigen nach aussen abwïrts und inserieren sich an die Innenflïche der dorsalen Spitzen des zweiten und dritten Kiemenbogens.

Menopoma weicht dadurch von allen uibrigen Gattungen wesentlich ab, dass der erste, allerdings auch durch seine Form und Lage von den übrigen sehr verschiedene Kiemenbogen (Taf. IV, Fig. 2, $b^{\prime}$ ) gar keinen Levator erhält. Seine Spitze ist ganz vom Cerctohyoideus extcrus eingehüllt. Die für die übrigen drei líemenbogen hestimmten Levatores (Taf. IV, Fig. 1, $(a)$ sind in zwei Portionen geschieden. Sie entspringen von der Fusriu dorsalis in dem mach hinten offenen Winkel. den der Ursprung der ersten Portion des Digustricus $(d y)$ mit der linteren Partie des Temporalis $\left(t c^{\prime}\right)$ bildet. Sie gehen schräg abwärts nach hinten und unten, und sind nach ihrem Ursprunge lateralwärts bedeckt von der zweiten Portion des Digatricus $\left(d g^{\circ}\right)$; sie bedecken selbst einen Theil des Dorsotracheculis $(r p)$. Die erste dieser beiden Portionen heftet sich an die dorsale Spitze des dem zweiten Kiemenbogen angehörigen knöchernen Dorsalsegments. Die zweite Portion, eben so stark wie jene, theilt sich bald in zwei ungleiche Theile, von denen der erste sich an die Spitze des dritten (Taf. I, Fig. 6, $b^{\prime \prime \prime}$ ), der andere sich an diejenige des letzten, vierten Kiemenbogens $\left(b^{\prime \prime \prime \prime}\right)$ heftet $\left.{ }^{1}\right)$.

Interessant ist es, die Veränderung zu beobachten, die bei Cryptobranchus japonicus mit den Levetores des dritten und vierten Kiemenhogeus von II cropom eingetreten ist. In der That scheint hier, wo diese beiden Kiemenbogen fehlen, nur ein einziger Levator zu existieren, nämlich der Levator arcus secundi, also der vorderste von denjenigen, die der verwandten Gattung aus Nordamerika eigen sind. Er entspringt dicht linter der zweiten Portion des Digastricus von der Fascia dorsalis, und geht mit convergierenden Fasern abwärts an das hinter der Zungenbeinspitze vorragende Ende des dem zweiten Kiemenbogen angehörigen Dorsalsegments.

2) Mayer sagt S. 80 von diesen Muskeln: "Im Nacken sieht man drei kleine IIuskelportionen,

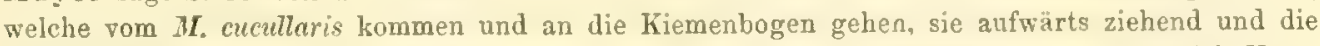
Kiemenlöcher öffnend. Sie entspringen an dem Rande des Cucullaris, welcher zugleich Hautmuskel ist.s 
Untersucht man aber die darauf folgenden, ebenfalls von der Fascia dorsalis entspringenden Muskelpartieen, welche von oben gesehen in Anfang ganz den Lecutores urcum tertii ct quurti von ITcnopomu gleichen, so ist man iiberrascht, diese Muskelu auch hier zu finden, obgleich rie betreffenden zwei Kỉiemenbogen nicht vorhanden siud. Auch sie'gehen von der Fascia dorsalis hinter dem Levator arcus secundi abwärts, inserieren sich aber an der Stelle jener hier fehlenden Bogen an eine von der Spitze des zweiten Kiemenborens sich nach hinten erstreckende Selme, welche nach unten an die Haut des Schlundes befestigt ist. Der Insertion dieser Muskelpartie ventralwirts gegenüber ist del Ursprung der vorderen Partie des Constrictor pharyngis (IIyotracherlis der ächten Derotremen) als deren oberel Bauch also der einer besonderen Kiemenbogen-Iusertion enthehrende Levator arcum tertii et quarti zu betrachten ist.

Ueber die Wirkung der Levatores arcum sind die Forscher, welche dieselben untersucht haben, verschiedener Ansicht. Mayer hält sie für Oeffner der Kiemenspalten. Leon-Vaillant dagegen, der die Levatores arcum von Siren als einen einzelnen Muskel beschreibt, der sich allein au den letzten Kiemenbogen inserieren soll, iussert sich dariber: "Ce muscle doit avor pour action d'élever l'os hyoide en portant le dernier arc branchial en arant, ce qui produit l'occlusion des orifices respiratoires." Wir haben schon gesehen, dass die Augabe über die Insertion der Lextores arcuem auf einem Irrthum beruht. und dass nicht der letate allein, sondern alle Küiemenbogen ron unserer Muskelpartie zur Anheftung benutzt werden. In der That ist es, wo nicht aus Experimenten, sondern allein aus der Form eines Muskels auf dessen Wirkung geschlossen werden kann. doppelt nothwendig, seine Insertionen genau zu untersuchen. Der Levator arcus primi nun inseriert sich bei keiner Gattung an die dorsale Spitze seines Bogens, sondern immer an den nach imnen und vorn offenen Winkel, den der aufsteigende Ast mit dem ventralen, horizontalen Theil des Dorsalsegments bildet. Zugleich erstrecken sich die Fasern dieses Nuskels nicht schlechthin medialwirts und nach oben, sondern sehr merklich auch nach vorn bis zum Hinterhaupt. Die Wirkung kam also nur die sein, das ganze Dorsalsegment des ersten Bogens nach oben und vorn zu biegen, welche Biegung in dem Gelenk stattfinden wird, welches das Dorsalsegment mit seinem Ventralserment rerbindet. Bei Amphumu, wo eine Gliederung 
dieses ersten Kiemenbogens nicht stattfindet, wird seine Beugung nach oben an der Stelle stattfinden müssen, wo er an den Zungenbeinkörper befestigt ist.

Wenn nun die Fasem der folgenden Levatores mit denen des ersten ganz parallel liefen, und sich, unter Beibehaltung der bei dem ersten schr deutlich ausgesprochenen Richtung von rom nach hinten, elsenfalls an die Concavitüt ihrer Kíemenbogen befestigten, so wïre ein Zusammenhaften der Kiemenbogen bei gleichzeitiger Wirkung aller zu diesem System gehörigen Muskelfaseru sehr wahrscheinlich. Dem ist aber nicht so. Die auf den ersten folgenden Levatores geben die Richtung von vorn nach hinten mehr und mehr auf, indem sie rorwiegend diejenige von innen nach aussen und von oben nach unten beibehalten. Es kann also nicht fehlen, dass bei gleichzeitiger Contraction aller der den Levatores angehörigen Fasern der erste kiemenbogen von den übrigen ab und mehr nach roru gezogen wird, als die letzteren, was cine Oeffumg der Kiemenspalten zur Folge haben muss.

Ferner aber inserieren sich die auf den ersten folgenden Levatores nicht an die Concavitiit, sondern an die dorsalen Spitzen ihrer Bogen. Es wird also nicht nothwendig der ganze Bogen, sondern nur seine Spitze herauf und an den Körper gezogen werden. Die Krümmung der auf den ersten folgenden Kiemenbogen wird hiurdurch wahrscheinlich vermelut, und so ehenfills wohl zur weiteren Oeffnumg der Kiemenspalten tunglich gemacht.

Endlich aber ist nicht zu vergessen, dass die Kiemenbogen das knöcherne oder knorpelige Gerüst des Schlundes vorstellen, an welche die Haut des letzteren von innen und oben her festgeheftet ist. Werden diese Bogen heraufgezogen, so wird nothwendig der Schlund verengt, und unsere Muskeh stellen somit ausserdem eine Frizinzungspartie der Constrictores phecryngis vor, als deren vordere Fortsetzung sie sich in der That auch durch Insertion und Lage erweisen.

Letzterer Umstand erklärt es, dass Gattungen, bei denen sich die Kiemenspalten nicht erhalten, dennoch mit diesem Muskelsystem in ausgezeichneter Weise bedacht sind. Bei Caecilia ammlata habe ich bei einer früheren Gelegenheit') diesen Muskel unter dem Namen Vortebrohyodales erwillnt. Li entspringt hier von der hinteren C'ristu des Hiuterlauptes und der die Riickenmuskeln in der Lïnge der vier ersten Wirbel äberziehenden, der IIaut dicht anhaftenden Aponeurose, steigt als sehr starker Muskel mit convergierenden Fasern nach unten, und heftet sich an die dorsalen Spitzen der beiden letzten Kiemenbogen (Taf. VI, Fig. 1, la). Dass gerade der erste Kiemenbogen, der, wie oben gezeigt, bei den Peremiloranchiaten und Derotremen für Oeffnung und Verschluss der Kícuenspalten von

1) Amphibiorum nudorum neurolog., pag. 42. 
besonderer Wichtigkeit ist, bei Caciliu ebenso wie bei C'ryptobranchus eines Levator entbelrt, erklärt sich leicht aus dem Mangel der Kiemenspalte und scheint gerade unsere Meinung ïber die Wirkung dieses IIuskels bei den Perennibrauchiaten und Derotremen zu unterstützen.

Wenn also die Levatores arcum ein System von Muskeln sind, das nach unserer Meinung - und namentlich gilt dies von dem für den ersten Kiemenbogen bestimmten Muskel - zur Oeffnung der Kiemenspalte bestimmt ist, so schliesst sich an diese erste Wirkung die fernere, dass der Schlund durch dieselben verengt wird. - Bei den Perennibranchiaten wird unser Muskelsystem wesentlich als Kiemenathmungsmuskel, und zwar als Ausathmungsmuskel (aus der durch dasselbe geöfneten Kiemenspalte) aufzufassen sein. Seine den Gattungen mit geschlossener Kiemenspalte verbleibenden Reste werden nur die - auch jenen zukommende - Verengerung des Schlundes bewirken und somit hier die bis in ihre Wirkungssphäre gelangte Luft in die Lungen drücken helfen. Letzteres würde zumal in dem Falle erfolgen, dass die Contraction ihrer Fasern successive von vorn nach hinten stattfände. -

Auch bei den ächten Batrachiern ist, wie es scheint, ein den Levatores arcuum vollkommen analoges System von Muskeln vorhanden. Wir müchten als solches die drei Muskeln betrachten, die Ecker ${ }^{1}$ ) als $\boldsymbol{M}_{m}$. petrohyoidei posteriores bezeichnet.

Ihre Nerven erhalten die Levatores arcum ohne alle Ausnahme aus dem System der Vayus. Es sind die ersten der auf den Glossopharyngeus folgenden Stämme, die von innen und rom nach hinten und aussen an diese Muskeln herantreten und sie mit ihren Zweigen versorgen, um dann ihren Weg in die Kiemenbüschel, oder, wo diese fehlen, an die Haut vor der Kiemenspalte fortzusetzen.

1) Anatomie des Frosches, pag. 78. 
Einige Muskeln, die bei Siren und Hypochthon ebenfalls zur Oeffnung der Kiemenspalten beitragen (die Adductores bronchiamm), sind wegen ihrer bei Siren sehr innigen Beziehung zum dritten Kiemenbuischel schon oben (S. 39) berührt worden. - Ein anderer Muskel dieser beiden Gattungen, der dieselbe Wirkung hat und sich vom Dorsalsegment des letzten Kiemenbogens an das Ventralsegment des zweiten erstreckt (Taf. I, Fig. 4, $h p^{\prime}$ ) und in seinem Ursprunge mit dem System des Constrictor pharyngis eng verbunden erscheint, ist auf Seite 79 als $\boldsymbol{M}$. protractor arcus ultimi beschrieben worden.

18. Constrictor pharyngis.

Ich bezeichne mit diesem Namen ein System von Muskeln, von welchem eiuzelne Partieen schon durch andere Forscher bekaunt, jedoch von diesen anders genaunt und anders gedeutet worden sind. Rusconi schreibt unserem Muskelsysteme die Wirkung zu, die Luftröhre $z u$ erweitern und den Kehlkopf zu öffnen. Ebenso betrachten Henle und Hyrtl (letzterer für Lepidosiren) den näher zu betrachtenden Complex von Muskelfasern als einen einzigen Muskel, dessen einzelne Partieen eine und dieselbe Wirkung hätten, nämlich den Eingang zur Stimmlade zu öffnen.

Ich glaube in den folgenden Beschreibungen zeigen zu können, dass es sich nicht nur bei den Derotremen um mehre ganz verschiedene Muskeln handelt, die nur durch ihre benachbarte Lage sich als ein einziges Muskelsystem darstellen, sondern dass jene erweiternde Wirkung auf Stimmlade und Luftröhre nur einer sehr kleinen Partie des letzteren zuzuschreiben ist. Die Hauptmasse dieses sogenannten Dilatator hat im Gegentheil, wie ich glaube, durch ihre Contraction eine Verengerung des zu den Lungen führenden Kínals zur Folge. - Wie dem aber auch sei, ganz unzweifelhaft muss eine Contraction aller der zu dieser Muskelgruppe gehörigen Partieen eine Verengerung des Schlundes zur Folge haben, weil sich alle ihre Fasern quer um denselben herumschlingen. Ich zog daher so misslich es ist, die durch so bedentende Autoritäten einmal aufgestellten Benennungen zu ïnderu - vor, der ganzen in Rede stehenden Muskelgruppe den Namen zu geben, der dieser Wirkung entspricht, und bezeichne mit einem besonderen Namen, Dorsolurynyeus, die wenigen Muskelfasern der Derotremen und der Gattung Sircn, die wirklich eine Erweiterung der Stimmlarle reranlassen. - So riel zur Rechtfertigung des neuen Namens. 
Ueber die verschiedenen Wirkungen der einzelnen Particen wird erst gehandelt werden können, nachdem eine Beschreibung derselben gegeben ist,

Bei allen Perenuibranchiaten lassen sich zwei zu dem System des Constritor phuryngis 'gehörige Muskeln unterscheiden, zu denen sich hei Siren und den Derotremen noch ein Iritter gesellt. Der erste jener beiden hat seine äussere Insertion an der Imnenfliche des letzten Kiemenbogens (d. h. von dessen allein ausgebildetem Dorsalsegment). Der zweite entspringt von der an die Dornfortsïtze der Rïickenwirbel befestigten, der Haut dicht anhaftenden Fascie, dicht hinter den Levatores urcum. Beide gehen mit quer verliafenden Fasern dem Schlunde dicht anliegend nach imeu, zum Theil bis ganz an die longitudinale Vittelebene des Körpers, und zwar so dicht hinter einauder, dass in der That die Faseru des zweiten IInskels als eine hintere Wiederholung von derjenigen des ersten erscheint. Ich werde den vom letzten Kiemenbogen entspringenden Inskel als IIyotrachealis, den von der Dorsalflïche des Kürpers hinter der Kiemenspalte herabsteigenden dagegen als Dorsotracheclis bezeichnen. Hierbei ist festzuhalten, dass beide Muskeln als Partieen eines einzigen Muskelsystems aufzufassen sind.

Bei Sirch, den Derotremen und der Gattnug C'ryptobranchus kommt zu jenen beiden Muskelin noch ein dritter, der mit dem Dorsotrachentis zugleich entspringend anfang's als eine besondere Portion desselben erscheint. Bis zur Bauchfliiche herabgestiegen, ändern jedoch seine Fasem ihre Richtung und streben nicht wie jene quer der Mittellinie zu, sondern steigen schrïg nach vorn an bis zum Kehlkopf. Dies ist die kleine Partie unseres Constrictor pheryngis, die allein den von früheren Autoren dem ganzen Muskelfaserncomplex beigelegten Namen eines Dilutator atlitus laryngis verdienen müchte. Wir bezeichuen dieselbe, um Nisverstïndnissen und Verwechselungen vorzubeugen, als Dorsolaryngens.

In Bezug auf die Form und namentlich auf die untere und mediale Insertion dieser drei Muskeln finden folgende Verschiedenheiten statt:

Bei Siredon entspringt sowohl der Hyotruchealis als der Dorsotrachealis mit je zwei Portionen., Die vordere Partie des Iyotrachculis (Taf. I, Fig. 1, 7.p) geht vom Innenrande der letzten zwei Drittheile des vierten Kiemenhogens quer nach innen und heftet sich nahe der Mittellinie an die hier liegende Luftröhre zugleich mit den Fasern der entsprechenden Partie der anderen Körperhïlfte. Dabei steigen seine vorderen Fasern nach voln an, so 
dass sie mit denen der anderen Seite in einem nach vorn spitzen Winkel zusammentreffen. - Die zweite Portion des Hyotrachealis entspringt von einer langen, medialwärts verlaufenden Sehne, die an die dorsale Spitze desselben vierter Kiemenbogens befestigt ist und eine Art Grenze zwischen dem Hyotrachealis und dem Dorsotrachcalis bildet.

Der letztgenannte MLskel entspringt bei Siredon ausnahmsweise nur mit wenigen seiner Fasern ron der die Nackenmuskeln überkleidenden Fascia dorsalis. Die vordere seiner beiden Portionen entspringt — was bei keiner anderen Gattung beobachtet wurde - von dem oheren rorderen Rande des linorpeligen Schulterblatthoils; ihre Fasem gehen schrag nach unten, rorn und dann nach innen an den lateralen Rand der Luftröhre. Hierbei verlaufen dieselben parallel mit denen des Hyotrachealis und so dicht hinter denselben nach innen, dass diese Partie als ein hinterer Theil jenes Muskels erscheint. - Die zweite Portion des Dorsotraclecalis entspringt rou einer langen feinen Selıne, die von der knöchernen Basis des Schulterblattes nach vorn geht. Auch ilure Fasern vereinen sich mit denen der vorderen Partie zu einem Muskel, der sich an den Aussenrand der Luftröhre heftet.

Der Hyotrachealis von Menobranch us entspringt ron der Innenflïche des dritten (hier letzten) Kiemenbogens, von wo seine Fasern nach innen und etwas nach vorn, dorsalwärts vom Herzen und den Kiemenarterien bis zur Mittellinie verlaufen, um sich hier zugleich mit den entsprechenden Fasern der anderen Körperhälfte an die Ventralfläche der Luftröhre anzuheften. - Der Dorsotrachealis (Taf. III, cp) entspringt eben linter dem Ursprunge der Im. levatores arcum (Taf. III, la) in der hinteren Abtheilung der halbkreisförmigen Linie, die diesen, wie oben erwähnt, als Ansatzlinie an die der Haut fest anhaftenden Fasciu dorsulis dient. Seine Fasern verlaufen wie die der Levatores arcum convergierend nach aussen und unten, steigen eben hinter den Spitzen der Kiemenbogen in die Tiefe, wenden sich dann nach innen und umschlingen so mit denen der anderen Seite von unten her den Schlund. Sie inserieren sich an die Aussenfliche der schmalen Luftröhre. - Es ist noch zu bemerken, dass nur die hinteren Fasern dieser Muskelpartie sich in ihrem Verlaufe ohne weitere Unterbrechung nach innen wenden. Die vorderen werden in ihrem Verlaufe durch eine schmale hinter der letzten Kiemenspitze gelegene und ihr angeheftete, longitudinal verlaufende Inscriptio tendinea unterbrochen. Diese letztere dient zugleich auch mehren Schulter- und Oberarmmuskeln zur Anheftung, so insbesondere einem als Analogon des Stemolicidomastoideus zu betrachtenden Muskel.

Untersucht man diesen Verlauf der beiden zum System des Constrictor pharymgis gehörigen Partieen ron unten her, indem man ihnen von der Mittellinie her nach aussen folgt, so geben sich ihre Fasern als diejenigen einer einzigen Muskelpartie zu erkennen. 
Das einzige, was die Fasern unseres Hyotrachacalis von denen des Dorsotrachcalis scheidet und an ihrer unteren und inneren Insertion eine Art ron Grenze zuwege bringt, ist, dass die Fasern ihres Antagonisten, unseres später zu beschreibenden Stemopharymgeus (einer Partie des Stemolyoideus) sich in derjenigen Querlinie an den Schlund setzen, in der die Fasern des Hyotruchealis aufhören, diejenigen des Dorsotruchcalis begimen.

Sehr interessant ist es, dass bei Menolranchus, und bei dieser Gattung allein, der Dorsotrachealis durch eine Muskelschicht verstirkt wird, die nicht wie jener von der dorsalen Fläche des Riïckens, sondern von der ventralen der Wirbelsïule herabsteigt. Nach Wegräumung der den Gammen und die hintere Partie des Iiachengewölbes von unten her berleckenden Hant sieht man unter der Wirbelsäule eine dimne Schicht von Muskelfasern quer nach aussen verlaufen, die sich um den Schlund hertum an die Seite und die VentralHïche des letzteren anlegt und hier mit denen des von oben herabkommenden Dorsoliacleatis vereinigt, um so ilure untere Insertion ebenfalls an der Aussenfliche der Truchea zu suchen. Unter der Wirbelsäule sind sie weder an diese noch an die Haut des Schlundes inseriert, sondern gehen hier ohne Unterbrechung in diejenigen der anderen über. Dabei ist ihr Spiel ganz frei, da sie nur durch lockeres Bindegewebe an Wirbelsäule und Schlund angeheftet sind. Diese Muskelschicht liegt gerade unter dem vierten Wirbel und nimmt in ihrer Breite dessen ganze Lünge ein. - Der Constrictor pharyngis erhält hierdurch einen zwar nicht belentenden, aber gerale für dis Verengerung des Schlundes sicher selı wirksamen Zuwachs. Dieser bildet einen wirklich ringfömigen Mnskel um die hintere Partie des Rachens und wird ihn durch seine Contraction zusammenschnïren miissen.

Ich hilse mich überzengt, dass diese Muskelpartie den Gattungen Menopoma, Amphiuma, Siredon, Mypochthon, Siren und Cinptobranchess japonicus abgeht. Nur Menobromchus ist damit versehen.

Auch bei Hypochthon, wo schon Rusconi diesen Muskel gesehen hat ${ }^{1}$ ), sind die gewohnlichen zwei Partieen des Constrictor phuryngis zu unterscheiden. Der Hyotracheulis (Taf. I, Fig. 4, hih ) entspringt von der Innenfliche des letzten Kiemenbogens. Seine

1) D) el Proteo anguino, parg. 78: ,Questo canale (die Luftröhre), ben considerato esternamente, e da quella banda che riguarda il cuore. si vele essere corredato di due muscoli sottilissimi, o per dir meglio, di due falde o espansioni muscolari, una per ogni banda, le fibre delle quali sono disposte como la barbe di una penna, vale a lire, si dispartono dalla linea media e longitudinale del canale, non che dalla glottide, e camminando dal avanti al indietro, si dirigono alla volta degli archetti branchiali; l'ufficio di queste due sottilissime falde muscolari c̀ senza dubbio quello li dilatare il canale, e di aprire la glottide." 
Fasern gehen wie gewöhnlich quer nach innen um den Schlund herum, ohne sich an denselben anzusetzen, und treffen in der Mittellinie mit denen der anderen zusammen. Dabei steigen die vorderen Fasern wie bei Sircdon mehr wach vorn an, so dass sie mit denen der anderen Seite unter einem nach hinten offenen spitzen Winkel zusammenstossen. Ja, die vordersten (Fig. 4, $h p^{\prime}$ ) folgen beinahe der Längsrichtung des Körpers, treffen nicht mehr mit denen der anderen Seite zusammen, sondem heften sich an die mediale Fläche des rudimentären, dem zweiten Kiemenbogen augehörigen Ventralsegments $\left(b^{\star d} v\right)$. Diese letzteren Fasern habe ich wegen ihrer besonderen vorderen Insertion oben als besonderen Muskel, nämlich als M. protractor arcus ultimi beschrieben (S. 79). - Der Dorsotrachealis (Fig. 4, cph) entspringt seitwiuts vom liumpf von der der Haut dicht anhaftenden Fascia dorsalis, dicht hinter den Levatores arcum, in einer Längslinie mit den letzteren. Seine Fasern steigen convergierend abwärts, werden jedoch innerhalb der dorsalen Spitze des dritten Kiemenbogens ron einer der Lüngsrichtung des Körpers folgenden kurzen Inscriptio tendinea unterbrochen, ron der aus sie ihren Weg um den Schiund nach inmen fortsetzen. Sie heften sich an die laterale Wand der" Luftröhe. - Die vorderen Fasern des Dorsotiachealis sind ron den letzten des Myotrachealis nicht abgesetzt, sondern folgen auf dieselben wie diejenigen eines einzigen Nuskels. Die Insertion an die Luftrölre erfolgt längs der ganzen Länge des unter diesen Muskel liegenden, durch Zellgewebe an jene angehefteten Herzbeutels.

Von der eben beschriebenen Form bei Hypochthon überzeugt man sich indes nur durch allmähliches Abtragen des Stcmohyoidens. Die dorsalen Fasem des letzteren (sh) inserieren sich - wie dies in unserer Figur angedeutet ist - in der Weise an die Haut des Schlundes, dass sie zwischen die quer gegen ihre eigene Richtung rerlaufenden Fasern des Constrictor hineingreifen. Letztere spielen frei zwischen denen des Stcmohyoidens und sind nirgends an die Haut des Schlundes angeheftet.

Amphiuma zeigt einige Abweichungen von den eben beschriebenen Formen. Der Hyotrachacalis (Taf. I, Fig. 5, hlhp) entspringt vou der hinteren und medialen Fläche des vierten Kiemenbogens. Seine Fasern verlaufen quer nach inmen, treten zunichst unter den Constrictor arcum $(c a)$, dann über die vorderste Portion des Dorsotracheulis ( $x$, unseren Dorsolaryngens) fort bis zur Mittellinie. Hier verschmelzen die ventralen Fasern dieses Muskels mit denen der anderen Kürperhälfte zu einem einzigen Quermuskel. Die dorsalen Fasern hefteu sich an die Ventraltiäche der Luftrölre, dicht hinter dem Kélılkopf (d). Der $\mathbf{M}$. dorsotrachealis entspringt wie gewöhlich ron der die Nackenmuskeln iiberziehenden Aponeurose, hinter den Levatores acum, mit diesen in derselben Liangslinie. Seine Fasern 
steigen hinter der Kiemenspalte herab und wenden sich hinter dem letzten Kiemenbogen ventralwärts (Fig. 5, cp), worauf die vorderen Fasern etwas nach vorn und dorsalwärts laufen, so dass sie dorsalwärts vom Hyotrulerulis (hly) liegen. Hierdurch ist schon die jetzt erst deutlich erfolgende Tremmug des Dorsutworludis in zwei Partieen ansodeutet. Die eine ( $x$, unser Dorsolaryngeus) steigt längs des Kehlkopfes an dessen äusserer Seite nach vorn an, um sich seitwärts an denselben zu inserieren. Die zweite $(c p)$ geht geradeswegs weiter bis zur Luftröhre, an deren Seite sie sich anheftet.

Bei Menopoma entspringt der Hyotrachalis (Taf. IV, Fig. 2, hph) von der letzten Hälfte der dem Leibe zugewandten Flïche des vierten Kiemenbogens $\left(b^{\prime \prime \prime)}\right.$ und geht als schmalex Munkel medialwirts bis zur Mittellinie, der Haut des Schlumles dicht anliegend. jedoch, wie immer, ohne sich an dieselbe anzuheften. In der Mittellinie ventralwïrts yon der Luftrölnre, hinter dem Kehlkopf treffen die ventral verlaufenden Fasern mit denen der anderen Köirperhälfte in einer von diesem Theil der Luftrïhre absteigunden sehnigen Aponeurose zusammen. Die dorsal verlaufenden I'asern dieser Muskelpartie heften sich an die Luftröhre selbst.

Der Dorsotrachealis entspringt an der lateralen Partie der Nackenmuskeln von der diese überziehenden der Haut anhaftenden Fascie (Taf. IV, Fig. 1, cp), in gleicher Längslinie mit den Levatores arcuum $(l a)$. Seine Fasern gehen nach unten, dann nach innen und divergieren nun stark (Taf. IV, Fig. 2, $c p h$ ), indem sie der Haut des Schlundes dicht anliegen, olne jedoch anders als durch Zellgewebe damit verbunden zu sein. Sie setzen sich in einer Iuschehumg, die derjenigen des unter ihnen licgenden Herzbentels gleichliommt, von aussen her an die Luftröhre. - Von einer Partie der ventral verlaufenden Faseru. dieses Muskels wird der Dorsolaryngcus $(x)$ gebildet. Er ist ein schmaler, schon von

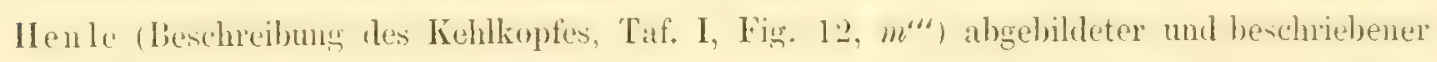
Muskel, der an der lateralen Seite der Luftröhre über den $\boldsymbol{M}$. hyotrochealis fortsteigt, um sich lateralwärts an die Cartilago arytacnoidea (Henle) anzuheften.

Bei Cryptobranchus japonicus ist als oberer Bauch des Hyotrachealis der auf Seite 84 geschilderte Levator arcus tertii et quarti zu betrachten, der aber hier einer eigentlichen Kiemenbogen-Insertion ermangelt und sich statt deren an eine longitudinal. verlaufende Sehne heftet, die von der dorsalen Spitze des zweiten Kiemenbogens aus sich nach hinten an die Haut des Schlundes erstreckt. - Dieser Insertion der eben genannten Muskelpartic der Levatores arcum tertii et quarti von Menopoma gegenuiber inseriert sich ein Muskel (Taf. VI, Fig. 2, $h p$ ), der dem Hyotrachealis der Perennibranchiaten und Derotremen völlig analog ist, obgleich als Insertionstliche kein entsprechender Kiemenbogen vor- 
handen ist. Nicht nur an jene longitudinale Selme indes inserieren sich seine Fasern, sondern auch an die laterale Partie des Plarynx selbst, laufen dann nach unten und quer nach innen und begegnen - über dem Bulbus arteriosus des Herzens, unter der Luftröhre - denen der anderen Seite, mit denen zusammen sie sich an eine von der Mittellinie der Luftröhre herabsteigende Aponeurose heften. - Der Dorsotrachealis (Taf. VI, Fig. 2, dp) entspringt hinter dem oberen Bauche des Hyotrachealis (dem Levator arcum tertii et quarti bei Menopoma). Seine Fasern gehen, ohne wie sonst wohl aurch eine Inscriptio tendinea unterbrochen zu sein, fast parallel mit denen des Híyotracheulis nach unten und innen. An der Ventralfläche des Körpers trennen sie sich in zwei Partieen. Die ventrale, unser Dorsolarymgens, ist schwächer und steigt ventralwärts von der stärkeren dorsalen Partie (dp) und dorsalwärts von der medialen Insertion des Hyotrachealis (hp) lïngs der Luftröhre ( $r r)$ nach vorn an und läuft bei meinem Exemplar von 34 Zoll Länge etwa $1^{1 / 2}$ Zoll weit an der Seite derselben nach vorn. Schliesslich heftet sie sich an die laterale Ecke (Taf. VI, Fig. 3, e) der ventralen, dreieckigen Kinorpelplatte $(\boldsymbol{a})$ des Kehlkopfes.

Die Gattung Siren ist die einzige unter den Peremibranchiaten, die sich durch schärfere Sonderung der einzelnen zu dieser Muskelgruppe gehörigen Partieen näher an die zuletzt geschilderten Formen der Derotremen und des Cryptobranchus anschliesst, ja sie sogar noch übertrifft.

Die grossen ventralen Knorpelplatten von Cryptobranchus sind bei Siren mehr an die laterale Fläche der Stimmlade gerückt (Taf. VI, Fig. 5 und 6, $a$ ). Sie sind auch hier muldenförmig ausgehöhlt und greifen sowohl auf die dorsale als anf die ventrale Fläche iiber. Doch reichen sie weder so nahe an die ventrale Mittellinie, wie bei jener Gattung, noch sind sie wie dort dorsalwärts durch eine Knorpelbricke verbunden. Ein seln starker lateraler hakenförmiger Fortsatz (e) gielot dem Dorsolaryngens und einer Partic des Constrictor aditus larymgis die geeignete Ansatzfläche. - An der ventralen Fläche findet man ausser dieser Knorpelplatte keine weitere knorpelige Bildung. An dex Dorsalfläche dagegen liegen an der hinteren Grenze des als "Kehlkopf»-zu bezeichnenden Endes der Luftröhre zwei kleine dreieckige Knorpelstiicke $\left(b, b^{\star}\right.$, Fig. 5) dicht neben einander. Letztere kehren die schmale Basis nach vorn (der Stimmlade zu), das spitze Ende nach hinten.

Was nun die einzelnen Partieen unserer Muskelgruppe betrifft (vgl. Taf. VI, Fig. 4), so streben die Fasem, des wie gewöhnlich vom letzten Kiemenbogen $\left(b^{\prime \prime \prime}\right)$ entspringenden IIyotrachealis (hp) nach innen und heften sich von aussen her an die Luftröhre. Die vorderen dieser Fasern sondern sich in eine veutrale $\left(h p^{\circ}\right)$ und eine dorsale (Fig. $5, h p^{\circ}$ ) Partie. Jene (Fig. 4 und $6, h p^{\prime}$ ) steigen nach vorn an bis zur Ventralfläche der Stimmlade 
und werlen auf ihrem Wege wesentlich verstïrt durch zahlreiche von der Ventralfläche der Luftröhre selbst entspringende Fasem. So wird hier, abweichend ron den übrigen Gattungen, jederseits eine neue, ziemlich starke Muskelpartie $\left(h p^{\circ}\right)$ gebildet, die von hinten nach rorn rerlaufend sich schliesslich durch Vermittelung einer den Constrictor lavyngis (cl) überziehenden Fascie an den rorderen Rand der Ventralflïche der Stimmlade heftet. (Auf der rechten Seite der Figur 6 ist dieser Muskel abgeschnitten und bis zu der Gegend seiner Insertion an die Luftröhre abgelöst dargestellt. Auf der linken Seite derselben Figur sieht man durch die Fascie, die seine Anheftung an den vorderen Rand der Stimmlade vermittelt, die Fasern des Constrictor aditus laryngis (cl) durchschimmern.) - Die dorsale Partie, die den vorderen Fasern des Hyotrachealis angehört (Taf. VI, Fig. 5, hp"), strebt ebenfalls nach vorn, jecloch gegen die Dorsalfläche der Luftröhre hỉn. Hier befestigen sich ihre vordersten Fasern an die laterale Kante des dreieckigen Knorpelstücks 6 . (Fig. 5), während sich die übrigen an die Seitenfläche der Luftröhre selbst befestigen. - Letztere Insertion ist auch allen hinteren Fasern (Th, Fig. 4 und 6 ) des Hyotrachcalis eigen.

Vom Dorsotrachealis (Fig. 4, dp), dessen Fasern auch bei Siren sïmmtlich medialwïrts der Luftröhre zustreben, um sich an deren laterale Fliiche linter einander zu befestigen, trennt sich schon früh, sobald derselbe bis zur Bauchflïche des Thieres herabgestiegen ist, ein sehr stark entwickelter Dorsolaryngeus ( $l l)$. Dieser läuft ventralwärts von den in ilrem Verlaufe mehr der Mittellinie zustrebenden Fasern des Hyotrachalis (hp) schräg nach innen und vorn und heftet sich schliesslich an den hakenformnigen lateralen Vorsprung (Fig. 5 und 6,e) der seitlichen Konorpelplatte $a$.

Die eben geschilderten Muskeln sind von allen bisherigen Autoren als ein zusanmengehöriges System von Muskelfasern betrachtet worden. Ausserdem ist allen dazu gehörigen Partieen eine und dieselbe Wirkung, nänlich eine Erweiterung der Luftröhre zugeschrieben. Rusconi, wohl der erste, der dieser Muskelpartie (bei Mypochthon) erwähnt, sagt (patg. 79): "L'ufficio di queste due sottilissime falde muscolari è senza dubbio quello di dilatare el canale e di aprire la glottide." - Später heschriel, Henle (A. a. O. S. 21, ff) diese ganze Muskelpartie als Dilatator aditus larymgis, Hyrtl (bei Lepidosinen) als Dilatutor isthmi funchu, woraus Leon-V aillant neuerdings sonderbarer Weise an verschiedenen Stellen seiner Schrift (z. P. S. 314. Pl. VIII, Fig. 2, No. 23) einen Dilatutor isthmac fanci gemacht liat 
Ich bin der Meinung, dass nur die Gattung Siren, die Derotremen mid Cryptobronchus japonicus mit einem besonderen Erweiterer der Stimmlade versehen sind, und dass diese Wirkung einzig der sehr kleinen - vom Dorsotrachealis sich abtrenzenden - Muskelpartie zuzuschreiben ist, die an der Seite der Luftröhre bis zum Kehlkopf ansteigt, um sich an den seitlichen Vorsprung seiner ventralen Knorpelplatte zu heften. - Alle anderen zu dieser Muskelgruppe gehörigen Partieen können schwerlich eine Erweiterung der Stimmlade bewirken. Der Dorsotrachacalis setzt sich von der Seite her an die Luftröhre an (vgl. Taf. VI, Fig. 2, dp; femer Taf. IV, Fig. 2, $c p h$; Taf. I, Fig. $5, c p$ ). Diese ist aber bei allen Gattungen (auch bei Mcnopomu und Cryptobranclus in der rom Dorsotrachealis eingefassten Partie) ein häutiger Schlauch ${ }^{*}$ ). Ein solcher aber', (ler von zwei gegentiberliegenden Seiten auseinandergezogen wird, erweitert sich nicht, er wird platt und schliesst sich. Der vordere Theil dieser Muskelpartie ferner, unser Hyotrachealis, dessen Fasern bei den Derotremen ventralwiarts von der Luftröhre mit denen der anderen Seite zusammentreffen, kann dieselhe ebensowenig erweitern. Er presst die Luftröhre und die Haut des Schlundes nach oben gegen die harten Theile der Rachendecke und wirkt somit ebenfalls abplattend und verengernd.

Die an die Luftröhre sich anheftenden Partieen dieser Muskelgruppe sind also wesentlich verschieden in Bezug auf Anheftung und Wirkung von denen, die bis zum Kehlliopf ansteigen. Jene, der Dorsotrachcalis und Hyotrachealis, schliessen die Luftröhre, dieser, unser Dorsolarymgers, öfinct die Kehlkopfspalte.

Ls kömute scheinen, als ob nur bei den Derotremen, bei Siren und bei Cryptobranchus die letztere Wirkung herrortreten lönnte, da nur sie mit einem wirklich ausgebildeten Dilatator versehen sind. Bei denjenigen Perennibranchiaten, wo letzterer felılt, mögen die vordersten Fasern des Hyotrachcalis diesen Dienst verrichten. Diese gehen hier nämlich nicht, wie bei den Derotremeu, quer vou einer Seite zur anderen hinüber, sondern steigen sehr merklich nach rorn an, so dass hiei die Muskelfasern beider Seiten einen nach voln spitzen Winkel mit einander bilden (vgl. Taf. I, Fig. 1, hp). Es werden dadurch die an die Seiten der" Stimmlade sich heftenden vorderen Muskelfasem ebensowohl eine Erweiterung

1) Nur dicht hinter der Stimmlade in einer ganz kurzen Ausdehnung ist lieser Schlauch ron beiden Seiten theils durch undeutliche Knorpelinseln, theils durch quer verlaufende (Siven) IBündel von sehr festem fibrösen Gerebe gestützt. Nur in dieser Strecke erhält sich die Röhrenform ohne Mitwirkung von Muskeln. In der That beginnt die Anheftung des abplattenden Hyotrachealis erst hinter dieser Streck. 
derselben bewirken können, wie die hinteren an die Seite der Luftröhre sich inserierenden die letztere abplatten und verschliessen müssen.

Letzteres scheint auf den ersten Blick eine gewissermassen sich selbst aufhebende und widersprechende Einrichtung zu sein. Was nuitzt es, dass die Stimmlade durch die vorderen Partieen eines Muskels geöffnet wird, wenn die hinteren Fasern die durch jene gebildete Oeffnung wieder schliessen? Es ist hierbei indessen nicht zu übersehen, dass die Fasern des Hyotrachealis (und auch die des Dorsotrachealis) in ihrer queren Lage ron vorn nach hinten auf einander folgen. Nichts hindert uns anzunehnen, dass auch ihre Contractionen successive von vorn nach hinten fortschreiten können. In diesem Falle würde eine in die geöffnete Stimmlade durch die vorderen Zungenbeinmuskeln hineingepresste Luftblase allmählich die Luftröhre himabgetrieben werden, weil mit den successive erfolgenden Contrationeu der Muskelfasern auch die Abplattung der Luftröhre ron vorn nach hinten fortschreiten und so jene Luftblase vor sich her drängen müsste. Auf diese Weise würde sich auch der Mangel eines Erweiterers der durch keine Knorpelringe steif gehaltenen Luftröhre erklären. Der die letztere rorstellende häutige Schlauch bedarf bei der Form unserer Muskeln weder eines Erweiterers noch der Knorpelringe. Seine Schlaffheit wird die in ihm entlang gepressten Luftblasen allmählich weiter gleiten lassen. - Diese Vermuthung findet eine auffallende Bestätigung in der Form ron Caccilia. Hier ist die Iuftröhre durch viele, theils ganz geschlossene, theils halb offene Knorpelringe steif, und stellt eine ihr Lumen stets bewahrende Röhre ror. Diesem entsprechend fehlt auch ein an die Seitenwandungen sich anheftender, aus queren Fasern an sie herantretender Muskel, der wie bei den Derotremen und Perennibranchiaten durch seine successiven Contractionen einzelne Luftblasen in derselben entlang zu schieben bestimmt wäre.

Ausser dieser Wirkung auf die Luftröhre haben alle in Rede stehenden Muskelpartieen noch die fernere, den Schlund zu verengern. Die sehr weite Rachenhöhle erstreckt sich bei den Peremnibranchiaten und Derotremen ausserordentlich weit nach hinten, bis über das Herz fort, unter den fünften Wirbel. Der Boden der vorderen Partie, der eigentlichen Mundhöhle, wird, wie friher gezeigt, durch ein oberfächlich gelegenes System von Constrictoren (den MIylohyoidcus) abgeplattet und verengt. Die Verengerung der hinteren Partie übernimmt unser wesentlich aus Hyotrachealis und Dorsotrachealis bestehender Constrictor pharyngis. Seine Fasern schlingen sich aussen um die Haut des Schlundes herum, muissen diesen also bei ihrer Contraction zusammenschmuren. Am deutlichsten ist die auf diese Wirkung zielende Form des Constrictor phamygis bei Mcnobrunchus ansgepräigt, wo seine Fasern nicht nur, wie hei den anderen Gattungen, von den Seiten und rentralwärts 
den Schlund pressen, sondern ilm ringförmig umgeben (s. oben S. 90). Uebrigens wird auch hier eine successive erfolgende Contraction der von vorn nach hinten auf einander folgenden queren Muskelfasern die angedeutete, für das Athmen und Schlingen gleich wichtige Wirkung wesentlich befördern können.

$\mathrm{Zu}$ diesen verschiedenen Wirkungen kommt aber bei allen Perennibranchiaten und Ierotremen noch eine andere, nïmlich die Wirkung auf die Kiemenspalte. Drerselbe Wuskel (Hyotrachcalis), der die Luftröhre abplattet und absperrt, zicht den letzten Kíemenbogen von den übrigen ab an den Leib, und öffnet so die unmittelbar vor dem letzteren liegende letzte (bei den Derotremen einzige) Kiemenspalte. Es scheint hiemach der Hyotrachealis wesentlich Kiemenathmungsmuskel zu sein. Er rersperrt dem eingenommenen Mledium den

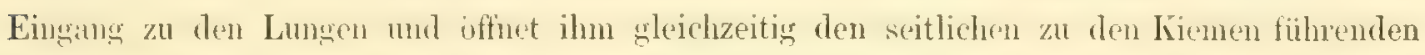
Ausweg. Dass übrigens bei Hypochthon (nach Léon-Vaillant auch bei Sircn) die eingeathmete Luft häufig aus den Kiemenspalten wieder entlassen wird, ist eine bekannte Sache. Bei diesem Vorgang ist ohme Zweifel vorzugsweise der Hyotrachealis betheiligt.

Der Dorsotrachealis kann auf die Kiemenspalte keinen Eintluss üben. Wohl aber verschliesst auch er die durch ihn abgeplattete Luftröhre. Dieser Muskel ist es vorzugsweise, dem ich die Weiterbeförderung der in die Luftröhre eingenommenen Luftblasen zuschreiben möchte. Er ist es, der sich mit seinen successive auf einander folgenden Fasern bei den Derotremen in grosser Ausdehnung an die Seitenwandung der Luftröhre heftet, während der Hyotrachudis bei diesen Thieren nur ein schmales unter derselben fortlaufendes Band vorstellt, gerade ausreichend, die Luftröhre nach oben zu drïcken und zu schliessen, aber nicht ausgedehnt genug, un in der erst angedeuteten Weise die Luftblasen in der Luftröhre auf eine weitere Strecke entlang zu schieben. Ist diese Vermuthung richtig, so wäre der Dorsotrachatis ebenso wichtig tür das Lungenathmen, wie der IIyotrachutis für die Kiemenathmung. Danit stimmt sehr gut zusammen, dass unser ohne allen Zweifel als Luftathmungsmuskel aufzufassender Dorsolaryngeus nicht vom Myotracheulis sich alstrennt, sondern als eine Partie des Dorsotrachealis erscheint. 


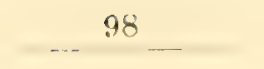

Uebrigens besteht zwischen dem System des Constrictor pharyngis einerseits und den

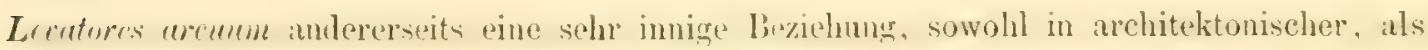
auch in physiologischer Hinsicht. Beide Muskelsystenne entspringen durch Vermittelung der die Rïckenunskehn ïberzichenden. der Hant dicht anhattenden Fresciu dorsalis von der Mittellinie des Riickens, und zwar so eng hinter einander, dass der Constrictor pharyngis (vgl. Taf. III, $p p$ ) bei der Untersuchung von der Dorsalfläche aus in der That als eine hintere Wierlerholung der unmittelbar vor ihm in gheicher Liingshinie entspringenden Levetores arcum (Taf. III, la) erscheint. Bei Cryptobranchus japonieus, wo der vierte Kiemenbogen von Mcnopoma fehlt, ist sogar der IIyotrochealis die directe Fortsetzung der Levatores tertii et quarti. Der Constrictor pharyngis schlingt sich ferner um den Schlund herum bis zur ventralen Wittellinie des Körpers; ebenso diese, jedoch durch Vermittelung der dem Schlunde anhaftenden Knorpel- oder Knochenleisten, der Kiemenbogen.

Es ist ferner oben als wahrscheinliche Wirkung der Levatores arcum die Oeffnung der Kiemenspalten bezeichnet. Sie heben die Kiemenbogen von cinander ab (namentlich den ersten von den folgenden), vermehren ferner die Krümmung der einzelnen Bogen und iffnen die durch deren Zusammenhaften verschlossen gewesenen Kiemenspalten. In dieser Wirkung werden sie durch den Hyotrachealis unterstiitzt, durch dessen Contraction der letzte Bogen von den iibrigen ab an den Leib gezogen wird.

Gleichzeitig aber werden durch die Levatores aremm die Kiemenbogen gehoben und der Schlund verengt. (Dass bei Cryptobranchus japonicus und bei den Caecilien nur diese Wirkung hervortreten könne, ist oben bemerkt (s. S. 86). Letztere Wirkung haben auch die Contractionen des Constrictor pharyngis; auch in dieser Hinsicht charaliterisieren sich also beide Muskelgruppen als zwei einander entsprechende Systeme.

Aehnliche Beziehungen bestehen zwischen dem Constrictor pharyngis und dem System des Mylohyoideuts.

Man wird doch die beiden Hälften des Untorkiefers mit zum Systeme der Visceralbogen zïhlen müssen, und findet dann, dass der Mylohyoidcus anterior sich gerade so zwischen diesen beileh vordersten Bogen erstreckt, wie der Constrictor anterior (unser Myotrachealis) zwischen den biden letzten. Die Fisern beider Muskeln gehen quer mach innen und stossen in der Mittallinie mit denen der anderen Seite zusammen. Der Mylohyoideus 
anterior, als oberflïchlicler Muskel. benutzt ventralwäts die Mittellinie der Küperhaut zur Anheftung. Der Hyotrachealis, als tiefster Muskel der Ventralseite, heftet sich dorsalwärts an die in der Mittellinie des Schlundes liegende Trachea. - Beide Muskeln nähern die entsprechenden Bogen beider Körperhälften einander, beide können der Ein- und Ausathmung dienen: der ersteren, wenn ihre Fasern sich successive von vorn nach hinten, der letzteren, wenn sie sich von hinten nach vorn an der Contraction betheiligen.

In ähnlicher Weise entsprechen einander die hinteren Partieen dieser beiden Muskelsysteme. Der Mylohyoidcus posterior heftet sich dorsalwärts an die Dorsalsegmente der folgenden bogentheile und die vom Nacken herabsteigende Fascia dorsalis. I) Iselben Fascie hintere Partie dient dem Dorsotrachealis zur Anheftung.

lieide Muskelsysteme, der IIylohyoulcus, wie der Constrictor pharyngis, sind wirkliche Constrictoren. Den ersteren könnte man als Constrictor externus oder superficialis bezeichnen, den letzteren als Constrictor profundus oder internus ${ }^{1}$ ). Diesen zwei Systemen von Constrictoren schliesst sich als drittes, zwischen beiden gelegenes, das der Levatores arcum an, ron welchem jedoch nur die Dorsalpartie ausgebildet ist, das seine verengernde Wirkums auf den Schlund nur durch Vermittelung der bis zur ventralen Vittellinie sich erstreckenden Kiemenbogen ausübt.

Unter den Muskeln der ächten Batrachier dürfte die von Ecker (a. angef. O. S. 83) als dritte Portion des $M$. oblique intermus bezeichnete Muskelpartie unserem Dorsotrachealis analog sein. Vielleicht ist hierher auch der Petrohyoidens anterior (Ecker, S. 77) zu rechnen.

1) Wir haben diese Numen vermieden, weil sie von eimigen Autoren auf andere Muskelpartieen angewendet wurden. 
Die zum System des Constrictor pharyngis gehörigen Muskeln erhalten immer ihre Nerven aus der bahn des Vugus. Zuweilen (rimblon) bilden diese einen eigenen schwachen Stamm, der aus dem $R$. intestinalis des Vagus entspringt. Bei anderen sind es Zweige dieses letaten Hauptstinnmes oder des Glossoplen'yngmes, die unere Muskeln rersorgen. Inmer treten diese Nerren ron hinten nach vorn an die Ventrilfliche unseres Muskelswstems heran, um sich in dessen Theilen auszubreiten, und bisweilen auch noch anderen Muskeln der Kiemenbogen (so bei Siren dem Constrictor arcuun, dem Protructor arcus ultimi) Zweige zu geben. Sie sind nicht mit den für die Haut des Schlundes bestimmten Rami pharyngei des Vagus verschmolzen. Diese verlassen schon viel friher, zwischen Glossopharyngeus und erstem Kiemennerven (bisweilen aus dem Stamme des Glossopharyngeus selbst) das Ganglion.

19. Constrictor aditus laryngis, Henle.

Mit diesem Namen bezeichnete Henle ${ }^{1}$ ) einen Muskel mit "am oberen Theil der Stimmlade von Sircdon kreisförmig verlaufenden Querfasern, die an der hinteren Fläche in einer Art weisser Linie zusammentreffen.» Alle Perennibranchiaten und Derotremen scheinen mit diesem Muskel ausgeriustet zu sein.

Bei Amphiuma liegen die Fasern dieses Muskels quer um die Stimmlade herum, ohne in verschiedene Partiecn gesondert zu sein. Doch sind hier seine Fasern nicht lang, ringförmig von einem Punkt ausgehend und um den Kehlkopf herum bis zu demselben Punkt wieder zurïcklaufend. Die Fasern sind vielmehr kurz, sphincterartig von einem Punkt bis zu einem ganz benachbarten quer verlaufend, von wo ihr Lauf alsdann durch andere fortgesetzt wird.

Bei Menopoma gruppieren sich die Fasern dieses Ringmuskels in vier Partieen, von denen jede einen Quadranten des kreisförmigen Durchschnitts der Stimmlade umfasst. Man unterscheidet also ein ventrales und ein dorsales Paar dieser Muskeln. Jene sind in der ventralen Mittellinie befestigt und heften sich an die Seitenkante der Henle'schen Giessbeckenknorpel. Diese entspringen ebenso von der dorsalen Mittellinie, hinter der

3) Vgl. anat. Beschr. des Kehlkopfes, S. 23. 
Stimmladenspalte und erstrecken sich medialwirts an dieselbe Kante, wie das ventrale Paar.

Die Stimmlade von Cryptobranchus japonicus weicht von derjenigen von Menopome durch eine schïfere Differenzierung ihrer einzelnen Partieen ab. Die Henle'schen Giessbeckenknorpel yon Menopoma haben sich in eine ventrale und eine dorsale Partie getrennt. An der Ventralseite der Stinmlade liegt jederseits eine grosse Platte (Taf. VI, Fig. 3, a) aus hyalinem Knorpel. Dieselbe stellt ein ungleichseitiges stumpfwinkeliges Dreieck vor, dessen längste Seite durch einen sehr kleinen Zwischenraum in der ventralen Mittellinie von derjenigen der anderen Körperhältte getrennt ist. Der stumpfe Winkel ist nach aussen gerichtet und bildet, da die I'latte gebogen und del' von ilır bedeckten Stimmlade entsprechend ventralwärts convex ist, nach aussen einen ziemlich merklichen Vorsprung (c), der unserem Dorsolaryngeus als Ansatzpunkt dient. Dieser Vorsprung liegt an der lateralen Fläche der Stimmlade, der Dorsalfläche derselben ziemlich nahe. - An der DorsalHäche der Stimmlade sind keine Kinorpelplatten von so scharf bestimmter Form wie an der Ventralfläche vorhanden. Es finden sich hier vielmehr eine Menge grösserer, durch Bindegewebe getrennter Knorpelinseln, die in ihrem Zusammenhang die dorsale Wand der Stimmlade bekleiden und eine Art Bricke von dem Vorsprunge $c$ der einen Seite bis zu dem der anderen Seite bilden. Die Kehlkopfspalte $(g)$ an der Dorsalfläche der Stimmlade liegt vor dem ganzen Knorpelapparat.

An dem Constrictor laryngis lassen sich ventralwärts zwei Partieen unterscheiden. Die vordere (Taf. VI, Fig. 2 und $3, \mathrm{cl}$ ) entspringt von der ventralen Mittellinie nahe dem medialen Rande der Iinorpelplatte a. Ihre Fasern gehen convergierend nach aussen und heften sich mit einer verhillnismässig starken Sehne an den lateralen Vorsprung e. Die grösste hintere Partie $(c l)$, welche ebenfalls in der ventralen Mittellinie entspringt, heftet sich mit einem Theil ihrer Fasern an die ventrale und laterale Fläche der Knorpelplatte $a$; der grössere Theil derselben schlingt sich um diese Platte und um die ganze Stimmlade, medialwärts von der Sehne des Dorsolaryngets ( $l l$ ) herum nach oben, um sich an die dorsale Fläche der Stimmlade, bis nahe an die dorsale Mittellinie festzulieften.

Bei Siren (Taf. VI, Fig. 4, 5 und 6) entspringt der Constrictor laryngis (cl) theils von der ventralen, theils von der dorsalen Mittellinie der Stimmlade, und geht mit quer um die letztere herum verlaufenden Fasern theils an den Vorsprung $e$ des Seitenknorpels $a$, theils an die der ersteren Ansatzlinie gegenïberliegende Mittellinie der Stimmlade. 
Der Constrictor aditus laryngis wird durch seine Contractionen sicher eine Zusammenschuiirung des Eingangs der Stimmlade hewirken. Auscrelem ist en wohl keinem Zweifel unterworfen, dass seine einzelnen Partieen - wenu jelle für sich allein thätig sein solltecine Form- und Lagenveränderung der die Stimmlade bekleidenden Ḱnorpel und der auch bei diesen Thieren angedeuteten Stimmbänder bewirken werden. Welcher Art diese Veränderungen sein, welchen Einfluss dieselben ferner auf den Athmungsprocess oder gar auf das Hervorbringen von Lauten ausïben mögen, dürfte schwer zu entscheiden sein. - Bekanntlich ist Siren die einzige Gattung, der eine Stimme zugeschrieben wird. Unter neneren Forschern ist es in der That Herrn Léon-Vaillant geglückt, dem Thiere durch heftige Qualen eine Art Schrei zu entreissen ${ }^{1}$ ).

Nur bei Siren und Cryptobranchus konnte ich die sehr feinen Nervenfäden verfolgen, die den Constrictor aditus laryngis versorgen. Bei beiden Gattungen sind es die Endzweige des Ramus recurens nervi Vagi. Nachdem dieser (Taf. VI, Fig. 4, rr) in seinem Verlauf nach vorn bis zur Stimmlade herangetreten ist und (bei Siren beobachtet) ventralwärts ron derselben mehre Schlingen $(s, s)$ mit dem entsprechenden Nerven der anderen Seite gebildet hat, rerbreitet er sich schliesslich in dem vordersten Ende des Dorsotrachealis und in dem Constrictor aditus laryngis.

1) Annales des sciences natur., 1863, pag. 324: “Nous n'avons jamais entendu l'animal crier à l'état de repos; en le tourmentant, en l'électrisant, nous sommes parvenus avec Mr. MartinMagron, à lui faire produire un cri rauque, comparable à celui que pousso la Grenouille sous l'influence d'une vive douleur dans les expériences plyysiologiques.? 
20. M. sternohyoideus $\boldsymbol{A} u \mathbf{t}$.

(M. pubiohyoideus, Cuvier, Rusconi.)

Obgleich den Derotremen und Perennibranchiaten ein Brustbein ebenso wenig eigen ist, wie den Salamandrinen, hat man sich doch gewöhnt, die vordere Partie des grossen Bauchseitenmuskels, die sich an das Zungenbein befestigt, unter dem Namen des Musculus sternohyoideus zu begreifen. Sie wird fast bei allen Gattungen durch Muskelpartieen verstärkt, die sich an das Schultergeriist anlehnen, während sie andererseits in ihren eigenen Inscriptiones tendincae gewissen Muskeln Stïtzpunkte gewährt, die sich entwerler an den Unterkiefer ( $\boldsymbol{M}$. geniohyoideus) orler an Theile des Kiemenborenapparates (Mm. adductores arcumm) begeben.

Die hinteren Insertionen der Fasem dieser Muskelpartie sind in wesentlichen bei allen Gattungen dieselben. Die vorderen Anheftungen zeigen dagegen einige physiologischinteressante Verschiedenheiten.

Bei Siren lacertina heften sich die von linten kommenden Fasern:

1) an die Vorsalfläche der Endplatte des Zungenbeinstiels. Sie benutzen zugleich zur Anheftung die Knorpelstreifen, die aus den knöchernen Fortsitzen dieser Endplatte hervorgehen (vgl. oben S. 29);

2) an die Dorsalfliiche de; die Endplatte tragenden Zungenbeinstiels selbst;

3) an die hintere und ventrale Flïche des dem ersten Kiemenbogen angehörigen Ventralsegments (Taf. I, Fig. 2, b'v);

4) an den Kungenbeinkörper. in dem nach hinten offenen Winkel, den die Ventralsegmente dor ersten Kiemenbogen beider Körperseiten mit einander bilden.

In ilırem Verlaufe nach vorn umhïllen die Fasern dieses Muskels wie auch bei den übrigen Gattungen den Herzbeutel. Die Inscriptiones tendineae, durch welche sie in dieser Gegend - wie durch ihre ganze iibrige Ausdehnung - quer durchsetzt werden, heften sich kranzförmig an den Herzbeutel fest, die vorderste da, wo der Arterienstiel aus dem Pericardium hervortritt.

Siredon pisciformis zeigt keine wesentlichen Abweichungen von Siren lacortina Bei beiden Gattungen fehlen die Insertionen an den Schlund und Stimmlade, die bei anderen Gattungen (Menolranchus, Amphiuma) beobachtet wurden. 
Die Verstiirkungsfasern, welche bei Menobranchus sich an. die aus dem geraden Banchmuskel stammende Hauptuasse des Stermolyoidtus anschliessen, entspringen in drei Portionen rom Schultergeriist:

1) ron der Dorsalfläche und dem ganzen Aussenrande der schmalen Pars claricularis:

2) vom medialen Riande;

3) ron der Basis derselben Knorpelplatte, letztere Portion in einer schräg von oben und vorn nach unten und hinten gehenden Linie, dicht vor der Gelenkpfanne für den Oberarm.

Der so verstärkte Muskel inseriert sich vorn:

1) an die Dorsalfläche des Zungenbeinstiels;

2) an das Ventralsegment des ersten Kiemenbogens nahe bei dessen Anheftung an den 'Zungenbeinkörper;

3) viele der an der Dorsaltläche dieses Muskels verlaufenden Fasern heften sich an die Haut des Schlundes, und zwar in eimer quer von aussen nach innen gehenden Linie. Dies ist dieselbe Linie, in der, wie oben (S. 90) bemerkt, die quer verlaufenden Fasern unseres Hyotrachatis anthören und diejenigen den Dorsotrurhealis anfangen. Die Richtung dieser Fasern des Stemohyoiders bildtet mit derjenigen der zu jenen beiden Muskeln gelö̈rigen Fascikeln einen rechten Winkel. wie dies mit den Fasern benachbarter Antagonisten so häufig der Frall ist. - Man könnte die letzte dieser Partieen als M. sternopharyngeus bezeichnen.

Auch bei Me nop oma stammt die Hauptmasse des Stemohoideus aus dem Bauchtheile des Seitenmuskels. Doch wird anch hier das Schultergeriist als accessorischer Stiutzpunkt benutzt. Es entepringen nïmlich von dem knöchernen stiele der Purs scounluris desielben da, wo diese den nach rorn offenen Winkel mit der Pars clavicularis bildet, zwei Muskeln, die, an der Ventralseite des Körpers gelegen, sich schräg medialwärts und nach vorn erstrucken. Ilıre Fasern gehen jedoch nicht direct in diejenigen des Stcmohyoudms über, sondern inserieren sich an die zweite und dritte der den letzteren quer durchsetzenden Inscriptiones tondineae. Diese Muskeln sind ventralwärts durch die Pars clavicularis des Schultergerüsts bedeckt. Die vordere Insertion des so verstärkten Stemohyoidens ist, da der Zungenbeinstiel und dessen Endplatte fehit, ron der Form der ächten Perenubranchiaten verschieden: Die Muskelfasern laufen medial. und lateralwärts an dem rorderen Theil des dem zweiten Ǩiemenbogen angehörigen Ventralsegments (Taf. I, Fig. 6, $b v$ ) vorbei, indem sie dasselbe einhïllen, ohne sich daran, wie bei den vorher geschilderten Gattungen, fest- 
zusetzen. Die medial verlaufenden Fasern befestigen sich vernittelst einer breiten und starken Sehne an eine starke Fascie, welche die Gelenkköpfe der beiden zweiten Ventralsegmente und den Zungenbeinkörper überzieht. - Die lateralen Fasern steigen an dem vorderen Ende des dem zweiten Kiemenbogen angehörigen Ventralsegments in die Höhe dorsalwärts ron der hier liegenden traubenfirmigen Iniise (Thyreoded). und hefestigen sich an den hinteren Rand des Zungenbeinkörpers.

Noch ist bei MLnopoma die Insertion der dorsalen Fasern des Stemohyoidens an den Herzbeutel zu beachten, deren wir schon bei den vorigen Gattungen erwähnt haben, und die ohne Zweifel für die Mechanik des Athmens von Wichtigkeit ist. Wie bei jenen nämlich lieften sich die beiden ersten Inscriptiones tondinear, welche die vordere Partie unseres Muskels quer durchsetzen, kranzfömig un das Pericardium herum fest, die erste am Anfange desselben, da wo die Kiemenarterien aus dem Arterienstiel hervorgehen, die zweite in der Mitte. Dem Muskel wird dadurch eine Einwirkung auf die Lage des Herzens ermöglicht. Die vordere Partie wird dasselbe bei ihrer Contraction — wenn der Zungenbeinkörper fixiert ist -- nach vorn, die lintere wird dasselbe zurückziehen könneu. Vielleicht, dass beide auch eine Volumveränderung des Herzens oder doch des Bulbus arteriosus zu reranlassen im Stande sind.

Endlich entspringt noch bei Menoproma von dem Sternohyoiders eine Gruppe von Muskelfasem (Taf. IV, Fig. 2, sp), die in Wirkung und Insertion dem Stemopharyngens ron Mcnobranchus analog sein dürfte. Doch sind ihrer viel weniger und ausserdem ist die Form des durch sie gebildeten Muskels etwas verschieden. Sie erscheinen nämlich nicht als eine rou der Masse des Muskels sich ablösende Partie, sondern entspringen als besonderer schmaler Muskel mit kurzer Sehne von derjenigen Inscriptio tondinca, die vor und theilweise über dem Schlüsselbeinknorpel den Stcmohyoiders durchsetzt. Von hier aus breiten sich die Fasem dieses Muskels fächerförmig aus, um sich von unten und innen her quer an die Haut des Schlundes und an den letzten Kiemenbogen da anzusetzen, wo die Fasern des Hyotrachealis sich von denen des Dorsotrachealis scheiden (vgl. S. 78).

Bei Cryptobranchus japonicus erfolgt die vordere Insertion des Stomolyoideus, der auch hier accessorische Stuitzpunkte am Schultergerüst benutzt, ganz wie bei Monopoma. Auch hier gehen seine Fasern unter dem Ventralsegment des knöchernen, als zweiter Kiemenbogen zu deutenden Bogens herum, ohne sich daran zu inserieren. Sie steigen vielmehr dorsalwärts von der Glandula thyrcoidea in der Spalte in die Höhe, die zwischen dem Anfange des ersten und des zweiten Kiemenbogens liegt. Hier heftet er sich mit einer sehr starken breiten sehne an den Zungenbeinkinper. Ansserdem befestigen sich 
seine ventralen Fasern an die Fascie, welche die vorderen Enden der beiden ersten Kiemen-

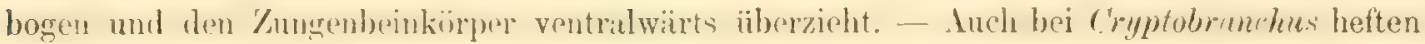
sich die zwei ersten der diesen Muskel durchsetzenden Inscriptiones tendineae kranzartig an das Pericardium, in derselben Weise, wie bei Menopoma.

Hypochthon zeigt in den vorderen Insertionen des Sternohyoideus eigenthümliche Abweichungen. - Wic gewöhnlich umfassen die Fasern des grossen Bauchseitenmuskels in ihrem Verlaufe nach vorn den Herzbeutel. Ventralwärts geht nur eine dünne Schicht unseres Muskels unter dem Herzen fort, die måchtigsten Partieen gehen lateralwärts und dorsalwäits an demselben vorbei. Auch hier heften sich die beiden vordersten der den Muskel durchsetzenden Inscriptiones tendincae kranzartig um den Herzbeutel fest, die eine ganz vorn um die Mündung des Bulbus, die andere in der Mitte.

Die vordere Insertion findet bei Hypochthon an folgende Theile statt:

1. Die der Mittellinie zunächst gelegenen Fasern heften sich an das äusserste hintere Ende des 'Zungenbeinstiels.

2. Die seitlichen der ventralen Fasern setzen sich mittelst einer feinen Sehne (vgl. Taf. I, Fig. 4, sh) an den unteren hinteren Rand des Zungenbeinkörpers.

3. Die Hauptmasse der über den beiden vorigen Partieen gelegenen ventralen Fasern inseriert sich an die ganze hintere Fläche des dem ersten Kiemenbogen angehörigen Ventralsegments $\left(b^{\star} v\right)$, von dem Winkel anfangend, den dieses mit dem entsprechenden Knochen der anderen Körperhälfte bildet bis zum Anfange des Dorsalsegnents $\left(b^{\prime}\right)$.

4. Die dorsalen Fasern (rechte Seite der Fig. 4, Taf. I) setzen sich dorsalwärts vom Herzen an die Haut des Schlundes in der ganzen Länge des Herzens und in der ganzen Breite vom letzten Kiemenbogen der einen bis zu demjenigen der anderen Körperhälfte. - Diese letzteren Fasem krenzen sich in ihrem Verlaufe mit den quer verlaufenden

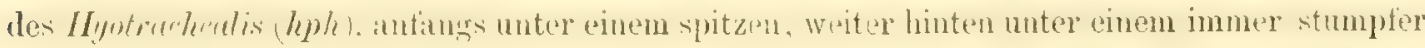
werdeuden, ıach hinten offenen Winkel. Sie befestigen sich dabei, wie in Fig. 4, Taf. I angedentet ist, in feinen Querschichten an die Haut des Schlundes, so dass immer zwischen zwei auf einander folgenden Schichten ein kleiner Zwischenranm bleibt für die quer zwischen ilmen hindurch nach der Mittellinie strebenden Fasern des Hyotrachealis (vgl. über diesen S. 91). Die letztéren spielen frei zwischen jenen, ohne sich anders als nahe der Mittellinie an die Luftröhre festzusetzen.

Amphiuma unterscheidet sich von den übrigen Gattungen dulurch, dass der Sternolyoidters ausser den iibrigen vorderen Insertionspunkten auch noch, wie schon Henle angiebt (vgl. anat. Beschreibung des Kehlkopfs, S. 22), die Stimmlade zur Anheftung be- 
nutzt. - Auch hier wird unser Muskel ('Taf. V, Fig. 2 und 3, sh) durch die vordere Partie des grossen Bauchseitenmuskels gebildet, zu dessen Fasern sich noch einige an der zarten Schlüsselbeinplatte entspringende Fascikel gesellen. Die vordere Insertion geschieht folgendermassen:

1. Die Hauptmasse der Fasern, namentlich aller ventral gelegenen, strebt dem nach hinten offenen Winkel zu, den die ersten Kiemenbogen beider Seiten (Taf. I, Fig. 5, $b^{\prime}$ ) mit einander bilden; und inserieren sich $\left(s h^{\circ}\right)$ an die hintere und ventrale Fläche ihrer vorderen Enden.

2. Die dorsalen Fasern unseres Muskels heften sich jederseits in zwei Portionen an den ventralen hinteren Rand der knorpeligen Stimmlade (Taf. I, Fig. 5, sh), die eine mittelst einer kurzen Sehne nahe der Mittellinie, die andere ebenfalls vermittelst einer kurzen Sehne an den Aussenrand ${ }^{1}$ ). Ihre Insertion erfolgt gerade an der Stelle, wo die erste der den Sternohyoideus durchsetzenden Inscriptiones tendineae liegt, und zwar vor dem Anfange des dorsilwïrts von dieser Partie liegendeu, quer verlaulenden IIyotracher is (hhp).

- Da die entsprechende Muskelpartie der anderen Körperhälfte diesslbe Insertion zeigt, so liefert der hintere Rand der Stimmlade den Fasern des Stemolyyoideus drei Insertionspunkte: den einen in der ventralen Mittellinie gelegen, von zwei den beiden Körperlıälften angehörigen Portionen benutzt; die beiden anderen lateralwïts, einander quer genenuiberliegend. Die DorsalHäche der Stimmlade ist der Haut des Schlundes fest angeheftet.

Nach den vorstehenden specialbeschreibungen des $\boldsymbol{M}$. stemblyovideus diurfte es nicht schwer sein, auf die durch seine Contractionen veranlasste Wirkung zu schliesien. Wir glauhen in ihm den

2) Henle sagt a. a. O.: CZugleich tritt bei diesem Thiere der gerade Bauchmuskel an den ganzen oberen (in unserem Sinne vorderen) liand der Stimmlade, indem ex sich, wie bei Menobranchus, zum Theil mit dem Erweiterer verflicht.» - Dies "Verflechten" ist hier wie an anderen Orten von Henle's Schrift wohl so zu verstehen, dass die Fasern des einen Muskels sich mit denen des anderen kreuzen, ohne mit einander zu verschmelzen. In der That spiclen die Fasern des Sternohyoideus frei zwischen denen des Hyotrachealis (Henle's Erweiterer). 
mïclitigsten Einathmungsmuskel der Perennibranchiaten und Derotremen zu finden, und als den bezirk seiner Wirkung namentlich den grösseren, hinteren, bis über den Anfang des Herzens sich erstreckenden Theil der Rachenhöhle zu erkennen.

Sich contrahierend zieht er zunächst ohne allen Zweifel den Zungenbeinkürper sammt den diran befestigten Ventralsegmenten der liemenhogen kräftig zurück. Die líemenbogen aber bilden das knorpelige, die Haut des śchlundes stützende, ihr fest angeheftete Gerüst der hinteren Rachenhöhle. Selbst da also, wo keine Fasen unseres Muskels sich direct an die hinter den Kiemenbogen gelegene Haut des Schlundes befestigen, wird letzterer nach unten und hinten ausgetieft werden müssen. Es bildet somit das Kiemenbogengerïst mit der an dasselbe angehefteten Haut des Schlundes eine Art Pumpenkolben, durch desien Zuriickziehung der Stcmohyoideus das Lumen der Rachenhöhle un so mehr erweitert, je grösser die von ihm zurückbewegte Fläche ist. Der atmosphärische Druck wird Wasser oder Luft in dieselbe eintreiben. Die Weiterbeförderung derselben werden alsdann, wie spiiter gezeigt werden wird, andere Nuskeln übernehmen. - Setzen sich ausserdem, wie bei Menobranchus und Hypochthon, dorsale Fasern unseres Muskels an die hinter dem Kiemenbogengrerüst folgende Haut des Schlundes, so kann durch diese vergrösserte Ansatzflïche des Stemohyoideus auch seine die Rachenhöhle erweiternde, den Schlund austiefende Wirkung nur vermehrt werden.

Dasselbe findet statt, wo der Muskel durch seine Inscriptiones tendineae sich an den Herzbeutel heftet. Das Herz selbst wird hiermit zu einem Theile jenes Pumpenkolbens, dem bei seinem Zurückweichen Luft oder Wasser in den Rachen nachdringen muss. Nur wird, wenn der vordere Anheftungspunkt, das Zungenbein, durch den Grniohyoidcus und Genioglossus fixiert sein sollte, gerade durch die eigenthümliche Befestigung dieser Fasern zugleich die Möglichkeit gegeben, das Herz auch vorwärts zu ziehen.

Bei Amphiuma gesellt sich hierzu noch auf die Stimmlade eine Wirkung, die nach meiner Ansicht nur eine erweiternde sein kim und somit die verengernde Wirkung des Hyotrucheralis (des Henle'schen Dilutator) aufzuheben geeignet wäre. Es stelle, um uns dies dentlich zu machen, auf Taf. VI, Fig. 7 der Ring $t r$ das Ende der Luftrühre vor, der bei $p h$ - wie die letztere mit ihrer Dorsalfläche an den Schlund - befestigt wäre, so wird ein darüber gelegtes Band ht (den Henle'schen Dilatutor, unseren Hyotrachatis vorstellend) denselben bei seinem Anziehen abplatten und verengern. Lassen dagregen die Bänder ht, ht auf beiden Seiten nach, und werden statt ihrer die an drei Punkten befestigten Bänder sh, unserem Sternohyoideus entsprechend, angezogen. so wird der bei ph fixierte Riug micht abgeplattet werden künnen. Sein Lumen wird in der Richtung ron a nach $b$, 
danu aber auch gleichzeitig in der Richtung von $c$ nach $d$ erweitert werden. Der Ring wird sich schräg nach hinten neigen, etwas von seiner Kreisform ei büssen, aber offen gehalten werden.

Derselbe Muskel also, der die Luft durch atmosphärischen Druck eintreten liess in die Rachenhöhle, öfnet ihr bei Amphiume auch den Weg in die Luftröhre. Es ist diese Partie des Sternohyoideus ein wirklicher Dilatator aditus laryngis, in seiner Wirkung unserem Dorsolaryngeus - der bei Amphiuma nicht beobachtet wurde - entsprechend.

Der Sternohyoidens erhält ohne Ausnahme seine Nerven aus dem durch die beiden ersten (bei Menobranchus durch den zweiten und dritten) Halsnerven gebildeten $N$. hypoglossus, der ausser ihm nur noch den $\boldsymbol{M}$. geniohyoideus versorgt. 


\section{Dritter Theil.}

\section{Das Athmen der Perennibranchiaten und Derotremen.}

In den vorstehenden Blättern habe ich bereits meine Ansicht über die muthmassliche Wirkung der einzelnen die Glieder des Visceralskelettes bewegenden Muskeln dargelegt. Dieselbe grïnlet sich lediglich anf die Form und Anheftung dex einzelners Munkelparticen. Wenn ich jetzt versuchen will, den Athmungsprozess dieser Thiere als Ganzes aufzufassen und ihn aus den combinierten Wirkungen der einzelnen Muskelpartieen zu erklïren, so habe ich noch mehr als dort zu beklagen, dass die Gelegenheit zur Beobachtung lebender Perennibranchiaten und Derotremen den europäischen Forschern nur äusserst selten geboten wird. Ausser einer kurzen Bemerkung Rusconi's und einer noch kürzeren von LéonVaillant (über das Luftschnappen von Siren, vgl. oben S. 53) sind uns keine Beobachtungen über das Athmen diewer Thiere bekannt. \%u physiologischen Experimenten an mit Lungen und Kiemen gleichzeitig ausgerüsteten Amphibien ist in Europa noch seltener Gelegenheit. Wo sich eine solche bot, ist sie leider unbenutzt gehliehen. Wir müssen hoffen, ditss die neuerdings mehr und mehr aufblühenden zoologischen Gärten aluch durch die den Forschern gegebene Gelegenheit zu solchen Experimenten der Wissenschaft nützlich werden mögen. 


\section{A. Das Einathmen der Batrachier und Salamandrinen.}

Nach der bisherigen Annabme weicht die Mechanik des Einathmens der Batrachier dadurch fundamental von derjenigen der Säugethiere, Vögel und Reptilien ab, dass der Luftdruck bei jenen zu einer viel beschränkteren Nitwirkung gelangt, als bei diesen. Bei dem Mangel aller ächten Rippen und eines eigentlichen Zwerchfells sind es nach Cuvier allein die Kehlmukehn, die eine Lineiterung des Lumens dor Mundhöhle bewirken, woranf eine (vorausgesetzte) klappenähnliche Vorrichtung der sich schliessenden Naslöcher das Wiederausströmen der ins Maul gelangten Luft verhindern, und letatere durch Schlingmuskeln in die Lunge gepresst werden soll ${ }^{1}$ ).

Ich habe versucht, die in dieser. Schilderuug entlaltenen Voraussetzungen einzeln zu verfolgen.

\section{Die Nasenlöcher.}

a. Die Batrachier und Salanandrinen kömen nur bei geschlossenem Maul durch die Naslöcher Luft einathmen. Mehren hesonders kräitigen Exemplaren von Salumandra terrestris, Triton cristutus und Rana csculenta wurden die Naslöcher mit einer Mischung von Copallack und Terpenthinöl verklebt. War der Lack vollständig angetrocknet, und durch die Loupe die Ueberzengung gewonnen, dass der Verschluss der Naslöcher vollständig erfolgt war, so hörten sofort die bekannten auf- und niedergehenden Bewegungen der Kehlmuskeln auf. Die Salamander waren nach 5 bis 6 Stunden todt. Die Tritonen hielten sich meist (im Wasser) 24 bis 28 Stunden am Leben. Bei den Fröschen trat nach einiger Zeit ein krampfhaftes Aufsperren und Schliessen des Maules ein. Eine rorgehaltene Dune ward aber nicht eingezogen ins Maul, sondern anfangs stossweise fortgeblasen, blieb aber dann ruhig und unbewegt. Ein Beweis, dass auch hier durch das Maul kein Luftstrom eindrang, sondern, sondern nur die noch in den Lungen vorhanden gewesene Luft entleert wurde. - Sobald der Verschluss der Naslöcher entfernt wurde, traten sofort die Athembewegungen der Kehlgegend wieder ein.

\) Leçons d'anat. comp., Tome VI, Hdit. 1805, pag. 368. 
b. Das Ausathmen von Luft erfolgt bei den Fröschen und Salamandern sowohl durch die Nasenlöcher. als durch das geöffnete Maul. Man überzeugt sich hiervon am besten, indem man die Thiere ins Wasser setzt. Beim Auf- und Untertauchen werden grosse Lufthlasen aus dem für einen Augenblick geöfneten Maule entleert, likeinere ans den Na-enlöchern. 'Tritonen scheinen beim Auftauchen die Luft zu wechseln, indem sie Luft durch die Nasenlöcher hei geschlossenem Maule einnehnen, unmittelbar daranf aber grone Luftblasen aus dem Maule entlassen. Wurden Tritonen mit sicher verschlonsenen Na-enlüchern ins Wasser gesetzt, so hörte auch das Ausstossen der Luftblasen auf, das man sonst beständig beim Auftauchen wahrnimmt. Solche ins Wasser gesetzte Tritonen halten sich weit länger am Leben, als wenn man sie im Trockenen lässt. Sie fahren unruhig an der Oberfläche hin und her, tauchen selbst bis zu einem Dritheil der Rumpfläuge aus dem Wasser hervor. Sie sterben jedoch, wenn der Verschluss sicher war, nach etwa 24 Stunden.

c. Die ungeschwänzten Batrachier allein können beim Athmen die Nasenlöcher durch eigene Muskeln öffnen und schliessen ( $M$. intermaxillaris, Dugès, Ecker; Mm. laterales narium, Ecker). Dies geschicht jedoch nicht regelmässig, den Athembewegungen der

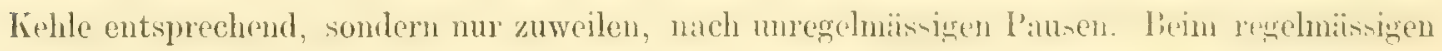
Athmen bleiben die Nasenlöcher unverändert. Letzteres ist bei Tritonen und Salamandern beständig der Fall. Durch wiederholte Beobachtungen des Riesensalamanders im zoologischen Garten zu Hambury habe ich mich überzengt, dass dessen Naseulöcher bestïndig offen bleiben. Man sieht lies Thier nie in regelmässigen Rhythmus athnen, wie die Frïsche und die auf dem Trockenen sitzenden Tritonen. Nach längeren I'ausen — von 15 bis 30 Minuten - taucht es mit der Schnautzenspitze aus der Wasserfläche hervor, um durch die Nasenlöcher Luft zu schöpfen. Man sieht dies an den Wasuertropfen. die bei der Gelegrenheit durch den eindringenden Luftstrom mit in die Nase hineingezogen werden. Beim Untertauchen entlässt es dann gewaltige Luftblisen aus dem Maule. kleinere - oder auch gar keine - aus den Nasenlöchern. Letztere behalten stets ihre runde Oeffnung.

d. Ueber das Einathmen der Perennibranchiaten und Derotremen wissen wir sehr wenig. Aus einer kurzen, schon oben (S. 53) mitgetheilten Notiz von Léon-Vaillant erfahren wir, dass Siren lacertina um Luft zu holen an die Oberfläche kommt und dann mit dem. Maule Luft schnappt, ganz ähnlich manchen Fischen. Zuweilen streicht die cingrathmete Luft dann sofort aus den Kiemenspalten wieder hervor, an den Kiemen vorbei. gerade wie Rusconi es von Proteus berichtet hat. - Wie dies Thier sich beim Wasserathmen verhalte, ob letzteres wie bei den Fischen durch das sich in kurzen Pausen 
öffuende und schliessende Maul geschehe, ja ob Sirm überhaupt Wasser athme, oder rielleicht auch der Kiemen sich bestïndigr zum Luftathmen bediene, - das sind lauter Fragen, über die wir gånzlich im Unklaren gelassen werden.

Die Frage, ob die Perennibranchiaten und Derotremen die Nasenlöcher schliessen und öffnen können, wird durch die anatomische Untersuchung verneint. Ls ist mir an meinen sehr frischen und guten Weingeist-Exemplaren nicht gegliickt, Muskelfasern in der Umgebung der Nasenlöcher zu finden. Ich muss sogar bekennen, dass ich den von LéonVaillant bei einer frisch getödteten Siren lacertina aufgefundenen "Abducteur de la mâchoire superieuren ${ }^{1}$ ) bei meinem Weingeist-Exemplare vergebens gesucht habe. Ich vermuthe daher, dass die Nasenlöcher dieser Thierformen sich beim Athmen verhalten mögen, wie diejenigen ron Cryptobrunchus juponicus, nämlich dass sie stets offen bleiben.

Eine Klappenrorrichtung, wie Cuvier sie bei seiner Schilderung des Athemvorganges voraussetzt (l'air chassé de la gorge, ne peut plus ressortir par les narines, où il existe sans doute une soupape, qui ne permet que son entrée), existiert also in den äusseren Nasenlöchern der Perennibranchiaten und Derotremen nicht. Wie Schliessmuskel der Nasenlücher des Frosches, die auf den ersten Blick für eine solche Klappenvorrichtung gehalten werden könnten, sind, wie erst gezeigrt, ebenfalls nicht beim regelsnüssigen Luftholen, den Athemzügen entsprechend, thätig. Gleichwohl muss die ins Maul genommene Luft durch irgend einen Verschluss von der äusseren Luft abgesperrt werden, wenn sie nicht, dem Drucke der sie hinabzuschlingen hestimmten Muskeln folgend, wieder ins Freie entweichen soll. Es wurden demgemäss die inneren in den Rachen mündenden Nasenlöcher dieser Thierformen untersucht. Wirklich finden sich hier in der Umgebung diever Oeffnungen bei mehren Gattungen eigenthimliche Hautsïume, die recht wohl geeignet seheinen, dieselben zu schliessen.

Bei Amphiuma waren diese Hautsäume schon Curier aufgefallen, der sie für geeignet hielt, zum Verschluss der inneren Nasenlöcher zu dienen ${ }^{2}$ ). Letztere liegen jeder-

1) Annal. des sciences natur., 1863, pag. 315: "Ce sont quelques fibres situées sur les còtés du museau et entourant les narines; elles se rendent de la partie antérieure du museau à un petit os, que Cuvier croit représenter le maxillaire supérieur, et à la lèvre. Ce muscle porte ces parties en haut, c'est l'analogue du rostrolabial de D ugés.»

2) Mémoires du mus. d'hist. nat., 1827, pag. 5: «Ces orifices sont des simples trous, dont le borl inférieur est membraneux, et pourrait faire fonction de valvule, pour empêcher l'air ou l'eau, de remonter de la bouche vers la narine. 
seits zwischen ren hinteren Enden der beiden Zahnreihen, ron denen die eine dem Oberund Zwischenkiefer, die andere dem Gaumen angehört. Vor jeder derselben liegt eine Falte der Gaumenhaut, die sich leicht nach hinten so über die Oeffinung legt, dass letztere vollstiindig verschlossen wird. - Bei Menopoma liegt das innere Nasenloch (Taf. VI, Fig. 11, in) jederseits fast unnittelbar hinter und in gleicher Bogenlinie mit den Zähnen der zweiten (Gaumen-) Reihe $(g)$. Lateralwärts von demselben und etwas dahinter ragt eine Hautfalte $(f)$ vor, vollkommen gross genug, um die Oeffnung genau zu verschliessen. - Bei Sircu lacertina hat die innere Nasenöffnung (Taf. VI, Fig. 9, in) eine dreieckige Gestalt mit nach aussen gewendeter Spitze ${ }^{1}$ ). Sie liegt lateralwärts der beiden zalıntragenden Platten ( $z^{\prime}$ und $\left.z^{*}\right)$, und zwar genau an der Grenze derselben. Vor den Zahnplatten — wio vor den Zahnreihen aller Derotremen und Perennibranchiaten — zieht sich eine Hautfalte herum $(s)$, die sich vorn, wo die beiden grösseren Zahnplatten beider Seiten zusammentreffen, in den, von beiden gebildeten Winkel hineinlegt. Kurz vor der inneren Nasenöffnung theilt sich diese Hautfalte in zwei Hautsäume ( $f^{\prime \prime}$ und f'), von denen der eine medialwärts, der andere lateralwärts von der Oeffnung verliiuft. Betike biklen hier eine kleine klappenähmliche Ansiackung, die sich also von beiden Seiten her über (richtiger unter) die Oeffnung herlegen kann. Die Hauptklappe liegt an dem hinteren Rande der Oeffuung. Sie ist quer gelegen $\left(f^{\prime}\right)$ und höher als die beiden vorigen. Alle drej kïnuen so ïber die Oefthung zusammengelegt werten, dass sie dieselbe vollstindig verschliessen; sie treffen dann mit ihren Ränderu unter der Nitte derselben zusammen. An die hintere dieser drei Klappen setzt sich ein schwacher Muskel $(m)$, der sich hinter der zweiten Zahnplatte an den die letztere tragenden Knochen (u) heftet (in Cuvier's Oss. foss. nit u bezeichnet). Hierdurch kann die durch den inneren Luftdruck geschlossene Klappenvorrichtung geöfnet und zum Ausathmen benutzt werden.

Bei Menobranchus (Taf. VI, Fig. 10) liegt das innere Nasenloch (in) hinter dem Ende der äusseren (Kiefer-) Zahnreihe (k), lateralwärts vom Ende der inneren (Gaumen-) Reihe $(g)$. Es ist ein länglicher Schlitz. Der hinter der ersten Zahmreihe herumgehende Hautsaum bildet medialwärts (nicht wie bei Menopoma lateralwärts) von demselben eine Art Aussackung $(f)$, die im Zustande der Ruhe die Oeffnung vollständig schliesst. Bei manchen Exemplaren muss man diesen Hautsaum erst von der Oeffnung abheben, um diese zu sehen.

3) Cuvier's Mittheilung (Rech. sur les reptiles douteux, pag. 105), dass die Nasenhöhlen nicht in die Mundhühle münden, bedarf keiner Widerlegung mehr. 
Bei Sirchon konnte ich in der Ungebung der inneren Nasenöffnungen keine den Formen der ïbrigen Gattungen entsprechenden Hautsäume entdecken. Bei dieser Gattung, wahrscheinlich aber auch ebensosehr hei den übrigen wird der zur Erzeugung eines Vacuums nöthige Verschluss der inneren Nasenöffnungen vorzugsweise durch die unmittelbar unter derselben liegenden Platten der Zungenbeinhörner bewirkt. Werden diese nach oben gedrückt (durch den Mylohyoideus anterior), so legen sie sich an die Gaumendecke an und verschliessen jene Oeftinungen.

Die vorstehenden Beobachtungen liefern in bezug auf die Curier'sche Amnahme nur insofern ein negatives Resultat, als sie die Abwesenheit einer klappenälmlichen Vorrichtung an den äusseren Nasenlöchern, wo sie von Curier vorausgesetzt wurde, darthun. Durch den Nachweis, dass die immeren Nasenöffnungen, sei es durch Hautsäume, sei es durch die Zungenbeinhörner, des Verschlusses fähig sind, kömen sie nur dazu beitragen, jene Hypothese im ganzen zu stützen und auch als auf die Derotremen und Perennibranchiaten anwendbar erscheinen zu lassen.

2. Die Muskeln zur Bildung ron Hohlräumen beim Einathmen.

Um über die Anwendlarkeit dex Curier'schen Hypothese auf die I'erennibranchiaten und Derotremen röllig ins IKlare zu kommen, ist ferner eine zweite Frage zu entscheiden. Es ist die mach den Mitteln, wodurch das - von der äusseren Luft abschliessbare Tacuum in der Rachenhühle elzeugt werden kann.

Ohne Zwreifel gehören lierzu die Muskeln, welche eine Austiefung der Mundhöhle bewirken. Namentlich sind es die beiden Coratohyoidei, die, wie früher (S. 69) gezeigt, durch ihre Contractionen eine Krimmung der Zungenbeinhörner vach unten, mithin eine Vergrösserung des Lumens der Mundhöhle zur Folge haben werden.

'Zu dieser, anch ron Curier angedeuteten Action eigenticher Kelımuskeln gesellt sich aber bei den Perennibranchiaten und Derotremen (auch den Salamandrinen) die in dieser Beziehurg noch viel wirksamere Thätigkeit eines eigentlichen Einathmungsmuskels, des Stemohyoideus. Die ungemeine Grüsse der sehr weit nach hinten bis unter den vierten und selbst fünften Wirbel ausgedehnten Rachenhöhle ward früher erwähnt. Auf dic Erweiterung dieser hinteren Partie der Iachenhöhle scheint die Action des Stemohyoidcus 
gerade so berechnet zu sein, wie die der Ceratohyoidei auf diejenige der vorderen Partie, der eisentlichen Nundhühle. Je grösser die von jenem müchtigsten Einathmungsmuskel zurïckbewergte Fliiche ist, der das gamze Kiemenbogengeriist als knorpeliges Gerüst die nöthige Festigkeit bei ihrer Zurückbewegungr gewährt, je mehr endlich diese Flïche noch dadurch vergrössert wird, ditss Fasern des Sternohyoidcus sich oft an die Haut des Schlundes und selbst an das Pericurdium befestigen (vgl. oben, S. 108), um so mehr wird sich die hintere Partie der Rachenhöhle durch seine Action zu einem grossen Hohlraum erweitern, in den der Luftdruck das eingeathmete Medium hineintreiben muss. - Es leuchtet ein, dass diese Wirkung des Sternohyoidens bei den geschwïnzten Amphibien nur dadurch möglich wird, dass sich das Schultergeriist bei ihnen nicht wie bei den ïchten Batrachiern durch ein eingeschaltetes Brustbein zu einem geschlossenen Güirtel fixiert hat. Durch die über einander fortgehenden Schliisselbeinplatten, über welche wiederum die Stränge des grossen Seitenbauchmuskels sich nach vorn als Sternohyoideus an jene Art von Pumpenkolben begeben, wird eben auch die ganze hintere Partie des geraden Banchmuskels zu einem ächten Inspirationsmuskel.

Auch dies Ergebnis unserer Untersuchung ist der Annahme Cuvier's nicht entgegen. Es veranlasst uns nur, den Raum, in den der Luftdruck das eingeathmete Medium hineinpresst, grösser anzunehmen, als die durch die Ceratohyoidei ausgetiefte eigentliche Mundhöhle, und in der bei weitem grösseren hinteren Partie der Rachenhühle den Hohlraum zu erkennen, in den durch die Action des Stemohyoideus Luft oder Wasser eingepumpt wird.

3. Die MLuskeln zum Hinabschlingen der Luft.

Ueber die Frage, durch welche Muskeln die so eingenommene Luft weiter befördert wird in die Lungen, habe ich mich schon bei Beschreibung der einzelnen Mnskeln ausgelassen. Alle Perennibranchiaten und Derotremen sind mit zwei Systemen von Constrictoren ausgerüistet, einem oberfliichlichen, dem System des Mylohyoideus (II. anterior und M. posterior), und einem tiefen, unserem Constrictor pharyngis. Die Fasern beider Systeme verlaufen quer von einer Seite zur anderen unter Mund- und Rachenhühle; sie folgen ron vorn nach hinten anf einander. Erfolgte die Contraction dieser Fasern successive ron vorn nach hinten, so müsste dis eingenomnene Luft nach hinten in die Lungen, erfolgte dieselbe 
in umgekehrter Reihenfolge, so müsste die aus den Lungen kommende Luft den entgegen. gesetzten Weg nach aussen geschoben werden. Dabei ist der Bezirk des Mylohyoideus rorzugsweise die eigentliche, durch die Action der Ceratohyoidci ausgetiefte Mundhöhle, wälurend der Constrictor pharyngis seine schlingende Thätigkeit nur auf die hintere, unter dem Einfluss des Sternohyoideus stehende Partie der Rachenhöhle äussern wird.

\section{Muskeln zum Verschluss der Kiemenspalten.}

Der so nach hinten gedrïngten Luft muss übrigens, wenn sie wirklich in die Lungen gelangen soll, der seitliche Ausweg aus den Kiemenspalten verschlossen werden. Dies geschieht theilweise, wie oben (S. 16) gezeigt, durch den Mylohyoidens posterior selbst, hauptsächlich aber durch den Constrictor arcum (vgl. S. 73, ff).

5. Muskeln zur Oeffnung der Stimmlade.

Die kehlkopfartige Erweiterung der Luftröhre muss ferner offen gehalten werden, um der durch die Constrictoren der Kehle und des Schlundes weiter gepressten Luft den Eingang zu gewïhren. Bei den Derotremen, bei Cryptobranchus und bei Sirn entspricht unser Dorsolriryngens dieser Function. Bei den übrigen Gattungen steigen, wie früher erwïhnt, die vordersten Fasern des Iyotrachealis unter so spitzem Winkel nach vorn an gegen die Stimmlade, dass sie bei ihrer Contraction eine Oeffnung ihres Einganges zur Folge haben diirften.

Eine Erweiterung der Luftröhre selbst scheint nicht nöthig zu sein, damit die hindurch gepresste Luft in die Lungen gelangen könne. Sie ist bei allen Gattungen ein ganz hïutiger Schlauch, der nur gauz vorn durch einzelne ihm seitlich anliegende Kinorpelstreifehen schwach gestiitzt wird, in seiner grösseren hinteren Partie aber schlaff und folglich zusimmengedrückt erscheint. Dem von rom auf die eingenommene Luft ansgeibten Drucke folgend wird er sich erweitern und die Luft durchtreten lassen. In der That fehlt den Perenni- 
hranchiaten und Derotremen ein Dilututor trachere. wie ar von anderen Autoren angenommen wurde. Wir haben oben im Gegentheil in dem Hyotrachealis und Dorsotrachealis ein

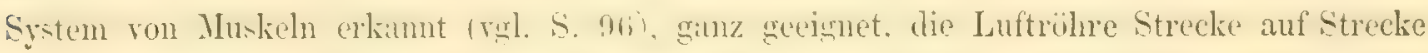
zu rerschliessen und so die eingenommenen Luftblasen in diesem Schlauche entlang zu treiben.

\section{B. Die Mechanik der Kiemen- (Wasser-?) Athmung.}

Thiere, welche mit äusseren Kiemen versehen sind, ist man natïrlich geneigt, für zum Wasserathmen geschickt zu erklären, d. h. ilnen die Fähigkeit zuzusprechen, den im Wasser aufgelösten Sauerstoff vermittelst der Kiemen zur Umwandlung des Blutes zu benutzen. Gewiss ist dies auch bei den Perennibranchiaten insofern richtig, als die ins Wasser hinemragenden Kiementiinchel bei ihr'm Vorwilen in dem ungebenden Meditim jene Aufnahme von Sauerstoff in das Blut vermitteln mögen. Eine andere Frage aber ist es, ob diese Thiere, wie die Fische, Wasser durch das Maul einathmen, um es bei den Kiemen vorbeistreichen zu lassen, mit anderen Worten, ob sie wie jene Wasser ein- und ausathmen. Diese Frage ist durch die bisherigen Beobachtungen noch keineswegs entschieden. Rusconi (ron Hypochthon) und neuerdings Léon-Taillant (ron Sircn) sprechen wohl von den eingeathmeten und dam aus den Kiemenspalten wieder entlassenen Luftblasen; ob aber auch bei dem ruhigen Verweilen unter der Oberthiche dthembewerungen stattfinden, ob das Oeffnen und Schliessen des Maules, wodurch das Athmen der Fische jedem Beobachter sofort auffillig wird, beobachtet wurde, ob irgend welche Umstände auf eine durch das Maul eingehende, aus den Kiemenspalten wieder hervortretende Strömung des Wassers schliessen lassen. dariber" erhalten wir nicht die leiseste Andeutung. Und doch sollte man denken, dass jene sehr auffälligen Anzeichen einer durch die Muskeln bewirkten Ein- und Ausgabe von Wasser jenen Beobachtern nicht hätten entgehen können. - Es bleibt also vorläufig durchaus nicht erwiesen, dass die Perennibranchiaten zum Zwecke der $\Lambda$ thmung Wasser durch die Kiemenspalten treiben. Die Möglichlieit bleibt bestehen, dass die Kiemenbüschel eben nur durch ihr ruhiges Verweilen und ihre eigenen Bewegungen den durch die Lungen ausgetührten Athmungsprozess unterstiitzcn. einen Prozess. der durch die 
nach Angaben der Beobachter häufig aus den Kiemenspalten ausgetriebenen, bei den Kiemenblättchen vorbeistreichenden Luftblasen nur befördert werden kann.

Wie dem aber auch sei, der Mechanismus, der Wasser aus den Kiemenspalten austreten liesse, würde offenbar derselbe sein, der zum Austreiben von Luftblasen aus denselben benutzt wird. Ohne daher die Frage entscheiden zu können, ob die Perennibranchiaten, den Fischen ähnlich, Wasser, oder ob sie Luft (wie Léon-Vaillant von Siren berichtet) durch das Ianl einnehmen und aus den Kiemenspalten austreiben, haben wir als Wasserathmungsmuskel in den voranstehenden Untersuchungen einzelne ILskeln berïht, die der Kiemenathmung dienen.

Als einen solchen Wasser- oder richtiger Kiemen-Athmungsmuskel haben wir oben (S. 53 u. 54) den Digastricus kennen gelernt. Durch seine eigenthümliche Form bei den Perennibranchiaten ütfnet er gleichzeitig Maul und Kiemenspalte, wird also dem durch die Einathmungsmuskeln eingezogenen Medium durch das erstere ein, durch letztere austreten lassen. Ehenso ist der Hyotruchcalis ein hierher gehöriger Muskel. Durch seine Contraction verschliesst er dem durch den Mylohyoideus und den Strmohyoidens nach hinten gepressten Medium die Luftröhre und üfnet gleichzeitig die letzte liemenspalte. Dass er, wenn letztere durch die Constrictores arcum geschlossen gehalten werden sollte, auch als Lungenathmungsmuskel fungieren künne, ist vorhin erwähnt. Die Lreture's aremem, welche die dorsalen Spitzen der Kiemenbogen yon einander (namentlich die des ersten von den übrigen) abzichen, also die Kiemenspalten öfnen, welche ferner die Kiemenborsm heben, also zusammenschmürend (ausathmend) auf die ïber diesen liengende Haut des Schlundes wirken, entsprechen ebeufalls den Hedingungen der Wasser-(Kiemen-) Athmung. Jedenfalls verstärken sie ausserdem durch ihre Contractionen die Bewegungen der an die Bogen befestigten Kiemenbuischel, Bewegungen, die durch die Levatures, Dipreswors und Addurtors branchiarm ausgefiihrt werden und eine öftere Ernenerung des die Kinmentüschel umgebenden Wassers zur Folge haben.

\section{Das Ausathmen.}

Was die Ausathmung betrifit, so ist der für das Ausstossen des ins Maul genommenen Wassers aus den Kiemenspalten erforderliche Muskelipparat eben besprochen worden. Zum Ausathmen der in die Lungen genommenen Luft dieneu zum Theil dieselben Muskeln. durch welche sie in jene eingepresst wurde. Wenn sich die Fasern der zum System des Con- 
strictor pharyngis gehörigen Muskeln in entgegengesetzter Reihenfolge zusammenziehen (ron hinten nach vorn) als diejenige war, in der sie (vou vorn nach hinten) bei der Einathmung wirksam gedacht wurden, so miissen sie die ron hinten her durch die Action der grossen Bauchmuskeln aus den Lungen ausgedrückten Luftblasen ebenso von hinten nach rorn, also aus der Luftröhre in die Rachenhühle entlecren, wie sie dieselbe vorhin in die Lungen treiben konnten. Das System des MIylohyoidens wird in derselben Weise die Weiterbeförderung der vom Constrictor pharyngis bis in die Rachenhühle getriebenen Luft übernehmen und schliesshich durch Abflachung der Mundhöhle die bis hierher gelangte Luft aus Mundoder Nasenöffnungen entleeren können.

Dass gleichzeitig die Wirkung der grossen Einathmungsmuskeln durch deren Antagonisten aufgehoben werden köme, bedarf keiner Erörterung mehr. Der gleich einem Pumpenkolben durch den Stemohyoidens nach hinten gezogene Kíiemenbogeuapparat wird durch die Action des Goniohyoudens und Geniog7ossus wieder in die normale Lage rersetzt, die durch die Ceratohyoidei bewirkte, den Mundboden austiefende Krümmung der Zungenbeinhörner durch die Contractionen des Mlylohyoidcus aufgehoben werden kümnen. 


\section{Zweite Abhandlung.}

Die Gehirnnerven

der

\section{Peremnibranchiaten und Derotremen.}




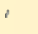




\section{Ursprünge.}

Die Ursprünge der Gehirmnerven wurden nur bei Sircdon und Ifonownches untersucht. Von Cryptobranchus juponicus sind dieselben durch F. J. Schmidt. Q. J. Goddard und J. van der Hoeven abgebildet und beschrieben worden ${ }^{1}$ ). Folgendes ist ihr Verhalten bei Siredon:

1. Der Olfactorius entspringt als einfacher starker Stamm ('Tif. II, I) von dem vordersten äusseren Theil der Hemisphären. Ein besonderer Lobus uffucturius, von welchem Triton und Salamandra eine Andeutung besitzen, ward nicht beobachtet. Ebenso weng eine wirkliche Anschwellung im Verlaufe des Nerven, der sich nach seinem lintritt in die Nasenhöhle mit Zweigen vom liamus nasalis des Trigemimus verbindet und damn fächerartig ausbreitet.

2. Der Opticus entspringt, wie gewöhnlich, von dem hintersten Theile der Hemisphären, an der Grenze der Hirnschenkel. Das Dasein eines Chiasma liess sich nicht erkennen.

3. Der Olfactorius hat eine getrente Wurzel an den vorderen Grenzen der Hirnschenkel, über dem Tuber cinereum. Er geht schräg nach aussen und vorn (Taf. II, 3), und hat ein eigenes Loch im Schïdel vor und über demjenigen des Trigemimus.

1) Aanteekeningen over de Anatomie van den Cryptobranchus japonicus. Haarlem 1862, pag. g4, Pl. XII. 
4. Der Patheticus (Taf. II, 4) entspringt von der hinteren Grenze der Vierhügel. Sein Ursprung wird am hesten von oben geschen. Geht schrïg nach aussen und vorn. Seino Austrittsöffnung liegt vor und dorsalwärts von der des Opticus.

5. Der Trigeminus entspringt mit einfacher starker Wurzel (Taf. II, 5) vom äusseren und ventralen Seitenrande der Mrdulle oblongah. da, wo die letztere nach Bildung eines vorderen Querwulst sich wieder verjüngt. Das Ganglion (A) ist einfich und liegt noch im Knochenkanal der Austrittsöffnung. In dasselbe mündet dorsalwïrts eine von der FucialisWurzel abgehende ziemlich ansehnliche Verstärkungswurzel.

6. Der Abducens entspringt einfach als äusserst feiner Faden nahe der ventralen Mittellinie des verlïngerten Marks, in sleicher Höhe mit der Frablis-Wurzel. Er geht schrïg nach aussen und vorn und tritt durch ein eigenes feines Loch eben vor dem des Trigeminus in die Orbita ein.

7. und 8. Die Wurzel des Facialis (7), von der des Acusticus (8) nicht getrennt, entspringt vom Aussentande der Mrdulla oblongata hinter derjenigen des Trigeminus. Sie sendet zunächst ein ziemlich starkes Wurzelbündel nach vorn in das Ganglion (A) des Trigcminus, und tritt dann $\left(C^{\prime}\right)$ in einen Kuochenkinal des Folsenbeins ohne eine Anschwellung zu zeigen. Sie trent sich hier vou dem in die Kapsel des Labyrinths eintretenden Acusticus, entsendet ventralwärts und nach vorn durch ein eigenes Loch ibren Ramus palatimes, und geht nach aussen, um durch ein hinterwärts gelegenes anderes Loch nach aussen zu treten.

9 und 10. Als Wurzel des Glossopharyngens (9) ist wohl die erste der drei in das grosse Ganglion $(B)$ des Vugus eintretenden Wurzeln zu betrachten. Diese entspringt hinter den vereinigten Wurzeln des Acusticus und Facialis, geht schrïg nach hinten und aussen und verbindet sich mit den zwei folgenden Wurzeln zu einem kurzen und dicken Stanm.

Die erste der beiden übrigen in das Ganglion eintretenden Wurzeln (10) ist die stärkste von allen und wird wieder aus mehren Büundeln zusammengesetzt. Sie geht nach aussen und verhindet sich noch im Schiddel mit der ersten und dritten Wurzel zu dem eben erwilhnten kurzen Stamm. - Noch weiter hinterwïrts, ebentills vom seitemrande der Medulla oldongutu entspringt die dritte Wurzel (Aressorine?), welche schrïg nach ausien und vorn geht, um in jenen gemeinschaftlichen Wurzelstamm einzumünden. Dieser geht durch das Formmen jugulare nach aussen und schwilt erst ausserhalb des schïdels zu einem grossen ovalen, platten Ganglion $(\boldsymbol{B})$ an. 
Der Hypoglossus wird beim Axolofl durch den ersten und zweiten Halsuerven gebildet. Der erste derselben entspringt von der ventralen Fliiche de's verliiugerten Markes, nahe dem Aussenrande denselben, und nimmt noch dine feinere, nahe hinter der dritten Vagus-Wurzel entspringende Wurzel auf, mit der er sich noch im Wirbelkanale verbindet. Eine dorsale Wurzel und ein Ganglion ward nicht beobachtet.

Menobranchus latcralis zeigt folgende Ursprünge der Gehirnnerven:

Der Olfactorius (Taf. VI, Fig. 8, 1) entspringt als der stärkste aller Gehirnnerven von dem vordersten äusseren Theil der Hemisphären. Diese zeigen daselbst eine sehr schwache Anschwellung ( $I I^{*}$ ), welche duch eine sehr geringe Vertiefung von ibrem ührigen Theile wenig abgesetzt erscheint und entfernt an die Abschnürung bei Salamandra und Triton erinnert. Kaum in die Nasenhöhle eingetreten, breitet sich der Riechnerv fächerförmig aus.

Ein Chicusmu des Opticus konnte auch hier nicht ermittelt werden.

Oculomotorius. Ein sehr feiner Faden, von der hinteren Seite der Vierhügel entspringend, nach aussen durch einen feinen Kanal im knorpeligen Scitentheil des Keilbeins (Ala temporalis:) durchtretend. Dieser Kanal liegt hinter dem des Opticus und geht mit letzterem parallel schrïg nach aussen und vorn.

Von dem Dasein einer getrennten, dem Patheticus zuzusprechenden Wurzel konnte ich mich nicht überzeugen.

Trigeminus. Die eigentliche Wurzel des fünften Paares $(V)$ entspringt vom vorderen Aussenrande des verlängerten Marks. Mit ihr vereinigen sich:

a) ein äusserst feiner, nur durch starke Loupen wahrnehmbarer Wurzelfaden (6), der vom lateralen Theil der Ventraltäche etwas hinter der eigentlichen TrigeminusWurzel entspringt, sclräig nach vorn und aussen geht und noch in der Schädelhöhle an die Trigeminus-Wurzel herantritt, um mit ihr zu verschmelzen ( $A b$ ducens?);

b) eine Verstärkungswurzel (*) vom Fuciulis, etwa halb so stark, wie die eigentliche Trigomims-Wurzel. Diese geht vom dorsalen und vorderen Theile der vereinigten Wurzeln des siebenten und achten Paares ab, so dass sie, wenn man den Schädel von der Ventralseite öffnet, nicht sogleich gesehen wird. Sie geht schrïg nach vorn und aussen, tritt von hinten her an den dorsalen 'Theil der eigentlichen Trigeminus-Wurzel heran und verschmilzt mit ihr noch in der Schädelhöhle; 
c) ein schr feiner Faden (1) schien mir rom hinteren Theil der Vierhügel herabzusteigen, sich von vorn und innen her an die Trigeminus-Wurzel anzulegen und mit dieser zu rerschmelzen (Patheticus?).

Der so aus verschiedenen Elementen gebildete Stamm des Trigeminus geht schräg nach aussen und vorn und bildet noch im Knochenkanale ein grosses, dreieckiges Ganglion (Taf. VI, Fig. 8, A), dessen eine Spitze nach hinten und medialwärts gerichtet ist. Aus dem vorderen, zweiten Scheitel geht durch ein besonderes Loch im Schädel der erste Ast $\left(5^{\circ}\right)$ hervor. Aus dem dritten lateralwärts gerichteten Scheitel des Ganglions geht der III. Ast hervor (5“"). Der II. Ast (5“) entspringt aus der dorsalen gewölbten Fläche des Ganglions und wird an seinem Ursprunge nur gesehen, wenn man von der Dorsalfäche aus den Schädel öfnet. Der II. und III. Ast haben ein von dem des I. Astes getrenntes Loch.

Facialis und Acusticus entspringen (7) vereint von der Seitentläche des verlängerten Markes hinter (d. h. dem Schwanzende näher) der Wurzel des Trigcminus. Un-

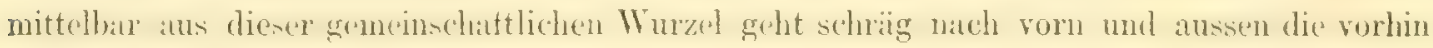

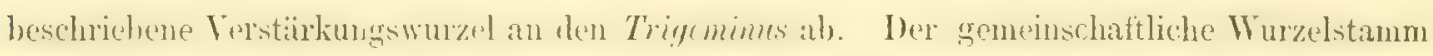
schwillt sodann zu einem sehr grossen spindelförmigen Ganglion $(C)$ an, aus dessen erstem, ganz in den Linochen des Felsentreins cingehällten Drittheil der Acusticus (s) in die benachbarte Höhle des Labyrinthes eintritt. Aus der äussersten Spitze des Ganglions gehen hervol:

a) der Ramus palatimus $(p)$;

b) der anfangs vereinigte Stamm des $R$. mentalis und $R$. jugularis (me und $j u$ );

c) eine sympathische Schlinge (s) mit dem Ganglion des Vagus;

d) der Rames alveolaris (a).

Der dem System des Vugus angehörige Wurzelstamm wird aus drei Wurzeln gebildet, die sich noch innerhalb der Schädelhöhle mit einander vereinigen. Die erste derselben (Taf. VI, Fig. 8, 9), die ich dem Glossopharyngeus zusprechen möchte, ist etwa halb so fein, wie die zweite, dem zehnten Paare selbst angehörige (10). Sie entspringt nicht weit hinter der gemeinschaftlichen Wurzel des Facialis und Acusticus und weicht dadurch von der entsprechenden Wurzel beim Axolotl ab, dass sie nicht, wie bei diesem, in einem besonderen linochenkanale verlïuft, sondern sich noch im schäidel selbst nit den folgenden Wurzeln vereinigt. - Die zweite, stårkere (Vagus) Wurzel (10) entspringt noch etwas weiter nach hinten (d. h. dem Schwanzende näher), nimmt gleich darauf noch eine dritte, weiter hinten entspringende (Aec'ssorius?) Wurzel auf, geht schrïg warch aussen und hinten 
und vereinigt sich mit der ersten (Gloswophrumguts-) Wurzel zu einem remeinschaftlichen Stamm. Dieser tritt durch das Foramen jugulare heraus und schwillt zu cinem ansehnlichen, halbkugelförmigen Ganglion $(B)$ an, das mit seinem medialen Theile noch im Foramen selbst liegt.

Der. N. hypoglossus wird bei Menobranchus durch Stämme des zweiten $(2 h)$ und dritten (3h) Halsnerven gebildet.

\section{Die Augenmuskelnerven.}

Die Untersuchung der Augenmuskelnerven bietet bei den Perennibranchiaten und Derotremen besondere Schwierigkeiten dar. Sie sind bei den meisten Gattungen von fast mikroskopischer Feinheit und ausserdem in so dichtes Zellgewebe eingebettet, dass es nur ausnahmsweise bei Sircdon gelang, die Verbreitung des dritten und vierten Paares zu ermitteln.

Der Oculomotorius tritt vor und unter der Insertion des $1 \%$. rectus inferior in die Orbita ein. Fr theilt sich in zwei 'Theile:

a) der eine wendet sich sofort nach oben und verbreitet sich im licctuss supcrior und Rectus internus;

b) der andere tritt von unten her an den Rcctus inferior und giebt ihm $/ 4$ weige. Ein Faden desselben tritt an der vorderen, lateralen Insertion dieses IIuskels wieder aus demselben hervor, liuft, dem Bulbus hart anliegend, an dessen Ventralthiche nach rorn und tritt in den M. obliques inferior ein, in welchem er endigt.

Der Patheticus von Sivedon tritt als iusserst feiner Nervenfiden durch cin eigenes, vor und über dem des Oculomotorius gelegenes Loch aus rem schädel, wentet sich nach oben und breitet sich im $M$. obliques superior ans. Er scheint anch cinzelne löiden in die Haut oberhalb des Auges abzugeben.

Der Verlauf des Aluducens konnte nicht ermittelt werden. 
Wenn wir uns mit dieser kurzen Schilderung der bei Sircton verfolgten Ausbreitungen einzelner Augenmuskelnerven begnïgen müssen, no sei hier doch bemerkt, dass die letzteren auch bei den übrigen Gattungen ihre Selbstständigkeit zu bowahren und nicht mit dem ersten Aste des Trigeminus zu verschmelzen scheinen. Bei Menopoma wurden Zweige des Oculomotorius in den $\boldsymbol{M}$. retractor bulbi und in den Obliques inferior verfolgt. Ebenso wird in dem Werke von F. J. J. Schmidt, Q. J. Goddart und J. van der Hoeven bei der Gattung Cryptobrune hus dem Oculomotorius und Putheticus ein selbststindiger Verlauf zugeschrieben, wïhrend die dem Abuccus entsprechenden Fisem vom liumus nasalis entspringen sollen (Aanteekeningen etc., pag. 56).

\section{Der N. trigeminus.}

Der Trigemimus, der bei allen Gattungen (auch bei (ivyptolbanchus japonicus) Fasern des Faciulis in seine Wurzel anfnimmt, zeigt iiberall fist denselben Verlauf seiner Zweige. Bei allen Gattungen sind die gewöhnlichen drei Inuptstimme zu unterscheiden, zu denen sich nur ausnahmsweise ein vierter direct ans dem Ganglion austretender Hauptzweig gesellt.

Bei Siredon (vgl. Taf. II) entspringen, vier Nerrenståmme aus dem Ganglion gasseri:

a) Der feinste (linke Seite der Figur, 5') entsteht aus der dorsalen lateralen Fläche des Ganglions, wendet sich zwischen Temporalis und Masseter nach oben, biegt, wenn er aus diesen Muskeln hervorgetreten ist, nach vorn um und geht dorsal- und medialwärts vom Auge bis zur Nasengegend, wo er sich in der Haut ausbreitet.

Dieser Nerv ist vielleicht als Analogon der bei Fischen ausgebildeten vorderen Partie der Seitennerven zu betrachten. Von Tritom habe ich friiher einen älnlich verlaufenden ans dem Ganglion des Trigomims hervorgehenden Nerven beschrieben. In dieser, wie ich friher sezeigt, einem Theil der vom Furialis st:mmenden Verstärkungswurzel entipricht, so duirfte dasselbe beim Axolotl der Fall sein.

b) Der zweite aus dem Ganglion des Trigcmimus hervorgehende Nerv ist der Ramus nasalis (rechte Seite der Figur, 5"). Dieser hat ein besonderes Loch im Schädel, etwas 
vor dem der übrigon Zweige gelegen. Er wendet sich, der scitlichen Schäilelwandung dicht anliegend, nach vorn und tritt über den Rectus externs $(r c)$, unter dem Rectus superior ( $r s)$ fort. Unter und eben vor letzterem Muskel giebt er einen Zweig lateralwärts ab, der sich in mehre Fäden auflöst. Einer derselben geht nach aussen und vorn und tritt eben vor dem Rectus superior in den Bulbus (Ramus ciliaris). Lin anderer geht schräg nach a ussen und vorm, unter dem Obliques superior (os) durch an die Haut uber dem Auge.

Nach Abgabe dieses Zweiges theilt sich der Ramus nasalis, der nun etwa an der Mitte des Augapfels (b) liegt, in zwei gleich starke Aeste, welche noch bis an den Musc. obliques superior zusammen verlaufen, dann aber sich trennen.

a) Einer derselben wendet sich schräg nach innen und vorn, tritt unter dem Os frontale extemum an den Riechnerven heran, giebt einen Faden nach oben an die Haut und verschmilzt gänzlich mit den mittleren Zweigen des Olfactorius (1).

B) Der zweite tritt ventralwärts vom $\boldsymbol{M}$. obliques superior durch nach vorn und aussen, längs der lateralen Kante des Os frontale extcrmm und theilt sich in zwei Zweige:

жa. Der eine breitet sich in der Haut vor dem Auge aus. Lr lässt sich bis zur Gegend des Nasenlochs rerfolgen.

$\beta \beta$. Der zweite tritt iber den Vomer fort und breitet sich zugleich mit dem Ramus palatimus des Facialis in der vorderen Haut der Nundhöhlendecke aus.

c. Beträchtlich schwächer als der Ramus nasalis ist der $R$. maxillaris superior (Taf. II, rechte Seite der Figur, 5*'). Sobald dieser aus dem Ganglion entsprungen, wendet er sich nach aussen und vorn, zwischen Temporalis und MFasseter. Er tritt unter dem

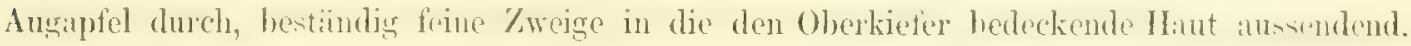
Er geht nach voru bis in die Gegend des Nasenlochs und breitet sich ganz in der Haut aus.

Der stärkste aller Trigeminus-Aeste ist der Ramus maxillaris inferior (5'"n). Dieser tritt, bedeckt von den MIm.temporalis und masseter, denen er Zweige giebt, nach aussen und unten, vor dem Os tympanicum abwärts laufend. Dicht vor dem Gelenk des Unterkiefers giebt er einen Zweig nach hinten (亏i) an die das Gelenk bedeckende Haut, wendet sich dann $(5 r)$ nach vorn auf der oberen und lateralen Kante des Unterkiefers. Letzterer wird etwa in der Mitte seiner Länge von einem Knochenkanal ron oben nach unten durchbohrt. Durch diesen Kanal tritt unser Nerv nach unten und theilt sich dann in zwei Hauptzweige: 
a) Der hintere, schwächere giebt Zweige an die Haut unter dem Unterkiefer, wendet sich dann nach innen und verzweigt sich von der Ventralseite aus in der hinteren Partie des Mylohyoidens cutterior.

b) Der vordere, stärkere theilt sich wieder in zwei Aeste:

$\alpha$. Der äussere läuft auf der Haut, welche den Unterkiefer ventralwärts bedeckt, etwas medialwärts von diesem Knochen nach vorn bis zum vorderen Winkel der beiden Unterkieferhälften, indem er sich mit vielen Fäden in der Hant ausbreitet.

$\beta$. Der innere, etwas schwächere, tritt nach innen, giebt gleich anfangs einige Zweige an die Haut, breitet sich sonst aber ganz im vorderen und mittleren Theil des Mylohyoideus anterior aus.

Der Mylohyoidaus posterior erhält keine Zweige vom Trigeminus. - Eine Verschmelzung der zuletzt geschilderten Zweige des $R$. maillaris infirior mit Zweigen des benachbart verlaufenden $R$. mentalis des Facialis findet nicht statt.

Bei Menobranchus lateralis tritt der erste Ast des Trigominus aus der vorderen Spitze des Ganglion (Taf. VI, Fig. 8, A) als starker Nervenstamm durch ein besonderes Loch aus der Schärblhöhle, läuft ventralwïrts rom $M$. temporalis und über dessen untersten (dem M. pterygoideus zu vergleichenden) Fasern nach vorn. Er tritt, in der Gegend des Auges angelangt, über den Reches extermes und unter dem $R$. superior fort. Unter letzterem Muskel theilt er sich in zwei Hauptzweige. Von diesen giebt der innere schwächere zunïchst cinen Zweig nach innen und oben an die Haut der Stron medialwïrts vom Auge, dann einen zweiten feineren nach aussen in den $B$ ulbus ( $R$. ciliaris), tritt endlich mit den beiden übrigen Hauptzweigen unter dem $\boldsymbol{M} \boldsymbol{I}$. obliques superior fort und in die Nasenhöhle. Hier verlaufen die Endzweige unsexes I. Astes eine Strecke dorsalwärts von den Ausbreitungen des Riechnerven und verbreiten sich mit den letzteren zugleich in der Schleimhaut.

Der II. Ast, mit dem III. aus einem gemeinschaftlichen, an der vorderen und inneren Grenze des Fliigelbeins gelegenen Loche hervortretend, verliuft zwischen IItsseter und Temporalis nach vorn, giebt gleich einen stärkeren (Taf. III, 5`) und mehre schwächere Zweige an die Haut der Stim, medialwärts rom Auge, wendet sich dimn unter dem Auge herum nach, vorn und verzweigt sich in der Haut der Wange bis in die Gegend des Nasenloches.

Der III. Ast giebt gleich nach seinem Ursprunge mehre feine Zweige in den Masseter und den Temporalis, läuft dann, verdeckt vom Musseter, an der vorderen und ventralen 
Kante des Os tympanicum nach aussen und unten und theilt sich vor dem Gelenk des Unterkiefers in drei Zweige. Der vorderste, stärkste lïuft lïngs des Unterkieferknochens an der lateralen und ventralen Kante desselben nach vorn und verbreitet sich an der diesen bedeckenden Haut. - Der mittelste durchbohrt von oben nach unten den Unterkiefer, wendet sich, aus dem Knochenkanale hervorgetreten, nach innen und verzweigt sich im Mylohyoidens anterior. - Der letzte dieser drej Zweige endlich geht ganz nach aussen und verzweigt sich in der das Gelenk des Unterkiefers bedeckenden Haut.

Auch bei ITenopoma (Taf. IV, Fig. 1) hat der erste Ast des Trigeminus (5“) ein eigenes, an der modialen und vordrren Kante des Os pterygoideum gelegenes Loch. Er läuft schräg mach rorn und etwas nach aussen, dem langen $M$. retractor bulbi (rs), der zugleich die Fasern des Tretus eitcrms und des Rectus suprior zu entlalten scheint, dicht anliegend. Nachdem er zwei feine Zweige für die Haut der Stirn $(\alpha, \beta)$ abgegeben hat, und indem er selbst medialwärts vom Auge nach vorn läuft, entlässt er einen Zweig $(x)$, der unter dem Obliques superior durch bis vor das Auge tritt, wo er sich mit dem von aussen an ihn herantretenden Ende des zweiten Astes (5“") zu einem kurzen Stamme ( verbindet, der von oben ler in den Knochen des Oberkiefers eintritt. Nach Mayers Untersuchungen durchbohrt dieser Stamm den Oberkiefer, um sich in der den letzteren bedeckenden Haut auszubreiten. - Nach Abgabe dieses Zweiges durchbohrt der Rest des ersten Astes die Deckknochen der Nase, dringt in die Nasenhöhle cin und rerbreitet sich theils in der Schleimhaut der letzteren, theils in der die Schnauzenspitze bedeckenden Haut.

Der zweite Ast des Trigemimus (5") tritt zwischen Massetor und Temporalis nach aussen an die das Ende des /wischenkiefers bedeckende Haut (ct), versorgt diese mit zahlreichen Zweigen (c), liuft unter dem Auge nach vorn und verbiudet sich endlich mit dem erst beschriebenen Zweige $x$ des ersten Astes.

Der dritte Ast $\left(5^{\prime \cdots}\right)$ tritt durch die Fasern des Masseter nach aussen und giebt diesem so wie dem Temporalis /weige (II). An der Ecke des Unterkiefers angelangt, theilt er sich in drei Aeste von ungleicher Stärke. Der schwächste (i) geht geradeswegs nach aussen und rersorgt mit Fasern (i) des Facialis zugleich die das Gelenk des Unterkiefer- 
bedeckende IIaut. Der mittlere (9) und bald darauf der vorderste stärkste (3) jener drei Endzweige des dritten Astes treten ron oben her, dicht ror dem Gelenk des Lnterkiefers in einen den letzteren von oben nach unten durchsetzenden Kanal. An der ventralen Kante des Knochens hervorgetreten, wendet sich dis Ende des dritten Astes nach innen und breitet

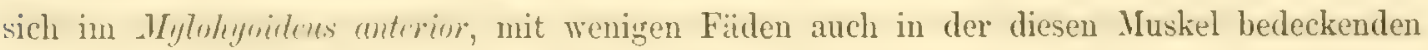
Haut aus.

Es dürte ïberflüssig sein, die Formen des Trigeminus bei Siren und Amphiuma näher zu beschreiben. Sie stimmen mit denen der eben ahgehandelten Gattungen und mit der frïher von mir beschriebenen Form von Hyporhthon ${ }^{3}$ ) so genau ïberein, dass man die von jenen gevelenen Beschreibungen als für die ganze Gruppe der Perennibranchiaten und Derotremen gültig betrachten kann.

\section{Der N. facialis.}

In Bezug auf die Form dieses Nerven schliessen sich die Perennibranchiaten und Derotremen sehr eng an die Salamandrinen an. Wenn auch immer noch einzelne seiner Elemente in der Bahn des Trigrminus verlaufen, da ganz constant seine Wurzel eine Verstärkung an diejenige des letzteren absendet, so gehen doch, abweichend ron den ächten Batrachiern sein $R$. palatimus und sein $R$. jugularis niemals aus $Z$ wreigen oder aus dem Ganglion des Trigeminus hervor.

1) Amphibiorum nudor. neurol. Spec. I, pag. 35. 
Bei Siredon zeigt der Facialis folgende Form:

Nachdem seine Wurzel (Taf. II, 7) die oben erwälnte Verstärkungswurzel in das Ganglion Gasseri entsendet hat, tritt der Stamm des Nerven $(C)$ in einen Kanal des Felsenbeins, der sich vor dem Labyrinth nach aussen um letzteres herumschlingt. Ohne dass ein Ganglion an ihm bemerklich wäre, entsendet er hier durch ein eigenes Loch den $R \iota^{-}$ mus pulatimus nach unten. Dieser, etwa ${ }^{1} ;$ so stark wie der Rest der Nerven, tritt an die Haut des Gaumens, auf der er im hinteren inneren Winkel der Fossa pterygoidca zum Vorschein kommt. Dex äusseren Kante des als Keilbein aufgefassten Knochens dicht anliegend, verläuft er auf der Gaumenhaut nach vorm bis zum Vomer, tritt über dessen Zahnplatte fort und verbreitet sich in der zwischen Vomer und Zwischenkiefer liegenden Haut der Mundhöhle.

Nach Abgabe des $R$. palatimus geht der Hauptstamm des Facialis nach aussen und tritt durch ein eigenes Loch aus dem Felsenbein hervor. Unmittelbax darauf theilt er sich in zwei Theile von gleicher Stärke, welche noch eine kurze Strecke zusammen nach aussen verlaufen.

a. Der vordere dieser beiden Stämme empfängt da, wo sich der Ramus communicans (k) des Glossopharyugeus $(g l)$ in den hinteren Stamm ( $l$ ) einsenkt, einen sehr feinen und kurzen Verstärkungszweig von diesem ihm jetzt noch sehr benachbarten hinteren Stamm. Unmittelbar darauf trenut er sich von diesem, und während letzterer (i) sich nach aussen und hinten wendet, geht er selbst längs der Hinterfläche des $O_{s}$ tympanicum abwärts. Er entlässt hier den gleich näher zu beschreibenden Ramus a/veolavis und theilt sich dann als Ramus mentalis, immer noch an der Hintertläche des Os tympanicum gelegen, in zwei Aeste, die sich beide in der Haut unter dem Mylohyoillens ausbreiten. Der vordere verläult unter beständiger Absendung von Hautnerven bis ganz nach vorn zum Winkel des Unterkiefers, ohne dass eine Verschmelzung mit den ganz benachbarten Endzweigen des dritten Astes des Trigeminus statt fände. - Der Ramus alveolaris tritt an der Hintertläche des Os tympanicum nach unten und aussen, dringt in ein unmittelbar hinter der Gelenkfläche des Unterkiefers gelegenes Loch dieses Knocheus ein und verlïuft in einem Kanale desselben bis fast an dessen vorderes Ende. Er entlässt aus dem Dorsalraude des Knochens hervor von Zeit zu Zeit feine Zweige in die den Unterliefer bedeckende Hant.

Der zweite der Aeste $(h)$, in deu sich der Hauptstamm $(C)$ des Fuciulis spaltet, empfängt bald nach seiuer Trennung vom eben beschriebenen ersten Aste den Romus communicans (k) aus dem Glossopharyngens $(g l)$. Genau an der Stelle, wo el cliesen Ast empfängt, giebt er einen feinen Zweig an den ersten Stamm und tritt daun weiter uach 
aussen als Rumus jugularis (i) durch die Fasern des Digustrimes (Ag). dom er Zweige giebt, hindurch. An dessen hinterem und unterem Drittheil tritt er aus diesem Muskel. nach aussen hervor, uber die verschmolzenen hinteren Partieen des Mylohyoudeus postrvior und des Ceratohyoidens cxterms. Eben hervorsetreten, giebt er einen Zweig nach hinten ab, der die Haut vor der Kiemenspalte versorgt. Er selbst weudet sich nach innen und breitet sich im Mylohyoideus posterior aus. Einzelne seiner Zweige treten dorsalwärts durch diesen Muskel hindurch, um sich im Ceratohyoideus externus zu verbreiten.

Menobranchus zeigt nur geringe Abweichungen ron Siredon:

1. Der R. palatimus hat ebenfalls ein besonderes Loch im Felsenbein.

2. Der $R$. mentalis läuft, bedeckt vom $M$. digastricus, an der Hinterfläche des $O s$ tympanicum abwärts und verbreitet sich mit zwei, dem Unterkieferrande parallelen Stämwen in der diesen bedeckenden Haut.

3. Der $R$. jugularis scheint keinen $R$. communicans rom Glossopharyngous zu empfangen. Allerdings steht der Stamm des Facialis hart an seiner Austrittstelle aus dem Schädel durch einen äusserst feinen Verbindungsnerven (Taf. VI, Fig. 8, s) mit dem Ganglion des Vagus in Zusanmenhang, den ich jedoch für den anch bei Ampliuma (hier zugleich mit dem $R$. communicans) und Siren vorhandenen Kopftheil des Sympathicus halten möchte. - Der $R$. jugularis wendet sich, bedeckt von der ersten Portion des Digustrims, nach hinten, tritt hinter derselben hervor und läuft, oberflächlich geworden, über der zweiten Portion des Digastricus und dem damit anfangs velbundenen Mylohyoidnes pustrvior nach unten, um sich, mit Ausnahne einiger feiner Hatutzeige, ganz in diesem Muskel auszubreiten.

4. Der Ramus alveolaris ist nicht wie bei Siredon anfangs 'mit dem $\boldsymbol{R}$. mentalis verbunden, sondern gleich anfangs ein selbstständiger Nervenstamm. Er läuft hinter dem O.s tympanicum und medialwärts von diesem Knochen nach unten, tritt hinter dem Gelenk des Unterkiefers in letzteren ein und verlåuft darin nach vorn. 
Auch Menopoma zeigt dieselben vier Stämme:

1. Den Ramus palatimus.

2. Den Ramus montalis (Taf. IV, Fig. 1, 7i). Dieser verläuft an der hinteren Flïche des Os tympanicum nach aussen und unten, bis zum Gelenk des Unterkiefer's, wendet sich dann nach innen und vorn und verlïuft nun parallel dem Unterkieferknochen, medialwïrts von demselben, unter den Fasern des Mylohyoidcus. An der Mitte des Unterkieferknochens angelangt, kreuzen sich seine Fasern mit einigen Zweigen des eben aus seinem Knochenkanal hervorgetretenen Restes des Muxillaris inferior Trigenini. Ein eigentliches Geflecht entsteht jedoch nicht. Nachdem es mit einiger Schwierigkeit gelungen, die den beiden Nervenstämmen angrehürigen Füden einzeln zu verfolgen, sieht man die des Furialis in der den Unterkiefer bedeckenden Haut endigen, ohne dass Muskelzweige aus ihnen hervorgingen.

3. Der Ramus alvcolaris $(7 \mathrm{~m})$, von Anfang an selbstständig, wenn auch dem Ramus jugularis (n) zuerst dicht anliegend, lüuft auch an der hinteren Flïche des Os tympanicum, diesem Knochen dicht anliegend, nach aussen und unten bis an das Unterkiefergelenk. Hier entlïsst er einen die Haut versorgenden Zweig ( 2 ), geht dann aussen um das Unterkiefergelenk herum und verlïuft dem dorsalen Rande des Knochens parallel nach vorn, lateralwïrts über die Fasern des bier nach unten vortretenden Masseter (Fig. 2, m) forttretend. Etwa in der Mitte des Unterkieferknochens tritt er von der Dorsalseite her in denselben ein und verläuft nun in einem Kanale desselben nach vorn. Bei vorsichtiger Oeffnung des Knochens gelang es, unseren Nerven in seinem Kanal bis fast zur Spitze des Unterkiefers zu verfolgen.

4. Der Ramus jugularis (Taf. IV, Fig. 1, $n$; der Nerv ist nahe an seinem Ursprung abgeschnitten) nimmt gleich nach seiner Trennung vom $R$. alvcolaris den $R$. communicans des Glossophurymgens auf und wendet sich dann nach hinten in die Fasern des Digastricus hinein, den er mit Zweigen versorgt. Am Unterkiefergelenk tritt er aus dem Muskel wieder hervor, wendet sich nach innen und breitet sich in dem Mylohyoicters posterior aus. 
Ampliuma (Taf. V, Fig. 2) zeigt in der Form des Facialis einige Abweichungen. Unmittelbar nach seinem Herrortritt theilt er sich in folgende Zweige:

1. Ein sehr feiner Faden $(9 c)$ wendet sich, dem Felsenbein dicht anliegend, nach linten, tritt medialwiirts rom $O s$ tympanicum $(t y)$ nach oben und etras nach innen und verschmilzt mit dem Ganglion des Fagus (Glossopharyngeus, 9) zu einer Schlinge. Ich halte diese letztere für den Iropftheil des Sympathicus.

2. Ein viel stärkerer $\Lambda$ st (Fig. $2, n$ ) ist ein Nerv von ganz eigenthümlicher, nur bei Amplizma beobachteter Form. Er geht zwischen der ersten $\left(d g^{\prime}\right.$, Fig. 1) und der zweiten Portion des Digastricus, den Fasern der letzteren dicht aufliegend, nach hinten. Bald nach seinem Ursprunge tritt er medialwärts unter dem $R$. commuicans Glossopharyngei $\left(9 c^{\circ}\right)$ durch, olme jedoch anders als durch Bindegewebe mit ihm verbunden zu sein. Er läuft geradeswegs nach hinten iiber die Kiemenspalte, innerhalb des letzten Lappens der ThymusDrüse (Fig. 1, l) durch, steigt dann medialwärts in die Tiefe ror den Dorsotrachealis und wendet sich nach rorn. Er giebt nur einen schwachen Faden an den ihm benachbart verlaufenden Hauptstamm des Vagus und rerliert sich zwischen den Fasem des der Luftröhre zustrebeuden $M$. Tyotrachealis.

3. Mehre sehr feine Zweige ( $m$ ) gehen nach hinten in den $\boldsymbol{M}$. digastricus.

4. Der Ramus jugularis (i), so stark wie der eben beschriebene zweite Ast, tritt ebenfalls, jedoch etwas mehr ventralwärts nach hinten. Er nimmt den lateralwärts über den zweiten und dritten Ast herabsteigenden Ramus communicans (9c) des Glossopharyngens auf, geht so verstärkt nach unten und breitet sich theils im Mylohyoidens posterior (my"), theils (l) im Levator maxillae inferioris ascendens (Fig. 1 und 3, las) aus.

5. Auch der liamus mentalis (Fig. 2, me) geht medialwärts rom Digastricus, dem IIylolyoidcus posterior (my“) lateralwärts anliegend, nach unten, tritt medialwärts rom Unterkieferfortsatz (mi) herum und wendet sich nach rorn. Indem er nun (Fig. 3, me) parallel der Kante des Unterkiefers und medialwärts von derselben uaclı vorn bis zum Winkel der Unterkieferiste verläuft, tritt er unter dem für den IIylohyoidas anterior (my') bestimmten Rest des Maxillaris infrior Trigomini (5*) fort und verbreitet sich mit allen seinen Zweigen an der den Unterkiefer und den Mylohyoideus anterior bedeckenden Haut.

Der Ramus palatinus ward bei Amphimma nicht rerfolgt. - Von dem Dasein eines Ramus alvcolaris des Fucialis konite ich mich nicht überzeugen. 
Bei Siren gehen aus dem Facialis folgende Zweige hervor:

1. Der Ramus palatimus geht längs der Aussenkante des Os tympanicum Cur. nach vorn, dem Kinochen dicht anliegend und bestindig feine Zweige in die Haut des Gaumens aussendend. Hinter der zweiten der beiden zahntragenden Platten angelangt, wendet er sich etwas medialwärts und verbreitet sich in der Haut des Gaumengewölbes.

2. und 3. Der Ramus mentalis und der Ramus jugularis treten dicht neben einander als zwei Stämme von gleicher Stärke nach aussen und durchbohren den $\boldsymbol{M}$. masseter. Beide verlaufen vor und über dem Diyustricus, der von dem hinteren jener beiden Stïmme, dem li. jugularis, mit zahlreichen Zweigen versorgt wird. Beide wenden sich dann um die hintere Ecke des Unterkiefers herum nach innen und verzweigen sich, der $R$. jugularis in dem Mylohyoidens posterior, der $\boldsymbol{R}$. mentalis in der den Unterkiefer von unten her bedeckenden Haut.

4. Ein in den Ramus jugularis eintretender $R$. commuicans des Glossopharyngeus ward nicht beobachtet. Wohl aber geht, dem Knochen des Felsenbeins ganz hart anliegend, ein sehr feiner Verbindungsast (Liopftheil des symputhicus) zum Ganglion des Vagus.

5. Der Ramus alveolaris, mit dem Ramus palatimus zugleich entsprungen, wendet sich gleich von diesem ab und tritt wach unten und von innen her an den Unterkiefer heran. Er verliuft an der medialen Flïche dieses Knochens, beständig feine Zweige in die denselhen bedeckende Haut absendend, und lïsst sich, den Knochen dicht anlicgend, bis etwa zur Hälfte desselben verfolgen. Hier tritt er von innen her in den Unterkiefer ein und verläuft in dem Knochenkanal nach vorn. Das Loch für seinen Eintritt in den Unterkiefer liegt etwas vor demjenigen, aus welchem das Ende des MLaxillaris inferior Trigemini hervorkommt.

Nach den eben gegebenen Specialbeschreibungen kommen dem System des fiacialis bei den Perennibrauchiaten und Derotremen viex verschiedene Stïmme ganz constant zu: Der $R$. palatinus, der $R$. mentalis, der $R$. jugularis und der $R$. alveolaris. Zu diesen kommen noch bei einigen Giattungen einige kleinere, bei den übrigen im $R$. jugularis mit enthaltene Muskelzweige und endlich bei Ampinuma ein für die Muskeln der Luftröhre bestimmter Zweig. 
Jeder der vier obigen Stïmme hat einen ganz constanten Verbreitungsbezirk, und zwar entsprechen die drei ersten derselben in ihrem Verlaufe den drei Hauptstämmen des Trigominus. Wie der Ramus nusalis des Trigemimus dorsalwäts von dem Basilarknochen der mittleren Schüdelpartie (dem Os sphenoideum, Cuvier) verlïuft, so geht an der Ventralfliche desselben Ḱnochens und mit jenem Nerwen parallel der Kumus pulatimes nach vorn. Der erstere ist vorzugsweise für die Schleimhat der Nase bestimmt, so der letztere für diejenige der Rachenhöhle. Beide haben besondere, von denen der ïbrigen Stïmme ihres Systems getrennte Austrittsöffnungen.

Der zweite Ast des Trigeminus, der $R$. maxillaris superior, ist vorzugsweise für die Haut des Oberkiefers bestimmt. Ihm entspricht der $R$. mutulis des Faciulis in seinem Verlaufe lïngs dem Rande des Unterkiefers und in seiner Verbreitung an der len'letzteren bedeckenden Haut.

In gleicher Weise wiederholt der $R$. jugularis des siebenten Paares die Form des R. maxillaris inferior Trigcmini. Beide enthalten Hautzweige, beide aber sind zugleich diejenigen Stïmme, aus denen die Muskelzweige ihres Systems herrorzugehen pflegen. Aus dem dritten Aste des Trigomimes findet die Versorgung des Temporalis und Mussiter statt, aus dem Ramus jugularis diejenige des entsprechenden (aber Senk-) Muskels an der Hinterflïche des Os tymumanim, des Digastricus. Jener verzweigt sich bestindig im Mylohyoideus anterior, dieser ebenso constant im Mylohyoidens posterior. Der $M$. pterygoideus erhilt bei Siren seine Nerven aus dem Fucialis; dasselbe System liefert bei Amphiuma (und Caecilia) die Fasern für unseren Levator maxillae inferioris ascendens.

Was den vierten der oben genannten Facialis-Stämme, den $R$. alveolaris maxillae inferiari, betrifft, so ward ein besonderer, für den Obukiefer bestimmter $R$. alcoluris des Trigemimus nicht beobachtet. Dass die Elemente emes solchen indes vorhanden sein, aber in der Bahn des zweiten Astes verlaufen mögen, geht aus der von IIayer bei Menopoma entdeckten, oben (S. 131) beschriebenen Endigung dieses Astes hervor.

Als besonderer Stamm des Facialis erscheint endlich bei Amphima noch ein für die Muskelı der Luftröhre bestimmter Nervenstamm. Dieser ist um so merkwürdiger, als keine der anderen Gattungen damit ausgeriistet ist, und als Amplimm selbst auch ausserdem noch den gewöhnlichen $R$. recurrens des Vagus besitzt.

Von Interesse fuir den Facialis ist ferner seine Verbindung mit dem Ganglion des Vugus, oder mit dem Glossophuryngeus, wenn dieser, we bei Siren, mit jenem nicht verschmolzen ist. Ich habe diese Verbindungsschlinge als Kopftheil des Sympathicus bezeichnet, weil sie sich nicht in einen der Stïmme dieser Nerven erstreckt, oder aus einem derselben 
hervorgeht, sondern in der That eine Schlinge rom Ganglion des einen Systems direct zu demjenigen des anderen bildet. Der betreffende, meist sehr schwer darzustellende Nervenfaden erstreckt sich, meist dem Schädel ganz dicht anliegend, vom Ursprunge des Fucinlis nach hinten zu demjenigen des Glossopharyngems. Nur bei Amphiuma (Taf. V, Fig. 2, 9c) ist die Darstellung dieses Nerven leicht. Er wird hier schon gesehen, wem die mediale Partie des ihn von aussen her bedeckenden Digastricus weggeräumt ist. - - Ob die von mir vorausgesetzte Dentung richtig ist, wird sich nur durch Untersuchung der Primitivröhren an frischen Exemplaren entscheiden lassen.

Ausser dieser Verbindung zwischen Facialis und Glossopharyngeus existiert jedoch noch eine zweite, die aber, wo sie vorhanden ist, nicht als Schlinge von Ganglion zu Ganglion, sondern als wirklicher. Verstiirkungsast des Glossopharyngeus zum Fuciulis, als eigentlicher, auch bei den Ecaudata und den Salamandrinen vorhandener $R$. communicuns auftritt. Er ward beobachtet bei Siredon, Acropoma, Amplimma, und ist von Schmidt, Goddart und van der Hoeven (vgl. das angeführte Werk, S. 57) auch von Cryptobranchus juponims (und zwar hier als doppelter Verbindungszweig) beschrieben. Ich vermisste ihn bei Siren und Menobranchus. Seine Abwesenheit bei Hypochthon habe ich bereits früher ${ }^{1}$ ) erwähnt.

Es ist schwer, auf rein anatomischem Wege ein Urtheil über die Natur dieses Ramus communicans zu bilden. Bass er mit dem erst beschriebenen Kopftheil des Sympathicus nicht zu verwechseln sei, geht theils aus seiner Form, theils auch daraus hervor, dass zuweilen (Amphiuma) beide Nerven gleichzeitig vorhanden sind. Er senkt sich, wo er sich fudet, stets mit Uebergehung aller iibrigen Facialis-Stämme in den $R$. jugularis ein.

1) Amphib. nudor. neurolog., 1843 , pag. 36. 


\section{N. glossopharyngeus und N. vagus.}

In der Regel sind die diesen beiden Nerven angehörigen Elemente schon in der Schïdelhöhle so mit einander verschmolzen, dass sie das Forumen jugulure als gemeinschaftliche Austrittsoffnung benutzen. In diesem Falle ist es schwer, die einem jeden derselben zugehörigen Elemente zu scheiden. Bei Siron lacertinu hat der Glossmpharyngeus ein eigenes, etwas vor demjenigen des Vagus gelegenes Loch. Hier und bei Amphiuma, wo das Ganglion des Vargus von dem mit ihm in gemeinschaftlicher Schädelüfnung liegenden Glossopharyngeus durch eine leichte Einschnürung abgesetzt erscheint, gelangt man zu dem Schlusi, dass dem Glossopharyngeus folgende Zwweige zuzuschreiben sein dürften: 1) Eine sympathische Schlinge mit dem Ganglion des Facialis; 2) der (nicht immer vorhandene) Rumus communicans mit dem Romus jugularis des Faciulis; 3) ein Rumus pharyngus; 4) ein Rumus lingualis; 5) der erste hiemenuerv. Dem Vagus selbst gehören dagegen: 1) der zweite und (wenn vorhanden) dritte Kiememnerv; 2) die Zweige für den $\boldsymbol{M}$. curullaris; 3) der auch den Ramus recurrens enthaltende Ramus intestinalis; 4) ein aus letzterem hervorgehender $N$. lateratis inferior sive superficialis; 5 ) ein meist direct aus dem Ganglion entspringender und gewöhnlich in zwei Aesten verlaufender $N$. Tuteralis superior sive profundus.

Bei Siredon pisciformis sind die Elemente beider Nerven mit einander verschmolzen. Aus dem grossen, platten, kreisfürmig-ovalen Ganglion (Taf. II, $B$ ) treten folgende Nerven hervor:

1) Der Ramus communicans (k) mit dem $R$. jugularis (i) des Facialis. Er nimmt auf seinem Wege nach aussen und vorn gleich nach seinem Ursprunge noch einen (in der Figur angedeuteten) Faden aus dem Romus phrryngcus (ph) des Glossopharyngeus (gl) auf und senkt sich in den $R$. jugularis des $F^{\gamma}$ uciulis ein, der durch ihn um etwa die Hiilfte verstärkt wird. 
2. Der $R$. lingualis oder Glossopharyngeus $(g l)$. Gleich nach seinem Ursprunge entlïsst er zwei feine Nerven, die sich nach rorn wenden und vou der Dorsalseite aus sich an der Haut des Schlundes ausbreiten. Einer derselben ( $p h$ ) geht bis zu dem eben beschriebenen $R$. commuicans, um mit ihm zu verschmelzen. - Nach Abgabe der Schlundnerven verfolgt der Glossopharyngues seinen Wegr nach aussen und hinten und tritt von $i_{n n e n}$ her an den $\boldsymbol{M}$. levator arcus primi $\left(l a^{\prime}\right)$ heran. Hier giebt er einen feinen Zweig ab, der mit einem 'Zweige des folgendes Astes zu cinem Stanm verschmilzt; dieser dringt in das erste Kiemenbiischel ein und verbreitet sich in dessen Haut und Muskeln. - Der Glossopharyngeus selbst tritt dann ebenfalls von innen her an den Levator arcus primi heran, geht durch ihn hindurch, indem er ihn mit Zweigen versorgt. und tritt in die hintere Partie der gemeinschaftlich entspringenden Min. Cerctolyguidens extemus und Mylohyoideus posterior. Er gielst denselben Zweige und tritt endlich himiiber an das Dorsalsegment des ersten Kiemenbogens. An der lateralen und ventralen Fläche des letzteren läuft unser Nerv nun nach vorn bis zum $\boldsymbol{M}$. ceratohyoideus interms, an den er von aussen herantritt. Dorsalwärts von diesem Muskel und demselben dicht anliegend lïuft er nun mach vorn bis zum Punkt der vorderen Insertion desselben. Hier tritt er von der Ventralseite her an den Winkel, den das Zungenbeinhorn mit dem Zungenbeinkörper bildet. und steigt nun in die Höhe bis zum Boden der Mundhöhle.

3. Es folgt der für das erste und zweite Kiemenbiischel bestimmte Nerv (br). Dieser tritt ebenfalls schrïg nach hinten und aussen, hinter dem langen Ligament, wodurch die dorsale Spitze des Zungenbeinhorns an den Schädel befestigt ist. Vor dem Levator arcus secundi $\left(l \alpha^{\prime \prime}\right)$ tritt er unter dem zweiten Lappen der Thymus-Drüse (d) und über das dorsale Ende des zweiten Kiemenbogens fort nach hinten und theilt sich in zwe Hauptzweige:

a. Einer derselben verschmilzt mit dem erst beschriebenen Aste des Glossophuryngens zu dem für die Muskeln und die Haut des ersten Kiemenbïschels bestimmten Nerven.

b. Der zweite, sehr feine, wendet sich nach unten und verschmilzt mit einem Aste des folgenden Stammes zu einem, für die Muskeln und die Haut des zweiten Bïschels bestimmten Nerven.

4. Der vierte aus dem Ganglion des Vagus austretende Stamm $\left(b r^{\prime}\right)$ enthält Fasern für das zweite und dritte Kiemenbiischel. Etwas medialwärts vom dritten Stamm verläuft dieser ebenfalls nach hinten, tritt zwischen den Levatores arcus secundi (7 $\left.a^{\prime \prime}\right)$ und arcus 
tertii (/ $\left.{ }^{\prime \prime \prime}\right)$, denen er Zweige giebt, nach aussen, geht über dats dorsale Fnde des dritten Kiemenbogens fort und theilt sich in zwei Aeste:

a. Der vordere verschmilat mit dem erst beschriebenen / weige des dritten Stammes zu dem für das zweite Büschel bestimmten Nerven.

b. Der bei weitem stärkere hintere geht in das dritte Kiemenbüschel und versorgt dessen Haut und Muskeln.

5. Ramus accessorius (rechte Seite der Figur, a). Dieser, beträchtlich feiner als die vorigen, geht schriig nach aussen und hinten, tritt von innen her an die dorsale Partie des Dorsolaryngeus heran und versorgt ihn, wie den benachbarten Cucullaris ${ }^{1}$ ) mit Zweigen.

6. Ramus cutanens. Dieser, nicht bei allen Gattungen als selbstståndiger Stamm ausgebildete Nerv (auf 'Taf. II mit $b{ }^{\prime \prime}$ bezeichnet) tritt von innen her an die Lappen der Thymus-I)riise heran und verbreitet sich theils in diesen, theils in der sie bedeckenden Haut vor und über der Kiemenspalte.

7. Der Ramus intestinalis. der stärkste aller Stämme (in). Er geht schräg nach hinten und aussen, letztere Richtung so weit verfolgend, dass er auf eine kurze Strecke noch lateralwärts von der Knorpelplatte des Schulterhlattes, zwischen dieser und dem $\boldsymbol{M}$. curulluris zu liegren kommt. Gerade an letztereu Muskel entsendet er hier einen Zweig, geht dann nach unten und innen und theilt sich in drei Aeste:

a. Der erste und feinste derselben ist der $N$. lateralis inferior. Er tritt lateralwärts vom gleich $\mathrm{zu}$ beschreibenden $R$. recurrens, sowie vom ersten und zweiten Halsnerven (Hypoglossus) nach unten und hinten, medialwärts vou der knöchernen Basis des Schulterblatts. Hinter letzterem und dessen Muskeln tritt er an die Haut. Unter derselben verfolgt er nun seinen Weg wach hinten, stets am unteren Drittheil der Seitenfliche verlaufend. Er ist etwa ebenso stark, wie der untere

1) Der $\boldsymbol{M}$. cucullaris ist hei fast allen Perennibranchiaten sehr entwickelt. Bei Siredon, Menobranchus u. A, entspringt derselbe breit von der an die Processus spinosi der ersten Rückenwirbel und an das Hinterhaupt angehefteten, mit der Haut verbundenen Fascia dorsalis, geht vor dem vorderen Rande des Schulterhlattes sich zuspitzend abwärts uni heftet sich in den nach vorn offenen Winkel, den die Pars scapularis des Schultergerüstes mit der Pars clavicularis bildet. - Er fehlt dem Frosche. Der von Ecker (S.84) als M. cucullaris heschriebene Muskel ist bei den Perennibranchiaten ausser dem obigen ebenfalls vorhanden, kann also wohl nicht mit diesem Namen bezeichnet werden. Cuvier's Vergleich mit dem Mr. levator anguli scapulae dürfte zutreffender sein. - Unser $M$. cucullaris der Perennibranchiaten belommt immer seine Nerven aus der Bahn des Vayus, der von Ecker unter jenem Namen verstandene Muskel dagegen von einem Spinalnerven. 
der beiden später zu beschreibenden, oberen Seitennerven. In seinem Verlaufe beständig schwächer werdend, liess er sich nur bis zur Gegend des Afters verfolgen.

b. Ramus recurrens, bedeutend stärker, als der vorige. Er krümmt sich medialwärts von dem ihn kreuzenden ersten Halsnerven nach rorn, tritt von aussen und hinten her an die Ventralfläche des $\boldsymbol{M}$. hyotrachealis und verläuft unter dessen Fasern schräg nach innen und vorn, beständig feine Zweige in diesen Muskel, so wie anfangs auch in den Dorsotrachealis aussendend. Ein feiner Endzweig liess sich bis zur Stimmlade verfolgen.

c. Der Rest des $R$. intestinalis geht medialwärts von den zwei ersten Halsnerven nach hinten und theilt sich in zwei Aeste, deren Endigungen sich in die Substanz der Lunge, so wie an Magen und Speiseröhre verfolgen liessen.

8. Der letzte aus dem Ganglion des Vagus austretende Stamm ist der N. lateralis superior $(l)$. Dieser theilt sich gleich nach seinem Ursprunge in zwei Zweige. Der eine, etwa halb so fein wie der andere, wendet sich schräg nach oben und hinten und läuft, nicht weit von der Mittellinie des Rückens, dicht unter der Haut nach hinten. Ich habe ihn bis zur Gegend der hinteren Extremitäten verfolgt, wo seine fast mikronkopische Feinheit ihn der weiteren Untersuchung entzog. - Der zweite, stärkere Ast des Lateralis superior geht gerade nach hinten, tritt medialwärts vom Rande des knorpeligen Schulterblatts durch und verläuft in der Tiefe, an der Grenze der dorsalen und ventralen Seitenmuskeh. Hinter der Gegend der Hinterbeine verlïsst er die Seitenlinie und wendet sich nach oben, um der Mittellinie des Rückens näher seinen Weg fortzusetzen, bis auch er sich durch ausserordentliche Feinheit der Beobachtung entzieht.

Auch bei Menobranchus ist der Glossopharyngeus mit dem Vagus vereint. Diese Gattung unterscheidet sich aber noch dadurch von allen übrigen, dass letzterer Nerv, weun auch nur für eine kurze Strecke, die Elemente des Hypoglossus in sich aufnimmt.

In folgender Ordnung (von vorn nach hinten gezählt) entspringen die einzelnen Aeste aus dem Ganglion (vgl. Taf. VI, Fig. 8, wo dieselben mit den in dieser Beschreibung gewählten Buchstaben und Zahlen bezeichnet sind): 
1. Ein ganz vorn aus dem Ganglion austretender feiner Nervenstamm theilt sich gleich nach seinem Ursprunge in zwei Theile:

a. Der Kopftheil des Sympathicus. Dieser wendet sich, dem Os occivitale laterale und dem Felsenbein ganz dicht anliegend, nach aussen und vorn bis zur Austrittstelle des Facialis, wo er sich (als Nerv $s$ ) in dessen Ganglion (C) einsenkt.

b. Rames pharyngeus. Dieser geht geradeswegs nach aussen und theilt sich in mehre Zweige, die sich an der hinteren Partie der Gaumenhaut und des Schlundes von der Dorsalseite her ausbreiten. Einige dieser Zweige lassen sich fast bis zur Ecke des Unterkiefers auf der Haut des Schlundes verfolgen.

2. Der zweite Vagusast $\left(2^{10}\right)$, beträchtlich stärker als der erste, låuft unter dem Levator arcus primi nach aussen, giebt auf diesem Wege einen feinen Zweig nach oben in diesen Muskel und theilt sich dann in zwei Aeste von gleicher Stärke:

a. Ramus glossopharyngeus. Der erste tritt von innen her an das Dorsalsegment des ersten Kímenbogens heran und läuft an dessen Convexität nach unten, vorn und innen, bis zum Gelenk dieses Bogentheils mit seinem Ventralsegment. Hier tritt er von aussen her an den $\boldsymbol{M}$. ceratohyoideus intermus heran, giebt ihm Zweige und låuft auf dessen dorsaler Fläche weiter nach vorn bis zu dem Winkel, den das Zungenbeinhorn seiner Seite mit dem Zungenbeinkörper bildet. Hier tritt er in die Höhe, indem er letzteren durchbohrt, und scheint in der Schleimhaut des Mundes zu endigen.

b. Ramus branchiac primae et secundae. Der andere Zweig unseres zweiten Astes steigt vor dem Levator arcus primi, hinter und lateralwärts vom $\boldsymbol{M}$. ceratohyoidens externus, dem er an dessen Ursprung Zweige giebt, zwischen diesem und dem nach hinten vorquellenden MIasseter in die Höhe, wendet sich nach aussen und hinten und tritt zwischen den dorsalen Spitzen des ersten und zweiten Kiemenbogens nach aussen. Hier theilt or sich in drei Aeste:

$\alpha)$ in die Haut vor der Kiemenspalte;

$\beta)$ in das erste Kiemenbüschel und dessen Muskeln;

$\gamma$ ) der dritte geht nach hinten, lateralwärts und vor der dorsalen Spitze des zweiten Kiemenbogens lierum, und verbindet sich mit einem ihm entgegen kommenden Aste $(3 \delta)$ des folgenden Stammes zu einer Schlinge, aus welcher ich keine Zweige hervorgehen sah.

3. Der dritte aus dem Ganglion hervorgehende Stamm $\left(3^{10}\right)$ ist stårker als der vorige. Er tritt unter dem Lcvator arcus primi nach hinten, und hinter demselben nach 
oben, so dass er durch letzteren rom zweiten Stamme getrennt ist. Auf seinem Verlaufe nach aussen giebt er folgende Zweige ab:

a) Mehre feine Fäden für die Schleimhaut der Rachenhöhle medialwärts von den Kiemenspalten;

B) eimen feinen Zweig hinter und unter der dorsalen Spitze des ersten Kiemenbogens nach vorn an die Haut des ersten Kiemenbüschels;

r) mehre Muskelzweige in den Levator arcus secundi.

Nach Abgabe dieser Zweige steigt unser Nerv nach oben. For der dorsalen Spitze des zweiten Kiemenbogens theilt er sich in zwei Theile.

a. Der erste derselben spaltet sich gleich wieder in zwei Aeste:

d) Von diesen wendet sich der eine nach rorn, um mit dem erst beschriebenen Nerven $(\gamma)$ des zweiten Stammes zu einer Schlinge zu verschmelzen;

ع) der zweite tritt zwischen den dorsalen Spitzen des zweiten und dritten Kiemenbogens nach aussen, giebt hier einen Nerven an den $M$. levator branchiae tertice und läuft nun an der Convexität des zweiten Kiemenbogens nach vorn. An dem $\boldsymbol{M}$. constrictor arcum tritt er von jenem Bogen ab, läuft dorsalwärts von diesem Muskel nach innen und tritt dann unter dem $\boldsymbol{M}$. ceratohyoidens internus fort, versorgt ihn mit läden und steigt ror ihm in die Höhe in dem Winkel, den die drei Kiemenbogen beider Seiten mit einander bilden.

b. Der zweite Theil unseres dritten Vagusstammes giebt ab:

5) 'Lweige in die Haut des zweiten und des dritten Kiemenbüschels;

3) einen 'Zweig nach hinten zur Bildung einer Schlinge mit dem dritten Kiemennerven (dem vierten Stamme).

4. Der vierte Stamm des Vagus $\left(4^{10}\right)$ läuft neben dem dritten als sehr feiner Nerv schräg nach aussen und hinten, tritt zwischen den $\mathbf{I T m}$. levatores arcus secundi und arcus tertii nach aussen und entsendet:

a. Einen feinen Zweig nach unten. Dieser läuft längs der Convexität des dritten Kiemenbogens abwärts und scheint sich in der denselben bedeckenden Schleimhaut auszubreiten.

b. Einen Zweig nach vorn, der sich mit dem eben unter $\eta$ ) beschriebenen Aste des dritten Stammes zu einer Schlinge verbindet. Er selbst $(4 c)$ dringt alsdann in das dritte Kiemenbiischel ein und verbreitet sich in dessen Haut und Muskeln. 
5. Der fünfte aus dem Ganglion hervorgehende Stamm $\left(5^{10}\right)$ ist der stärkste von allen. Gleich nach seiner Trennung von den übrigen Stümmen entlässt er:

a. Den $N$. lateralis supcrior $(l s)$. Dieser theilt sich bald nach seinem Ursprunge in zwei Aeste:

a) der obere, viel feiner als der untere, läuft medialwärts vom oberen knorpeligen Rande des Schulterblatts nach hinten, tritt hinter dem letzteren zwischen die oberflächlichen Faseru der epaxonischen Partie des Seitenmuskels und verläuft zwischen diesen nach hinten, beständig etwa zwei Linien von der dorsalen Mittellinie entfernt;

ß) đer untere, viel stärkere tritt über das knorpelige Ende des dem dritten Wirbel angehörigen Querfortsatzes fort nach hinten und verfolgt nun seinen Weg in der Seitenlinie selbst, beständig über die Querfortsätze der Wirbel forttretend. Am Schwanze noch liegt er in der Seitenlinie, etwa am oberen Drittheil der Höhe.

Der Hauptstamm selbst verfolgt nach Abgabe der oberen Seitennerven seinen Weg nach hinten. An der Gegend der Kiemenspalte angelangt, entlässt er:

b. Einen feinen Zweig in die dorsale Partie des $\boldsymbol{M}$. dorsotrachealis.

c. Einen ebenso feimen nach vorn an den $M$. omopharyngeus ${ }^{1}$ ).

d. Einen Zweig in den $\boldsymbol{M}$. cucullaris.

e. Den stärksten von allen, den $R$. intestinalis, der sich bald spaltet und an den Eingeweiden der Rumpf höhle ausbreitet.

Der Rest unseres Nerven theilt sich in zwei 'Theile von fast gleicher Stärke:

f. Der eine von ihnen, $R$. recurrens, wendet sich nach innen und verläuft ventralwiirts von den Fasern der Mm. dorsotrachealis und hyotrachealis schräg nach innen und vorn. Auf seinem Wege giebt er Zweige an diese beiden Muskeln, an den Constrictor arcum und an die Adductores arcum. Ein feiner Endfaden liess sich bis zur Stimmlade verfolgen.

g. Der zweite verschmilzt mit dem aus den Rami descendentes des zweiten und dritten Halsnerven (II $h$ und III $h$ ) gebildeten Nerven ( $h a)$ zu einem kurzen Stamm $(s)$, der sich bald wieder in zwei Theile spaltet.

1) Dieser Muskel erstreckt sich vom vorderen Rande der knöchernen Scapula nach vorn an diesel be Inscriptio tendinea, die dem Dorsotracheal is zur Insertion dient. 
c) der eine $(h g)$ ist als $R$. hypoglossus zu bezeichnen und enthält nach der Analogie mit den übrigen Gattungen die den beiden genannten Halsnerven entsprechenden Elemente. Er tritt hinter den Fasern des Dorsotrachealis nach aussen, läuft medialwärts vom Stemokleidomastoideus nach unten und krümmt sich an der lateralen Fläche des Sternohyoideus nach vorn. An der Bauchkante angelangt, giebt er einen feinen Faden nach aussen an die vom Schulterblatt entspringende, den M. stcmoradialis bedeckende Partie des Sternohyoideus, läuft damn an dessen lateraler Kante, lateralwärts von der äusseren Kante der Pars clavicularis des Schultergerüstes nach vorn und versorgt den Sternohyoideus mit Zweigen. Schliesslich tritt er von der Dorsaltläche her in den MI. geniohyoidens ein und breitet sich in demselben aus;

$\beta$ ) der zweite, $R$. lateralis inferior (Ii) wendet sich nach hinten bis zu dem Winkel, den die Pars scapularis des Schultergerüstes mit der Pars clavicularis bildet, tritt medialwärts vom Schultergerüst nach hinten und dann an die Haut. Der letzteren dicht anliegend, geht er uach hinten, in seinem Verlaufe immer dünner werdend. Ich habe ihn über die Mitte der Körperlänge verfolgt.

Bei Siren ist der Glossopharyngeus schon beim Austritt aus dem Schädel rom Vagus getrennt. Er hat seine eigene Austrittsöffnung im Os occipitule laterale, dicht vor derjenigen des Vagus, von der die seinige durch eine schmale aber feste Knochenbrücke getrennt ist.

Gleich bei seinem Austritt erscheint der Glossopharyngeus in drei Theile gespalten.

a. Ein sehr feiner, der sich, dem Knochen dicht anliegend, nach vorn wendet, um in das Ganglion des Facialis einzutreten. Wir haben diesen Nerv bei den übrigen Gattungen als Kopftheil des Sympathicus bezeichnet.

b. Ramus lingualis. Er tritt nach aussen und hinten, um das dorsale Ende des Zungenbeinhorns herum, durchbohrt von innen her den starken $\boldsymbol{M}$. levator arcus primi und versorgt ihn mit Zweigen. Er tritt dann von der medialen Seite her an den $M$ r. ceratohyoideus externus, dem er ebenfalls Zweige giebt, und dann an 
das Dorsalsegment des ersten Kienenbogens, um, demselben dicht anliegend, nach unten zu laufen. Ganz an der Ventralfläche des Körpers angelangt, theilt er sich in zwei Theile:

a) der eine, sehr feine, geht nach oben an die Haut des Schlundes;

$\beta)$ der zweite, stärkere (Taf. VI, Fig. 4, b $\beta$ ), tritt über den $\boldsymbol{M}$. constrictor arcum $(c a)$ fort. Vor diesem Muskel hervorgetreten, verschmilzt dieser Nerv mit dem Ende des gleich $z u$ beschreibenden dritten Astes $(c b)$ zu einem Stamm $(x)$, der ventralwärts rom $\boldsymbol{M}$. cercutolyyoideus internus nach vorn läuft und sich in ihm ausbreitet.

c. Der dritte Stamm des Glossopharyngens enthält Elemente für das erste und zweite Kiemenbüschel. Auch er tritt nach aussen und hinten, läuft jedoch etwas mehr dorsalwärts, als der zweite Stamm. Er tritt von innen her an den $\boldsymbol{M}$. levator arcus secundi heran, versorgt ihn mit Zweigen und dringt, in drei Aeste gespalten, durch seine Fasern hindurch nach aussen über den Zwischenraum zwischen den dorsalen Spitzen der beiden ersten Kiemenbogen. Von diesen drei Zweigen geht

a) der zuerst abgegebene nach hinten und verschmilzt mit einem Zweige des folgenden Stammes zu einem, an Haut und Muskeln des zweiten Kíemenbüschels sich ausbreitenden Nerven;

$\beta)$ von den beiden anderen, länger mit einander verbunden gebliebenen Zweigen geht der eine in das erste Kiemen büschel;

y) der dritte (Taf. VI, Fig. 4, cl) läuft an der lateralen Flïche des dem zweiten Kiemenbogen angehörigen Dorsalsegments $\left(b^{\prime \prime}\right)$, dem letzteren dicht anliegend, nach unten und innen, tritt über den Constrictor arcum (ca) fort, wendet sich dann nach vorn und verschmilat mit dem vorhin unter $b \beta$ beschriebenen Endzweige des Ramus lingualis.

Aus dem Ganglion des Vagus selbst entspringen bei Siren zunächst noch einige für die Kiemen bestimmte Zweige:

1. Der erste tritt vorn an den $\mathbf{M}$. levator arcus tertii heran und giebt ab:

a. Finige feine ' Zweige für diesen Muskel.

b. Einen Zweig, der vor demselben nach aussen tritt, um mit dem folgenden Stamm zu verschmelzen.

c. Das Ende dieses ersten Stammes selbst geht weiter zwischen den MIm. levatores arcum primi et secundi nach aussen, tritt über den Zwischenraum zwischen den dorsalen Spitzen des ersten und zweiten Kiemenbogens von innen her an den (bei 
dieser Gattung einzigen) $\boldsymbol{M}$. levator branchiae tertiae (vgl. S. 38), versorgt ihn mit

Zweigen und geht medialwärts von demselben in das dritte Kiemenbüschel hinein.

2. Der zweite Stamm des Vagus ist viel schwächer, als der vorige. Auf seinem Wege nach aussen und hinten giebt auch er einen Zweig an den $\boldsymbol{M}$. lecutor arus tortii, tritt dann zwischen den 1 Lm. levatores armum tertii et quarti durch nach aussen und verschmilat mit dem erst unter 1, b beschriebenen Zweige des ersten Astes zu einem Stamm. Letzterer dringt von hinten und innen her in das dritte Kiemenbuischel ein und verbreitet sich in dessen Haut.

3. Der dritte Stamm ist nur für den $M$. levator arcus quarti bestimmt. Er tritt als feiner Nerv von innen und vorn her an diesen Muskel beran und löst sich ganz in ihm auf.

4. Der vierte Stamm ist der stärkste von allen. Gleich nach seinem Ursprung entsendet er den

a. Nervus lateralis superior. Dieser theilt sich sofort wieder in zwei Theile:

c) Der feinere, $N$. lateralis superior superficialis, tritt nach oben und medialwärts vom oberen Rande des knorpeligen Schulterblatttheils nach hinten. Er verläuft unter der Haut, nur wenige Linien von der dorsalen Mittellivie entfernt;

$\beta)$ der stärkere, $N$. lateralis superior profundus tritt zwischen die Fasern der epaxonischen Rïckenmuskeln ein und lïuft über die Enden der Rippen und Querfortsätze der Wirbel fort nach hinten. Nachdem auch er medialwärts vom Schultergerüste durchgetreten ist, verfolgt er seinen Weg in der Seitenlinie selbst.

b. Einen Zweig an den $M$. dorsotrachealis, an dessen Fasern derselbe von innen her herantritt.

Indem nun der Stamm auf seinem Wege nach hinten bis fast zur Gegend des Schultergerüsts gelangt ist, entsendet er:

c. Den starken Ramus recurrons. Dieser tritt nach aussen, schlingt sich um den 11. dorsotrachealis herum, wendet sich danm nach vorn und entlässt folgende Lweige:

a) einen Zweig (Taf. VI, Fig. 4, a) für den $\boldsymbol{M}$. constrictor arcum (ca);

$\beta$ ) einen anderen $(\beta)$ für den $\boldsymbol{M}$. protractor arcus quarti $(p r)$;

$\gamma$ ) einen dritten $(\gamma)$ für den $\boldsymbol{M}$. hyotrachealis $(h p)$ und den $\boldsymbol{M}$. dorsotrachealis $(d p)$. Dieser Zweig läuft längs unseres $\boldsymbol{M}$. dorsolaryngeus $(d l)$ an 
dessen medialer Seite nach vorn bis zur Stimmlade. Zwei seiner feinsten Zweige $(s, s)$ treten kurz hinter der letzteren und an der Ventralseite derselben quer zur anderen Seite hinüber und verschmelzen mit den entsprechenden Zweigen der letzteren zu zwei Schlingen, aus denen keime Fasern hervorgeheu. - Der Rest unseres Nerren steigt bis zur Stimmlade nach voru an und verzweigt sich in dem $\boldsymbol{M}$. constrictor aditus larymgis $(c l)$ und im $\boldsymbol{M}$. dorsolaryngeus kurz hinter dessen vorderer Insertion.

d. Aus dem vierten Stamm des Vagus entspringt ferner ein feiner Zweig für den $\boldsymbol{M}$. adductor branchiae tertice (vgl. S. 39).

e. Endlich noch der Nenus lateralis inferior. Dieser tritt medialwairts rom Schultergerüst nach linten und rerfolgt diese Richtung dicht unter der Haut am unteren Drittheil der Körperhöhe.

f. Der Rest unseres vierten Stammes ist der Romus intestinalis. Er tritt medialwärts vom $N$. hypoglossus nach hinten und innen, um sich an den Eingeweiden zu verbreiten. Seine Terzweigung ward nicht bis ins einzelne verfolgt.

Nach den vorstehenden Specialbeschreibungen des Vagus bei Siredon, Menobranchus und Siren düfte eine ebenso detaillierte Schilderung seines Verhaltens bei Menopoma und Amp hiuma übertlüssig sein. In der That sind die Abweichungen äusserst gering. Sie sind nur darin von einigem Interesse. dass die bei den Perennibranchiaten fïr die Kiemenbüschel und deren Muskeln bestimmten Zweige bei den Derotremen (und C'mptobranchus) zwar an eben derselben stelle vorhanden sind, wie bei jenen, aber lediglich die Haut dieser Gegend versorgen.

Bei Menopoma ist der Glossopharyngens mit dem Vagus verschmolzen. Das Ganglion (Taf. IV, Fig. 1, B) liegt ganz ausserhalb des Schildels. Aus demselhen gehen hervor:

1. Ein $R$. communicans $(k)$ cum nervo faciali. Dieser verbindet sich mit dem $R$. jugularis des letzteren gleich nach dessen Ursprung.

2. Ramus accessorius. Ein ganz kurzer Nerv, der sich gleich mach seinem Ursprung nach uben in die tiefen Nackenmuskeln schlingt und sich im M. introtrunserwarus cupitis inferior (Ecker) ausbreitet.

3. R. pharyngens. Ein schwacher kurzer Nerv, geht gleich nach seinem Ursprunge nach unten und breitet sich an der Haut des Schlundes aus. 
4. Ramus glossopharyngeus (Taf. IV, Fig. 1 und 2, gl) sive lingualis. Ein starker Stamm, der an der Ventralseite des Curtohydudcus (ceh) nach rom und endlich zwischen die Fasern des letzteren eintritt und ihn mit Zweigen versorgt. Er endet hinter der Einlenkung des ersten Kiemenbogens an den Zungenbeinkörper mit feinen, nach oben an die Haut der Mundhöhle tretenden Zweigen.

5. Ein dem ersten Kiemennerven der Perennibranchiaten analoger Stamm (br). Er tritt von innen her an den $\boldsymbol{M}$. levator arcus secundi $\left(l_{\boldsymbol{t}}\right)$ heran, giebt ihm und der Glandula thymus der Autoren (linke Seite von Fig. 1, d), sowie der Haut vor der Kiemen. spalte starke Zweige $(r c)$, läuft dann $(\pi)$ medialwärts vom M. ceratohyoideus externus nach vorn, um ebenfalls an der ventralen Haut der Mundhöhle zu endigen.

6. Der Hauptstamm des Vagus entlässt bald nach seinem Ursprunge den zweiten Kiemennerv $\left(b r^{\alpha}\right)$, der den Levator areus tertii und die Haut vor der Kiemenspalte versorgt. Er selbst $(i n)$ entsendet Zweige an den $M$. cucullaris, an den $M$. dorsotrachealis, kreuzt sich mit dem ersten Halsnerven (Hypoglossus), ohne mit ilım, wie bei Mcnobranchus, zu verschmelzen, giebt den $I$. recurrens an die Muskeln der Luftröhre und Stimmlade ab, und verbreitet sich schliesslich als $R$. intestimalis an den Eingeweiden der Rumpfhöhle.

7. Der R. latcrulis superior $(l)$. Dieser läuft eine Strecke auf der dorsalen Kante des $\boldsymbol{M}$. trachelomastoideus. Kurz vor dessen hinterer Insertion wendet er sich von diesem ab und tritt medialwärts zwischen die Fasern der geraden Nackenmuskeln, zwischen denen er bis zur dritten Rippe verläuft. Hier tritt $\mathrm{er}^{\mathrm{in}}$ die tiefe Seitenlinie ein, in der er immer über die Enden der Querfortsätze der Wirbel forttretend, nach hinten läuft.

Die Verbreitung des Vagus bei Lmptiuma erinnert noch melr als bei Menopoma an die Formen der Perennibranchiaten.

Das im Knochenkanale selbst liegende Ganglion ist durch eine leichte Einschnürung in zwei Theile getheilt, von denen einer, wie es scheint, dem Glossopharyngus, der andere dem Vagus selbst entspricht. - Aus dem vorderen kleineren Theile des Ganglions gehen hervor:

1. Der oben (S. 136) erwåhnte Kopftheil des Sympathicus (Taf. V, Fig. 2, 9c).

2. Der Ramus communicans cum nervo faciali $\left(9 c^{\prime}\right)$; dieser verschmilat mit dem $R$. jugularis des letzteren.

3. R. glossopharyngeus sive lingualis. Dieser tritt an der medialen Fläche des ersten Kicmenbogens nach innen und unten und kommt an der Ventralfliche des Thieres. 
medialwirts rom $\boldsymbol{M}$. cratohyoideus exterms zum Vorschein. Er versorgt den letzteren Muskel. und steigt dicht hinter dem Zungenbeinkörper bis zum Boden des Mundes in die Höhe.

4. Der erste Kiemennerv. Dieser versorgt die Haut vor der Kiemenspalte, giebt Zweige an die Haut des Schlundes und läuft an der Convexitït des zweiten Kiemenbogeus nach unten, tritt medial- und dorsalwärts rom Constrictor arcum, dem er Zweige giebt, nach innen, und steigt vor diesem Muskel als feiner Nerv in die Wöhe an die Schleimhaut des Mundes.

Aus dem hinteren grösseren Abschnitte des Ganglion entspringen folgende Zweige:

5. Der zweite Kiemennerv. Ein sehr feiner Stamm. Versorgt die Haut dorsalwärts von der Kiemenspalte und die Thymus-Drüse (Taf. V, Fig. 1, d), giebt Zweige an die $\mathbf{M} \mathrm{m}$. levatores arcum tertii et quarti und läuft als feiner Faden an der Convexität des dxitten Kiemenbogens nach innen und unten. Sein Ende war zu fein, um seine schliessliche Ausbreitung ermitteln zu lassen.

6. Der folgende Stamm ist der stärkste von allen. Gleich nach seiner Isolierung von den übrigen Stämmen entlässt er:

a. Den $N$. lateralis superior. Dieser theilt sich bald nach seinem Ursprunge in zwei Aeste. Der feinere, $N$. lateralis superior superficialis, läuft der Mittellinie des Rückens ziemlich nahe unter der Haut nach hinten. - Der stärkere, $N$. lateralis superior profundus, tritt in die Fasern der geraden Nackenmuskeln ein und läuft, zwischen denselben versteckt, nach hinten. Er tritt über die Enden der Querfortsätze der Wirbel fort. - Beide Zweige wurden bis zum Anfang des zweiten Drittheils der Körperlänge verfolgt.

Nach Abgabe des $N$. lateralis superior wendet sich der Hauptstamm nach unten und hinten, medialwärts vom $\boldsymbol{M}$. dorsotrachealis, und liümmt sich hinter der Liemenspalte abwärts. Auf seinem Wege hierher entsendet er:

b. Zwei feine Zweige in den $\boldsymbol{M}$. dorsotrachealis.

c. Den $R$. lateralis inferior. Dieser verläuft medialwärts von der Pars scapularis des Schultergerüstes nach hinten, tritt dicht an die Haut und verfolgt, der letzteren dicht anliegend, seinen Weg an der Bauchkante des Thieres. Ich verfolgte seinen Verlauf bis auf ein Drittheil der Körperlänge, ohne eine Abnahme seiner schon anfangs sehr geringen Stïrke zu bemerken. 
Aus den vorstehenden Beschreibungen ergiebt sich eine so grosse Uebereinstimmung des $N$. vagus in seiner Verbreitung bei den einzelnen Gattungen, dass die Form einer ein. zigen als der Typus für alle übrigen gelten kann. Zugleich aber ergiebt sich auch eine grose Tehereinstimnung zwischen der Anordnung der Vugu-Zweige bei den salamantrinen und derjenigen der Perennibranchiaten und Derotremen. Ueber die Form der ersteren und die muthmassliche Natur der einzelnen, dem Glossopharyngeus und Vagus angehörigen Elemente habe ich mich in meiner friheren Schrift ausgesprochen. Im folgenden sollen daher nur einige Punkte hervorgehoben werden, die durch meine jetzigen Untersuchungen ein specielleres Interesse erlangen dürfteu.

\section{Der Kopftheil des Sympathicus und der R. communicans cum nervo faciali.}

Es ist schon oben (S. 139) erwïhnt, dass es schwer halten dïrfte, auf rein anatomischem Wege über die Natur dieser beiden Nerven ins Klare zu kommen. Der erstere, rom Ganglion des Vagus (Glossopharyngeus) zu demjenigen des Fucialis, scheint uiberall vorbanden zu sein. Die Darstellung dieses äusserst feinen Nervenfadens ist bisweilen sehr schwierig, da er dem Knochen (Os occipitale laterale und Felsenbein) oft so dicht anliegt, dass er nur sehr schwer vom Periosteum zu isolieren ist. Daher die Vermuthung, dass er auch bei Menopoma, der einzigen Gattung, wo ich mich von seinem Dasein nicht überzeugen konnte, nur wegen seiner versteckten Lage nicht gesehen wurde. Die verwandte Gattung Amphinma liess, wie oben gesagt, uiber seine Anwesenheit und seine Form lseinen Zweifel. Ja, diese Gattung, die ausserdem noch mit dem $R$. commmicans ausgerüstet ist, zeigt eben hierdurch, dass letzterer Nerv - der sich ausserdem nie in das Ganglion des Facialis, sondern stets in dessen $R$. jugularis einsenkt - mit dem Kopftheil des Sympathicus nichts gemein hat, als den gemeinschaftichen Ursprung aus dem Glossopharyngers.

Ueber diesen $R$. communicans dïrfte sich ohne Reizversuch an lehenden Thieren ebenfalls schwerlich ein sicheres Urtheil gewinnen lassen. Dass er motorische Fasern aus dem Vagus (Glossopharyngous) in den Facialis überführe, dürfte aus dem Umstande, dass er stets den $R$. jugularis des letateren verstïkt, nicht mit absoluter vicherheit genchlossen werden. Denn dieser Stamm, ohroleich der einzige des Furulis, aus welchen Munclzweige hervorgehen, entlässt ausserdem auch Hautäste. Aus Volckmann's bekannten Versuchen 
hat sich in der That ergeben, dass der Ramus commenicans beim Frosche keine motorische Fasern enthält.

\section{Die Zweige für die Kiemen und die Hautnerven des Vagus.}

Die auf den $R$. commuicans (wo dieser vorhanden ist) folgenden zwei oder drei Stämme des Vagus haben bei allen Perennibranchiaten einen ganz gleichen Verlauf. Sie enthalten die für die Muskeln und die Haut der Kiemenbüschel bestimmten Zweige, senden die letzteren aber nicht in der Weise aus, dass jeder dieser Stämme einem einzelnen der drei Kiemenbüschel entspräiche. Sie rerhalten sich vielmehr ganz ähnlich, wie die entsprechenden stimme der Fische; die fur die tuzeln'n Biischel bestimmten Nerven gehen aus der Vereinigung von Zweigen hervor, die aus je zwei jener Stämme entspringen. So betheiligt sich also umgekehrt jeder der letzteren an der Versorgung zweier Kiemenbüschel.

Den Derotremen fehlen die Kiemenbüschel. Gleichwohl finden sich dieselben Stämme des Vagus an derselben Stelle und von gleicher Stäke. Hier sind es indes Zweige für die Haut geworden und verbreiten sich an letzterer vor der Kiemenspalte, also gerade da, wo bei den Perennibranchiaten die Kiemenbïschel sitzen.

Von den Perennibranchiaten geht nur bei Siredon aus dem Ganglion des Vagus ein selbstständiger, für die Thymus-Drüse bestimmter Zweig hervor, der auch feine Hautäste absendet. Bei keiner der anderen Gattungen der Perennibranchiaten konnte ich mich von dem Dasein ron selbstständigen Hautzweigen des Vugus üherzeugen. Wir dürfen wohl deu Schluss hieraus ziehen, dass die Hatzweige der Derotremen den Kiemenästen der Peremibranchiaten analog sind, und dass sie sich bei jenen vor der Verwandlung ihnlich verhalten, wie bei diesen das ganze Leben hindurch.

Hierdurch fällt ein eigenes Licht auf die Natur der aus dem Vagus entspringenden, dem $N$. auricularis des Menschen verglichenen Hautåste des Frosches und der übrigen Ecaudatu. Ich war früher geneigt ${ }^{1}$ ), diese Nerren als den letzten Rest des bei den Larveu der letzteren ebenso wie bei den Perennibranchiaten ausgebildeten systems der Seiten-

1) Amphib. nudor. naurol., pag. 59. 
nerve n zu betrachten. Aus den niv damals unbekannten Formen der Derotremen dürte sich dagegen schliessen lassen, dass der $N$. auricularis als der nach der Metamorphose verbleibende Rest der Kiemennerven zu betrachten ist.

\section{Der Ramus recurrens.}

Im Gegensatz zu der sehr einfachen Form dieses Vagusastes bei den Salamandrinen ${ }^{1}$ ) hat derselbe bei den Perennibranchiater einen sehr erweiterten Verbreitungsbezirk. In seiner Bahn verlaufen die Elemente

1. für die Muskeln: $\boldsymbol{M}$. dorsolaryngens; 1 . dorsotrachealis. Der erstere dient zur Oeffnung des Einganges der Stimmlade; der letztere (S. 97) zur Weiterbeförderung der eingenommenen Luft in die Lungen;

2. fuir den $M$. constrictor laryngis und den $M$. hyotrachcalis. Ersterer verschliesst den Fingang zur Stimmlade, letzterer die Luftröhre selbst (vgl. S. 102 u. S. 96). Da der $\boldsymbol{M}$. hyotrachealis gleichzeitig die Kiemenspalten öffnet, so sind beide wohl als Muskeln zur Kiemenathmung aufzufassen;

3. für den $M$. constrictor arcum und den $M$. protractor arcus ultimi (die betreffenden Nervenzweige wurden bei Sircn beobachtet, $v g l$. S. 149). Beide Muskeln stehen zur Kiemenathmung in nächster Beziehung, ersterer auch wohl zur Lungenathmung, weil der durch ihn bewirkte Verschluss der Kiemenspalten gerade für letztere von Wichtigkeit ist.

Hiernach verlaufen also bei den Perennibranchiaten sowohl solche Elemente in der Bahn des $R$. recurrens, die zur Lungenathmung, als auch solche, die zur Kiemenathmung in Beziehung stehen. Dass ausserdem einige der erwähnten Muskeln eine Aenderung in der Lage und Form der die Stimmlate ungebenden Knorpel hewirken diirften, welche vielleicht auf die Hervorbringung einer Stimme (wie sie der Gattung Sirn nachenesant wirdl von Einfluss ist, wurde oben (S. 102) erwähnt.

1) Vgl, meine Arbeit über die Gehirnnerven der nackten Amphibien, S. 31. 
Bei Cryptobranchus japonicus verläuft, ganz ähnlich wie bei Siren, der Rames recurrens des Vagus nach Abgabe ron Zweigen für die Mm. hyotracheatis und dorsotrachrolis an del medialen seite des schüg nach innen und vorn ansteigenden $\boldsymbol{H}$. dorsoluryngous (Taf. VI, Fig. 2, $d l$ ), steigt mit letzterem Muskel über den $\boldsymbol{M}$. hyotrachealis (hp) nahe bei dessen medialer Insertion fort, läuft nun länğs der Luftröhre nach vorn und breitet sich schliesslich in den zum System des Constrictor laryngis gehörenden Muskeln $\left(c l, c^{\prime}\right)$ aus. Es fehlen hier natürlich diejenigen Zweige, die bei Sircn in die, bei Crypto-

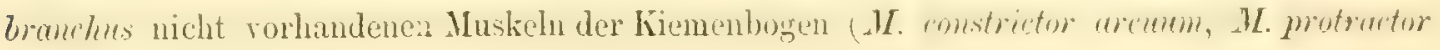
arcus ultimi) gehen.

Von besonderem Interesse ist die eigenthümliche Verschmelzung mehrer aus dem $R$. remrens hervorgehender Nerven mit den entsprechenden Zweigen der anderen Küperhiilfte

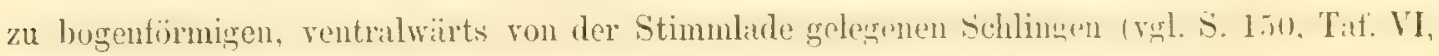
$s, s)$. Ich habe vor zwölf Jahren eine gleiche Verschmelzung der gegenständigen $R$. la-

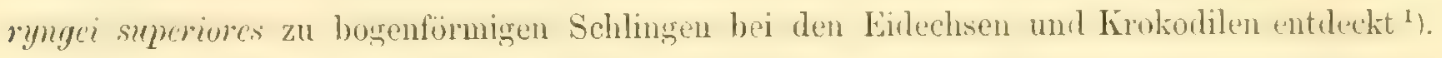

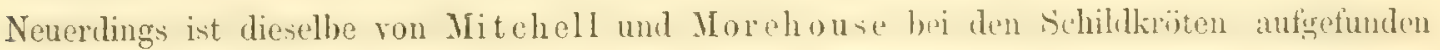
worden $\left.{ }^{2}\right)$. Diese Schlingenbildung, aus der überall Zweige füir die Kehlkopfmunkehn hervorgehen, gewinnt doppeltes Interesse durch die von diesen beiden Forschern mit vieler Vorsicht und Gentuigkeit angestellten Experimente an lebenden Sohildkriten. Hirnach versorst der genannte Nerv nicht nur die Kehlkopfmuskeln seiner Seite, sondern es werden durch jene Schlinge auch Elemente an die Muskeln der entgegengesetzten Seite hinübergeführt, ein Verhalten, das die genannten Autoren veranlasst, in jener Schlingenbildung eine Art von peripherisch gelegenem Chiasma zu sehen.

$\left.{ }^{1}\right)$ Die Gehirnnerven der Saurier, 1852, S. 46.

2) Smithsonian contributions to knowledge, No 169, 1863, pag. 29, ff. 


\section{Die Seitennerven.}

Auch die Seitennerven der Perennibranchiaten und Derotremen verdienen im Vergleich mit denen der Salamandrinen (Triton) und der Froschlarven einer Erwähnung.

Drei Stämme ron hinteren Seitennerven sind bei allen Perennibranchiaten ausgebildet, zwei obere, aus desn Ganglion des Vagus selbst oder doch kurz nach dem Ursprunge des Hauptstammes aus dem letzteren entspringende, und ein unterer, beständig aus dem Ram. intestinalis an seiner Kreuzungsstelle mit dem $N$. hypoglossus hervorgehender. Der letztere ist stets oberflächlich, der Haut dicht anliegend; er verläuft überall an der Bauchseite des Thieres, weit ron der eigentlichen Seitenlinie entfernt. Die oberen beiden, aus dem Gianglion entspringenden Seitennerven sind anfangs zu einem kurzen Stamme verschmolzen, trennen sich aber bald. Beide treten medialwärts vom Schulterblatt nach hinten, der untere als N. lateralis profundus in der Tiefe zwischen den Fasern der Rückenmuskeln versteckt, über die Enden der Rippen und Querfortsätze forttretend. El folgt in seinem Laufe der Seitenlinie selbst. Der obere, feinere wendet sich dorsalwärts, um nicht weit von der Mittellinie des Riickens nach hinten zu laufen. Er liegt dicht unter der Haut bei Siredon, Sirn, ist dagegen unter den oberflichlichen Schichten der Riickemmuskeln rersteckt bei Menobranchus und Hypochthon.

Der untere Seitennerv entspringt nie aus dem Ganglion. Wemn der Hauptstamm des Vagus auf seinem Wege nach hinten in der Gegend der Kiemenspalte angelangt ist, und sich in seine Zweige für die Eingeweide und in den $R$. recurrens spaltet, entsendet er nach hiuten den $\mathrm{N}$. lateralis inferior, der medialwiirts rom Schultergerïst durchtritt, un dicht unter der Haut nach hinten zu laufen. Er liegt dabei der Bauchfläche ganz nahe, weit von der Seitenlinie entfernt.

So sind die Perennibranchiaten eigentlich mit drei hinteren Seitennerven versehen: cinem oberen, einem mittleren und einem unteren. Während der mittlere stets in der T'iefe, der untere bestïndig oberflïchlich verlïuft, ist der obere bald dicht unter der Haut gelegen, bald zwischen den oberflächlichen Schichten der Rückenmuskeln versteckt.

Von den Derotremen schliesst sich Amphiuma in jeder Hinsicht an die Perennibranchiaten an. - Um so auffallender ist es, dass ich trotz aller Sorgfalt bei Menopoma nur einen Seitemnerven finden konnte. Es ist der $N$. lateralis superior profundus der Perennibranchiaten. Dieser theilt sich nicht, sondern läuft in der Tiefe, der Seitenlinie 
ganz wahe, nach hinten, beständig iiber die Enden der Rippen und Querfortsätze forttretend. Aus clem Hauptstamme des Vagus sah ich keinen Nerven hervorgehen, der dem $N$. lateralis inferior der Peremibranchiaten entsproc'sen hätte.

\section{N. hypoglossus.}

Der Hypoglossus der Perennibranchiaten und Derotremen erinnert durchaus an die Formen der Salamandrinen. Er wird überall ans den Rami descendentes der ersten Halsnerven zusammengesetzt und zwar meist des ersten und zweiten. Nur bei Menobranchus entsteht er durch Verschmelzung des zweiten und dritten. Der erste Halsnerv dieser Gattung hat nü̈mlich einen selbstständigen Verlauf. Aur nur ciner ventralen Wurzel ent:sprungen,

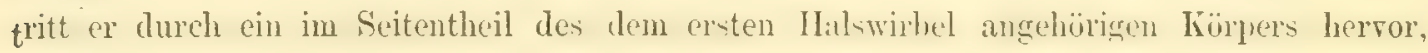
wendet sich dorsalwärts und verbreitet sich in dem kurzen $M I$. occipitalis minor (vom ersten Inalswirbel an die obere Fläche des Hinterhuptheins). Monolmandhes ist übrigens die einzige Gattung, bei der ich einen dem $N$. accessorius Willisii entsprechenden Nerren von ganz selbstständiger Form fand. Diesem Umstande entsprechend sind es nicht der erste und zweite, sondern der zweite und dritte Halsnerv, die bei dieser Gattung sich zur Bildung des X. hypoglossus vereinigen. Bei Amphiuma scheinen die Elemente des letzteren ührigens nur aus der Bahn eines einzigen Halsnerven, des ersten, hervorzugehen.

Die Vereinigung der beiden Stämme - wo deren zwei vorhanden sind - erfolgt nie unmittelbar nach deren Hervortritt aus dem Wirbelkanal. Sie ,wenden sich vielmehr getrennt von einander nach aussen und hinten und pflegen erst in der Gegend der Kiemen spalte (bei Siren sogar erst an der Ventralfläche des Körpers), hinter welcher sie den Hauptstamm des Vugus. kreuzen, zu einem einzigen Stamme zu vereinigen. IDicser krümmt sich alsdann nach vorn, so dass er medialwärts vom $N$. lateralis inferior vorbei geht, und tritt von aussen her an den MI. stemolnyoidens heran. Nachdem er diesem Muskel mehre Zweige gegeben hat und sclbst in dessen Fasern nach rorn gelanfen ist, tritt das Ende des $N$. hypoglossus von hinten her in den MI. geniohyoideus ein, um sich in diesem auszubreiten. 
Dieser Verlauf und diese Endigung des Hippoglossus sind constant dieselben bei allen Gattungen. - Bei Siren durchbolrt unser Nerv bei seinem Uebertritt an den Geniolyyoideus den jederseits sich weit nach hinten erstreckenden Lappen der sehr entwickelten Glandula thyreoidea. - Bei Menobranchus verschmilzt der aus dem Stamm des zweiten und dritten Halsnerven gebildete Hypoglossers anf eine kurze Strecke mit dem Hauntstamme des $N$. vagus. Von diesem trennt er sich jedoch bald wieder, und zwar gerade da, wo aus dem letzteren der nach hinten laufende $N$. lateralis inferior hervorgeht. Dies sind die einzigen wichtigen Abweichungen, die ich im Verlauf dieses Nerven bei den einzelnen Gattungen entdecken konnte. 


\title{
Erklïrung der Abbildungen.
}

\author{
Tafel I.
}

Diese Tafel giebt Abbildungen vom Zungenbein-Kiemenbogen-Apparat der Perennibranchiaten, Derotremen und den Larven der Salamandrinen. Die Präparate sind von der Ventralseite aus gesehen dargestellt.

Folgende, in den einzelnen Figuren sich wiederholende Bezeichnungen bedeuten:

mi Unterkiefer. - ch Zungenbeinkörper. - $c h^{\star}$ Vordere Copula. - $h, h$ Zungenbeinhörner. - $h^{*}, h^{\prime}$, Vordere Segmente der Zungenbeinhörner. - $h^{\prime \prime}, h^{\prime \prime}$ Mittlere Segmente derselben (bei Amphiuma), - $b^{\prime}$ in Fig. 5 u. 6 Erster Kiemenbogen. $-b^{d}, b^{\prime \prime}, b^{\prime \prime}$, $b^{\prime \cdots}$ Dorsalsegmente resp. des ersten, zweiten, dritten und vierten Kiemenbogens. - $b^{\prime} v, b^{\prime \prime} v$, $b^{\prime \prime \prime} v$ Ventralsegmente resp. des ersten, zweiten, dritten Kiemenbogens. $-s$ Zungenbeinstiel.

Für die einzelnen Figuren sind noch folgende Bezeichnungen zu merken:

\section{Figur 1.}

Der Zungenbein-Kiemenbogen-A pparat von Siredon pisciformis. Dreimal vergrössert.

Die Bezeichnungen $m i, c h, h, b^{\prime}, b^{\prime \prime}, b^{\prime \prime \prime}, b^{\prime \prime \prime}, b^{\prime} v, b^{\prime \prime} v, s$ sind oben angegeben $b r^{\prime}, b r^{\prime \prime}, b r^{\prime \prime}$ Anfänge des ersten, zweiten, dritten Kiemenbüschels. - $a b^{\prime}, a b^{\prime \prime}, a b^{\prime \prime} \mathrm{Mm}$. depressores branchiarum primae, secundae, tertiae (S. 39). - $1 b^{d}, 1 b^{\prime \prime}, 7 b^{\prime \prime \prime} \mathrm{Mm}$. levatores 
branchiarum (S. 37, 38). - pa M. ceratohyoideus internus (S. 72). - ca, $c a^{\prime}, c a^{\prime \prime}$ M. constrictor arcuum branchiarum (S. 74). - qa, qa $\mathbf{I m}$. adductores arcuum (S. 77). $7 p$ MI. hyotrachealis (S, 88).

\section{Figur 2.}

Der Zungenbein-Kiemenbogen-Apparat ron Siren lacertina.

Natürliche Grösse.

Sämmtliche Bezeichnungen sind vorliin erklïrt.

Fig. 2 a und 2 b: Zwei durch die Gestalt ihrer Endplatten abweichende Zungenbeinstiele von zwei rerschiedenen Individuen.

\section{Figur 3.}

Kungenbein-Kiemenbogen-Apparat von Menobranchus lateralis.

Viermal vergrössert (nicht zweimal, wie die Bczeichnung der Abbildung angiebt). $m i, c h, h, h^{4}, b^{\prime}, b^{\prime \prime}, b^{\prime \prime}, b^{\prime \prime \prime}, b^{4} v, b^{\prime \prime} v, s$ sind oben erklïrt. - $b r^{\prime}, b r^{\prime \prime}, b r^{\prime \prime}$ Die drei Kiemenbüschel. - $d r$ Glandula thyreoidea. - $c a, c \iota^{\prime}, p u$ wie in Fig. 1.

\section{Figur 4.}

Zungenbein-Kiemenbogen-Apparat von Hypochthon anguinus.

Viermal vergrössert.

Die Bedeutung der Zeichen mi, $c h, h, l^{\prime}, b^{\prime \prime}, b^{\prime \prime}, b^{\prime} v, b^{\prime \prime} v, s$ ist oben augegeben. $g h_{6}$ M. geniohyoideus. - hp M. ceratohyoideus externus. - $p a$ M. ceratohyoideus internus anterior. - $p a^{\prime}$ M. ceratohyoideus internus posterior. - $s h$ M. sternohyoideus. - $c p h$ M. dorsotrachealis. - hph M. hyotrachealis. - $l i p^{\prime}$ M. protractor arcus ultimi. - $d r$ Glandula thyreoidea.

\section{Figur 5.}

Zungenbein-Kiemenbogen-Apparat von Amplíuma tridactylum.

Viermal vergrôssert.

Die Zeichen mi, $c h, c h^{\prime}, h, h^{\prime}, h^{\prime \prime}, b^{\prime}, b^{\prime \prime}, b^{\prime \prime}, b^{\prime \prime \prime}, b^{\prime} v, b^{\prime \prime} v, b^{\prime \prime} v$ sind oben erkiärt. dr Glaudula thyreoida. - $c a, c t^{\prime}$ M. constrictor arcuum. - $c p$ M. dorsotrachealis. - 
hhip M. hyotrachealis. - $x$ M. dorsolaryngens. - cl M. constrictor aditus láryngis. $s h$, sh Portionen des Sternohyoideus, die sich an den hinteren Ventralrand der Stimmlade befestigen. - sht Insertion des Sternohyoideus an den ersten Kiemenbogen.

\section{Figur 6.}

Zungenbein-Kiemenbogen-Apparat von Menopoma alleghanieuse. Natürliche Grösse.

Die Bezeichnungen sind oben erklärt.

\section{Figur 7.}

Zungenbein und Kiemenbogen der Larve ron Triton marmoratus. Sehr rergrössert. (Copiert nach Dugés' Recherches sur l'ostéologie et la myologie des batraciens, Paris 1834, Pl. XV. Fig. 114.)

a Zunge (glosso-hyal). - $b$ Zungenbeinkörper (basi-hyal, Dugès). - $c$ Zungenbeinstiel (uro-hyal, Dugès). - e Zungenbeinhorn (stylo-hyal, D u gès). - d Vorderes Segment desselben (sus-lingual ou corne styloïlienne, Dugès). - $f$ Ventralsegment des ersten Kiemenbogens (première pièce de la corne thyroïdienne, Dugès)。 - $g$ Ventralsegment des zweiten Kiemenbogens. $-h, i, j, k$ Kiemenbogen (arcs branchiaux). -8 II. ceratohyoideus externus (inuscle hyo-pré-styloïdien on pré-stylo-postbranchial, Dugès). - $\delta$ II. ceratohyoideus internus (m. pré-stylo-prébranchial, Dugès). - \& M. constrictor arcuum (m. interbranchial).

\section{Figur 8.}

Zungenbein und Kiemenbogen einer jungen Salamandra terrestris (nachdem die Kiemen geschwunden sind).

Mehr als viermal vergrössert. (Copiert nach Dugès, Pl. XY, Fig. 113.)

Die Bezeichnungen wie in Fig. 7.

c Endplatte des (im Verlauf der Entwickelung geschwundenen) Zungenbeinstiels (urohyal, D ugès; ossiculum thyreoideum, Sieb). 


\title{
Figur 9.
}

\author{
Zungenbein des a usgewaclisenen 'Triton marmoratus. \\ Zweimal vergrössert. (Nach I) ugès, Taf. XIY, Fig. 98.)
}

Die Bezeichnungen wie in Fig. 7.

$$
\text { 'Tat's IIa }
$$

\section{Kopf und Ursprünge der Gehirnnerven von Siredon pisciformis, von der Dorsalfiäche aus gesehen.}

Viermal vergrössert ${ }^{1}$ ).

6 Auge; $z$ dorsaler Fortsatz des Zwischenkiefers; $c r$ Seitenwand der Schïdelhöhle; d Glandula thymus.

II u skeln: m M. masseter. - dg M. digastricus. - la, $l a^{\prime \prime}, l a^{\prime \prime \prime}, l a^{\prime \prime \prime}$ Mm. levatores arcuum branchiarum. - do Gerade Rückenmuskeln. - os M. obliquus superior. - rs M. rectus superior. - re M. rectus externus.

Die Ursprïnge der Gehirnnerven sind Seite 124 beschrieben.

$1 \mathrm{~N}$. olfactorius; $3 \mathrm{~N}$. oculomotorius; $4 \mathrm{~N}$. patheticns; 5 Wurzel des $\mathrm{N}$. trigeminus; 7 Verstärkungswurzel aus dem mit dem Acusticus (8) zusammen entspringenden Facialis in das Ganglion Gasseri (A).

A Ganglion Gasseri. - 5' (linke Seite der Figur) Hautzweig des Trigeminus, einer vorderen Partie des Systems der Seitennerven zu vergleichen. - 5" (rechte Seite der Fig.) Ramus nasalis (vgl. S. 128), - $5^{\prime \prime}$ R. maxillaris superior (S. 128). - $5^{\prime \prime \prime}$ R. maxillaris inferior (S. 128). - $r$ und 8 Gemeinschaftliche Wurzeln des Facialis und Acusticus.

$C$ Gauglion des N. facialis. - $h$, $i$ Der Ramus jugularis; er empfängt den R. communicans (k) des Glossopharyngeus.

1) Nicht zweimal, wie dic Bezeichnung der Abbildung angiebt. 
$B$ Gemeinschaftliches Ganglion des Vagus und Glossopharyngeus. - $k$ R. communicans cum nerro faciali. - $p h$ Ramuli pharyngei. - $g l$ R. lingualis sive glossopharyngeus. - $b r, b{ }^{*}$ Kiemennerven. - a Zweig für den M. cucullaris (letzterer ist an seiner dorsalen Insertion abgeschnitten und mit der Haut nach aussen zuriickgeschlagen dargestellt). - in Hauptstamm des Vagus (S. 142). - l N. lateralis superior.

Die Specialbeschreibung der zum System des Vagus gehörigen Elemente siehe Seite 140.

\section{Tafel IIIa und IIIb.}

\section{Muskeln und Nerven an der Dorsalseite des Kopfes von Menobranchus lateralis. Zweimal vergrössert.}

ct Zurückgeschlagene Haut. - bi Auge. - $d, d^{\prime}$ Glandula thymus. - $b^{\prime}$ Dorsalsegment des ersten, $b^{\prime \prime}$ dorsales Ende des zweiten Kiemenluogens. - $b \boldsymbol{r}^{\star}, b \boldsymbol{r}^{\prime \prime}$, $b \boldsymbol{r}^{\prime \prime}$ Kiemenbiischel. - $h$ Dorsale Spitze des 'Lungenbeinhorns. - fr Stimbein. - ty Os tympanicum. - se Dorsaler Rand des Schulterblatts. - $f$ Rechter Vorderfuss.

II uskeln: $t$ M. temporalis. - $m$ M. masseter. - $d g^{\prime \prime}$ Zweite, vom Dorsalsegment des ersten Kiemenbogens entspringende Portion des M. digastricus. - la Mm. levatores arcuum. - cp M. dorsotrachealis. - $l b^{\prime}, 7 b^{\prime \prime}, l b^{\prime \prime \prime} \mathrm{Mm}$. levatores branchiarum. - cu M. cucullaris. - do Gerade Rückenmuskeln. - ps M. protrahens scapulae. - os M. obliquus superior. - rs M. rectus superior. - re M. rectus externus.

Nerven: 1 N. olfactorius. - 5" Ramus nasalis Trigemini. - 5" Ramus maxillaris superior Trigemini. - $5^{\prime}$ Dessen Zweig an die Haut der Stirn medialwärts vom Auge. - 5“" Ramus maxillaris inferior Trigemini. - $5 \mathrm{~m}$. Dessen Muskelzweige für M. masseter und H. temporalis. - $5 c$ Dessen Zweige für die das Unterkiefergelenk bedeckende Haut. - 7 Ramus mentalis des $\mathrm{N}$. facialis. - $\gamma i$. $7 m$ Dessen zwei für die den Unterkiefer bedeckende Haut bestimmten Zweige. - gl Zweiter Ast des Vagus (vgl. S. 144), enthaltend den IRmus glossopharyngeus sive lingualis und den ersten Kiemenast. Letzterer entsendet: $b c$ einen Zweig für die Haut vor der ersten Kiemenspalte; bm einen zweiten für die Muskeln des ersten Kiemenbiischels; und einen dritten, der mit einem aus dem dritten Vagusaste hervorgehenden Nerven eine Schlinge bildet. - $b^{\prime}$ und $b^{\prime \prime}$ dritter und vierter 
Ast des Vagus (beschrieben S. 145). - $10 \mathrm{~m}$ Muskeläste aus dem Hauptstamme des Vagus für den M. cucullaris (cu). - ph Zweig desselben Stammes für den M. omopharyngeus. $10 i$ Hauptstamm des $\mathrm{N}$. vagus. - in Desselben $\mathrm{R}$. intestinalis. - $l \mathrm{~N}$. lateralis superior, in zwei Aeste gespalten.

\section{Tafel IV.}

\section{Muskeln und Nerven am Kopfe von Menopoma alleghaniense.}

Natürliche Grösse.

Figur 1.

Ansicht der Dorsalfläche.

$b$ Auge. - ct Zurückgeschlagene Haut. - $d$ Glandula thymus. - pa Os parietale. - fr Os frontale.

Nuskeln: $m$ I. masseter. - te Erste Portion des M. temporalis. - te Zweite Portion des M. temporalis (S. 61). - $t$ (rechte Seite der Figur) Sehne dieses Muskels. $d g$ Erste Portion des M. digastricus (S. 51). - $d g^{\prime}$ Zweite Portion desselben Muskels. la Mm. levatores arcuum (auf der rechten Seite der Figur an dem dorsalen Insertionspunkte abyenchnitter und literalwärts zurïckgeschlagen). - my II. mylohyoideus pasterior. - $c$ M M. dorsotrachealis. - do Gerade Rïckenmuskeln. - os M. obliquus superior. rs M. rectus superior und M. retractor bulbi.

Nerven: $5^{\prime \prime}$ Erster Ast des Trigeminus. - Ueber die Zweige dieses Astes $\alpha, \beta, \gamma$, $\delta, \varepsilon$ und $x$ vgl. S. 131. - $5^{\prime \prime \prime}$ Zweiter Ast des Trigeminus. Ueber seine Zweige $\zeta, \zeta, \zeta$ und seine Endigung $r$ vgl. S. 131. - 5 "“" Dritter Ast des Trigeminus. Seine Zweige ", $i, \eta$, it sind S. 131 beschrieben. - $\eta_{i}$ Ramus mentalis des N. facialis. - $7 m$ R. alveolaris des N. facialis. - 2. Dessen Zweig für die das Unterkiefergelenk bedeckende Haut. $n$ Ramus jugularis des $\mathrm{N}$. facialis, empfängt gleich nach seinem Ursprunge den $\mathrm{R}$. communicans $n$ des Glossopharyngeus. $-B$ Ganglion des Vagus und Glossopharyngeus - $k \boldsymbol{R}$. communicans cum nervo faciali. - gl R. glossopharyngeus. - $b r$ Erster Kiemennerv. la Dessen Zweig in den M. levator arcus secundi. - le Dessen Zweig in die Haut vor der Kiemenspalte. - $b r^{\prime}$ Zweiter Kiemennerv, aus dem Hauptstamme des Vagus entsprungen. 
- la und $r$ Dessen 'Zweige für den M. levator arcus tertii und für die Haut vor der Kiemenspalte - in $\mathrm{R}$. intestinalis nervi ragi. - $l \mathrm{~N}$. lateralis superior. $-I$ und $I$ Erster und zweiter Halsnerv, vereinen sich an der Ventralfläche des Körpers zum N. hypoglossus (lipg).

\section{Figur 2.}

Ansicht von der Ventralseite.

Ueber die Zeichen $c h, h, h^{\prime}, b^{\prime}, b^{\prime \prime}, b^{\prime \prime \prime}, b^{\prime \prime \prime}, b^{\prime \prime} v$, mi vgl. die Erklärung zu den Figuren der 1. Tafel.

tr Luftröhre. - lar Stimmlade. - ct Zurückgeschlagene Haut. - cl Pars clavicularis, cor Pars coracoidea des Schultergeriists.

Muskeln: $m$ Ventrale Insertion des M. masseter. - $d g$ M. digastricus. - sm M. submentalis. - mh M. mylohyoideus anterior. - mh M. mylohyoideus posterior. - $g h$ M. geniohyoideus. - $g h^{\circ}$ und $g h^{\prime \prime}$ Dessen hintere Ursprungsportionen (S. 56). - sh MI. sternolyoideus. - sp Dessen Portion für den letzten Kiemenbogen und den Schlund (S. 105). - $c a$ M. constrictor arcuum. - $c p h$ M. dorsotrachealis. - hph M. hyotrachealis.

- $x$ M. dorsolaryngeus.

Nerven: $g l$ R. glossopharyngeus. - hpg N. hypoglossus.

\section{Tafel $\mathrm{T}^{\mathrm{T}}$.}

\section{Muskeln und Nerven am Kopfe von Amphiuma tridactvlum.}

Zweimal vergrössert.

\section{Figur 1 und 2.}

Ansichten der rechten Seite.

6 Auge. - mi Unterkiefer. - sp Kiemenspalte. - d Thymus-Drüse. - ty Os tympanicum. - $x$ Knochenkamm an der Vorderfläche desselben. - $c$ Pars clavicularis des Schultergerüsts. 
Muskeln: te M. temporalis anterior. - $t c^{*}$ M. temporalis posterior. - $t s$ Sehme des letzteren Muskels. - $m^{\prime}$ Erste Portion, $m^{\prime \prime}$ zweite Portion des M. masseter. - my' M. mylohyoideus anterior. - my" M. mylohyoideus posterior. - $d g^{\prime}$ Erste, $d g^{\prime \prime}$ zweite Portion des M. digastricus. - $c a, c a^{d}$ M. constrictor arcuum. - las M. levator maxillae inferioris ascendens. - la Mm. levatores arcuum. - cp M. dorsotrachealis - cu M. cucullaris.

Nerven: $m e, m n, i, l, n$ Zweige des $\mathrm{N}$. facialis, auf Seite 136 beschrieben. - $9 c$ Kopftheil des Sympathicus. - $9 c^{\prime} \mathrm{R}$. communicans nervi glossopharyngei cum nervo faciali. - gl Ramus glossopharyngeus nervi vagi.

\section{Figur 3.}

\section{Ansicht der Ventralflächз.}

mi Unterkiefer. - $h$ Zungenbeinhorn. - $c$ Schlüsselbeinplatte.

Mi uskeln: $m y^{\prime}, m y^{\prime \prime}, c a, c a^{\prime}$, las wie in Fig. 2. - gh M. geniohyoideus. - sh M. sternohyoideus. - ceh M. ceratohyoideus externus. - gg II. genioglossus.

Nerven: 5" Ende des dritten Astes des Trigeminus, im M. mylohyoideus anterior sich ausbreitend. - me R. mentalis nervi facialis. - hog N. hypoglossus.

\section{Taftel VI.}

\section{Figur 1.}

Zungenbein-Kiemenbogen-Apparat vou Siphonops annulatus.

$h$ Zungenbeinhorn. - $b^{\prime}, b^{\prime \prime}, b^{\prime \prime}$ Erster, zweiter, dritter Kiemenbogen. - lar Stimmlade. - tr Luftröhre. - ceh M. ceratohyoideus. - $c a, c a$ I. constrictor arcuum. - la, Ia $\mathrm{Mm}$. levatores arcuum secundi et tertii. 


\section{Figur 2.}

Muskeln der Stimmlade und der Luftröhre von Cryptobranchus japonicus. Von der Ventralseite gesehen.

Natürliche (irösse.

tr. Luftröhre. - $c l, c l^{\prime}$ Mm. constrictores aditus laryngis. - dl M. dorsolaryngeus. - Ip M. dorsotrachealis. - hp M, hyotrachealis.

\section{Figur 3.}

Ventralansicht der Stimmlade ron Cryptobranchus japonicus. Dreimal vergrössert.

a Seitenknorpel. - $e$ Dessen lateraler Vorsprung zur Anheftung des M. constrictor aditus laryngis und des II. dorsolaryngeus. - g Dorsale Spalte der Stimmlade. - $\mathfrak{r}$ Luftröhre. - $\mathrm{cl}, \mathrm{cl}^{\mathrm{H}} \mathrm{Mm}$. constrictores aditus laryngis. - ll M. dorsolaryngeus.

\section{Figur 4.}

Muskeln und Nerven der Stimmlade und der Luftröhre von Siren lacertina.

Ventralansicht.

Dreimal vergrössert.

g Stimmritze. - $t ;$ Luftröhre. - $b^{\prime}, b^{\prime \prime}, b^{\prime \prime \prime}, b^{\prime \prime \prime}$ Dorsalsegmente der vier Kiemenbogen. - $b^{\prime} v, \cdot b^{\prime \prime} v$ Ventralsegmente der beiden ersten Kiemenbogen.

Muskeln: $m y^{\prime}$ M. mylohyoideus posterior, an seiner medialen Insertion durchgeschnitten und lateralwïrts zurïckgeschlagen. - ceh M. ceratohyoideus exteruus. - cci MI. ceratohyoideus internus. - $c a$ M. constrictor arcuum. - pr M. protractror arcus ultimi. cl M. constrictor laryngis. - dp M. dorsotrachealis. Von ihm trennt sich an der VentralHïche dl M. dorsolaryngeus. - hp M. hyotrachealis. - $h p^{\prime}$ Dessen vordere, grossen Theils von der Luftröhre selbst entspringende Partie.

Nerven: b3 Zweiter Ast des R. lingualis des Glossopharyngeus (S. 148). - ab Dritter Zwoig des aus dem Glossopharyngeus entstehenden ersten Kiemennerven (S. 148, $r$ ). - $x$ Der aus den beiden vorigen Nerven gebildete, in den M. ceratohyoideus internus (cei) eintretende Stamm. - $w$ Ramus recurrens nerri vagi. - $\alpha, \beta, \gamma$ Seine Zweige für den II. constrictor arcuum (ca), den M. protractor arcus ultimi (pr) und zur Stimmlade, 
Letzterer Zweig $(\gamma)$ entlässt zwei Zweige $s$, $s$, welche mit den entsprechenden Zweigen der anderen Körperhälfte zu Schlingen zusammentreten (S. 150 und 156). - $\varepsilon$ Zweig für den II. dorsolaryngeus $(a l)$. - $\zeta$ Zweig für den M. constrictor aditus laryngis $(c l)$.

\section{Figur 5.}

Muskeln an der Dorsalseite der Stimmlade und der Luftröhre von Siren lacertina (vgl. S. 93).

Viermal vergrüssert.

y Stimmritze. - a Seitenknorpel. - $e$ Dessen hakenförmiger Fortsatz für die Anheftung des M. dorsolaryngeus und des M. constrictor laryngis. $-b, b$ dreieckige Knorpe] am Hinterrande der Stimmlade. - tr Luftröhe. - cl M. constrictor aditus laryngis. dl M. dorsolaryngeus. - Tp M. hyotrachealis.

\section{Figur 6.}

\section{Dasselbe l'räparat von der Ventralfläche gesehen.}

Viermal vergrüssert.

Ueber die Bedeutung der Zeichen $g, a, e, t r, c l$ vgl. die vorige Figur. - $h p$ M. hyotrachealis. - $7 \not p^{\prime}$ Dessen vordere, zum grossen Theil von der Ventralfiäche der Luftröhre selbst entspringende Partie (vgl. S. 93). An der rechten Seite der Figur ist $7 p^{\prime}$ an seiner vorderen Insertion losgeschnitten und bis zu dem Punkte zuriickgeschlagen dargestellt, wo die von der Luftröhre entspringenden Fasern an letztere angeheftet sind. - h $w^{\prime \prime}$ Die vordere, an der Dorsalflïche bis zu dem Kinorpelstïckchen $b$ (Fig. 5) sich erstreckende Partie des M. hyotrachealis.

\section{Figur 7.}

Schematische Figur zur Erläuterung der Wirkung des M. hyotrachealis und einer Partie des M. sternohyoideus bei Amphiuma (vgl. S. 108). 


\section{Figur 8.}

Ursprünge und Hauptzïge der Gehirnnerven von Menobranchus lateralis. Von der Ventralseite gesehen.

Viermal vergrössert.

Ueber die Ursprïnge der Gehirnnerven vgl. S. 125. Ueber die Hauptzüge des Trigeminus S. 130. Ueber die Stämme des Facialis S. 134. Ueber das System des Vagus und Glossopharyngeus S. 14:3. Ueber den ans dem zweiten und dritten Halsnerven gebildeten Stamm des Hypoglossus vgl. S. 158 des Textes.

\section{Figur 9.}

Klappenähnliche Vorrichtungen in d,er Umgebung der inneren Nasenöffnung von Siren lacertina. Von der Ventralseite gesehen. Vgl. S. 114.

Viermal vergrössert.

$l$ Oberlippe. $-z^{\prime}$ und $z^{\prime \prime}$ Vordere und hintere Zahnplatte. $-s$ Hautsaum, der sich lateralwärts um die letztere herumzieht und in der Gegend der inneren Nasenöffnung (in) zwei klappenähnliche Aussackungen $f^{\prime \prime}$ und $f^{\prime \prime \prime}$ bildet. - $f^{\prime}$ Hintere Klappe. - $m$ Muskelfasern für die letztere.

\section{Figur 10.}

Dieselbe Vorrichtung bei Menobranchus lateralis. Vgl. S. 114. $Z$ weimal vergrössert.

l Oberlippe. - g Innere (Gaumen-) Zahnreihe. $-k$ Aeussere (Kiefer-) Zahnreihe. in Innere Nasenöffnung. $-s$ Hautsaum lateralwärts von der inneren Zahnreihe. Derselbe bildet eine Art Klappe $f$ zur Bedeckung der imneren Nasenöffnung.

\section{Figur 11.}

Dieselbe Vorrichtung von Menopoma alleghaniense.

Dreimal vergrössert.

Die Bedeutung der Zeichen ist dieselbe wie für Figur 10.

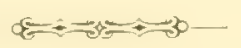




\section{Inhalts-Verzeichnis.}

\section{Erste Abhandlung.}

Die Visceralbogen und deren Muskeln bei den Perennibranchinten und Derotremen.

\section{Erster Theil: Die Visceralbogen.}

Benennungen der einzelnen "Theile des Visceralskeletts ................. 11

I. Die Zungenbeinhörner ........... 12

Deren Gliederung und Anheftung.... 12

Deren sulstanz ....... . . .... 1t

Deren Form ................ 1:

Deren Bezichung zu den Muskeln.... 1i

II. Lie Kiemenbogen.............. 16

Deren Zahl und Verhältnis zu den Kïmen .................... 16

Deren Gliederung und Anheftung .... 18

Deren Consistenz................ 2. 2

Diren tivestalt . . . . . . . . . . . . 28

Deren Bezielung zu den Muskeln.... It

III. Die medialen Verbindungsglieder der Bogenpaare: Zungenbeinkörper und vordere Copula...................

IV. Der Zuncrenteinstiel . . . . . . . . . .

V. Der Zungenbein- und KíemenbogenApparat der Salamandrinen .........

\section{Zweiter Theil: Muskeln.}

I. Muskeln der K̈iemenbïschel ........ 37

$\mathrm{Mm}$. levatores branchiarum........ 37

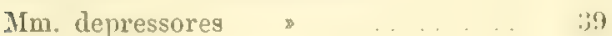

Mm. adductores $\quad$ \# ....... 39

Nerven für diese Muskeln......... th s.ite.

II. Muskeln der Visceralbogen .......... 41

Muskeln des Unterkiefers .......... 11

a. Constrictores.

1. MI. mylohyoideus anterior ...... 41

2. II. mylohyoideus posterior...... 41

Nerven für diese beiden Muskeln ... 45

Wirkung dieser Muskeln ......... 45

3. M. submentalis und seine Wirkung 47

$$
\text { b. Depressores. }
$$

4. II. digastricus. . . . . . . . . . . . 49

Wirkung seiner drei l'ortionen ..... 53

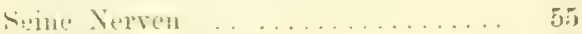

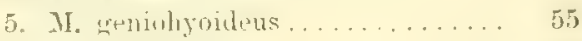

Seine Wirkung. ............ 58

Seint Nerven ............. 59

c. Levatores.

6. M. Massuter . . . . . . . . . 59

seinn. Wirknngr............. 60

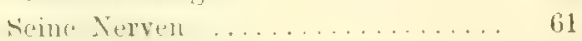

7. M. tempnoralis ........... (b1

8. II. pteryroideus ........... 63

9. I. levator maxillae inferioris ascendens bei Imphiuma und Caecilia 64

Ilessen Nerven............. $60^{2}$

1. Muskeln der Zunge.

10. M. genioglossus ............ 66

11. M. hyoghusus. ........... 67 
e. MIuskeln des Zungenbeins und der hiemenbogen.

12. M. ceratohyoideus externus ..... Siess. Wrktung

seme Yerven

13. M. ceratohyoideus internus..... 7

Seine Wirking und seine Nerven... 73

14. M. constrictor arcuum brandiatum . ......... . .

Sime Xirwn ,........ .

15. $\mathrm{MTm}$. adductores arcuum....... TT

Ieren Wirknug .............. 78

16. 11. protractor arcus ultimi ..... 79

17. .m. levatores arcuum ........ 80

Deren Wirkung .............. 84

Ilerm Nerven . . . . . . . . . . . 86

18. M. constrictor pharyngis $u$, dessen einzelne an Luftröhre u. Stimmlade sich erstreckende Partieen.......

bei sirelum

bei Menoloranchus ..........

bei Hypochthon ............

bei Iuphtiuma .......... 91

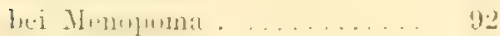

bei Cryptobranchus japonicus . (12

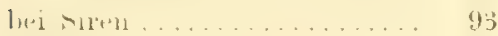

Jeren Stimmlarle..........

Wirkung der einzelnen Partien dieser

IIuskelgruppe ..............

Ihre Beziehungen zu den Nim. levatores arcuum nud zum System des Mylohyoideus............
Ihre Analoga bei den ächten Batra-

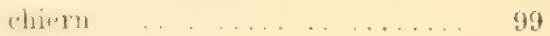

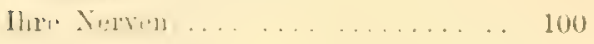

19. Il. constrictor aditus laryngis II $" 11, \ldots \ldots \ldots \ldots$

Die Stimmlade von Cryptoinanchus i:lpmicus

Die Nerven für den M. constrictor ahtus larymeris.

20. .11. sternohyoideus ............

Dessen liedeutung als Einathmungsmustiel ................. 108

lesenti Nerven.

109

\section{Dritter Theil: Das Athmen.}

Cuviers Annalume für die äcliten Batrachier 111 Analyse der dieser Annahme zu Giunde liegenden Voraussetzungen ........... 111

1. Die Nasenlöcher.............. 111

Die klappen-Forrichtungen in der

Umgebung der inneren Nasenlöcher

2. Die Muskeln zur Bildung ron Hohlräumen beim Fiuathmen.........

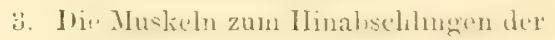

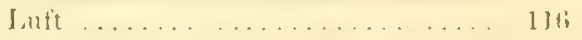

4. Muskeln zum Verschluss der liemenspalte...

5. Muskeln zur Oeffuung der Stimmlade

Die Mechanik der Kiemenathmung....... Ins Iusathuen

\section{8}

09

$11: ;$

11;

$11 \%$

117

$11 n$

119

\section{Zweite Abhandlung. \\ Die Gehirnnerven.}

İrsprünge hui siredın . . . . . . . . . . 123

Ursprünge bei Menobranchus . . . . . . . 125

Augenmuslimtintron. . . . . . . . . . . . . . 1:7

Der Trigeminus bei Siredon........... 1:8

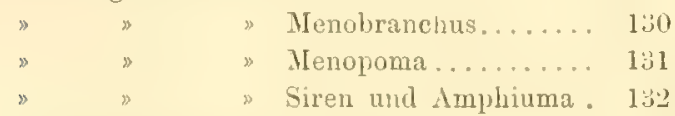

Der Nervus facialis bei Siredon ........ 133

" " "Nenobranchus... 134

> $>$ Menopoma...... 13is

, \$ \$ Amphiuma...... 13i;

$\$ \gg$ Siren ......... 1:3

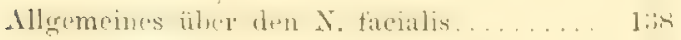

Nervus glossopharyngeus und $\mathrm{N}_{\text {. vagus .. } 140}$

Deren Form bei siredon............... 141

» $\gg$ Ienohranchus ........ 143
Deren form bei sures. . . . . . . . . 147

1,11

$1: 1$

Betrachtung einzelner Theile dieses Systems 153

1. Der Kopftheil des Sypathicus u. d. R. communicans cum nervo faciali...... 15:3

2. Die Zweige für die Kriemen und die Hautuerven des $N$. vagus ......... lit

3. Der liamus recurrens........... 15.

Form dieses Nerven bei Cryptobran-

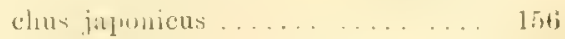

I) as peripherische Chiasma dies. Nerven 150

4. Die Seitennerven .............. $15 \%$

Der Nervus lyypnglossus.............. 155

Erklärung der Abbildungen ........... 161 


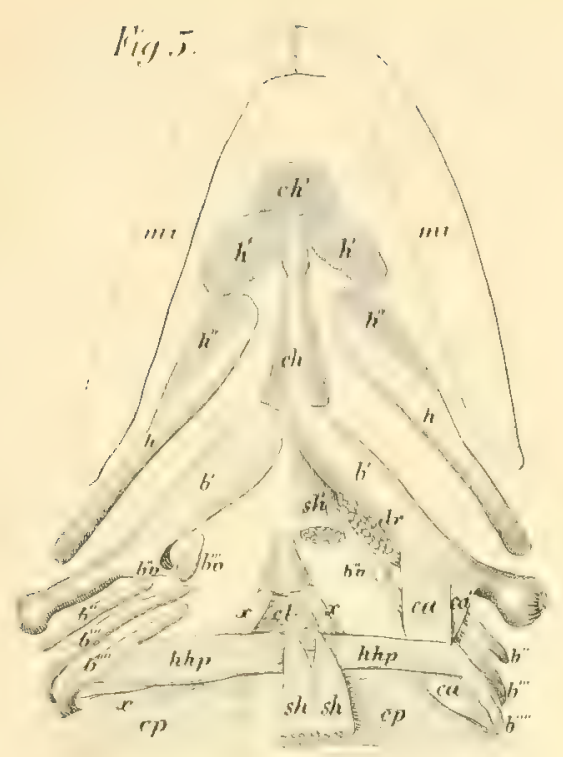

Amphinema, "1.

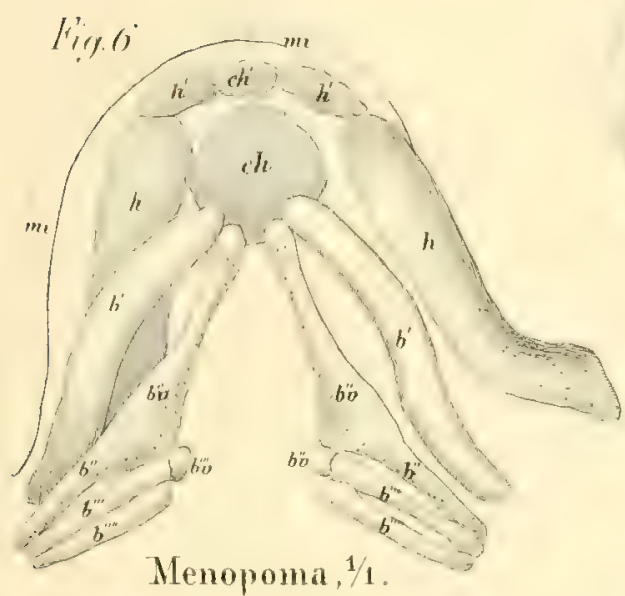

Menopoma, $1 / 1$

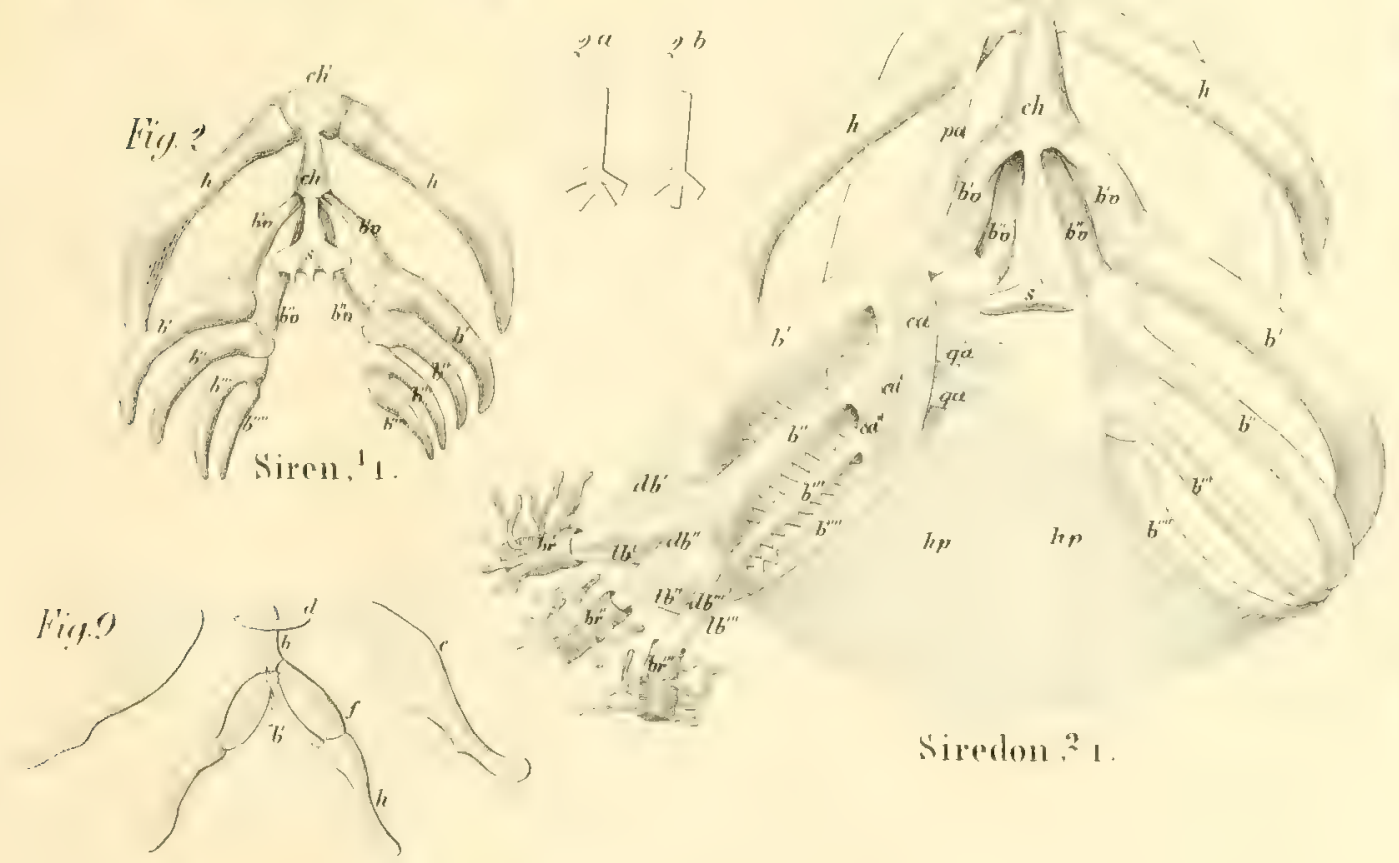

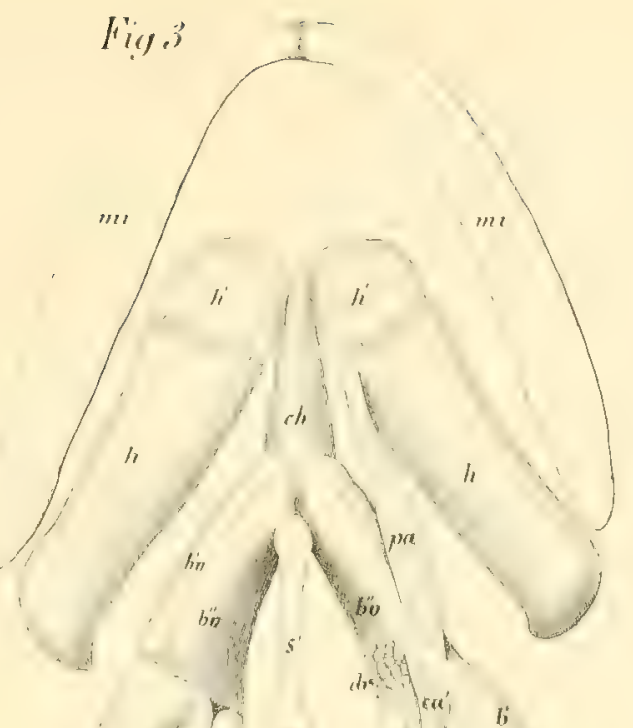

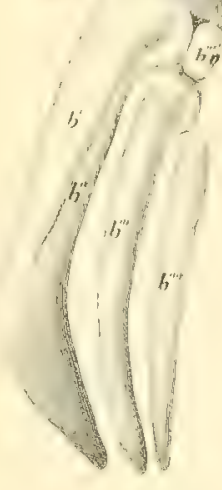

Menobranthus," 1
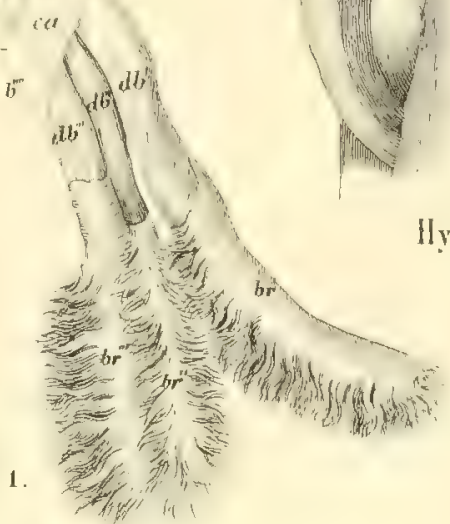

Firg."

Fig. 1

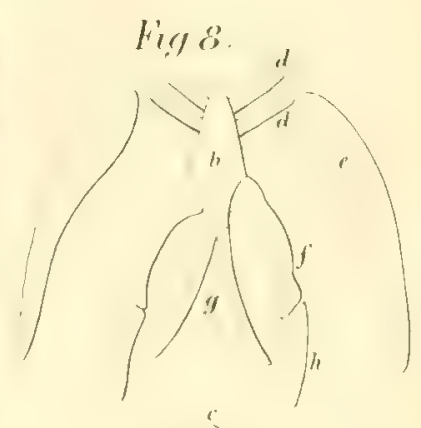

Fing 's

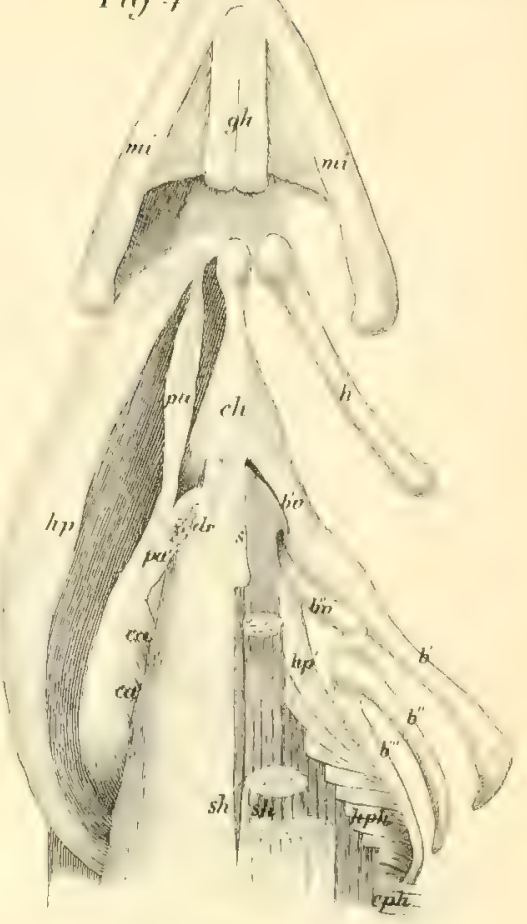

Hypochihon, "1

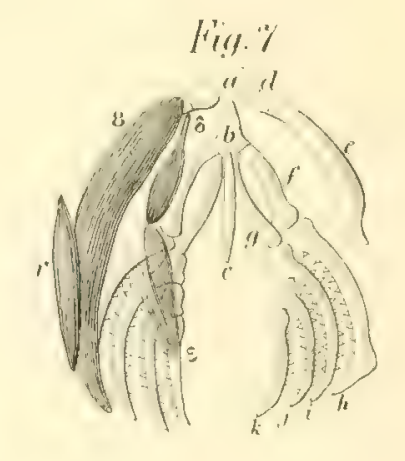

Tirf 1.

$$
\text { nen }
$$





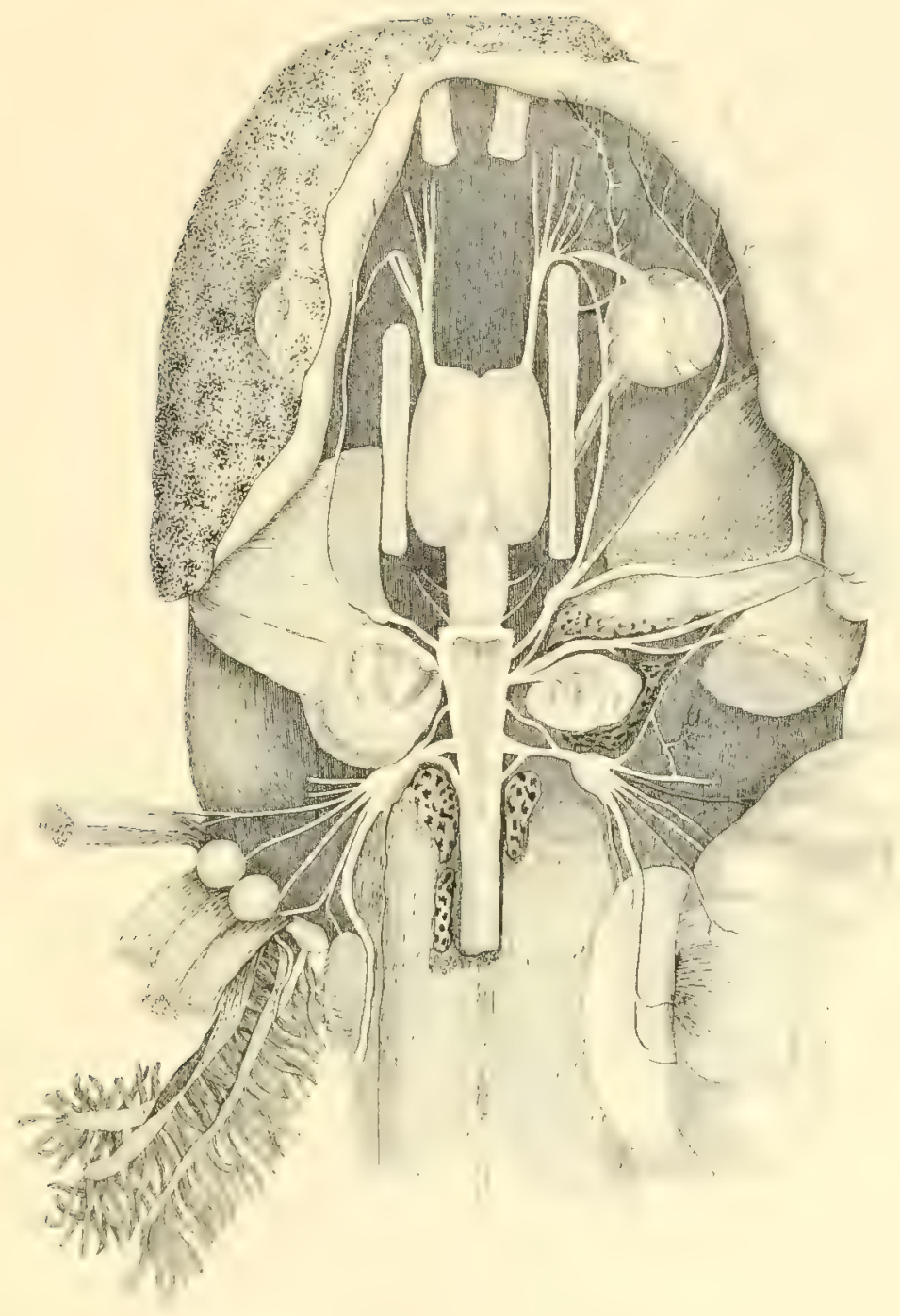

Sirredon." 

Thef. II ${ }^{b}$

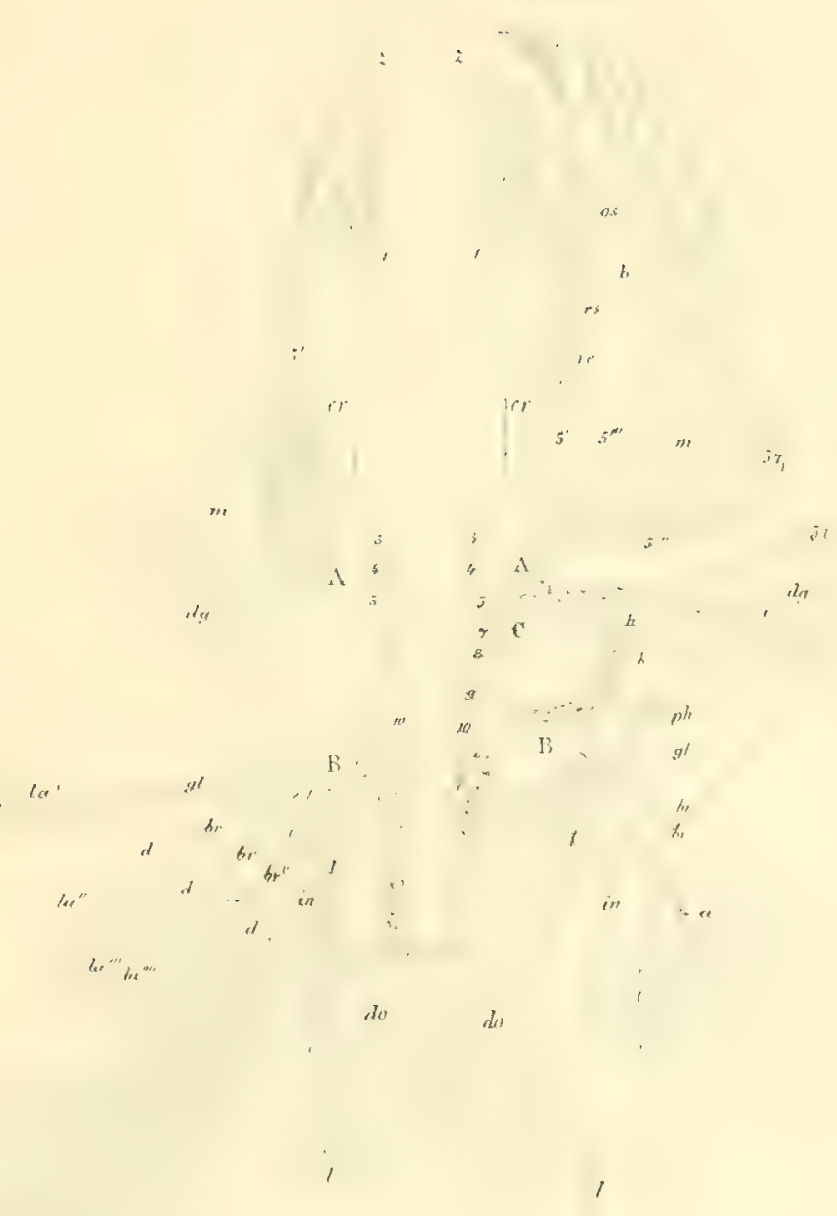



Tiif III!"

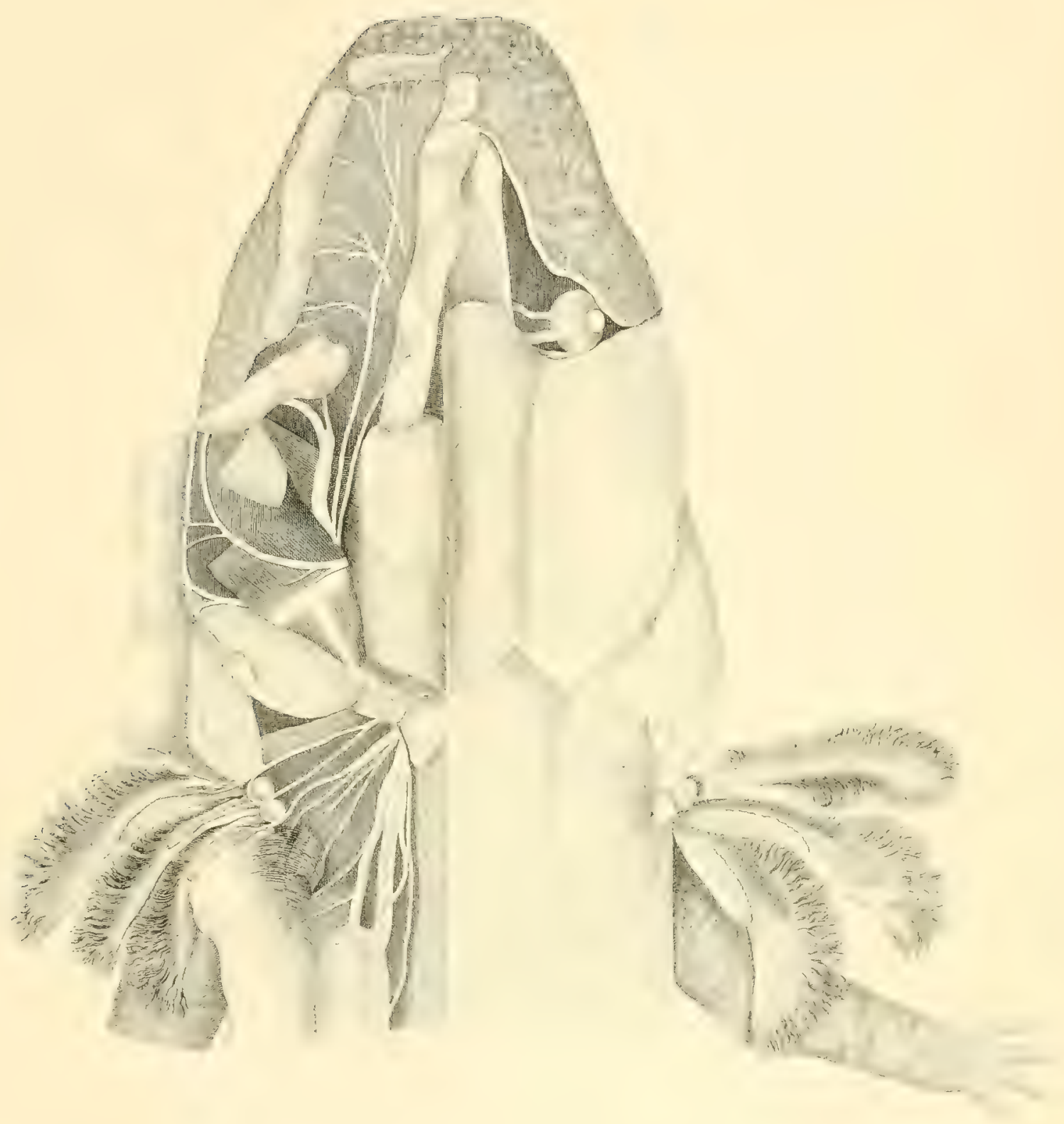

Menobranchus lateralis, $0 / 1$. 

Trif. III!

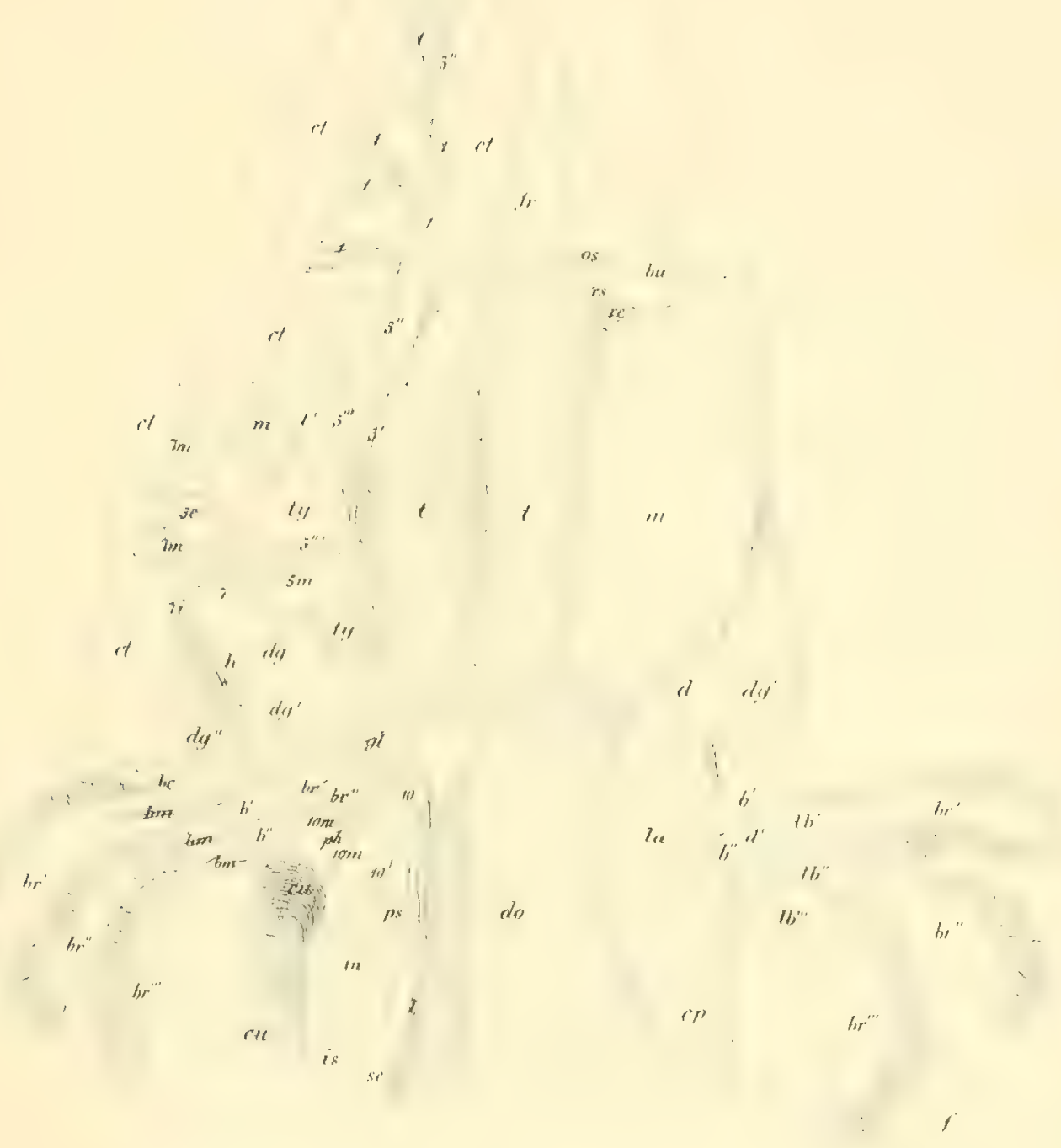




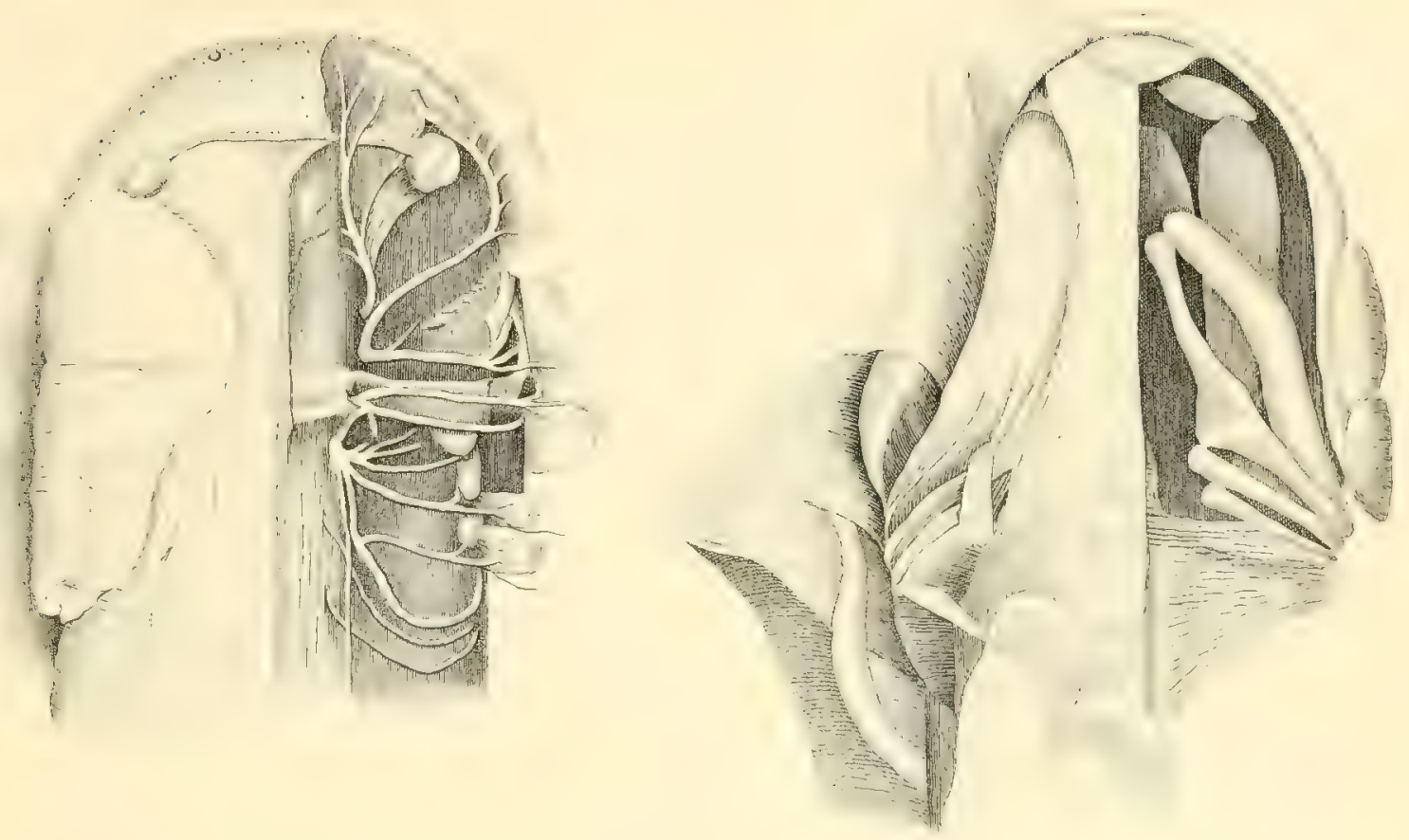

Menopoma 1/1.
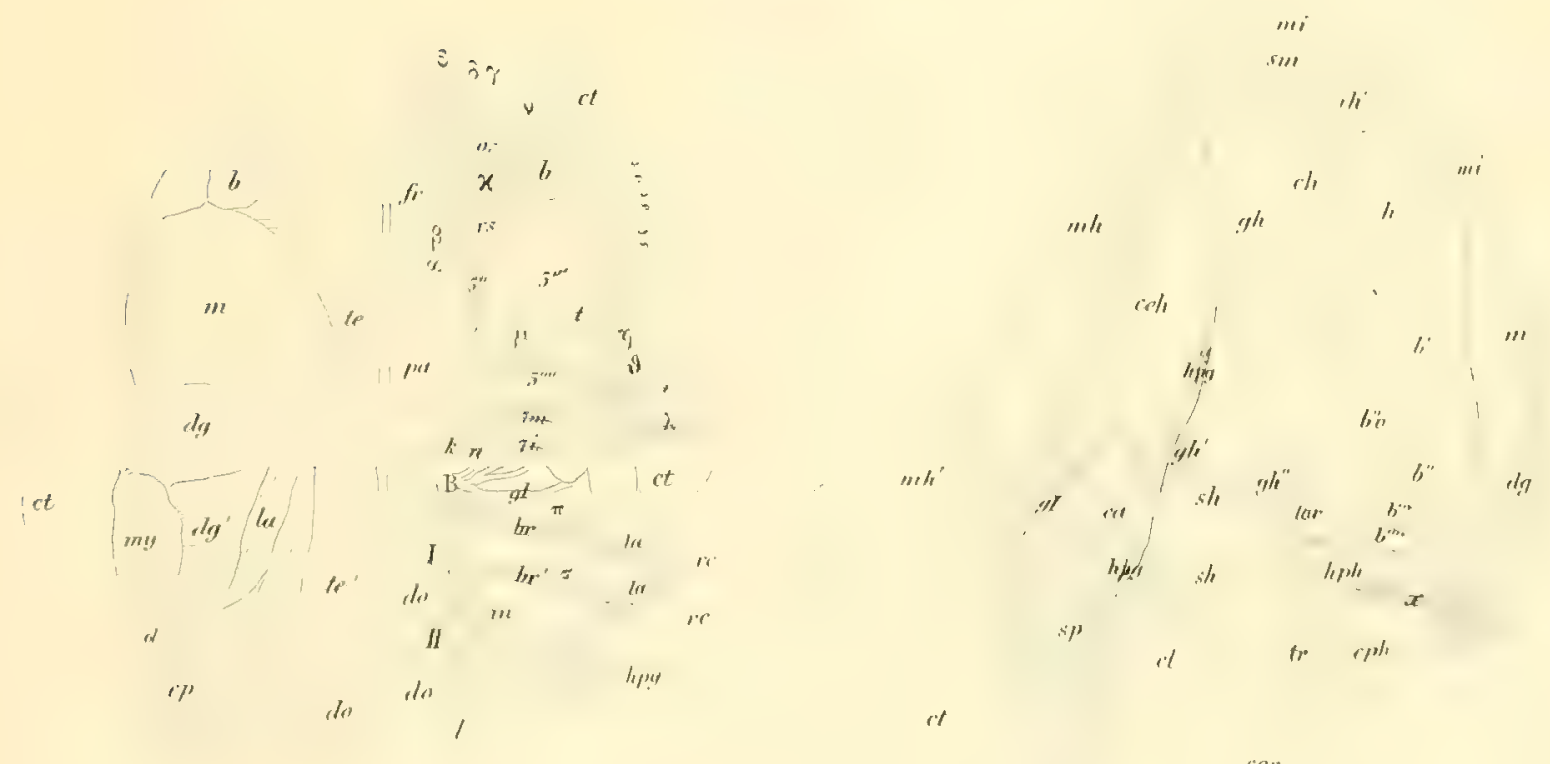

Fig: I.

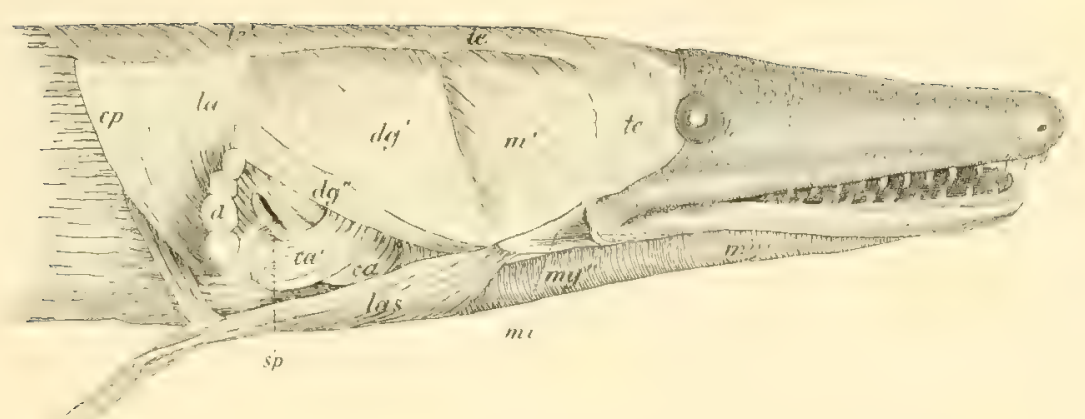

Figy?

2699
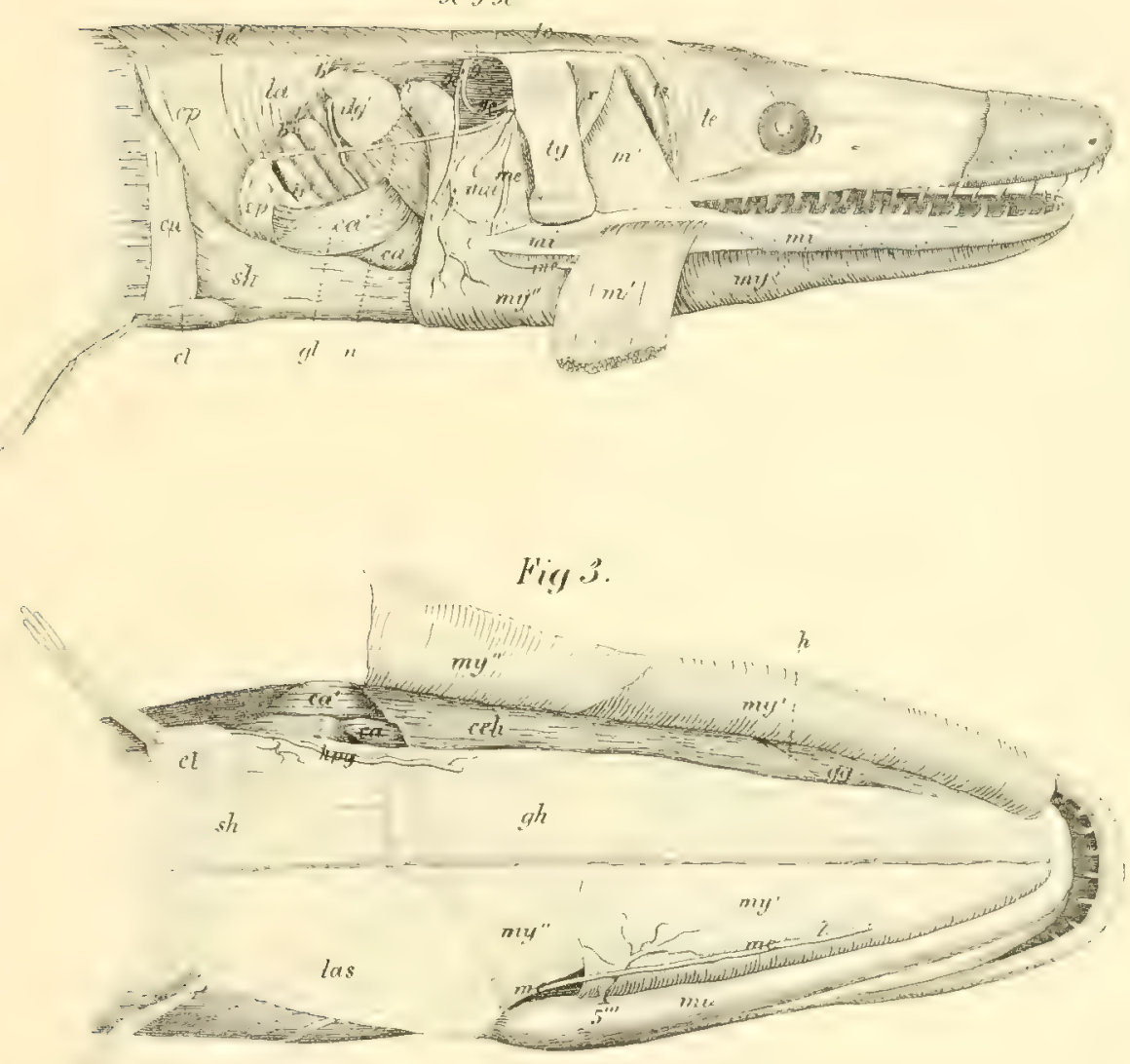

Anphinma $\% / 1$. 



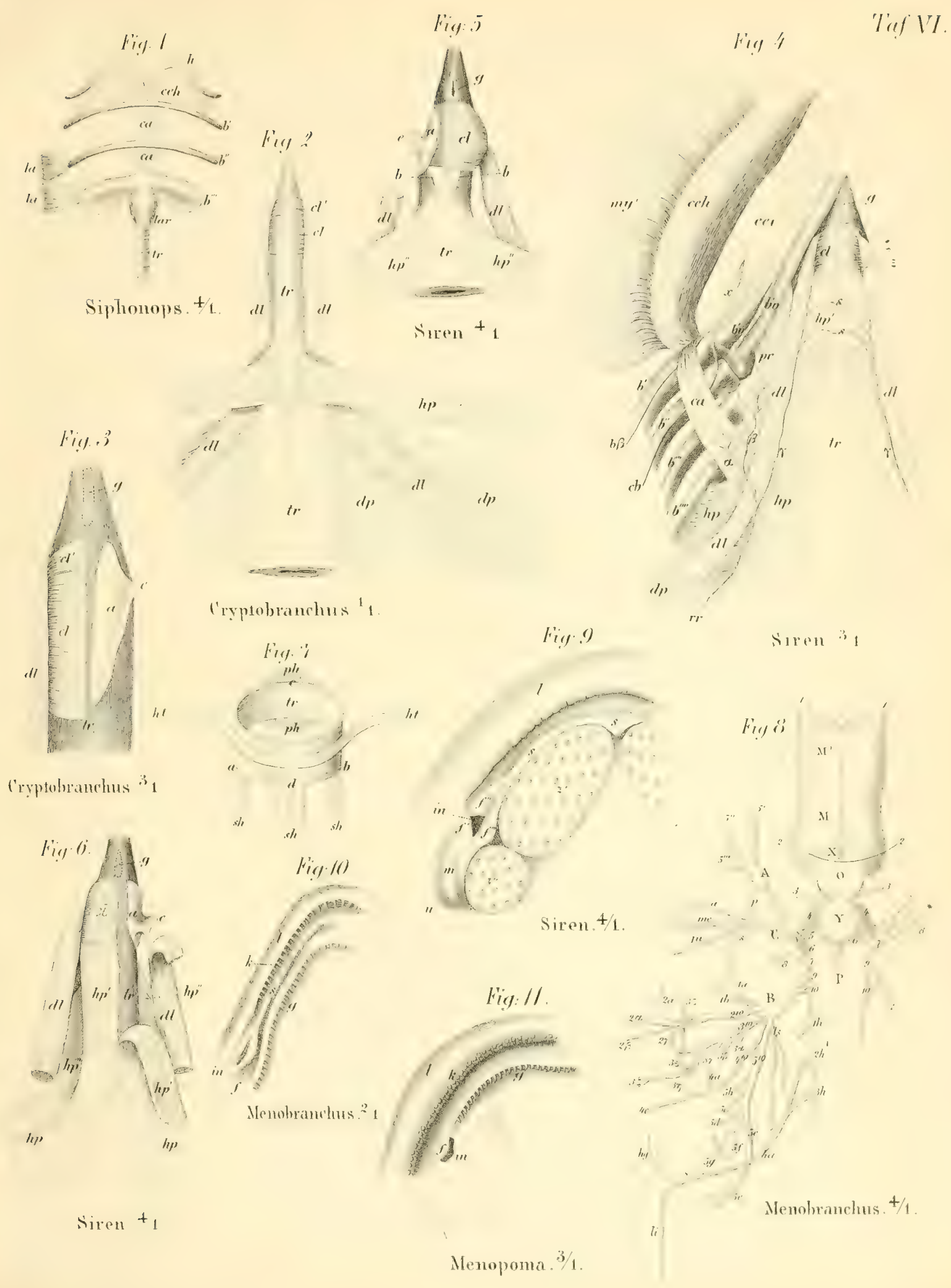




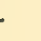





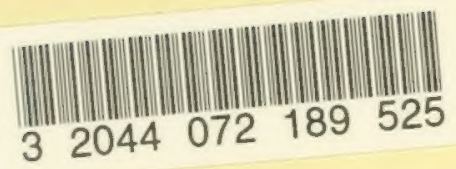



